\title{
Strategizing for Legitimacy in Pluralistic Contexts: \\ New Zealand's Science Sector
}

\author{
By
}

Rebecca Suzanne Bednarek

Submitted to the Victoria University of Wellington in fulfilment of the requirements for the degree of Doctor of Philosophy in Management

Victoria University Wellington

2011 



\section{ABSTRACT}

How do organizations strategize for legitimacy in pluralistic contexts? Little is known about the strategies organizations use to manage their legitimacy with multiple internal and external stakeholders within pluralism. For instance, how strategies interrelate and are combined simultaneously by organizations has not been researched. Through addressing this question the thesis seeks theoretical elaboration that contributes to our understanding in this regard and addresses this gap in the legitimacy literature. In particular, a combinatorial picture of legitimacy strategies is provided that provides insight into how strategies might be combined and interrelate.

Based on a novel tabulation that brings the various strands of the literature together a framework is developed for investigating the research problem. Theoretical extension is then sought through an empirical focus on the pluralistic setting of New Zealand's science sector. Six case studies based on two layers of replication are explored, principally through 58 multi-stakeholder interviews. The findings show that multiple embedded tensions and complex diffused power relationships characterise these organization cases. This provides a basis for investigating legitimacy strategies amidst pluralism: the basis of the analysis

A picture of agency intensive legitimation is provided with organizations found to construct and change, as well as conform to, legitimacy demands. This informs the research agenda focused on redressing an identified 'conformity bias' (Kitchener, 2002) in much legitimacy theory. Further, a traditional preoccupation with overarching field level systems within dominant strands of legitimacy research has been recognized (Kraatz \& Block, 2008). This research contributes by seeking to rectify this imbalance through adopting a framework of legitimacy strategies at the organizational level.

The result is five propositions and extension to the theoretical framework. Prior work has tended to associate an organization with a dominant single strategy. This thesis finds multiple legitimacy strategies and strategic combinations being implemented by organizations amidst pluralism. Propositions are offered in this regards. The result is increased understanding of both infrequently explored legitimacy strategies and the relationships between them. Such theoretical development blurs the 'demarcating lines' 
that and are implicit in many frameworks and empirical studies. Additional propositions are also provided regarding why similar organizations experiencing similar pluralism might implement different legitimacy strategies. It is proposed that differences in stakeholder perceptions of pluralism's dimensions are associated with the implementation of different legitimacy strategies by organizations.

Overall, both the creative potential and challenges inherent in strategizing for legitimacy amidst pluralism are illustrated. A nuanced picture in this regard is enabled by the diverse array of strategies surfaced both within and across the focal pluralistic organizations. 


\section{ACKNOWLEDGEMENTS}

I am grateful to a large number of people, without whom this thesis and the journey associated with it would not have been possible and/or the same.

I have been extremely fortunate in my supervisors A/Professor Urs Daellenbach and Professor Sally Davenport. I feel privileged to have benefited from the wisdom, dedication, and energy of such a great supervisory duo. I recall a few years ago Urs saying to me "what you're talking about is legitimacy." His calm insightful presence has been a constant for me ever since. Amongst many other things Sally has provided unwavering enthusiasm as well as a doorway into the complexity of the RS\&T environment.

The Victoria Management School provides a wonderful "home" for a PhD student. I am thankful for the environment, financial assistance, and collegiality provided. I have appreciated the conversations and support along the way from VMS staff, in particular Mark Ahn, Stephen Cummings, and Sally Riad. Thanks also to Deborah Jones as PhD Coordinator and Megan Key and Sophia Lum for all their help in making the whole process less stressful.

PhD colleagues have been journeying through the same process and I have valued sharing offices and experiences with them: Ainie Aluwi, Mary Ashby, Terry Bowe, Simon Collins, Bruce Edman, Maree Foley, Cesar Guala, Alexie Koveshnikov, June Longjit, Zanele Ndaba, Huong Nguyen, Lois Parkes, Wayne Pihema, Garoon Pongsart, Heike Schaenzel, Dung Tran, and Suze Wilson.

As always I benefit from the unwavering support of my partner, family, and friends. Thank you to my parents (Deborah and Simon); grandfather (Ian); siblings (Andrea, Victoria, and Nicholas); and friends, in particular Flora and Renee. An especial thank you to James who has lived through this $\mathrm{PhD}$ alongside me, encouraging and affirming the whole way.

I gratefully acknowledge my scholarship in the form of a Tertiary Education Commission's "Top Achievers Doctoral Scholarship." I know how instrumental this was in determining my experience as a PhD student. 
Finally, one of the most enjoyable aspects of this PhD has been the opportunity to meet the people I met and have the conversations I have had with them. I will always be grateful for their generosity, insight, and openness. I am privileged that they shared with me what they did. 


\section{CONTENTS}

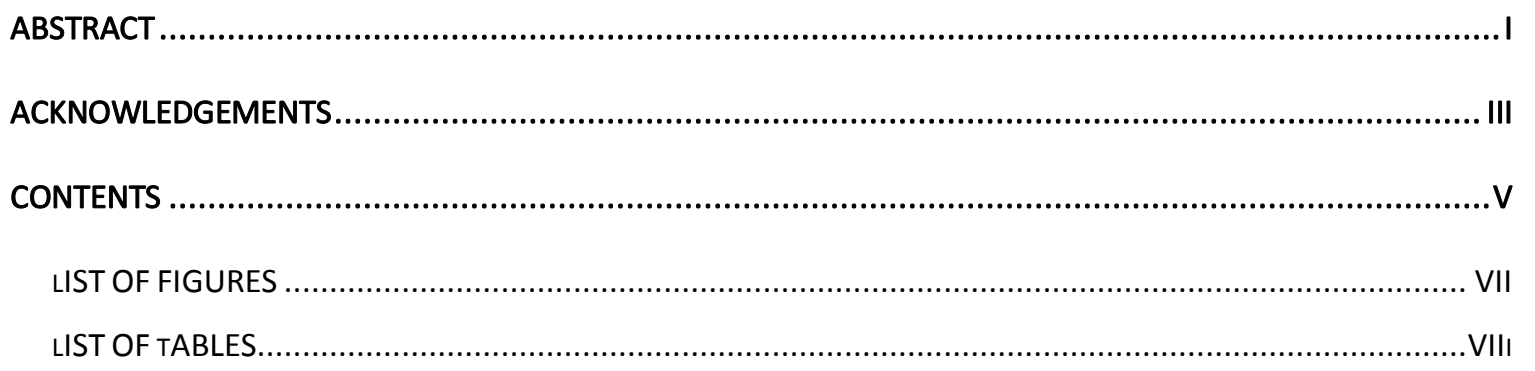

CHAPTER ONE: INTRODUCTION: STRATEGIZING AT THE CLASHING POINT............................................. 1

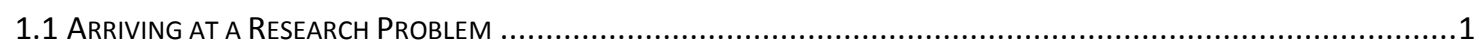

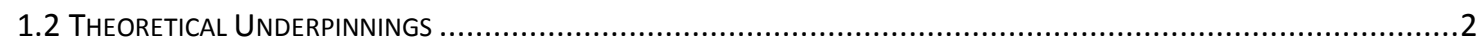

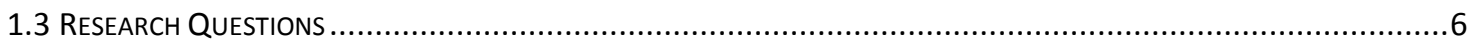

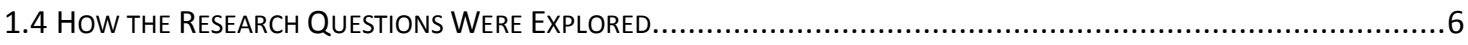

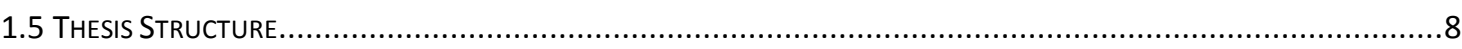

CHAPTER TWO: LITERATURE REVIEW: PLURALISM AND LEGITIMACY STRATEGIES............................... 12

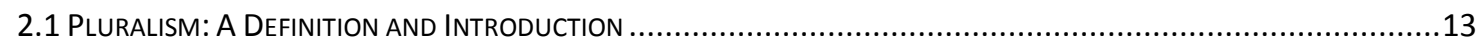

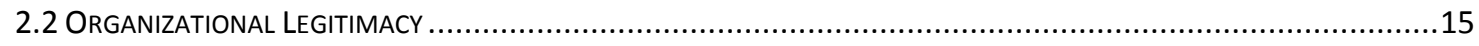

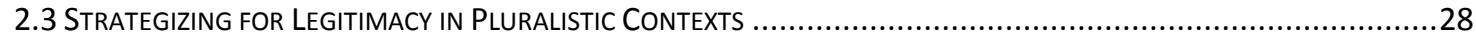

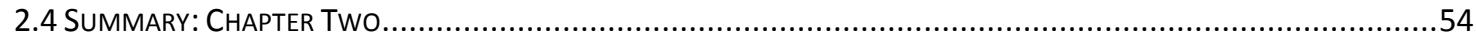

CHAPTER THREE: METHODOLOGY AND CONTEXT: NZ'S SCIENCE SECTOR ....................................... 56

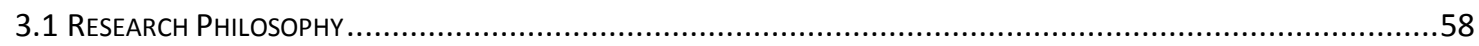

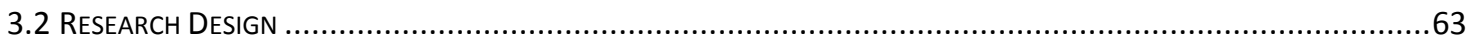

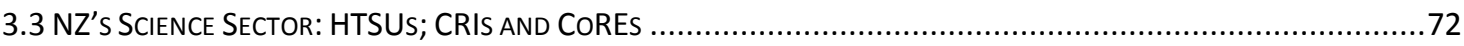

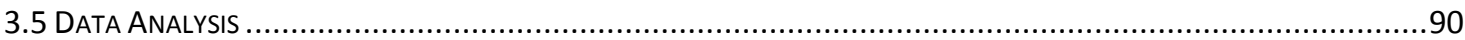

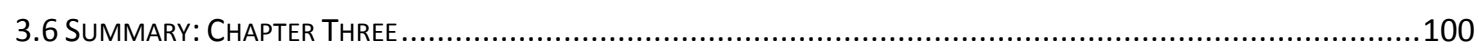

CHAPTER FOUR: FINDINGS: CONTEXTUAL DESCRIPTIONS ............................................ 102

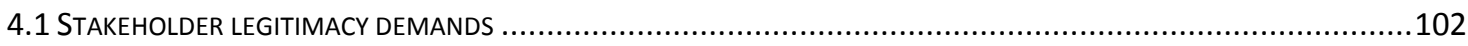

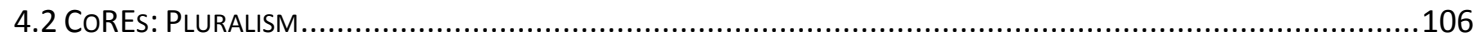

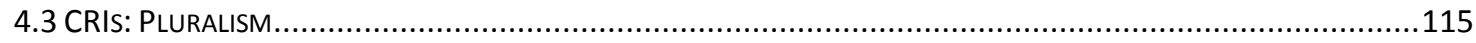

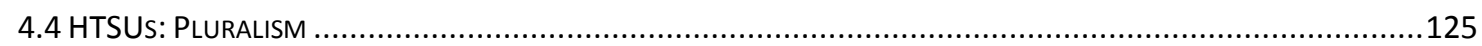

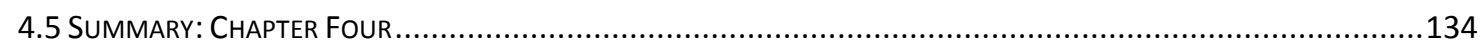

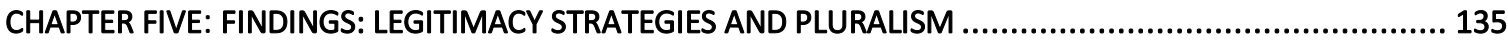

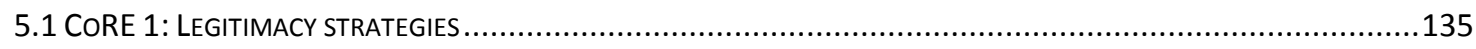

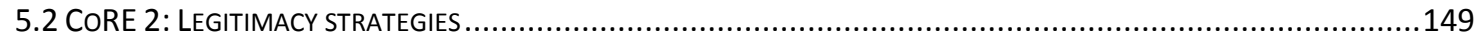




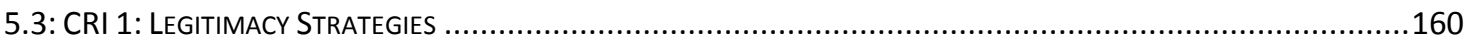

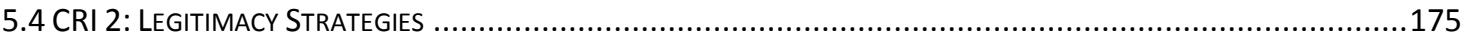

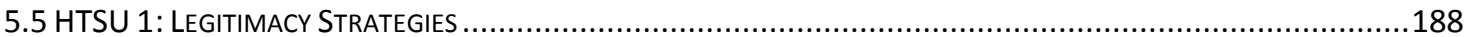

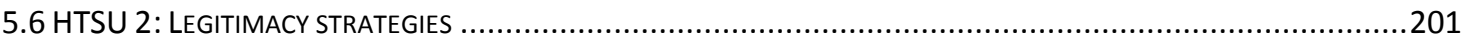

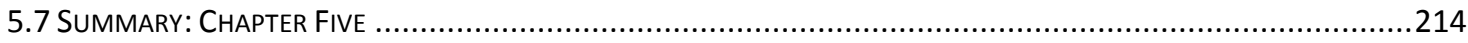

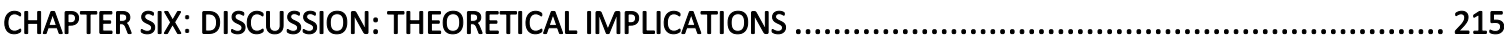

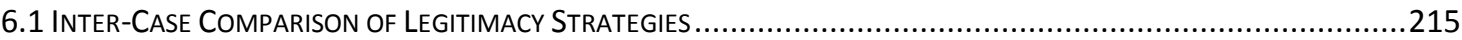

6.2. Legitimacy Strategies and Perceptions of Pluralism ...................................................................22

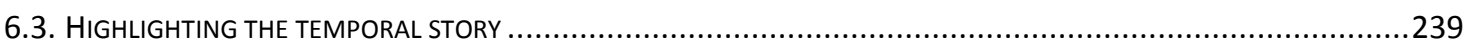

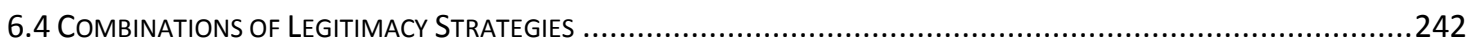

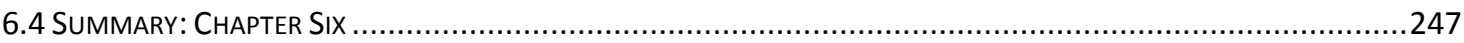

CHAPTER SEVEN: CONCLUSION: CREATIVE CHANCES AT THE CLASHING POINT............................. 248

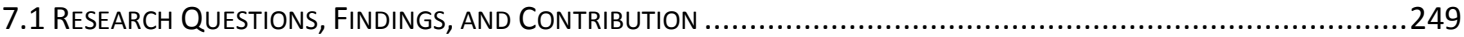

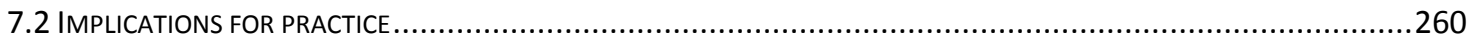

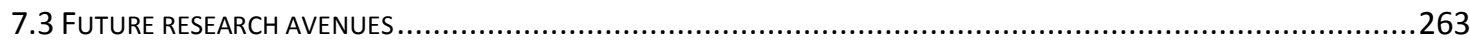

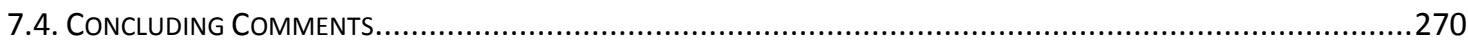

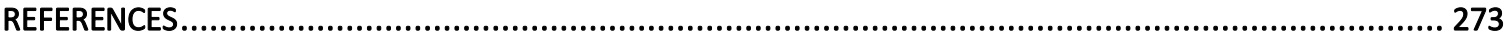

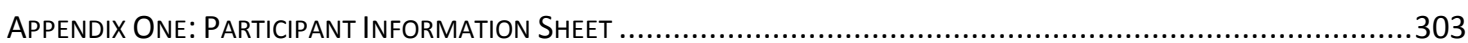

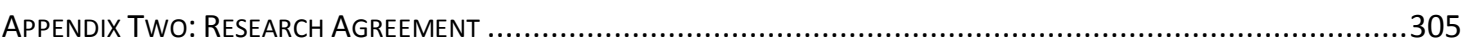

Appendix THReE: Human Ethics Committee Approval: Memorandum .................................................300

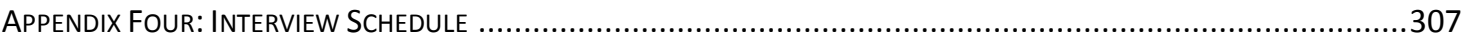

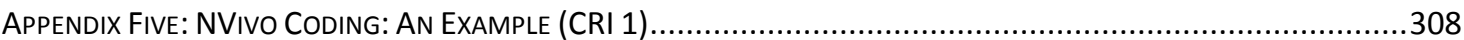




\section{List of Figures}

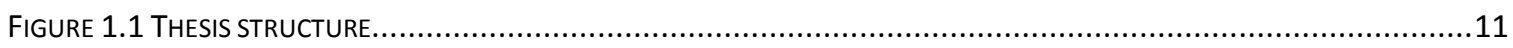

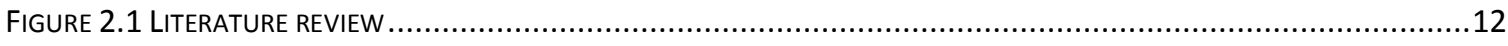

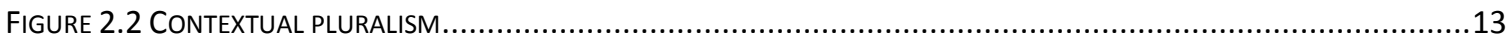

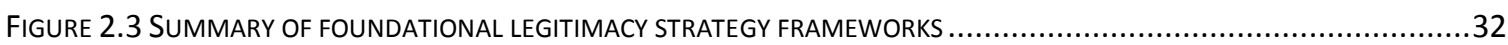

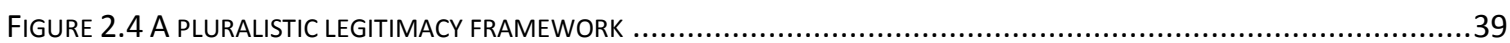

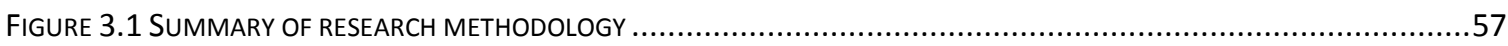

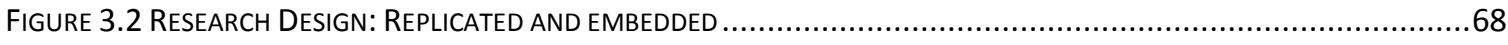

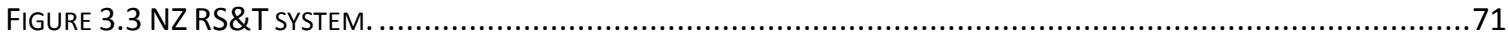

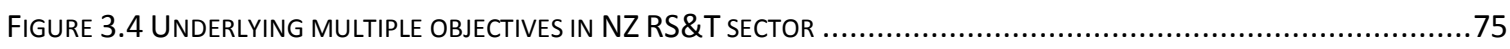

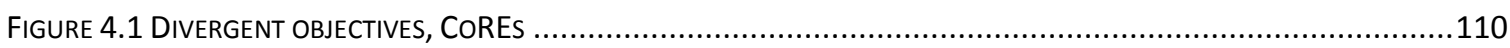

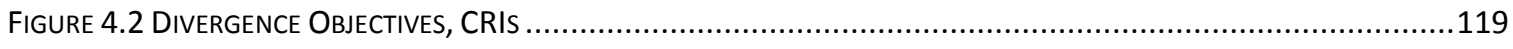

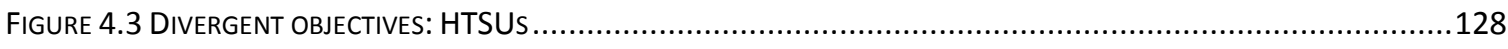

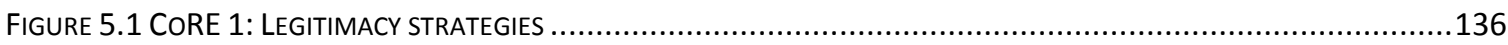

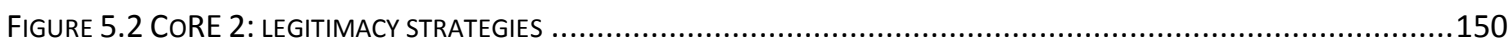

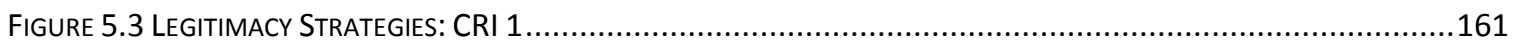

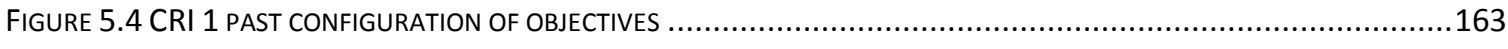

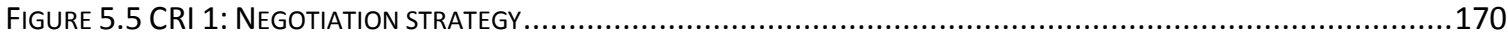

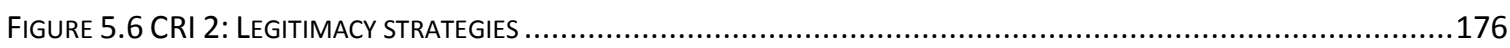

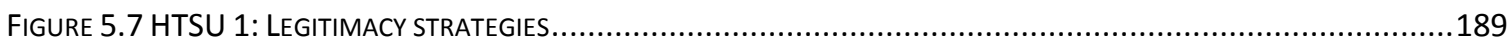

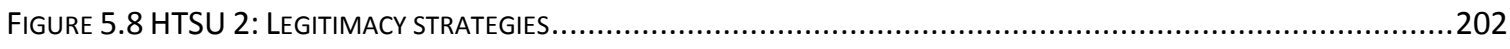

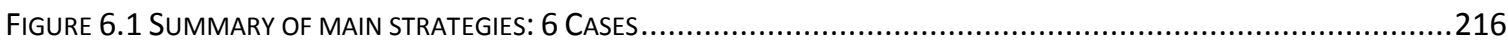

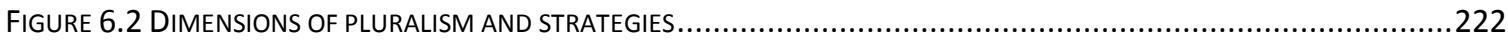

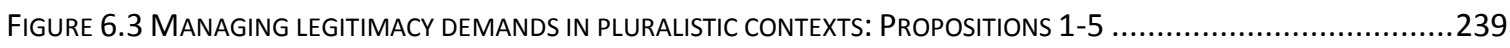

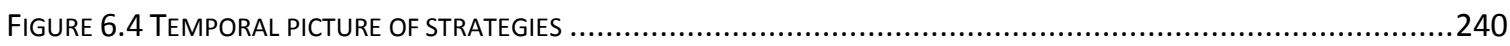

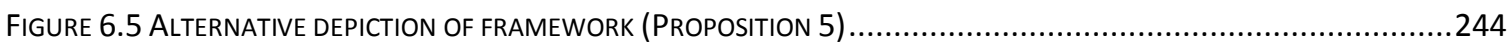

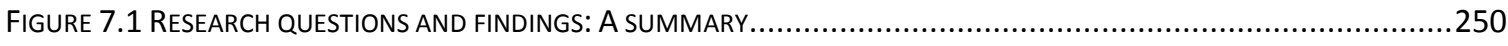

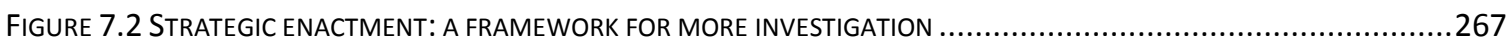




\section{List of Tables}

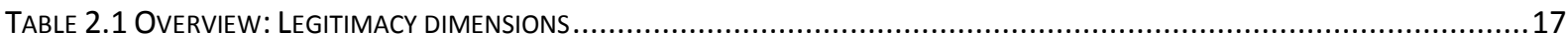

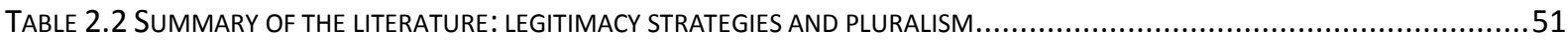

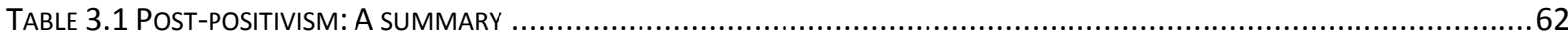

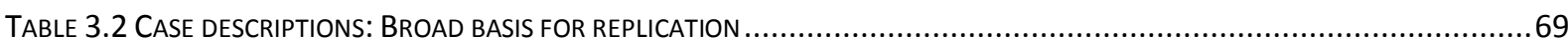

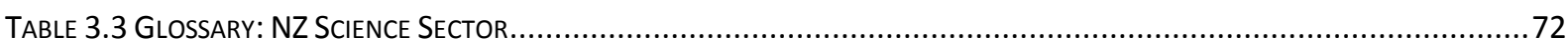

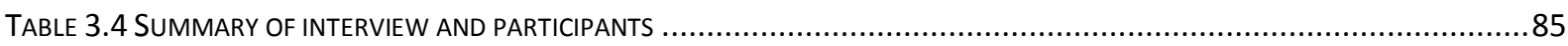

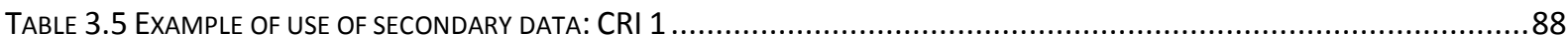

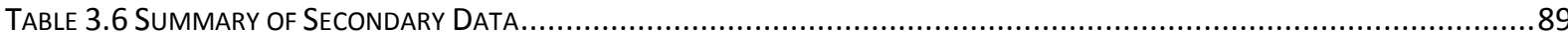

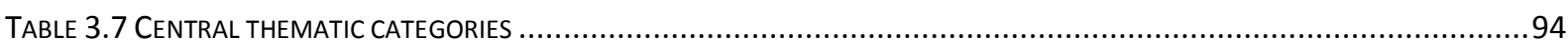

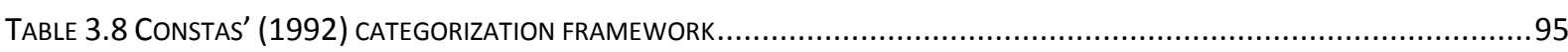

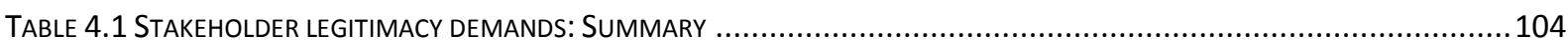

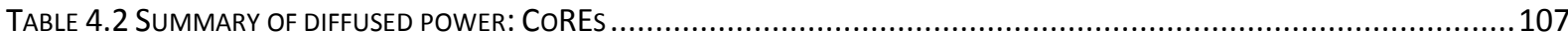

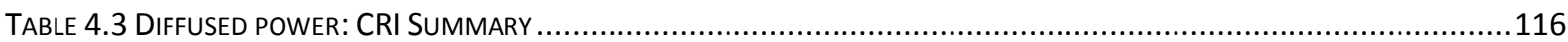

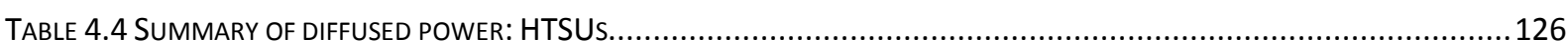

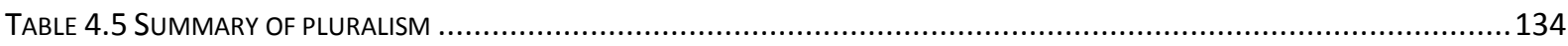

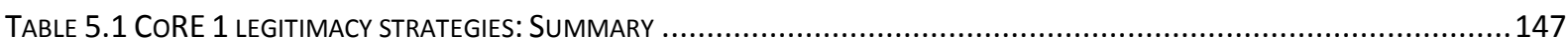

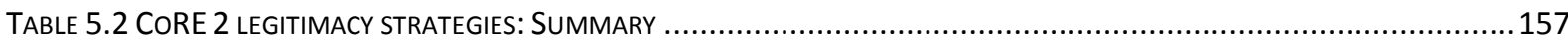

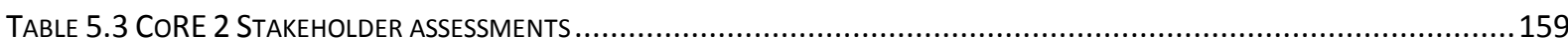

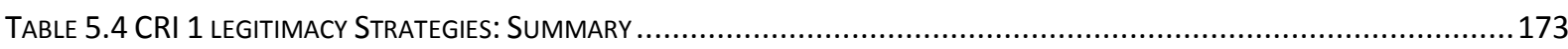

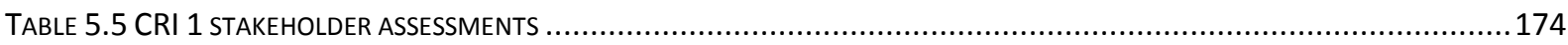

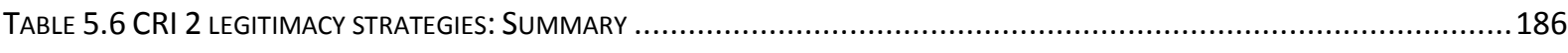

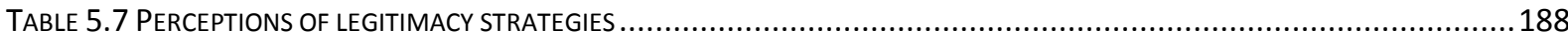

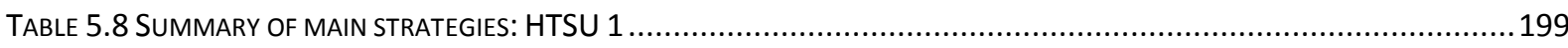

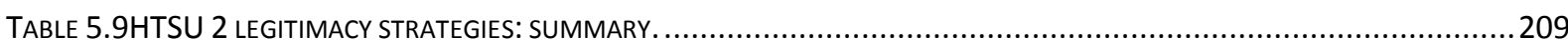

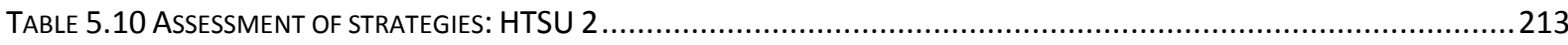

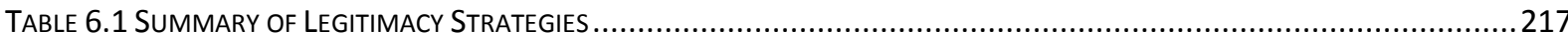

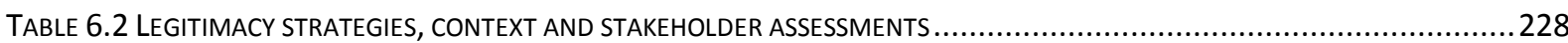




\section{CHAPTER ONE}

\section{Introduction: Strategizing at the Clashing Point}

The clashing point of two subjects, two disciplines, two cultures of two galaxies, so far as that goes ought to produce creative chances. (Snow, 1959, p. 16)

It's been two different planets almost. This is the public good planet and this is the making money planet. (Manager, CRI 1)

With this thesis I ask: How do organizations strategize for legitimacy in pluralistic contexts? As the above quotations suggest, this study is consequently focused on contexts in which stakeholder demands come from 'different planets' and investigates the strategies implemented at the multiple 'clashing points' that pluralism presents. The legitimacy strategies apparent in the findings here included innovative organizational responses and combinations of strategies. This is something that Snow alludes to above regarding the creative possibility amidst pluralism; it is also reiterated in the organizational literature (Kraatz \& Block, 2008; Smith \& Tushman, 2005). I address this under-investigated question through six qualitative case studies within New Zealand's (NZ) science sector: a sector selected because it is characterized by pluralism at multiple levels (Colyvas \& Powell, 2006; Leitch \& Davenport, 2005). In this endeavour a strategy framework at the intersection of pluralism and legitimacy literature will be used (Kraatz \& Block, 2008). Below I introduce how I arrived at this research problem; highlight the theoretical underpinnings and associated research gap; present the research questions guiding this research; introduce how these questions were investigated; and, finally, outline the structure of this thesis.

\subsection{Arriving at a Research Problem}

As I looked for a research problem to guide my investigation, my focus fell upon the case of a Steiner School, an alternative education provider with which I was familiar. What were strategically important issues for them? One was their balancing of government's demands (NZ Steiner schools are required to meet obligations as state-funded entities) while also meeting the ideologically stringent demands of their school community. This school community was made up of both internal (teachers) and external (parents and other community benefactors) stakeholders. These stakeholders' demands were experienced by 
school managers as divergent. For instance, the Ministry of Education expected adherence to the State curriculum (for example, implementation of NZ's National Certificate of Educational Achievement (NCEA)) while the school community felt such demands put the alternative pedagogy of the school at risk (for example, the implementation of NCEA was resisted).

I translated this into the theoretical language of 'legitimacy': the issue was framed in terms of what stakeholders considered a desirable and appropriate Steiner school to be. I also utilized the concept of 'pluralism': the school was operating within a pluralistic context of multiple salient but divergent stakeholder demands. Thus, I focused my attention on the strategies used to manage legitimacy within pluralistic contexts. Framing what I perceived to be a central strategy question for the Steiner school in terms of 'legitimacy' implicitly linked my interest in strategy to the call to "bring society back in" (Friedland \& Alford, 1991, p. 232). In this case society was brought 'back in' through an appreciation of both the task environment (and the provision of resources) and the institutional environment (associated rules, values, and norms) within which organizations operate. Such issues were put forward as something that organizations engaged with strategically (Oliver, 1991).

As I arrived at a theoretical expression for my research its empirical setting also shifted. My focus turned to the pluralism of the NZ science system and the organizations operating within it. It is the divergent 'planets' contained in this sector that are represented in the quotations introducing this chapter.

\subsection{Theoretical Underpinnings}

We suspect that the effective management of pluralism may be a critical organizational (and managerial) capability. Its relative scarcity may be one reason why most organizations do not survive very long (Kraatz \& Block, 2008, p. 250).

Legitimacy strategies amidst pluralism. Pluralism is described as an increasingly pertinent contextual dynamic (Denis, Langley, \& Rouleau, 2007; Jarzabkowski \& Fenton, 2006) and, as Kraatz and Block (2008) suggest above, successfully managing this plurality can be classified as an important performance determinant for organizations. Glynn, Barr and Dacin (2000, p. 732) point out that there is a consequent need for more organizational research that addresses the current imbalance vis-à-vis pluralistic contexts: "[t]he world is changing and 
becoming more pluralistic; as organizational students, we have to keep pace." The aim here is to address this issue as it relates to legitimacy theory. The assumption is that situating legitimacy within the pluralistic context will enable more 'accurate' and 'nuanced' theory (Glynn et al., 2000; Jarzabkowski \& Fenton, 2006; Rescher, 1993). Accordingly, the contribution envisaged here is one of theoretical extension and refinement (Dubois \& Gadde, 2002).

There is longstanding acknowledgement of the existence of pluralism within legitimacy literature (D'Aunno, Sutton, \& Price, 1991; Kostova \& Zaheer, 1999; Meyer \& Rowan, 1977; Pfeffer \& Salancik, 1978). However, what this means for our understanding of organizational-level legitimacy strategies remains both under-theorized and underempirically investigated (Jarzabkowski, Matthiesen, \& Van de Ven, 2009a; Kraatz \& Block, 2008; Lounsbury, 2007; Pache \& Santos, 2010; Reay \& Hinings, 2009).

This lack of attention to pluralism is reflected in a gap highlighted by several authors regarding institutional theory's (a dominant approach within the legitimacy literature) neglect of both the organizational level of analysis and organizational agency (Covaleski \& Dirsmith, 1988; Kraatz \& Block, 2008; Lawrence, Suddaby, \& Leca, 2009; Oliver, 1991). At the broadest level this research is positioned as part of a 'strategic institutional' approach (Alexander, 1996), seeking to address this imbalance in the treatment of legitimacy and explicate an understanding of organizational level agency as part of legitimation. The contribution made here is also aligned with Deephouse and Suchman's (2008, pp. 54, 68) statement that the future of legitimacy research lies in exploring "the various internal and external audiences" (or 'stakeholders') who make legitimacy demands and the corresponding "struggles over what is legitimate." The incorporation of pluralism brings multiple stakeholders and the tension between their legitimacy demands to the fore.

Some definitions. Before elaborating on this research gap more fully the following definitions are provided for clarification purposes:

Pluralism. The definition adopted depicts pluralism as a contextual phenomenon. It is a organizational context characterized by 1) diffused power and 2) divergent objectives (Denis et al., 2007; Jarzabkowski \& Fenton, 2006). 
Legitimacy. An explicitly stakeholder-focused definition of legitimacy is used. This draws from both the institutional and more strategic strands (e.g., resource dependence theory) of legitimacy research (Suchman, 1995). These theoretical traditions will be laid out in Chapter 2, with legitimacy defined as: A perception or assumption by particular internal and external organizational stakeholder groups that the actions of an entity are desirable, proper or appropriate (Hybels, 1995; Suchman, 1995). In pluralistic contexts, organizations face multiple demands based on different perceptions and assumptions of what is desirable, proper, or appropriate.

Legitimacy strategy. The increase, maintenance, or repair of legitimacy that is achieved or attempted through a consistent stream of action (Aldrich \& Baker, 2001; Mintzberg, 1978; Mintzberg \& Waters, 1985; Vaara, Tienari, \& Laurila, 2006). At times labelled legitimacy management (Suchman, 1995).

Extended discussions of these definitions will be provided in Chapter 2 below.

A research gap. In pluralistic contexts, what legitimates an organization with one stakeholder group can make it illegitimate with another (Elsbach \& Sutton, 1992; Jarzabkowski \& Fenton, 2006; Pfeffer \& Salancik, 1978; Seo \& Creed, 2002; Stryker, 2000). Organizations therefore need to develop strategies to attain, maintain, or defend sufficient legitimacy from multiple salient stakeholders with divergent demands. Situating research within pluralistic settings therefore provides an opportunity for increased understanding of strategies that, despite being outlined in existing legitimacy frameworks (Oliver, 1991; Kraatz \& Block, 2008; Suchman, 1995), have rarely been explored empirically. In particular, Kraatz and Block's legitimacy strategy framework focused on the organizational level was selected to guide this thesis due to its alignment with the identified research problem.

The literature discusses a preoccupation with conformity and isomorphism within much legitimacy theory (Fligstein, 1997; Kitchener, 2002; Kraatz \& Block, 2008; Oliver, 1991). However, such an approach is fraught with difficulty in pluralistic settings (Oliver, 1991; Pfeffer \& Salancik, 1978; Seo \& Creed, 2002). Pluralism in this way expands the range of 
potential and/or necessary legitimacy strategies engaged in. Strategies less central in more homogenized settings take on greater import (Kraatz \& Block, 2008; Lounsbury, 2007; Mars \& Lounsbury, 2009; Seo \& Creed, 2002). Pluralism in this way enables investigation of strategies that have previously been less of a research focus. Specifically, insight into aspects of Kraatz and Block's (2008) theoretical framework is enhanced through being empirically investigated as legitimacy strategies for what appears to be the first time.

Another particular aspect is a lack of understanding into how organizations may combine multiple strategies simultaneously. It was observed that there is an implicit assumption within the presentation of some foundational legitimacy strategy frameworks (e.g., Kraatz \& Block, 2008; Oliver, 1991) that a single legitimacy strategy will be dominant within an organization. With regards to empirical work, it is argued (Pache \& Santos, 2010; Binder, 2007) that studies have tended to focus on the identification and exploration of idiosyncratic responses (e.g., Battilana \& Dorado, 2010; D'Aunno et al., 1991; Elsbach \& Sutton, 1992). These empirical studies have also infrequently reflected their findings back to or proposed general legitimacy strategy framework such as the one provided by Kraatz and Block (2008). Understanding how different strategies might interrelate or be combined by organizations is, consequently, partially lacking. This study focuses this issue.

Increasing research interest. An illustrative description of this theoretical domain is contained in my own experience with the literature. Since commencing this PhD I have watched the research interest at the specific intersection between legitimacy strategy and pluralism increase markedly. This was particularly the case regarding empirical studies outlining strategies for managing divergent legitimacy demands in the form of institutional logics (Battilana \& Dorado, 2010; Reay \& Hinings, 2009), a related but slightly different frame from the one adopted here. The foundational framework this research draws from (Kraatz \& Block, 2008) was similarly unpublished at the time I identified the broad research gap I sought to address. This has meant that since starting my PhD journey, the literature has provided a framework and an increasing number of empirical studies to draw from that have helped increase the understanding of specific strategies. This suggests that the research problem identified here has been increasingly recognized as important for legitimacy strategy frameworks and institutional theory more broadly. This growing body of work provided me with an increased capacity to refine (and hopefully strengthen) the 
contribution made here as the conversation I was engaged in progressed. As a result, a more nuanced discussion regarding combining legitimacy strategies was enabled.

\subsection{Research Questions}

My thesis is that pluralism has much to contribute to our understanding of legitimacy strategies. The overarching question I explore is: How do organizations strategize for legitimacy in pluralistic contexts?

The following sub-questions further focused the investigation:

1. How are stakeholder legitimacy demands and pluralism experienced by different organizations in NZ's science sector?

2. What strategies are perceived by stakeholders as being implemented by organizations to manage their legitimacies in pluralistic contexts?

3. How, if at all, are organizations perceived to combine different legitimacy strategies in pluralistic contexts?

4. Why might particular legitimacy strategies, rather than others, be implemented by organizations in pluralistic contexts?

\subsection{How the Research Questions Were Explored}

The focus in these research questions on participant perception reflects the post-positivist approach adopted here. The perceptions and experiences of research participants are the means through which the complexity and tensions associated with legitimacy and pluralism are investigated. Such a position is aligned with pluralism as it moves beyond uncovering singular truth and instead embraces the existence of pluralistic perceptions. A post-positivist approach that focuses on the perspectives of participants is important when investigating legitimacy (Crotty, 1998; Phillips \& Burbules, 2000). While maintaining a belief in a mindindependent reality, post-positivism argues with constructivist perspectives that knowledge and beliefs, including legitimacy, are human constructions (Meyer \& Rowan, 1977). It also 
provides a foundation for research seeking to explore concepts like legitimacy that cannot be presented as objective reality (Eriksson \& Kovalainen, 2008; Hammersley, 2001; Miles \& Huberman, 1994; Miller, 2000, p. 38; Phillips \& Burbules, 2000).

Selecting an empirical setting was primarily based on the requirement that it enabled the investigation of legitimacy strategies within a pluralistic setting. The science sector was therefore selected, being identified as experiencing both divergence objectives and diffused power (Ziman, 1994). Science organizations are outlined as frequently facing science, public good, and commercially based legitimacy demands (Colyvas \& Powell, 2006; Mars \& Lounsbury, 2009; Rip, 2004; Ziman, 1994). Within the NZ context specifically, researchers have described the sector as characterized by a "relevance debate" and multiple divergent objectives (Devine, 2003; Leitch \& Davenport, 2005). Diffused power also characterizes the science sector and organizations within it. For example, there are high levels of resource dependence (Pfeffer \& Salancik, 1978), collaboration is increasingly necessary (Powell, Koput, \& Smith-Doerr, 1996), and finally accountability to and evaluation by the public funders of research has increased (Ziman, 1994). This also represents a novel empirical setting within which to study pluralistic legitimacy strategies, with previous studies not exploring this particular context. Accompanying this primary rationale was my growing personal interest in NZ's science sector. In particular, the dialogue regarding the vital nature of the science sector in determining NZ's future prosperity (e.g., Callaghan, 2009) held strong personal resonance.

Within this sector, six qualitative case studies were undertaken. The structure of the sector enabled replication of different types of science organizations that nonetheless dealt with broadly similar pluralism. This included a replication of similar organizational types (for example, two high-tech start-ups). It also included a degree of theoretical replication. Three types of organizations defined by the literature (Stone \& Brush, 1996) as likely to be pluralistic were selected: public (two Crown Research Institutes), non-profit (two Centres of Research Excellence), and start-up (two high-tech start-ups) organizations. The pluralistic contexts within which these organizations operate and the legitimacy strategies they implemented as a response are explored through in-depth multi-stakeholder interviews. Fifty-eight interviews were conducted as the primary data collection method, supplemented 
with secondary data (approximately 136 documents). It is rare for research to incorporate multiple case studies to explore a legitimation amidst pluralism in this way.

Thematic analysis (Miles \& Huberman, 1994) was conducted based on an analytical framework which incorporated stakeholder legitimacy demands, the dimensions of pluralism, and a legitimacy strategy framework (Kraatz \& Block, 2008). A multi-step process in this regard will be outlined more fully in Chapter 3. This follows the example of other institutional and legitimacy studies that have contextualized a discussion of strategies within a description of divergent demands (Erkama \& Vaara, 2010; Jarzabkowski et al., 2009a; Reay \& Hinings, 2009). This approach exhibits what has been described as a rare abductive treatment of a legitimacy strategy framework amidst pluralism (Pache \& Santos, 2010). Both abduction as well as the case study research strategy are suited to theoretical extension and development which underpins the contribution and intent of this thesis (Dubois \& Gadde, 2002; Miles \& Huberman, 1994; Yin, 2009).

\subsection{Thesis Structure}

This thesis is comprised of seven chapters, including this introduction (Figure 1.1). It follows a traditional thesis structure and incorporates Wolcott's (1994) advice to separate the analysis (findings chapters) from interpretive (discussion) aspects of the research endeavour. The thesis structure is outlined in Figure 1.1 below before being described more fully.

Chapter Two provides the theoretical framework guiding this thesis. First, a review of the concept of pluralism is provided. Second, the theoretical foundations of legitimacy research are outlined and the intersection between legitimacy theory and pluralism explored. In the third sub-section traditional legitimacy strategies are reviewed before the question of legitimation in pluralistic contexts is focused on. In this final sub-section a theoretical framework (Kraatz \& Block, 2008) is outlined and the sparse literature is reviewed around that conceptualization.

Chapter Three outlines the methodological approach and methods adopted in this study. It expands on the post-positivist assumptions and the case study strategy guiding this research. The concepts of pluralism and legitimacy are more fully contextualized within the 
empirical setting of NZ's science sector. Detailed explanation of case selection, the data collection processes and the stages of thematic analysis and interpretation are provided.

Chapters Four and Five outline the findings that emerged from the analysis. Chapter Four focuses on using the empirical data to explore the pluralism experienced in the three types of organization included in this study. The findings highlight that the organizations experience a complex array of legitimacy demands, embedded tensions, and power diffusion. The organizations of a similar type are shown to experience broadly similar contextual dynamics; however, slight differences in perspective regarding these dimensions are also highlighted. Chapter Five focuses specifically on the 'strategy question' and its structure is based on six case studies organized around the theoretical framework. Multiple different strategies and strategic patterns were found. Strategic stories that highlight the possibilities and challenges of legitimation amidst pluralism were evident.

Chapter Six, the discussion chapter, moves into the more interpretive realm of this thesis. This involves three interrelated aspects: 1 ) incorporating both the literature and empirical findings; 2) cross-case comparison; and 3) bringing together the 'context' and 'strategy' parts of the analysis. The findings provide support for focal framework as a useful way of understanding legitimation in pluralistic settings while also enabling theoretical extension of it. Increased understanding and empirical elaboration of some seldom investigated strategies is also gained. Propositions 1-4 are put forward to help understand why particular strategies are utilized by an organization in a particular pluralistic setting. They are based on the different perspectives of pluralism observed between similar organizational cases. Proposition 5 highlights the importance of understanding combinations of, sometimes paradoxical, strategies in pluralistic contexts.

Chapter Seven outlines more fully the contribution contained in the theoretical elaboration that is enabled by the thesis' findings. Future research avenues and an overview of the associated limitations of this current study are also discussed. The central picture with which this conclusion ends is one of organizations utilizing a gamut of strategies that traverse the sharp delineation between them. This ability to combine multiple strategies contributes to the opportunity for organizations to exhibit creativity (Snow, 1959) and high degrees of legitimacy (Kraatz \& Block, 2008) within pluralism. The difficulty of harnessing 
this potential nonetheless sits alongside this discussion of creative possibility within pluralistic contexts. 


\section{Figure 1.1 Thesis structure}

\section{Research question: How do organizations strategize for legitimacy in pluralistic contexts?}

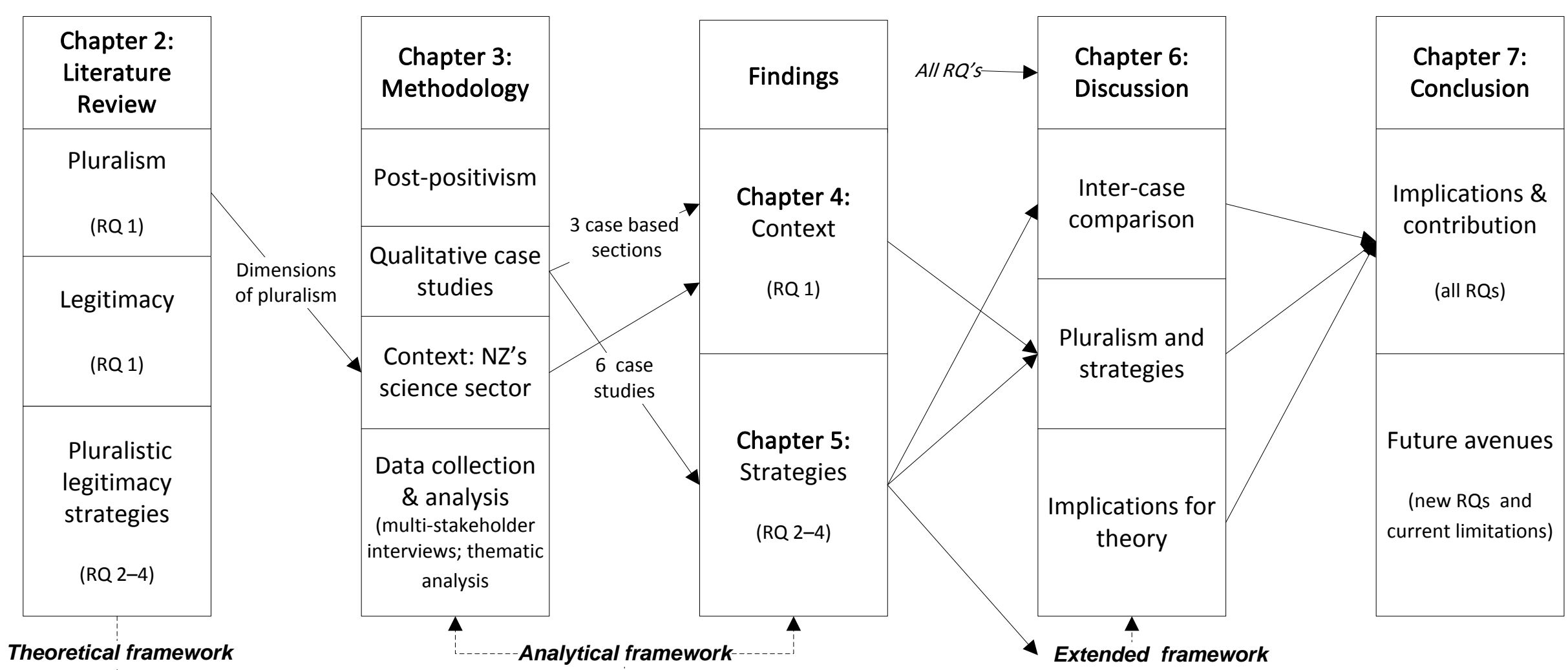




\section{CHAPTER TWO}

\section{Literature Review: Pluralism and Legitimacy Strategies}

This chapter positions this thesis in relation to contextual pluralism and organizational legitimacy. It highlights the literature gap concerning strategizing for legitimacy in pluralistic contexts. Third, a theoretical framework for understanding and investigating this research problem and question is provided. This structure is briefly illustrated in Figure 2.1 as is the comparative 'size' of each body of literature.

Figure 2.1 Literature review

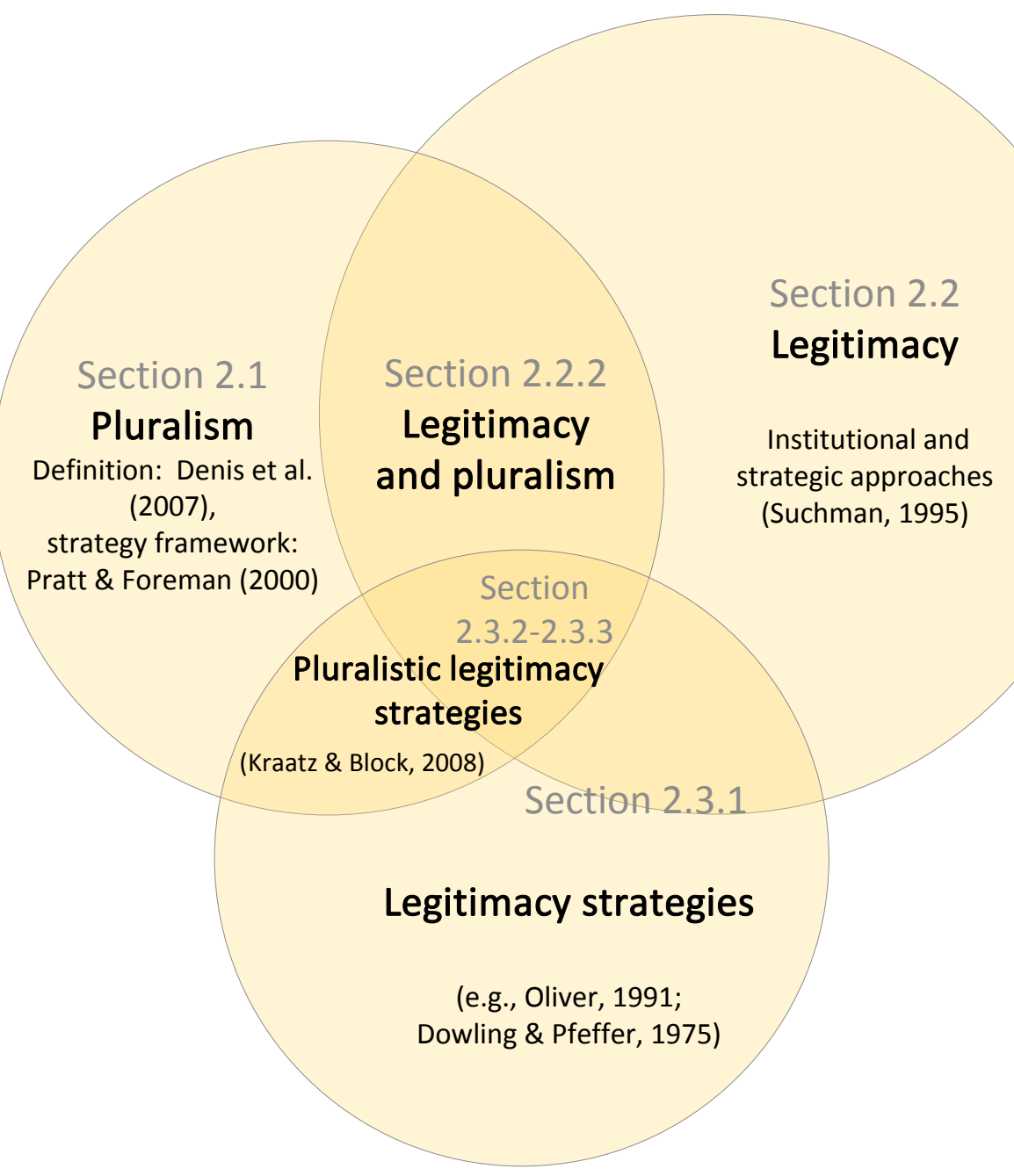




\subsection{Pluralism: A Definition and Introduction}

Pluralism is defined as contexts characterized by: 1) divergent objectives and 2) diffused stakeholder power (Denis et al., 2007). It denotes contexts consisting of divergent objectives held by multiple salient stakeholders (Cohen \& March, 1986; Jarzabkowski \& Fenton, 2006; Jarzabkowski et al., 2009a). Power is the capability for a group or individual to "bring about the outcomes they desire" (Salancik \& Pfeffer, 1977, p. 3). Diffusing power amongst multiple stakeholders therefore affects the relative power of managers and their ability to impose top-down decisions (Cohen \& March, 1986; Denis, Lamothe, \& Langley, 2001; Denis, Langley, \& Rouleau, 2006, p. 368; Denis et al., 2007). ${ }^{1}$ The concepts of diffused and relative power are therefore understood here as closely related. Figure 2.2 also illustrates that the degree of divergence and diffusion lie on a continuum (Denis et al., 2007). The level of divergence between objectives may be perceived as partly commensurable $(+)$ or incommensurable $(++)$; while power may be similarly more $(++)$ or less $(+)$ highly diffused.

Figure 2.2 Contextual pluralism (adapted from Denis et al. (2007)).

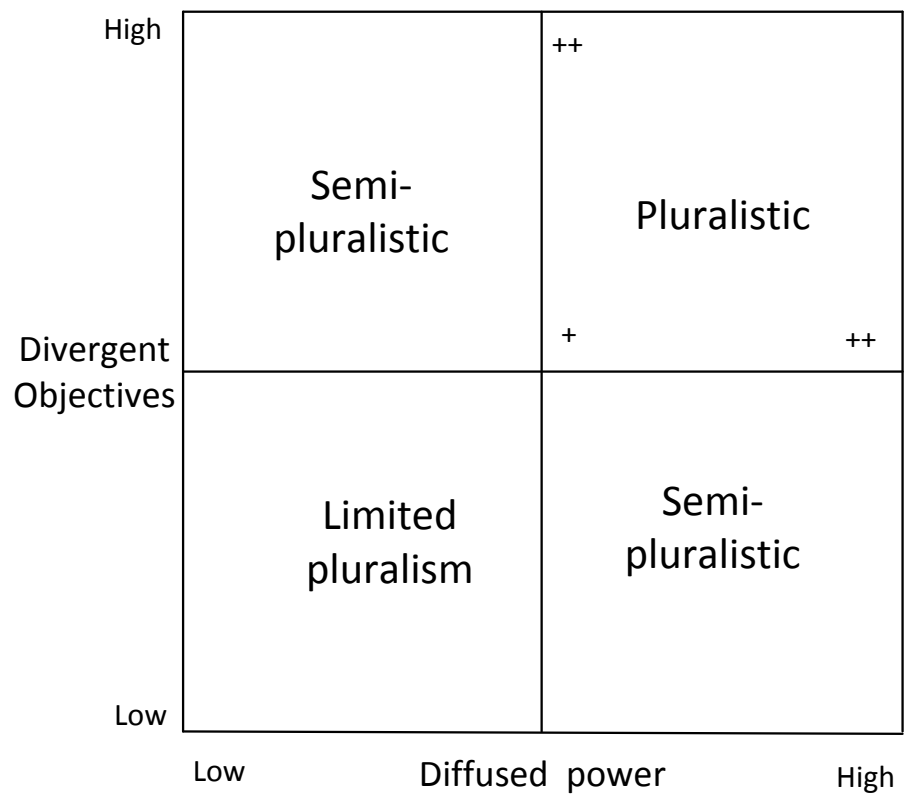

\footnotetext{
${ }^{1}$ The assumption underlying this mirrors that made by Jones when discussing stakeholder management of utilising 'managers' as the representation of 'the organization', as their primary role is one of "contracting on behalf of the firm (directly or indirectly) with other stakeholders" (Jones, 1995, p. 408).
} 
A brief overview of pluralism is followed by a more comprehensive review of the specific intersection between pluralism and legitimacy. In relation to pluralism and management research, authors make three points: 1) interest in pluralism is increasing (Denis et al., 2007; Jarzabkowski \& Fenton, 2006); 2) pluralism, however, has not been fully translated into our theories of management (Denis et al., 2007; Glynn et al., 2000); and 3) this compromises the relevance of organization theories as pluralism is an increasingly prevalent $21^{\text {st }}$ century dynamic (Glynn et al., 2000; Jarzabkowski \& Fenton, 2006; Seo \& Creed, 2002). In particular, how organizations strategize in pluralistic contexts has received less attention and is in need of further exploration (Denis et al., 2001; Denis et al., 2007; Jarzabkowski \& Fenton, 2006; Jarzabkowski et al., 2009a; Kraatz \& Block, 2008; Pache \& Santos, 2010; Pratt \& Foreman, 2000). The resultant argument is that there is a need for a picture of strategy that incorporates pluralism in a way that conventional strategy research does not.

Pluralism has, though, been evoked in many disparate strands of organizational literature. For example, pluralism is inherent in the recognition of multiple conflicting identities (Fiol, Pratt, \& O'Connor, 2009; Pratt \& Foreman, 2000) and multiple conflicting institutions and institutional logics (Friedland \& Alford, 1991; Kraatz \& Block, 2008; Scott, 1991; Seo \& Creed, 2002). The effect of pluralism on decision making (Cohen \& March, 1986; Cohen, March, \& Olsen, 1972); governance (Molz, 1995), leadership (Alvesson \& Sveningsson, 2003; Denis, et al., 2001; Denis, Langley, \& Rouleau, 2010), strategizing in the public sector (Bryson, 1988; Nutt, 1984; Ring \& Perry, 1985), and strategy more generally (Jarzabkowski \& Fenton, 2006; Jarzabkowski, Sillince, \& Shaw, 2009b; Stone \& Brush, 1996) have also been touched upon.

One particular body of work has highlighted various organizational tensions through a 'paradox lens' (Andriopoulos \& Lewis, 2009; Lewis, 2000; Quinn \& Cameron, 1988). This perspective focused on contradictory yet interrelated tensions that exist simultaneously and persist over time (Smith \& Lewis, 2011). Smith et al. (2010, p. 450) use the term 'paradoxical strategy' to denote the simultaneous implementation of contradictory yet interrelated strategies. Paradox differs from the broader contextually based definition of pluralism adopted here. Further, as Smith and Lewis (2011) outline, the paradox literature has tended to restrict its focus to specific dualities. By comparison, studies utilizing the concept of 
pluralism are more likely to incorporate a multiplicity of competing demands and embedded points of divergence (e.g., Jarzabkowski \& Sillince, 2007).

Another applicable theoretical tradition is stakeholder theory. It outlines that organizations should, for both normative and performance reasons, take note of a range of stakeholders and potentially divergent objectives and commitments. A foundation for a broader conception of who is salient beyond a traditional shareholder-centric focus is provided and this is also central to understanding pluralism (Donaldon \& Preston, 1995; Freeman, 1984; Frooman, 1999; Mitchell, Agle, \& Wood, 1997). Nonetheless, it has been argued that from a pluralism perspective (Kraatz \& Block, 2008), stakeholder theory has not yet fully explored how corporations can effectively manage the divergent stakeholder interests. From Kraatz and Block's perspective the complexity associated with moving beyond shareholdercentrism is not yet fully addressed by stakeholder research.

A number of general strategy frameworks have been proposed in the above literature for managing pluralism. Frameworks for meeting divergence demands exist in the identity (Pratt \& Foreman, 2000), paradox (Poole \& Van de Ven, 1989; Werner \& Baxter, 1994), and legitimacy literature (Kraatz \& Block, 2008). It is the specific legitimacy/pluralism intersection represented by Kraatz \& Block's framework that will be reviewed further below. First, however, the next step is to situate this within the legitimacy literature.

\subsection{Organizational Legitimacy}

Organizational legitimacy has been associated, using a variety of measures, with the enhancement of organizational survival (Baum \& Oliver, 1991; Hamilton, 2006; Meyer \& Rowan, 1977; Ruef \& Scott, 1998; Singh, Tucker, \& House, 1986). It has been connected to resource attainment (Deeds, Mang, \& Frandsen, 2004; Parsons, 1960; Pfeffer \& Salancik, 1978), and indicators of performance such as IPOs (Higgins \& Gulati, 2006; Pollock \& Rindova, 2003) and new venture growth (Zimmerman \& Zeitz, 2002). The broad consensus is that legitimacy matters. 


\subsubsection{Organizational Legitimacy: An Overview}

Weber's (1925/1968) conceptualization of legitimacy is the starting point of many organizational legitimacy reviews (e.g., Johnson, Dowd, \& Ridgeway, 2006; Ruef \& Scott, 1998; Suchman, 1995). He introduced legitimacy into sociological theory and subsequently into organization studies and provided the first categorization of different legitimacy dimensions (Deephouse \& Suchman, 2008). ${ }^{2}$ This incorporation of legitimacy into organizational research was part of a movement towards contextually focused theory. From the 1960s the proliferation of open system theories (Katz \& Kahn, 1966; Thompson, 1967/2005) had meant the "imagery of organizations" was developing. Specifically, organizational boundaries were re-conceptualized as "porous and problematic" (Suchman, 1995, p. 571). Legitimacy is one concept that focused on this "relationship between organizations and their environments" (Richardson \& Dowling, 1986, p. 94) and was incorporated as part of this research agenda (e.g., Epstein \& Votaw, 1975; Maurer, 1971; Parsons, 1960; Perrow, 1970; Terreberry, 1968). In particular, legitimacy became central to institutional theory (Meyer \& Rowan, 1977) and resource dependence theory (Pfeffer \& Salancik, 1978).

Legitimacy dimensions. The literature has been somewhat preoccupied with classifying legitimacy's dimensions (Deephouse \& Suchman, 2008). Suchman (1995) distinguished between authors who have defined organizations as legitimate when they are desirable (evaluative definitions) and those who have defined organization as legitimate when they are understandable (cognitive definitions). Evaluative definitions encapsulate socio-political legitimacy, which can be further subdivided to include legitimacy as adherence to norms and values (normative legitimacy), explicit rules and regulations (regulative legitimacy), and the self-interested calculations of an organization's stakeholders (pragmatic legitimacy). Cognitive legitimacy, by contrast, highlights that for something to be legitimate it must be understandable. The end-point is 'taken-for-grantedness', which in contrast to the

\footnotetext{
${ }^{2}$ In additional to the studies reviewed here some organizational research has used Weber's "ruled-based conception of authority" to focus on legitimacy as inherent in "structures of domination" (Courpasson, 2000; Gordon, Kornberger, \& Clegg, 2009, p. 15). Incorporating this aspect of legitimacy's Weberian foundation has, however, not been central within the research informing this study.
} 
dimensions above implies a lack of evaluation (Aldrich \& Fiol, 1994; Ruef \& Scott, 1998; Suchman, 1995) (Table 2.1).

These categorizations provide a useful frame through which to understand legitimacy's theoretical strands (Suchman, 1995). These dimensions have not developed as a single theory, but rather as a collection of concepts with different conceptual histories (Deephouse \& Carter, 2005; Suchman, 1995). Specifically, resource dependence ('strategic'), institutional, and population ecology research have been central to legitimacy theory.

Table 2.1 Overview: Legitimacy dimensions (Bridwell-Mitchell, 2008; Deephouse \& Suchman, 2008)

\begin{tabular}{|c|c|c|c|c|}
\hline $\begin{array}{l}\text { Weber } \\
(1925 / 1968)\end{array}$ & $\begin{array}{l}\text { Aldrich and Fiol } \\
\text { (1994) }\end{array}$ & $\begin{array}{l}\text { Scott }(1995) ; \\
\text { Ruef \& Scott } \\
(1998) .\end{array}$ & Suchman (1995) & $\begin{array}{l}\text { Overarching } \\
\text { Summary }\end{array}$ \\
\hline \multirow[t]{2}{*}{$\begin{array}{l}\text { Traditional } \\
\text { (tradition \& } \\
\text { custom) }\end{array}$} & $\begin{array}{l}\text { Cognitive } \\
\text { (Taken-for- } \\
\text { grantedness) }\end{array}$ & $\begin{array}{l}\text { Cognitive } \\
\text { (pre-conscious } \\
\text { taken for granted } \\
\text { rules) }\end{array}$ & $\begin{array}{l}\text { Cognitive } \\
\text { (understandability; } \\
\text { taken-for- } \\
\text { grantedness) }\end{array}$ & $\begin{array}{l}\text { Schema for } \\
\text { resolving } \\
\text { uncertainty }\end{array}$ \\
\hline & \multirow{4}{*}{$\begin{array}{l}\text { Socio-political } \\
\text { (recognized } \\
\text { principles, } \\
\text { accepted rules } \\
\text { and standards) }\end{array}$} & \multirow[t]{2}{*}{ Normative } & \multirow[t]{2}{*}{$\begin{array}{l}\text { Moral } \\
\text { (normative } \\
\text { evaluation) }\end{array}$} & \multirow[t]{2}{*}{$\begin{array}{l}\text { Norms and } \\
\text { values }\end{array}$} \\
\hline $\begin{array}{l}\text { Charismatic } \\
\text { (individual } \\
\text { saviour) }\end{array}$ & & & & \\
\hline \multirow[t]{2}{*}{$\begin{array}{l}\text { Rational/legal } \\
\text { (rational rules and } \\
\text { binding norms) }\end{array}$} & & $\begin{array}{l}\text { Regulative } \\
\text { (explicit } \\
\text { regulative } \\
\text { processes) }\end{array}$ & \multirow[t]{2}{*}{$\begin{array}{l}\text { Pragmatic } \\
\text { (self-interested } \\
\text { calculations) }\end{array}$} & \multirow[t]{2}{*}{$\begin{array}{l}\text { Laws, policies, } \\
\text { and obligations } \\
\text { - exchange } \\
\text { based } \\
\text { relationships }\end{array}$} \\
\hline & & & & \\
\hline
\end{tabular}

Resource dependence definitions. Parsons (1960) emphasized that organizations are part of a larger social system upon which they depend for scarce resources. The value systems of an organization must, therefore, be congruent with those of that super-ordinate system. Within this interaction with the environment, legitimacy involves "the appraisal of action in terms of shared or common values" (p. 175). Parson's evaluative (rather than cognitive) understanding (DiMaggio \& Powell, 1991, p. 16) has been the basis of resource dependence theory treatment of legitimacy. Suchman (1995) labelled this theoretical tradition the strategic approach to legitimacy (e.g., Ashforth \& Gibbs, 1990; Dowling \& Pfeffer, 1975; Pfeffer \& Salancik, 1978). 
From such a perspective, Dowling and Pfeffer define organizational legitimacy as:

Congruence between the social values associated with or implied by their activities and the norms of acceptable behaviour in the larger social system of which they are a part $(1975, \mathrm{p}$. 122).

They state that legitimacy "may be assessed by an examination of the values and norms prevalent in a society" (1975, p. 124) as well as resource allocation (e.g., Terreberry, 1968). This indicates that, despite the focus on resource dependencies and the 'technical' or 'task' environment (Oliver, 1991; Scott \& Meyer, 1991) this definition also incorporates values and norms. Similar definitions of legitimacy as congruence (Epstein \& Votaw, 1975; Hannigan \& Kueneman, 1977) ensued, and the resource dependence definition was used as a foundation for much research that followed (Ashforth \& Gibbs, 1990; Deephouse, 1996; Elsbach \& Sutton, 1992). The resource dependence definition retains an external focus (e.g., Pfeffer \& Salancik, 1978, p. 194). However, the strategic treatments of legitimacy have since moved beyond this and include both internal and external sources of legitimacy (Elsbach \& Sutton, 1992).

Resource dependence theory depicted legitimacy as "ambiguous, retrospective and socially constructed" (Pfeffer \& Salancik, 1978, p. 195). This implied that a degree of strategic control over legitimacy was possible and legitimacy strategies were a resultant focus (see Section 2.3). In this way the strategic school provided a foundation for addressing legitimacy from an impression management perspective (e.g., Arndt \& Bigelow, 2000; Elsbach, 1994; Elsbach \& Sutton, 1992; Hearit, 1995; Massey, 2001; Stryker, 2000). More recently, this instrumental perspective of "legitimacy as a resource to be manipulated" has been connected to stakeholder theory. The connection has been made both in terms of understanding 'stakeholder legitimacy' as part of stakeholder salience (Driscoll \& Crombie, 2001, p. 445; Mitchell et al., 1997) and in how a stakeholders' perspective is crucial to 'organizational legitimacy' (the focus here) (Hybels, 1995; Sonpar, Pazzaglia, \& Kornijenko, 2010; Woodward, Edwards, \& Birkin, 1996). Finally, insights from resource dependence theory have provided a foundation for integrative efforts that have resulted in a more strategic approach to legitimacy within institutional theory (e.g., Alexander, 1996; Kraatz \& Block, 2008; Oliver, 1991). 
Institutional theory and legitimacy. A foundation to a cognitive understanding of legitimacy is provided by Berger and Luckmann (1966): “legitimation is not just a matter of 'values.' It always implies 'knowledge' as well" (p. 86). This became part of the basis of institutional theory (Seo \& Creed, 2002; Zilber, 2002), which similarly incorporates a cognitive understanding of legitimacy. Within the seminal 1970s texts (Meyer \& Rowan, 1977; Zucker, 1977) 'new institutionalism' paid attention to previously neglected facets of the environment: institutionalized beliefs, rules, and roles (Scott, 1991, p. 346). ${ }^{3}$ In fact it is said that legitimacy is "perhaps the most central concept in institutional research" (Colyvas \& Powell, 2006, p. 308).

Meyer and Rowan (1977) focus on legitimacy but do not explicitly define it. They variously discuss legal mandates (regulative), rational effectiveness (pragmatic), and valued means and goals (normative) (Deephouse \& Suchman, 2008, p. 50). They differ, however, from the strategic approach by including cognitive rules that specify existence and meaning (Ruef \& Scott, 1998). For instance, they argue that "institutionalized rules...may be simply taken for granted...[they] often enter into social life primarily as facts which must be taken into account" (p. 341). Legitimation in this sense is about creating accounts that prevent questioning (Meyer \& Rowan, 1977, p. 349) and "appearing to be rational" (Greenwood, et al., 2008, p. 5).

Meyer and Scott (1983) provide the first explicitly institutional definition of legitimacy (Deephouse \& Suchman, 2008). Legitimacy is:

The extent to which the array of established cultural accounts provides explanations for its existence, function, and jurisdiction, and lack or deny alternatives...a completely legitimate organization would be one about which no question could be raised (Meyer \& Scott, 1983, p. 201).

\footnotetext{
${ }^{3}$ The definition of institutions used here is tied to Scott's $(1995$, p. 33) three institutional pillars of legitimacy. This broad definition defines institutions as consisting of "the cognitive, normative, and regulative structures and activities that provide stability and meaning to social behaviour. Institutions are transported by various carriers - culture, structures, and routines - and they operate at multiple levels of jurisdiction." (also see Greenwood, Oliver, Sahlin, \& Suddaby, 2008). Some conceptual slippage can occur between the definitions of institutions and legitimacy (Hybels, 1995; Johnson et al., 2006). The legitimate cannot be conceptualized apart from the institutionalized. Consequently, Johnson et al., (2006) define institutions as "legitimate conventions."
} 
While this cognitive dimension has defined the institutional perspective (e.g., DiMaggio \& Powell, 1991; Suddaby \& Greenwood, 2005), the conceptualization of legitimacy by institutional theory has incorporated and focused on regulative, normative, and cognitive 'pillars of legitimacy' (Baum \& Powell, 1995; Galvin, Ventresca, \& Hudson, 2005; Ruef \& Scott, 1998). These pillars of legitimacy are largely understood as constraining organizations - or "legitimacy as being a source of action as well as a product of it" (Kraatz \& Block, 2008, p. 247). This contrasts with the strategic strand of research's depiction of legitimacy as a resource (e.g., Ashforth \& Gibbs, 1990).

Population ecology definitions. Population ecology's density dependence theory provides empirical evidence of lower founding and higher disbanding rates when industries are small, due to the lack of (external) legitimacy associated with their low density (Aldrich \& Fiol, 1994; Archibald, 2008; Barron, 1998; Dobrev, 2001; Hannan \& Carroll, 1992). This means that population ecology focused on cognitive legitimacy: the greater the density the greater the taken-for-grantedness and survival chances (Baum \& Powell, 1995; Hannan \& Carroll, 1995; Hannan, Carroll, Dundon, \& Torres, 1995). Due to its lack of focus on organizational level strategies, population ecology theory does not explicitly add insight into the research question guiding this study.

Multidimensional definitions. Because of this fragmented history, legitimacy theory threatened to "degenerate into a chorus of dissonant voices" (Suchman, 1995, p. 572) (see, for example, the discussion between institutional (Baum \& Powell, 1995) and population econology (Hannan \& Carroll, 1995) theorists). However, the 1990s brought integrative multidimensional definitions as well as increased clarification (Aldrich \& Fiol, 1994; Ruef \& Scott, 1998; Scott, 1995; Suchman, 1995). These definitions incorporating and outlining multiple legitimacy dimensions were summarized in Table 2.1.

Of these, Suchman's (1995) definition of legitimacy has become the most widely used. It had the expressed goal of synthesizing and incorporating insight from both strategic and institutional theory. Both traditions are encapsulated in his definition of legitimacy as:

A generalized perception or assumption that the actions of an entity are desirable, proper, or appropriate within some socially constructed system of norms, values, beliefs and definitions (p. 574). 
Suchman outlines that legitimacy is generalized as it is potentially "resilient to particular events, yet dependent on a history of events." It is a perception or assumption, as an organization may diverge from societal norms but remains 'legitimate' as long as this divergence goes unnoticed. Similarly, legitimacy is socially constructed because organization can deviate from an individual's values but remain legitimate because of the lack of collective disapproval (Johnson et al., 2006, p. 213; Weber, 1925/1968). This understanding of legitimacy draws from both institutional and resource dependence theoretical perspectives, and provides a foundation for this thesis. However, it will be revisited once the intersection between pluralism and legitimacy is explored.

\subsubsection{Legitimacy Literature and Pluralism: An Overview}

Neither institutional theory nor resource dependency theory has adequately addressed the issue of conflicting pressures. (Alexander, 1996, p. 832)

As Alexander (1996) suggests, an assumption of a 'single' legitimacy can be observed in many legitimacy definitions. The critique reiterated here is that much research has collapsed legitimacy into a "solitary construct...attributable to an entire industry" (Galvin et al., 2005, p. 78). Despite some of the theoretical foundations, particularly within institutional and population ecology, of legitimacy research being antithetical to pluralism (Kraatz \& Block, 2008; Stryker, 2000), there has, however, been increasing acknowledgement that multiple conflicting legitimacy demands can confront organizations (e.g., D'Aunno et al., 1991; Deephouse \& Suchman, 2008; Elsbach \& Sutton, 1992; Kostova \& Zaheer, 1999). While much of the history of legitimacy theory has a 'monolithic feel' (Jarzabkowski et al., 2009a, p. 284; Lounsbury, 2007) there is growing appreciation of pluralism.

Drawing from the concept of 'institutional demands' (Pache \& Santos, 2010), and the definitional link between legitimacy and conformity, 'legitimacy demands' are defined as pressures for conformity (Kraatz \& Block, 2008; Suchman, 1995). The focus is on demands made by various stakeholders (i.e., sources of legitimacy) that organizations are required to respond to, in order to be perceived as "desirable, proper and appropriate" by those stakeholders (Suchman, 1995). In conceptualizing this both 'institutional logics' and 'stakeholders' are important. For clarity, the discussion below is segmented into two subsections: a discussion of multiple contradictory institutional logics and, secondly , a linking of 
that to a stakeholder perspective. Clemens and Cook (1999, p. 457 emphasis added) state that these two aspects are important for understanding legitimacy amidst pluralism: "the institutional effects attributable to normative legitimacy or taken-for-grantedness...are reinforced by the more explicitly political mobilization of a set of stakeholders" (also see: Stryker, 2000, p. 214).

Conflicting institutional logics. Institutional theory offers a view of legitimacy that discounts pluralism (e.g. Greenwood, Diaz, Li, \& Lorente, 2010; Lounsbury, 2007; Powell, 1991; Suchman, 1995). It has instead traditionally emphasized "widely shared and taken-forgranted social values and ideas" (Greenwood et al., 2008, p. 12). For example, Zucker (1983, p. 5) and Tolbert \& Zucker (1983, p.25) argue that institutionalization means "alternatives may be literally unthinkable." Further, a focus on isomorphism means that institutionalism highlights "sameness" rather than difference (Dacin, 1997; Deephouse, 1996; DiMaggio \& Powell, 1983; Greenwood et al., 2008; Meyer \& Rowan, 1977). Indeed, the assertion that legitimacy lies in isomorphism implies a common conception of what is legitimate, namely, that which the organization is becoming similar to. As Kraatz and Block (2008) state, at first glance institutionalism appears to be incommensurable with pluralism.

Attempts to develop a view of legitimacy that incorporated pluralism is observable from as early as the 1980s with DiMaggio (1988) arguing that institutional theory must account for conflict. Indeed, while this is most obvious in recent theory, such a foundation is also observable in early institutional research. Meyer and Rowan (1977, p. 356) state that: "institutional environments are often pluralistic and organization and societies promulgate sharply inconsistent myths." Meyer, Scott \& Strange (1987) and Scott \& Meyer (1991) similarly expanded on these ideas through the idea of fragmentation. Their point is that conflicting institutional demands are likely to emerge within fields defined by uncoordinated organizations. Focusing more explicitly on legitimacy, D'Aunno et al. (1991) applied this literature in their analysis of drug abuse units caught between the conflicting 'rational myths' of mental health and drug abuse treatment. They argued that their study was the first to address the difficulty of conformity to strong beliefs and rules in fragmented environments. 
Friedland and Alford (1991) cement the intersection between institutional theory and pluralism by illuminating the idea of contradicting institutional logics. ${ }^{4}$ Theirs is a macroview, with a focus on the capitalist market, the bureaucratic state, families, democracy and religion as conflicting institutional logics. Logics provide a foundation for theorizing "sources of heterogeneity" through alternative logics of actions, and "sources of legitimacy", within the institutional system (Battilana \& Dorado, 2010; Seo \& Creed, 2002, p. 243; Thornton \& Ocasio, 2008, pp. 104, 108). For example, Suddaby and Greenwood (2005, p. 35) outlined institutional logics as the basis "by which legitimacy is assessed." This framework has been the dominant one for institutional theorists seeking an understanding that has incorporates pluralism.

An array of both theoretical (Pache \& Santos, 2010; Seo \& Creed, 2002) and empirical studies have since followed, exploring multiple conflicting logics and sources of legitimacy within institutional theory. An indicative review of institutional theory shows an extensive, largely recent, building of knowledge in this regard. Understanding legitimacy amidst divergence has been explored in this way within settings as varied as law and accounting (Greenwood \& Suddaby, 2006; Purdy \& Gray, 2009; Stryker, 2000; Suddaby \& Greenwood, 2005), tobacco and gambling industries (Galvin et al., 2005), multinational corporations (Kostova \& Zaheer, 1999; Kostova \& Roth, 2002); artistic organizations (Alexander, 1996; Glynn, 2000; Glynn, 2002; Glynn \& Lounsbury, 2005); health care (D'Auuno, Succi, \& Alexander, 2000; Dunn \& Jones, 2010; Fiol \& O'Connor, 2005; Heimer, 1999; Reay \& Hinings, 2009; Ruef \& Scott, 1998); the effect of regional and family logics on Spanish firms (Greenwood, et al., 2010); banking and finance (Lounsbury, 2007; Marquis \& Lounsbury, 2007); rape crisis centres (Zilber, 2002); Taiwanese computer industries (Hung \& Whittington, 1997); companies in highly regulated industries (Jarzabkowski et al., 2009a) and organizations with a social mandate (Binder, 2007; Tracey, Phillips, \& Jarvis, 2011). Within institutional theory this discussion has frequently centred on a professional logic (for example, around medicine) encountering a managerial one in broad institutional fields

\footnotetext{
${ }^{4}$ Logics provide "the formal and informal rules of action, interaction and interpretation that guide and constrain decision makers" (Thornton, 2004, p. 70). They represent shared understanding of what "constitutes legitimate goals and how they might be pursued" (Battilana \& Dorado, 2010, p. 1420)
} 
(Cooper, Hinings, Greenwood, \& Brown, 1996; Kitchener, 2002; Rao, Monin, \& Durand, 2003; Reay \& Hinings, 2005; Scott, Ruef, Mendel \& Caronna, 2000; Thornton, 2002).

Despite the studies reviewed above, Kraatz and Block (2008, p. 246) recently noted that "the recognition of institutional pluralism [still] points towards a major void in our collective understanding" (also see Greenwood et al., 2010; Lounsbury, 2007; Reay \& Hinings, 2009). A common critique (Kraatz \& Block, 2008) is that institutional studies, including many of those cited above, have focused on divergent legitimating logics at the broad field level rather than seeking to understand its implications specifically at the organizational level (e.g., Driscoll, 2006; Dunn \& Jones, 2010; Galvin et al., 2005; Goodrick, 2002; Greenwood \& Suddaby, 2006; Lounsbury, 2007; Meyer \& Hammerschmid, 2006; Meyer \& Hollerer, 2010; Reay \& Hinings, 2005; Ruef \& Scott, 1998; Thornton, Jones, \& Kury, 2005). ${ }^{5}$ Indeed, institutional research (Clemens \& Cook, 1999; D'Auuno et al., 2000; Rao et al., 2003; Seo \& Creed, 2002; Suddaby \& Greenwood, 2005; Townley, 2002) has generally focused on the issue of explaining and theorizing change within a broad field rather than a specific focus on the effect of pluralism on organizational level legitimacy (and associated strategies). It is suggested (Dunn \& Jones, 2010; Jarzabkowski et al., 2009a; Purdy \& Gray, 2009; Reay \& Hinings, 2009) that such a focus has meant that pluralism is considered a temporary phenomenon as entire sectors such as publishing or healthcare move from one dominant logic to another (whereby one logic is replaced or suppressed) (D'Auuno et al., 2000; Greenwood \& Suddaby, 2006; Greenwood, Suddaby, \& Hinings, 2002; Hinings, Greenwood, Reay, \& Suddaby, 2004, p. 316; Hoffman, 1999; Lounsbury, 2002; Rao et al., 2003). To highlight an illustrative example, Thornton (2002) discusses the 'market period' and the 'editorial period' in a publishing industry. Within that study a period in time when a transition occurred between these 'logics' as the basis of legitimacy for the publishing industry is outlined. This differs from a focus on the tension of organizations existing in fields where both market and editorial (for example) demands exist simultaneously as a source of ongoing tension (notable exceptions include Cooper et al., 1996; D'Aunno et al., 1991; Reay \& Hinings, 2005). To summarize, legitimacy research from an institutional

\footnotetext{
${ }^{5}$ DiMaggio and Powell (1991, p. 13) define this focus as: "nonlocal environments, either organizational sectors or fields roughly conterminous with the boundaries of industries, professions, or national societies."
} 
perspective has only infrequently dealt with pluralism as multiple specific stakeholder expectations affecting organizations (Deephouse \& Suchman, 2008).

\section{Multiple conflicting stakeholder demands.}

When we speak of legitimacy...we must also ask, "Legitimacy to whom?" or "endorsed by whom?" (Hudson, 2008, p. 262)

From its inception the 'strategic-school' has incorporated conflict into its image of legitimacy. According to Suchman (1995, p. 576), the strategic approach starts with the observation that "one of the elements of competition and conflict among social organizations involves the conflict between...systems of belief or points of view." Contrasting with institutionalism, the strategic perspective predicts recurrent conflicts between managers and stakeholders regarding legitimacy (Ashforth \& Gibbs, 1990; Suchman, 1995). Legitimacy in this way is viewed as "purposive, calculated, and frequent/y oppositional' (Stryker, 2000; Suchman, 1995, p. 576; emphasis added).

Legitimacy is also treated within this approach as an intangible resource conferred by both internal and external stakeholders (Ashforth \& Gibbs, 1990; Elsbach \& Sutton, 1992; Hamilton, 2006; Perrow, 1970). ${ }^{6}$ Simultaneously, organizations are dependent on those multiple stakeholders for resources, a relationship that depends on legitimacy being perceived or assumed (Pfeffer \& Salancik, 1978; Rutherford \& Buller, 2007). This picture of multiple stakeholders making divergent legitimacy demands assist in an account that incorporates pluralism. While institutional theory has been critiqued for "inattention to the audience responsible for conferring legitimacy" (Zuckerman, 1999, p.1398); these sources of legitimacy have also been highlighted by some institutional studies (Reay \& Hinings, 2005; Ruef \& Scott, 1998). Such a focus is outlined as pivotal for the future of legitimacy theory (Deephouse \& Suchman, 2008).

Elsbach and Sutton's (1992) empirical study offers an early example of research that explicitly distinguishes between the legitimacy demands of different stakeholder groups, in

\footnotetext{
${ }^{6}$ Freeman's classic definition is that "a stakeholder in an organization is (by definition) any group who can affect or is affected by the achievement of the organization's objectives" (1984, p. 46). According to the pluralistic dimension of diffused power, the focus here is on those who can affect an organization's objectives.
} 
their case activists and stakeholders, such as politicians, in the wider community. Hybels' (1995) theoretical article was one of the first to explicitly integrate 'constituents' into a legitimacy framework. The underlying assumption is that the legitimacy demands of such groups would differ. However, Hybels does not explicitly incorporate pluralism in this way. Woodward, Edwards \& Birkin (1996) more directly argue that different stakeholder groups can hold divergent legitimacy conferring expectations. Deephouse (1996) also incorporates stakeholders into his definition stating that "a key step in defining it is identifying relevant social actors" (p. 1025). The evaluations of two social actors are included and Deephouse acknowledges this limitation regarding focusing on only two sources, rather than including a wider variety of stakeholders. A similar pattern is evident in other quantitative studies (Deephouse \& Carter, 2005, p. 337; Ruef \& Scott, 1998).

Nonetheless, a growing number of empirical studies have included a range of stakeholders as a way of incorporating pluralism. Examples include Brown's (1995) study of different internal stakeholder perceptions and how this affected the legitimacy of an IT project. Glynn's (2002) study from an institutional perspective incorporated different stakeholders (critics, managers, musicians) and linked their different perspectives to conflict between logics. Driscoll's (2006) study of the Canadian forest industry discussed legitimacy management where marginalized perspectives in the context of multi-stakeholder contexts undermined the dominant logic. Sonpar et al. (2010), meanwhile, outline the importance of addressing the demands of multiple stakeholders rather than a single dominant source of legitimacy (government). These provide empirical examples of relating broader legitimating 'logics' to struggles regarding legitimacy demands between stakeholders (also see Jarzabkowski et al., 2009a; Reay \& Hinings, 2005; Reay \& Hinings, 2009).

An omission within the literature remains a predominant focus on external sources of legitimacy. Legitimacy's main theoretical strands are all critiqued for not emphasizing internal legitimacy dynamics (Stryker, 2000). Indeed, while a theoretical foundation for incorporating internal stakeholders as legitimacy-conferring constituents now exists (Pache \& Santos, 2010; Stryker, 2000; Woodward et al., 1996), few legitimacy studies have included internal stakeholders (Greenwood et al., 2008). Nonetheless, exceptions are growing and show that incorporating internal stakeholders is important in understanding legitimacy and 
legitimacy strategies amidst pluralistic contexts (Battilana \& Dorado, 2010; Brown, 1995; Glynn, 2002; Jarzabkowski et al., 2009a; Sonpar et al., 2010; Zilber, 2002). Indeed, as studies of legitimacy within multinational organizations remind us: "organizations themselves can be complex and fragmented" (Kostova \& Zaheer, 1999, p. 67).

Erickson (2006) criticizes legitimacy authors (e.g., Hybels, 1995) for failing to acknowledge the relative importance of each stakeholder group they identify. Understanding legitimacy entails a focus on those with the power to determine what "counts as legitimate" (Brown, 1994, p. 862). A key issue becomes stakeholder salience, or the degree to which a stakeholder's legitimacy demand can affect an organization (Deephouse \& Suchman, 2008; Driscoll \& Crombie, 2001; Erickson, 2006; O'Donovan, 2002; Ruef \& Scott, 1998). Mitchell et al. (1997) provide a framework of stakeholder salience that incorporates power, legitimacy (of the stakeholder) and the urgency of the demand. Stakeholder salience explains Pfeffer and Salancik's (1978) observation that an organization need only be endorsed by a segment of society and can remain legitimate in the face of external attack by less salient groups (Suchman, 1995). Other empirical studies have explicitly incorporated the broad idea of salience in their studies of legitimacy (Brown, 1995; Driscoll \& Crombie, 2001; Elsbach \& Sutton, 1992; Erickson, 2006). This incorporation of stakeholder salience is connected to pluralism's diffused power dimension (Denis, et al., 2007).

\subsubsection{A Stakeholder-Centric Legitimacy Definition}

The overview above provides a theoretical base from which to settle on a definition of legitimacy for this project. Through integrating insights from both the strategic and institutional conceptions of legitimacy this definition positions this study as drawing from both theoretical strands. Such positioning has a broad basis in the literature (Elsbach \& Sutton, 1992; Oliver, 1991; Suchman, 1995) with Alexander (1996) labelling it 'strategic institutionalism.'

Suchman's (1995) definition of legitimacy has become widely used; however, its selection here is not automatic. Hybels (1995) offers both a critique of the vagueness of legitimacy definitions and his own stakeholder-focused conception of legitimacy, something which the above discussion has suggested is important for a conception of legitimacy that incorporates 
pluralism. For Hybels it is "necessary above all to identify the critical actors, both internal and external, whose approval is necessary to the fulfilment of an organization's function" ( $p$. 243). The argument is that contemporary legitimacy research should be contextualized, with analysis grounded in concrete actors and their interests (Galvin, et al., 2005; Stryker, 2000; Van Leeuwen, 2007). ${ }^{7}$

In order to more explicitly incorporate pluralism Suchman's (1995) definition is expanded upon. Legitimacy is defined here as:

A perception or assumption by particular internal and external organizational stakeholder groups that the actions of an entity are desirable, proper or appropriate.

This moves research, in accordance with Deephouse and Suchman's (2008, p. 68) call, beyond the traditional focus on "analytic distinctions among the various dimensions of legitimacy" to (potentially multiple and conflicting) sources of legitimacy, i.e., included here via stakeholders. It also allows for a conception of 'legitimacies' rather than a singular 'generalized legitimacy' (Suchman, 1995). This provides a foundation for investigating strategies for managing those multiple, potentially divergent, stakeholder legitimacies.

\subsection{Strategizing for Legitimacy in Pluralistic Contexts}

Historically, different assumptions about organizational agency and cultural embeddedness have distinguished the "strategic tradition" from institutional theory and led to the former's focus on organizational level legitimacy strategies (Suchman, 1995). There is a long history of literature establishing that organizations take steps to ensure their continued legitimacy (Parsons, 1960; Perrow, 1970). Resource dependence theory (Pfeffer \& Salancik, 1978, p. 3), in particular, argued that research attention had been paid to the "problem of using resources" rather than on "the problem of acquiring resources." Legitimacy strategy focuses us on this less developed side of strategy. By contrast:

The lofty concern for populations has left institutionalists exposed to accusations of

\footnotetext{
${ }^{7}$ While emphasising the 'particular', this definition does not contradict the long-held definition of legitimacy as collectively rather than individually conferred (Deephouse \& Suchman, 2008; Johnson et al., 2006, p. 57; Suchman, 1995, p. 574) due to maintaining an emphasis on groups of stakeholders rather than locating it with individuals.
} 
marginalizing individual agency and smothering diversity in aggregation (Hung \& Whittington, 1997, p. 553)

As this suggests, institutional theory can be seen as a strand of legitimacy literature that has not focused on exploring different legitimacy strategies. A 'conformity' bias in its explanations of the organizational world is widely recognized and used as a basis for critique (Covaleski \& Dirsmith, 1988; DiMaggio, 1988; Fligstein, 1997; Kitchener, 2002; Kraatz \& Block, 2008).

Legitimation is the process whereby legitimacy (as defined above) is "established or defended" (Driscoll, 2006; Hybels, 1995; Kostova \& Zaheer, 1999; Kraatz \& Block, 2008; Richardson \& Dowling, 1986, p. 91; Richardson, 1985). The concept of "legitimacy strategies" refers to legitimation (the increase, maintenance or repair of legitimacy) achieved or attempted through a consistent stream of action (Aldrich \& Baker, 2001; Mintzberg \& Waters, 1985; Suchman, 1995; Vaara et al., 2006). These strategies have been clustered under the label 'legitimacy management' by some authors providing legitimacy strategy frameworks (Ashforth \& Gibbs, 1991; Suchman, 1995). In pluralistic contexts, legitimation involves strategies for adapting to divergent legitimacy demands (Kraatz \& Block, 2008). Reflecting an appreciation of pluralism this definition here of legitimacy strategy recognizes strategies as action resulting "from strategic managerial action or emerge more naturally from interaction of constituent groups" (Kraatz \& Block, 2008, p. 285).

\subsubsection{Foundational Legitimacy Strategy Frameworks}

This sub-section outlines the foundational legitimacy strategy frameworks while the next sections review legitimation amidst pluralism specifically.

Strategy frameworks. In the earliest legitimacy strategy framework Dowling and Pfeffer (1975) outline three broad strategies. Legitimacy can be achieved by: 1) adapting to conform to prevailing definitions of legitimacy in its environment; 2) altering the definition of legitimacy so that it conforms to the organization's current practice; or, 3) identification of organizations with legitimate symbols. Many other authors have made similar distinctions (Epstein \& Votaw, 1975; O'Donovan, 2002; Sethi, 1979) or explicitly used this framework 
(Pfeffer \& Salancik, 1978). The agency continuum apparent in Dowling and Pfeffer's framework between an organization adapting (low agency) versus altering (high agency) stakeholder's legitimacy demands is well cemented in legitimacy research (Suchman, 1995). In particular, Oliver (1991) integrates institutional and strategic legitimacy theory and, through her typology refining the 'agency' continuum, proposes that organizational strategies vary from acquiescence to manipulation. In its incorporation of agency, Oliver's framework was central to institutional theory moving beyond its 'structure' and 'conformity' centralism (Heugens \& Lander, 2009).

More agency-intensive strategies such as 'altering legitimacy definitions' (Dowling \& Pfeffer, 1975) or 'manipulation' (Oliver, 1991), remain the least understood of legitimacy strategies, with many authors mentioning them but simultaneously dismissing them as difficult and less viable than more adaptive strategies (Ashforth \& Gibbs, 1990; Dowling \& Pfeffer, 1975; Epstein \& Votaw, 1975; Suchman, 1995). For example, two studies that statistically test Oliver's framework do not include the most agency-intensive strategy of manipulation (Goodstein, 1994; Ingram \& Simons, 1995).

A distinction between 'substantive action' and 'symbolic management' observable within Dowling and Pfeffer's (1975) framework is further developed by Ashforth and Gibbs (1990, pp. 178, 180). They describe this as the difference between "real, material change" and symbolic processes that "appear consistent" (also see Richardson \& Dowling, 1986; Richardson, 1985). Based on this distinction, Ashforth and Gibbs outline ten specific strategies, many of which draw from impression management theory. Although no empirical work has explicitly applied their framework, many studies have followed integrating impression management and institutional theories (Arndt \& Bigelow, 2000; Bansal \& Clelland, 2004; Elsbach, 1994; Elsbach \& Sutton, 1992; Massey, 2001). An additional distinction highlighted by Ashforth and Gibbs' framework is between gaining, maintaining, and defending (or repairing) legitimacy. It is argued that strategic action will differ depending on which of these is the focus (Ashforth \& Gibbs, 1990; Massey, 2001; O'Donovan, 2002). 
In another comprehensive framework, Suchman (1995) elaborates on Ashforth and Gibb's (1991) theorizing based on this distinction between legitimation activities. He also further differentiates between strategies focused on pragmatic, normative or cognitive legitimacy. However, Deephouse and Suchman (2008) argue that any legitimacy strategy may operate on a variety of dimensions so that a strict demarcation between legitimacy forms is perhaps less central than Suchman (1995) suggests. Finally, Suchman is another example of a legitimacy strategy framework utilizing an agency continuum. His moves from 'conformity to the environment' to 'selecting the environment' to 'manipulating the environment.' Zimmerman \& Zeitz (2002) expand on this through an additional category of 'creation'; however, this can be still understood as part of 'manipulation'. A summary of these foundational frameworks from the strategy strand of literature is provided in Figure 2.3. 
Figure 2.3 Summary of foundational legitimacy strategy frameworks (Ashforth \& Gibbs, 1990; Dowling \& Pfeffer, 1975; Oliver, 1991; Suchman, 1995)

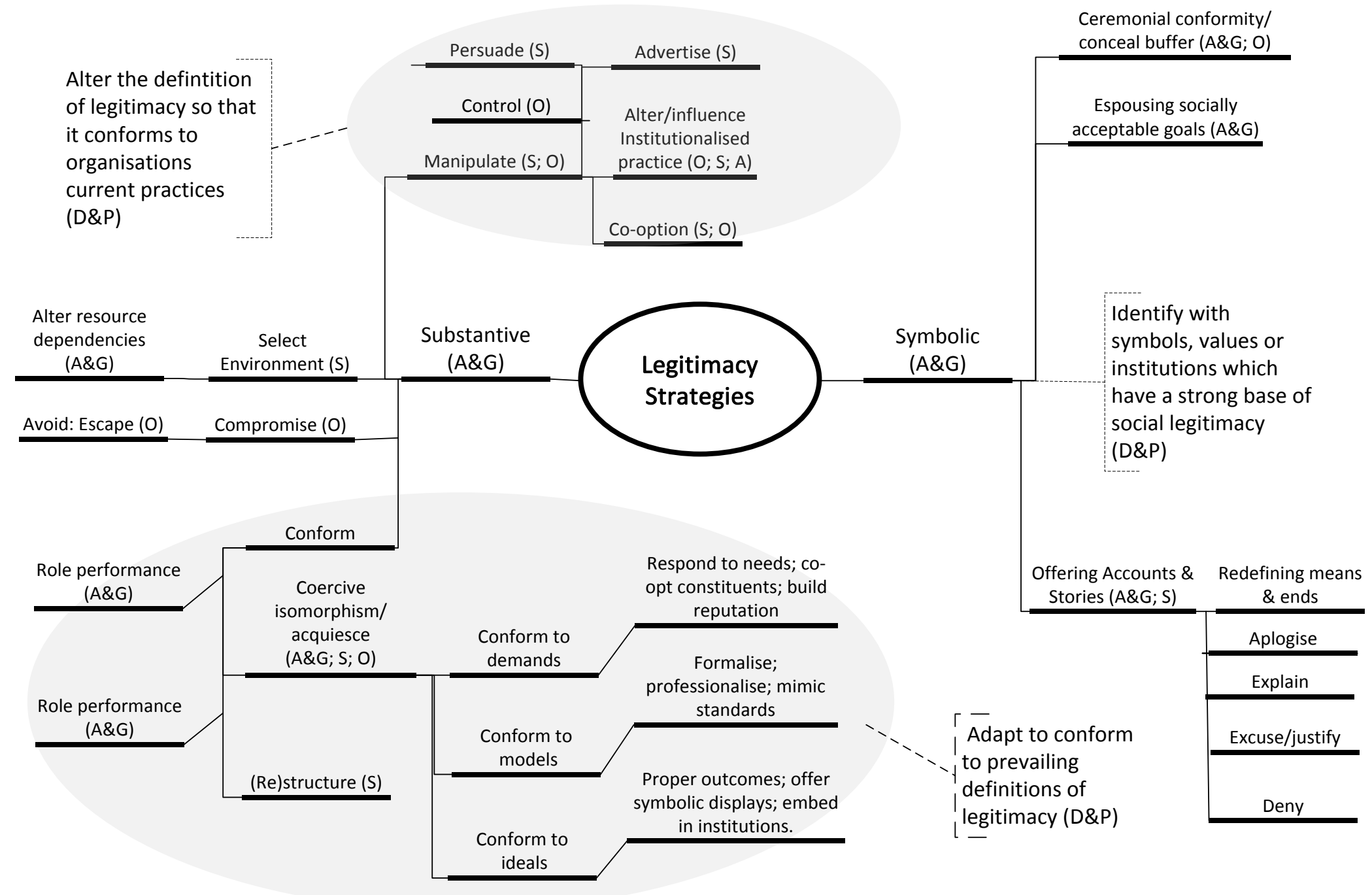


Institutional theory and legitimacy strategies. Despite the centrality of resource dependence theory in the development of an understanding of legitimacy strategy, insight from institutional theory is still prevalent in the summary in Figure 2.3. First, institutional theory provides much of the theoretical foundation regarding "conformity" as a strategic response. This is the concept of isomorphism whereby organizational forms, structures, policies, and practices that are similar to others institutionalized in their environment are adopted (Deephouse, 1996; Deephouse \& Carter, 2005; DiMaggio \& Powell, 1983; Meyer \& Rowan, 1977). Indeed, isomorphism is the most empirically supported legitimacy strategy (Dacin, 1997; Deephouse, 1996; Deephouse \& Carter, 2005; Glynn \& Abzyg, 2002; Haveman, 1993; Heugens \& Lander, 2009; Ruef \& Scott, 1998). Second, from the inception of institutional theory Meyer and Rowan (1977) outline decoupling, separating structures "from each other and from ongoing activities" (p. 340), as a legitimacy strategy (Boxenbaum \& Jonsson, 2008). Isomorphism, decoupling, and more broadly the language of institutional theory (e.g., "altering socially institutionalized practices" (Ashforth \& Gibbs, 1990, p. 178)) are adopted within the strategy frameworks outlined above.

While institutional literature has tended to downplay the potential for organizations and organizational actors to actively manage their contexts, this can be exaggerated (e.g., Lawrence, 1999). In particular, Oliver's (1991) framework of institutional response strategies, already outlined above, is a seminal example of incorporating a strategic approach with institutional theory (Lawrence \& Suddaby, 2006). Indeed, broad theoretical frames within institutional theory have increasingly directly addressed the over-deterministic view of the environment. Focused on the issue of explaining institutional change, institutional entrepreneurs' are defined as individual actors with the capacity to develop strategies and shape institutions (Battilana \& Dorado, 2010; DiMaggio, 1988), and institutional entrepreneurship has becomes a broad term to mean any action geared at creating or changing institutions (Levy \& Scully, 2007). Drawing from Oliver (1991) a closely related term, 'institutional work' has been defined as being less focused on 'heroic' actors. It is a more a general view of "the purposive action of individuals and organizations aimed at creative, maintaining and disrupting institutions" (Lawrence \& Suddaby, 2006, p. 215; Lawrence, Suddaby, \& Leca, 2009). In short, institutional work encompasses a wider variety 
of actors (beyond the institutional entrepreneur) and agency-intensive activity beyond institutional creation (Lawrence \& Suddaby, 2006; Perkmann \& Spicer, 2008).

Discursive legitimacy strategies. Recently, the impression management strategies contained in foundation strategy frameworks have been extended through critical discourse (Vaara et al., 2006; Van Leeuwen, 2007; Van Leeuwen \& Wodak, 1999) and rhetorical (Erkama \& Vaara, 2010; Green, 2004; Hearit, 1995; Suddaby \& Greenwood, 2005) legitimacy strategy frameworks. This 'turn to language' has been evident both within (Creed, Scully, \& Austin, 2002; Phillips, Lawrence, \& Hardy, 2004) and outside (Vaara \& Monin, 2010) an institutional approach. One example is Suddaby and Greenwood's (2005) identification of five rhetorical legitimacy strategies within change processes. These are ontological (rhetoric based on assumptions about what can/cannot exist or co-exist), historical (appeals to history and tradition), teleological (divine purpose or final cause), cosmological (emphasis on inevitability), and value-based theorizations (appeals to wider belief systems). This different level of analysis provides a distinct conceptualization of legitimacy strategy.

\subsubsection{Effect of Pluralism on Legitimacy Strategies}

That pluralism increases the complexity of legitimacy management is widely recognized (D'Aunno, et al., 1991; Kostova, Roth, \& Dacin, 2008; Kostova \& Zaheer, 1999; Kraatz \& Block, 2008; Seo \& Creed, 2002; Suddaby \& Greenwood, 2005). For instance, Meyer and Scott (1983, p. 202), argue: "the legitimacy of a given organization is negatively affected by the number of different authorities sovereign over it and by the diversity or inconsistency of their accounts of how it is to function." Three tensions will be briefly touched upon to highlight the complexity strategizing for legitimacy amidst pluralism entails.

Most notably, in pluralistic contexts, organizational efforts to legitimize themselves with one stakeholder group may have a negative effect on its legitimacy with another (Kraatz \& Block, 2008; Pfeffer \& Salancik, 1978, p. 27). As Stryker (2000, p. 209) outlines, in pluralistic contexts "you are damned if you do, damned if you don't" as the "search for legitimacy will produce some unintended delegitimation." This issue was explored empirically by Elsbach and Sutton (1992) in their study of social movement organizations where attacks by some hostile stakeholder groups were directly related to legitimacy conferment by other groups. 
In particular, as outlined above, a cornerstone of the institutional understanding of legitimation is isomorphism (Boxenbaum \& Jonsson, 2008; Deephouse, 1996; Deephouse \& Carter, 2005; Lawrence, 1999). However, isomorphism becomes problematic when the assumption that the organization operates in a single, clearly defined field does not hold (Kostova et al., 2008; Kostova \& Zaheer, 1999). Indeed, isomorphism and acquiescence potentially decrease legitimacy: becoming isomorphic to particular institutional arrangements can heighten conflict and reduce legitimacy with respect to those stakeholders whose expectations differ (Elsbach \& Sutton, 1992; Kraatz \& Block, 2008; Seo \& Creed, 2002).

Another tension exists between ambiguity and clarity. The pluralism literature suggests the merits of strategically utilizing ambiguity (Jarzabkowski et al., 2009b; Ring \& Perry, 1985; Stone \& Brush, 1996). Ambiguity can enable multiple relationships to a broadly communicated objective and, therefore, can be helpful within pluralism (Contractor \& Ehrlich, 1993; Davenport \& Leitch, 2005; Eisenberg, 1984; Jarzabkowski et al., 2009b). Within the legitimacy literature the strategic use of ambiguity is contained in the concept of decoupling, where "goals are made ambiguous" (Meyer \& Rowan, 1977, p. 354). Other legitimacy literature, though, considers ambiguity to be a threat to legitimacy. For example, the foundational concept of cognitive legitimacy, making something understandable and knowable, explicitly contradicts the ambiguity argument (Aldrich \& Fiol, 1994; Suchman, 1995). Stone and Brush (1996, p. 647) outline this contradiction when arguing that formal planning is integral to attaining legitimacy, yet in pluralistic contexts this clarification can exacerbate stakeholder conflict.

A tension between conformity to stakeholder demands and consistency (in response and over time) is highlighted. The consistency/legitimacy link is articulated by Kraatz and Block (2008, p. 261): stakeholders "anthropomorphize organizations and look for evidence of integrity and self-consistency in their actions...the legitimacy-seeking organization needs not only to be multiple things to multiple people, but also something unto itself." They argue that organizations are not only expected to symbolize their conformity with immediate legitimacy demands but also to demonstrate cross-temporal and spatial consistency. Consistency has been similarly emphasised in other legitimacy research (Aldrich \& Fiol, 1994; Massey, 2001). However, a tension remains between the consistency prerequisite and many 
of the ideas associated with managing legitimacy demands amidst pluralism (Brunsson, 2002). Pluralism means that adopting only those beliefs that produce internally consistent practices is too "risky" (D'Aunno et al., 1991, p. 641) and "organizations in search of external support and stability incorporate all sorts of incompatible structural elements" (Meyer \& Rowan, 1977, p. 356). Achieving the organizational flexibility and adaptability required in pluralistic contexts (Denis et al., 2007; Jarzabkowski \& Fenton, 2006) also becomes difficult if consistency is over-emphasized. This issue appeared to have been largely unexplored (Kraatz \& Block, 2008).

Rather than depicting this complexity as negative (Meyer \& Scott, 1983), pluralism can also be viewed as offering organizations an expanded array of potential strategic options (Kraatz \& Block, 2008). From an institutional theory perspective, "the presence of multiple institutional orders or alternatives constitutes an opportunity for agency" (Clemens \& Cook, 1999, p. 459). Pluralism helps explain strategic activity and institutional entrepreneurship in the face of constraining forces that demand conformity; that is, the problem of embedded agency (Greenwood \& Suddaby, 2006; Seo \& Creed, 2002). ${ }^{8}$ Pluralism therefore enables an expanded gamut of strategic possibilities (Aurini, 2006; Lounsbury, 2007; Marquis \& Lounsbury, 2007). It can create increased opportunity for organizations to exercise strategic choice (Kraatz \& Block, 2008; Mars \& Lounsbury, 2009; Pache \& Santos, 2010; Seo \& Creed, 2002). In this way pluralism can assist in extending legitimacy theory away from the dominant focus on 'isomorphism' (e.g., DiMaggio \& Powell, 1983) or 'congruence' (e.g., Ashforth \& Gibbs, 1991; Deephouse, 1996; Dowling \& Pfeffer, 1975). In this way pluralism can be an avenue to contribute to the broad research gap regarding what has been labelled the "pro-conformance bias" that underpins institutional theory's treatment of legitimacy (Fligstein, 1997; Kitchener, 2002, p. 411; Kraatz \& Block, 2008).

\footnotetext{
${ }^{8}$ The embedded agency problem is the paradox of "how institutional change is possible if actor's intentions, action, and rationality are conditions by the institutions they wish to change" (Dorado, 2005, p. 285). That actors gain their agency from the presence of multiple, potentially divergent, institutions is a central 'solution' evident in the literature (Seo \& Creed, 2002; Dorado, 2005).
} 


\subsubsection{Legitimacy Strategies amidst Pluralism: A Framework and Review}

Kraatz \& Block (2008, p. 244) state that despite broad recognition of institutional pluralism "there has to date been little apparent attempt to systematically assess its practical and theoretical implications." As already outlined, this has included a dearth of research focusing on the strategies organizations use to manage their legitimacy in pluralistic contexts. Indeed, authors argue that increased acknowledgement of pluralism by legitimacy literature has not translated into research that has addressed this strategy question (Jarzabkowski et al., 2009a; Pache \& Santos, 2010; Reay \& Hinings, 2009). In particular, the question of how organizations strategize for legitimacy in such contexts remains rarely empirically investigated. Binder (2007) and Pache and Santos (2010) point out that the few studies in this space have tended to focus on the identification and exploration of a single, often idiosyncratic, strategy. Similarly, empirical studies (e.g., D’Aunno et al., 1991; Reay \& Hinings, 2009) have tended not reflected their findings back to or proposed a general legitimacy strategy framework such as the one proposed by Kraatz \& Block (2008). ${ }^{9}$

While insightful, most foundational legitimacy strategy frameworks outlined above (Ashforth \& Gibbs, 1990; Pfeffer \& Salancik, 1978; Suchman, 1995) do not adequately address such a pluralistic context. For instance, Ashforth and Gibbs (1990, p. 177) mention that "organizations are answerable to a number of diffuse constituencies with frequently conflicting expectations and perceptions", but do not reflect on how affects legitimacy strategies. This is mirrored by Suchman (1995, p. 590) who argues that organizations only "occasionally find themselves" in pluralistic contexts when they cannot choose a more unitary one. Consequently, he discusses the managing legitimacy in pluralistic contexts only peripherally, and this discussion is not represented in his framework. Pluralism, despite being acknowledged, has therefore been rarely used to extend, or reflect on these dominant legitimacy frameworks.

\footnotetext{
${ }^{9}$ An exception is Purdy and Grey (2009) who found four legitimacy strategies used by "state dispute resolution offices" within a context of conflicting logics. However, they only spend one or two paragraphs exploring each of the strategies they found.
} 
The dominance of field-level studies has also meant that broad resistance dynamics in the face of pluralistic demands have been studied at the field level rather than developing an understanding of organization level strategies (Greenwood et al., 2010; Lounsbury, 2007; Marquis \& Lounsbury, 2007; Suddaby \& Greenwood, 2005). Further, these studies have explored resistance through focusing on a single practices, such as workforce downsizing (Greenwood et al., 2010) or CEO incentive plans (Westphal \& Zajac, 1995). This issue was identified by Kraatz and Block (2008, p. 249) who instead provided a theoretical framework at the organizational level for understanding how organizations can manage "pluralistic legitimacy criteria." In focusing on legitimacy strategies at the organizational level, they draw from old-institutionalism (Selznick, 1957; Selznick, 1992) and label their approach "institutional organizationalism." While old-institutionalism did not focus in legitimacy in the way 'new' institutionalism did, Selznick's theorizing was used to focus their legitimacy framework on the heterogeneous "internal and local environment" of specific organizations (Arndt \& Bigelow, 2000, p. 512; Greenwood \& Hinings, 1996), and more local influences, such as community, rather than broad sectors or fields (Marquis, Glynn \& Davis, 2007). 'New institutionalism' has traditionally been focused at the field level and highlighted homogeneity. By contrast, incorporating 'old-institutionalism' focuses research on 'local community' dynamics, the organizational level, and a strategic approach (DiMaggio \& Powell, 1991).

Kraatz and Block's (2008) framework is adopted here due to this direct focus on the intersection of legitimacy strategies and pluralism at the organizational level. ${ }^{10}$ They outline four strategies for adapting to legitimacy demands within pluralism. Organizations can 1) attempt to eliminate the pluralism, 2) compartmentalize and deal with legitimacies separately, 3) reign in tensions through finding balance, and 4) forge new orders and become self-legitimating. While they provide rich pictures of these strategies, they do not

\footnotetext{
${ }^{10}$ Additional frameworks for understanding legitimation in contested organizational environments have been provided, addressing the discourse (Creed et al., 2002; Vaara et al., 2006) and rhetorical strategies that individuals and groups can use to persuade (Erkama \& Vaara, 2010; Suddaby \& Greenwood, 2005); or what Zilber (2002) labels as the micro-politics of meaning. By adopting Kraatz and Block's (2008) model, although recognizing the importance of such understanding, I am focused on a different broader picture of response strategies concerning what organizations do as well as say that is distinct from these frameworks. Such a framework is aligned with recent observations of the dominance of 'discourse' within studies of institutional entrepreneurship and a call to 'expand the methods' to include to account for other dimensions such as practices and material resources (Battilana, Leca, \& Boxenbaum, 2009).
} 
develop the dimensions underlying their framework. In order to refine our understanding two additional frameworks are turned to.

Although not specifically focused on pluralism, Oliver's (1991) response strategy framework has been previously applied to theorize about legitimation within such contexts (Pache \& Santos, 2010). It provides greater insight vis-à-vis pluralism than other foundational theorization due to its incorporation of 'compromise' and even 'defiance' as potential responses, something not explicitly incorporated by other foundational frameworks (e.g., Dowling \& Pfeffer, 1975; Suchman, 1995). To reiterate, a central aspect of Oliver's framework is an organizational agency continuum. This can be usefully linked to Kraatz and Block's (2008) strategies. For instance, their fourth strategy (labelled transcension here) highlights the ability to construct "a logic of its own" (p. 20) and attain autonomy as a way of managing legitimacy amidst pluralism. This is indicative of the high degree of agency inherent at one end of Oliver's continuum. Likewise, Kraatz and Block refer to Oliver's compromise strategy in describing the lower agency response of balancing demands. This link will be further discussed below. While Oliver's framework adds key supplementary insight it is not the central framework adopted here: Kraatz and Block (2008) incorporate internal stakeholders into their strategic picture (as sources of both legitimacy and pluralism) whereas what the organization is 'responding to' in Oliver's framework is firmly external.

Pratt and Foreman's (2000) identity framework incorporates another useful dimension: strategies that seek to integrate versus segregate demands. This distinction is also explicitly, although briefly, mentioned within legitimacy theory (Suchman, 1995). Pratt and Foreman's framework is also incorporated due its explicit utilization by Kraatz and Block (2008). The latter directly link Pratt and Foreman's categories to their first three strategies. With regards to their fourth 'transcension' strategy, Kraatz and Block implicitly illustrate the strategy's integrative impulse, describing it as entailing "the ability to integrate" (p. 252) multiple legitimacy demands.

The updated framework is depicted in Figure 2.4. The strategies will now each be explored as a way of further reviewing the literature. This 'pluralism legitimacy' framework draws from foundational strategy frameworks (see figure 2.3) which were developed with 'less pluralistic' (see figure 2.2) contexts in mind to the extent that they provide insight into 
Kraatz and Block's framework. That is, to the extent that they are also applicable to pluralistic contexts. It also incorporates the growing number of empirical studies that have increased insight into specific strategies. In reviewing these empirical studies the example provided by the central theoretical articles (Kraatz \& Block, 2008; Pache \& Santos, 2010; Suchman, 1995) is followed whereby "institutional response strategies" (e.g., Oliver, 1991) and legitimacy strategies are viewed as closely interlinked. Institutional research that discusses strategies for managing conflicting institutional logics, without framing them as "legitimacy strategies" per-se, therefore also form part of this review.

Figure 2.4 A pluralistic legitimacy framework ${ }^{11}$

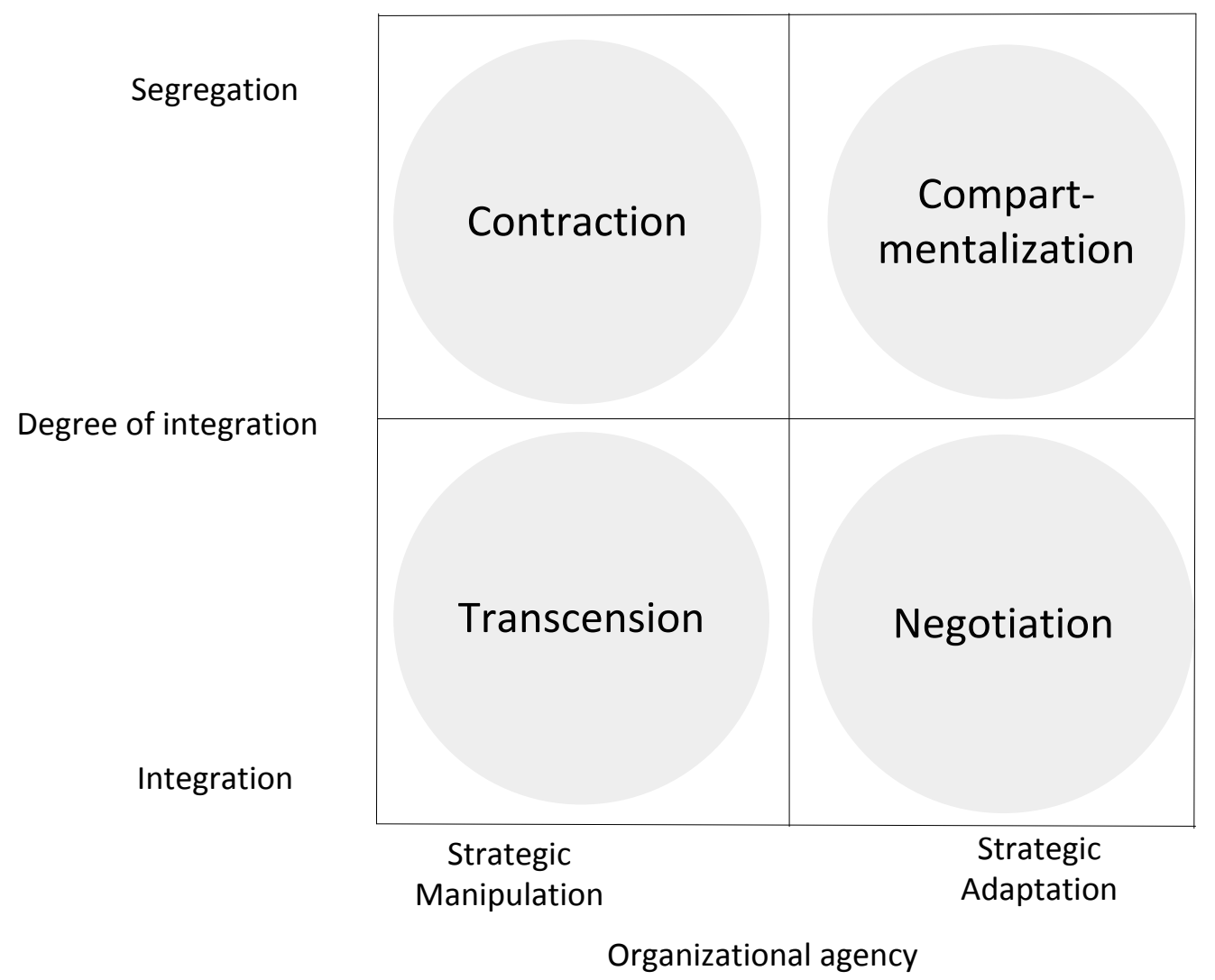

\footnotetext{
${ }^{11}$ The placement of the strategies along the agency continuum is based on Oliver's (1991) positioning. The adaptation of this continuum in the framework illustrated here (e.g., 'strategic' rather than 'passive' adaptation/ reflects that acquiescence is defined as less applicable to pluralistic contexts (Oliver, 1991, p. 163; Pache \& Santos, 2010). The placement along the integration continuum partly reflects insights developed by Pratt and Foreman (2000) and Suchman (1995). While this framework has focused on and drawn on the literature specifically addressing legitimacy strategies, a degree of alignment with dialectical or paradox frameworks is evident (Poole \& Van de Ven, 1989; Werner \& Baxter, 1994). These include: ignoring one pole (contraction here); satisfying the poles sequentially (compartmentalization here); moderation through satisfying them both at once (negotiation here); and reframing them as complementary (transcension here).
} 
Segregation strategies. Segregation implies that some legitimacy demands are not included or that they are separated from each other (Pratt \& Foreman, 2000; Suchman, 1995). Organizations can either delete or marginalize some of them (contraction); or deal with them individually and in a targeted fashion (compartmentalization). These segregation strategies are distinguished by the degree of organizational agency involved. With contraction, an organization is seeking to transform the pluralistic context with which it is faced. Compartmentalization, meanwhile, entails a more adaptive impulse through still seeking to comply, or at least being perceived to comply, with multiple stakeholder demands (Oliver, 1991).

Contraction. Contraction seeks to reduce the number of legitimacy demands to which an organization is required to respond. Based on the assumption that pluralism is a 'problem', organizations can manage their legitimacy through "trying to eliminate pluralism" (Kraatz \& Block, 2008, p. 250). Foundational to this strategy is resource dependence theory's assumption that organizations can either control or choose their contexts so that they provide more unitary legitimacy expectations (Ashforth \& Gibbs, 1990; Dowling \& Pfeffer, 1975; Suchman, 1995). Indicative of this is Pfeffer and Salancik (1978, p. 27) statement that "faced with conflicting demands, the organization must decide which groups to attend to and which to ignore."

Here, contraction is considered to be a matter of degree: a specific demand can either be deleted completely (e.g., 'deletion' (Pratt \& Foreman, 2000); 'escaping' or 'dismissing' (Oliver, 1991) strategies) or marginalized (e.g., 'defiance' strategies of 'challenging' or 'attacking' institutional demands (Oliver, 1991), or 'marginalization' (Kraatz \& Block, 2008)). An example of a deletion strategy is an organization outsourcing parts of their operations to an alternative labour market to circumvent regulative legitimacy demands (e.g., related to employees or environmental regulation) in their home countries (Oliver, 1991; Pfeffer \& Salancik, 1978). Marginalization occurs when an organization seeks to marginalize a stakeholder or particular demand. One can observe such a strategy in reports of some petroleum companies actively attempting to undermine the climate change lobby (through such things as sponsoring research and reports that throw doubt on the lobbyists claims) (Kolk \& Levy, 2001; Levy \& Kolk, 2002). 
The choice of whether to play in one or more "games" (Kraatz \& Block, 2008, p. 243) is often, however, outside the control of organizations (Humphreys \& Brown, 2002). As Pfeffer and Salancik (1978, p. 27) warn: "favouring one group offends another." It may be that multiple stakeholders are all too salient (Mitchell et al., 1997) to 'offend' let alone 'delete.' This is particularly true for organizations in pluralistic contexts, which are characterized by multiple salient stakeholder voices (Boyle, 2004; Denis et al., 2007). From the paradox literature, Lewis (2000) suggests that contraction may actually generate a vicious self-reinforcing cycle of exacerbated contradiction as the marginalized rally in response to their observation of that strategy.

The majority of examples of contraction are of failures and are illustrative of this proposition (Lewis, 2000). Humphreys and Brown (2002) show how attempts to delete a identity were unsuccessful within a higher-education institute seeking university status. In their study of how a utility company coped with pluralistic logics, Jarzabkowski et al. (2009a, p. 307) outline how at one stage particular stakeholders: "demonized any actions that countered its [organizational division] market-based beliefs." This attempted marginalization meant the conflict escalated rather than pluralism being successfully reduced. Similarly, Sonpar et al. (2010, p. 17) highlighted how a strategy of "singularly focusing on the government mandate for market-based logics and largely ignoring the concerns of their stakeholders" fostered anger and activism from certain stakeholders rather than successful management of pluralistic legitimacy demands. In these latter two examples the result was a transition to more integrative strategies.

By contrast, there are limited examples of successful contraction. Successful 'marginalization' has usually entailed utilizing a lack of diffused power as a way of managing divergence (e.g., Driscoll \& Crombie, 2001). An exception is Purdy and Gray's (2009) example where they highlighted a strategy of 'exiting' a particular context. They observed that some law offices were able to leave one environment (judiciary and the state) to join another (university) within which they could gain legitimacy based on more unitary demands. However, they did not explore the intricacies of how they did this, including how powerful stakeholders were managed. In sum, this discussion perhaps suggests that contraction may be utilized in isolated areas, rather than in an all-encompassing fashion (Zimmerman \& Zeitz, 2002). 
Compartmentalization. Compartmentalization is the isolation of legitimacy demands from each other so that they can be dealt with separately in a targeted fashion (Kraatz \& Block, 2008; Massey, 2001; Pratt \& Foreman, 2000). Sets of "structures and processes," one for each legitimacy demand, are segregated so as not to interfere with one another (Brunsson, 2002, p. 7). The rationale behind such a strategy is articulated by Meyer and Rowan (1977, p. 357): "because integration is avoided, disputes and conflicts are minimized, and an organization can mobilize support from a broader range of external constituents." Such processes are discussed in terms of decoupling and loose coupling and can be implemented in a variety of ways including structurally and symbolically (Pratt \& Foreman, 2000).

Separate accounts can be promulgated through the process that Meyer and Rowan (1977, p. 357) defined as 'decoupling', where "elements of structure are decoupled from activities and from each other" (also see Boxenbaum \& Jonsson, 2008; Edelman, 1992; Hirsch \& Bermiss, 2009; Westphal \& Zajac, 2001). An organization can manage a heterogeneous context by responding to some legitimacy demands symbolically and others with substantive action, something that relies on separation between the two (George, Chattopadhyay, Sitkin, \& Barden, 2006 Fiss \& Zajac, 2004; 2006). Oliver (1991) links the response strategies of 'concealment' (disguising nonconformity) and 'buffering' (reducing external evaluation) to this concept.

Decoupling has infrequently been explored as a legitimacy strategy in response to pluralism (Boxenbaum \& Jonsson, 2008; Scott, 2001; Westphal \& Zajac, 2001). One example is Elsbach and Sutton's (1992) description of how, through decoupling the actions of SMO members from the SMO itself, two organizations were able to successfully adapt to the legitimacy demands of both SMO activists who demanded decisive action and more 'mainstream' stakeholders who considered such activities illegitimate. There is scope to extend Elsbach and Sutton's (1992) study through looking at organizations other than SMOs (which are potentially distinctive) and focusing explicitly on pluralism rather than Elsbach and Sutton's focus on managing illegitimate actions. Another example is Beverland and Luxton's (2005) description of how luxury wineries deliberately separate their image of craftsmanship from their own internal commercially driven operations as a way of managing divergent objectives. Aurini (2006) shows how decoupling by alternative education providers enabled them to craft a legitimation project of strategic isomorphism. Finally, Westphal \& Zajac's 
$(1995,2001)$ statistical studies indicate that decoupling can be used to manage the specific tension between CEOs and shareholders regarding incentive and stock repurchasing plans.

Kraatz and Block (2008) argue that loose coupling is a more suitable concept (than decoupling) for managing pluralism as it does not entail the distinction between the 'peripheral' (those demands responded to symbolically) and 'core' (those demands responded to with substantive action). They argue that this distinction is different in pluralistic contexts where something peripheral to one stakeholder group can be central to another. They therefore position compartmentalization as loose coupling: managing multiple demands through separating them (Orton \& Weick, 1990; Pratt \& Foreman, 2000). Such a strategy is depicted empirically by Brown (1995) who showed how an IT project's implementation team understood the legitimacy demands of different powerful stakeholder groups and offered them separate tailored legitimacy accounts. Hypocritically offering such targeted interpretation was a prerequisite for legitimacy. Binder (2007), meanwhile, provides an example of a transitional housing organization (i.e., social organization) using compartmentalization whereby some sub-units focused on responding to funding demands ("money") and others to focus on "really doing the program" separately from the funding requirements (p. 562).

While the idea of targeting strategies and accounts at specific groups is an important one, there are limitations. Organizations are usually responding to an interconnected network of stakeholders rather than to individual stakeholder groups (Rowley, 1997). Stakeholder groups overlap, may communicate directly, or have access to similar communication channels; there is a limit to how contradictory or selectively targeted legitimacy strategies can be (Kraatz \& Block, 2008, p. 248). This is especially true for smaller organizations, which have reduced capacity to separate the conflicting practices and parties in time and/or space (D'Aunno et al., 1991). As such, it is unlikely that different legitimacy strategies are able to be applied to isolated groups as if the multiple contexts are independent and themselves homogenous.

Integrative strategies. An alternative approach is to integrate legitimacy demands. Such strategies do not seek to separate the legitimacies but rather appeal to multiple divergent demands simultaneously (Kraatz \& Block, 2008; Pratt \& Foreman, 2000; Suchman, 1995). 
Integration in this sense is about a focus on the interconnections between legitimacy demands rather than necessarily complete 'synthesis' (Pratt \& Foreman, 2000). Also contained in the term 'integrative' is the idea of inclusion of multiple demands rather than their exclusion (Kraatz \& Block, 2008). Again, the degree of agency involved distinguishes the two integrative strategies. Negotiation can be described as involving greater adaptation, with its focus on seeking balance and compromise. By contrast, transcension tends to imply an ability to set, shape and redefine legitimacy demands (Kraatz \& Block, 2008; Oliver, 1991).

Negotiation. The aim of negotiation is to achieve an accepted balance between multiple legitimacy demands. The 'negotiation' label appears in multinational enterprise (MNE) research (Kostova et al., 2008; Kostova \& Zaheer, 1999), which argues that legitimacy must be individually negotiated by the MNE with each of its relevant constituencies. Resource dependence theory similarly provides a theoretical foundation through having outlined the “'negotiated environment' of organizations (Pfeffer \& Salancik, 1978, pp. 143-187), assuming that organizational relations with the environment are open to negotiation and the exchange of concessions" (Oliver, 1991, p. 154). Kraatz and Block (2008) describe it in terms of 'reining in' tensions, 'balance', 'compromise' and 'cooperation' as stakeholders recognize, sometimes grudgingly, a degree of mutual dependence. This strategic category corresponds to Oliver's 'compromise' strategy of "balancing the expectations of multiple constituents" (1991, p. 52). The political theory concept of mutual adjustment (Lindblom, 1965 ) is used by some studies (Jarzabkowski et al., 2009a) to further theorize Kraatz and Block's strategy. Mutual adjustment is outlined as a strategy whereby stakeholders adjust in various ways to each other with no overarching coordinating device or purpose. This adjustment can be more or less passive moving from seeking to avoid adverse consequences for another party to more active bargaining strategies.

One way negotiation can be implemented is through what Pratt and Foreman (2000) label aggregation. Here a degree of distinction is retained but, in contrast to compartmentalization, efforts are made to forge links and exploit synergies between demands. While aggregation is not discussed explicitly within the legitimacy literature, a parallel can be drawn to Boyle's (2004) discussion of how legitimation efforts in business schools included linking the values of higher education and business as a way of managing the conflicting demands from both contexts. Similarly, Suddaby and Greenwood (2005, p. 50) 
field-level study discusses how the "Big Five" accounting firms attempted to blur the lines between professional and market logics to legitimate a new contested organizational form.

Another strategy is partial adaptation, based on D'Aunno et al.'s (1991) empirical study and resulting conclusion that organizations have limited ability to respond to conflicting demands and will therefore conform to each of them only partially. Additional empirical studies have reached similar conclusions (Alexander, 1996; Glynn, 2002). Partial adaptation can be seen as a continuum. It can attempt to incorporate several legitimacy demands (roughly) equally, relating to, for example, Oliver's (1991) strategy of a balance where parity amongst multiple logics is reached. It can also represent a 'managing the periphery' strategy, where the 'core' is protected through doing enough to pacify other so-conceived less central demands. This is reflected in Oliver's 'pacifying' strategy and what Pratt and Foreman (2000) evocatively labelled 'nurturing the unchosen'. The main distinction between this and the two segregative strategies is that this partial adaptation remains a negotiated compromise amongst stakeholders (Oliver, 1991; Pratt \& Foreman, 2000).

This strategy is illustrated by Glynn (2002, p. 83), who shows how a symphony orchestra made marginal changes to the programme to satisfy a new managerial philosophy, while keeping the core orchestra repertoire and traditional artistic philosophy intact. It was instead "at the margins" that changes were made. Similar conclusions were reached by Alexander (1996, p. 805) who outlines how museum curators protected their museums most "crucial functions by allowing change in more peripheral areas." Montgomery and Oliver (1996, p. 665) show how hospitals dealing with AIDS utilized Oliver's (1991) compromise strategy in managing multiple pressures. They highlight a strategy where "a general preferences for the interests of the more dominant constituent group" was supplemented "with evidence that rights of other constituent groups are taken into account as well" (1996, p. 665). This also refers to D'Aunno et al. (1991) highlighting the importance of 'ranking' demands as part of partial adaptation. Meanwhile, Purdy and Gray (2009) describe 'grafting' as a strategy used by some organizations, whereby they add or graft additional legitimacy demands within existing practices rather than replacing those foundational ways of operating. 
Negotiation can be also understood as a response that explicitly incorporates bargaining tactics by stakeholders (Lindblom, 1965). This reflects Oliver's (1991) more agency intensive 'bargaining' strategy where concessions from another party are sought. For example, Glynn's (2000) other study of the orchestra case focuses on the conflict-ridden nature of bargaining regarding resources in the give-and-take associated with resolving a musicians' strike. Similarly, Sonpar et al. (2010) outline how organizations in Canadian health care moved from a contracted focus to processes of renegotiation due to strikes and activism. Because of these 'bargaining' activities the organizations (Canadian Regional Health Authorities) compromised to partially adapt to those demands.

While 'competition' is dominant in the above discussion (D'Aunno et al., 1991; Glynn et al., 2000; Sonpar, et al., 2010), one can conceive of this process of negotiation being instead based on cooperation. Stakeholders and organizations negotiate away some of their legitimacy demands in the spirit of collaboration and conflict reduction: a process of collaborative compromise. Reay and Hinings (2009, p. 630), show how stakeholders in the health sector managed rivalry between institutional logics through "collaborative efforts" based on pragmatic recognition of their interdependence. Simultaneously maintaining the distinction between the interests of collaborators was also shown to be important. Jarzabokowski et al. (2009a, p. 300) provide another example showing how stakeholders moved beyond open conflict to more collaborative mutual adjustment. Each party tried "to accommodate the other, advocating tolerance of the other's position in relation to their own logic." In this way divergent legitimacy demands can be managed through collaboration that maintains independence. This rests on acknowledgement by stakeholders, grudgingly or otherwise, of their mutual dependencies (Jarzabkowski et al., 2009a; Reay \& Hinings, 2009).

Transcension. Transcension as a strategy entails rising above the divergence between legitimacy demands. This is based on the distinction made by Kraatz and Block (2008, p. 251) that while negotiation is often based on grudging acceptance, some organizations can instead "rise above" the conflicting interests. They become self-legitimating while simultaneously addressing all legitimacy demands. They link this strategy of transcending divergent legitimacy demands to Selznick's (1957) 'old' institutionalism whereby institutionalized organizations become "infused with value" by multiple constituencies 
beyond their short-term interests. The organizational autonomy this then entails can be related to a higher-level of agency, articulated in Oliver's (1991) manipulation strategies, where an organization seeks to construct for itself its own legitimacy criteria (Ashforth \& Gibbs, 1990; Suchman, 1995). For example, Aurini (2006, p. 103) argues that the heterogeneity was part of what enabled alternative schools to "define the terms of their legitimation", or their own logic of confidence as she labels it, rather than being determined by pre-defined legitimating 'cultural schema.'

The legitimacy literature outlines that organizations are sometimes able to exert influence on their immediate stakeholders to transform (or manipulate) the legitimacy demands with which they are faced (Oliver, 1991). Resource dependence theory in particular argues that, although difficult, organizations can 'manipulate' and transform the legitimacy demands confronting them (e.g., laws, regulations, evaluation criteria) (Ashforth \& Gibbs, 1991; Dowling \& Pfeffer, 1975; Suchman, 1995). Purdy and Gray (2009) highlight how only a limited number of organizations were able to successfully transform the legitimacy demands deriving from the context in which they operated. While this remains rarely discussed as a legitimacy strategy amidst pluralism, a growing number of examples illustrate that an organization can transform divergent legitimacy demands in a way that enables them to be more easily aligned and managed. An empirical example is Alexander's (1996, p. 828) study of how, through creative enactment, museum curators were able to "extend the possibilities of the environment beyond standards limitations." They were able to create innovative integrative possibilities and solutions. Battilana and Dorado (2010) show how a commercial microfinance organization, drawing from conflicting 'development' and 'banking' logics, sought to transform their internal staff through socialization and education as a way of managing this divergence internally. Finally, Kitchener (2002), while focused on change in the 'basis of legitimacy' rather than pluralism specifically, does highlight how managers 'manipulated' legitimacy assessments from internal and external stakeholders through their 'selling' of a merger.

Another transcension strategy is the idea of infusing an organization with value (Selznick, 1957; Selznick, 1992). Kraatz and Block (2008) outline that organizations can create durable identities of their own that provide them with "social fact status" and enable them to legitimate their "own actions, within limits" (p. 251). In so doing they can integrate and 
transcend the divergent legitimacy demands. Such organizations are perceived by their diverse stakeholders as 'theirs'; they are "infused with value" by those stakeholders as a conduit through which they can pursue their ideals or identity (p. 152). A illustrative example is the cult-like status Apple and its products has with its customer base (Belk, 2005; Kahney, 2004). As Selznick explains: "as the source of integration shifts from goals to values, from specific objectives to ways of thinking...a sense of community" and corresponding high level of commitment to the organization are created (1992, p. 236). While not discussing legitimacy, Mintzberg (2009, p. 140) similarly uses the term 'community' to describe how companies can bind people together "for the greater good" and foster their "sense of belonging to and caring for something larger than themselves." With this strategy an organization can retain freedom and continued support, even when it makes decisions that conflict with a particular stakeholder's immediate interests and "parochial" values. As part of this, symbolism is important because a stakeholder focus solely on material outputs and short-term objectives makes cooperation amid pluralism difficult (Kraatz \& Block, 2008, p. 252). This concept provides an extension to the question of how organizations can implement agency intensive strategies (Oliver, 1991; Suchman, 1995), which legitimacy research does not appear to have fully pursued.

Selznick (1992) also outlines that infusion with value can be thought of in psychological terms and also in more practical ways such as developing strong ties and selectively recruiting staff. Along these lines, co-opting is discussed as a more specific strategy. Defined as "the process of absorbing new elements into the leadership or policy-determining structures of an organization as a means of averting threats to its stability or existence" (Selznick, 1949, p. 13) this is about drawing the external environment in (Honig \& Hatch, 2004). Including regulators on the Board of Directors is a common example (Hillman, 2005; Pfeffer \& Salancik, 1978; Selznick, 1949). Through co-opting stakeholders with divergent legitimacy demands, an organization may transform some of their demands and blur boundaries between the internal and external demands.

Another potential transcension strategy involves tapping into an overarching objective or vision (Battilana \& Dorado, 2010; Pratt \& Foreman, 2000). Pluralism literature was turned to as a foundation for explicating this strategy due to the fewer examples in the legitimacy literature. The paradox literature (Smith \& Tushman, 2005; Smith et al., 2010) discuss this as 
a process of shifting to a super-ordinate level or overarching frame and linking contradictory objectives to this. In particular, the idea of tapping into a universal narrative "gives meaning to the apparent contradiction" and is transformative, as "tensions become viewed as complementary and interwoven" (Lewis, 2000, p. 764). This can be connected to Jarzabkowski and Sillince's (2007, p.1647) discussion of a "synergy rhetoric" which "constructs a context in which multiple activities are compatible and mutually supportive. Within the legitimacy literature a "bridging" strategy is described by Purdy and Gray (2009) is indicative. They observed organizations meeting divergent expectations through a broad mission enabling them to appear legitimate in relation to both. Zilber (2002) meanwhile shows how individuals were able to attribute diverse meanings (based on feminist and therapeutic logics) to shared practices within a rape crisis centre. Another example is Battilana and Dorado's (2010) illustration of hybrid organizations constructing a single integrative identity and vision as a way of managing 'duelling' demands internally. They discuss the particular importance of creating a common organizational identity and argue that this highly integrative approach prevented sub-group formation and that this was integral to organizational sustainability. Battilana and Dorado's example differs slightly from the above discussion (e.g., Smith \& Tushman, 2005) in being a particularly synergistic argument. Indeed, Pratt and Foreman (2000) discuss how varying degrees of integration can be associated with the use of an overarching 'identity' or objective. Additional examples in legitimacy research are rare. Boyle (2004) provides a brief example, discussing how 'citizenship activities' are considered legitimate to both the corporate and university 'worlds' and can therefore potentially be used by business schools to seek integration between the two.

This framework and associated literature is summarized in Table 2.2 below. 
Table 2.2 Summary of the literature: legitimacy strategies and pluralism

\begin{tabular}{|c|c|}
\hline & Additional literature summary \\
\hline $\begin{array}{l}\text { Contraction (Kraatz \& Block, } \\
\text { 2008) } \\
\text { Label origin: incorporation by } \\
\text { author of impulses of 'deletion' } \\
\text { \& 'marginalization' (Pratt \& } \\
\text { Foreman, 2000; Kraatz \& Block, } \\
\text { 2008). } \\
\text { Indicative characteristics: High } \\
\text { agency; Low integration (Oliver, } \\
\text { 1991; Pratt \& Foreman, 2000). }\end{array}$ & $\begin{array}{l}\text { Theoretical: } \\
\text { - Institutional theory: Oliver (1991; Pache \& Santos, 2010) [Avoid - } \\
\text { 'escaping'; 'dismissing'; 'Defy - 'challenging'; 'attaching']. } \\
\text { - Insight from identity theory: Pratt \& Foreman (2000) [Deletion]; } \\
\text { - Strategy / resource dependence literature: Ashforth \& Gibbs } \\
\text { (1991); Pfeffer et al. (1975; 1978); Suchman (1995) [Choosing and } \\
\text { creating unitary contexts]. } \\
\text { Empirical examples: } \\
\text { - Less successful contraction: (Humphreys \& Brown, 2002; } \\
\text { Jarzabkowski et al., 2009a; Sonpar et al., 2009) } \\
\text { - Successful contraction: Exit (Purdy \& Gray, 2009). }\end{array}$ \\
\hline $\begin{array}{l}\text { Label origin: Kraatz and Block } \\
\text { (2008); Pratt \& Foreman (2000). } \\
\text { Indicative characteristics } \\
\text { Low agency; Low integration } \\
\text { (Oliver, 1991; Pratt \& Foreman, } \\
\text { 2000). }\end{array}$ & $\begin{array}{l}\text { Theoretical: } \\
\text { - Institutional theory: Meyer and Rowan (1977)[decoupling]; Oliver } \\
\text { (1991; Pache \& Santos, 2010) [buffering]. } \\
\text { - Identity theory: Pratt \& Foreman (2000) [compartmentalization]. } \\
\text { Empirical examples: } \\
\text { - Decoupling explored extensively; however explicitly applied to the } \\
\text { pluralistic contexts by: Elsbach \& Sutton (1991); Beverland \& } \\
\text { Luxton (2005); Aurini (2006). } \\
\text { - Different sub-units with different foci (Binder, 2007); targeted } \\
\text { legitimacy accounts (Brown, 1995). }\end{array}$ \\
\hline $\begin{array}{l}\text { Negotiation } \\
\text { (Kraatz \& Block, 2008) } \\
\text { Label origin: Kostova et al. } \\
\text { (1998, 2008). } \\
\text { Indicative characteristics } \\
\text { Low agency; High integration } \\
\text { (Oliver, 1991; Pratt \& Foreman, } \\
\text { 2000). }\end{array}$ & $\begin{array}{l}\text { Theoretical: } \\
\text { - Institutional theory: Oliver (1991; Pache \& Santos, 2010) } \\
\text { [compromise]. } \\
\text { - Identity theory: Pratt \& Foreman (2000) [aggregation]. } \\
\text { - Resource dependence literature (Pfeffer \& Salanick, 1978): the } \\
\text { 'negotiated environment of organizations'. } \\
\text { - MNC literature: Kostova et al. (1998, 2008) [negotiation]. } \\
\text { Empirical examples: } \\
\text { - D'Aunno et al., (1991); Glynn (2002); Alexander (1996); } \\
\text { Montgomery \& Oliver (1996); Purdy \& Gray (2009) [partial } \\
\text { adaptation/managing the periphery; grafting]. } \\
\text { - Sonpar et al. (2010); Glynn (2002): Bargaining/activism. } \\
\text { - Jarzabkowski et al. (2009a); Reay \& Hinings (2009) [mutual } \\
\text { adjustment; collaboration]. }\end{array}$ \\
\hline $\begin{array}{l}\text { Transcension } \\
\text { (Kraatz \& Block, 2008) } \\
\text { Label: Kraatz \& Block (2008); } \\
\text { paradox literature (Lewis, 2000). } \\
\text { Indicative characteristics: } \\
\text { High agency; High integration } \\
\text { (Oliver, 1991; Pratt \& Foreman, } \\
\text { 2000). }\end{array}$ & $\begin{array}{l}\text { Theoretical } \\
\text { - Institutional theory: Oliver (1991; Pache \& Santos, 2010) } \\
\text { [manipulation; also see: Dowling \& Pfeffer, 1975; Suchman, 1995). } \\
\text { - Identity theory: Pratt \& Foreman (2000) [integration]. } \\
\text { - Selznick (1957, 1992) [theoretical framing used by Kraatz and } \\
\text { Block (2008); Infused with value]. } \\
\text { Empirical examples } \\
\text { - Creative enactment (Alexander, 1996); transformation (Purdy \& } \\
\text { Gray, 2009); logic of confidence (Aurini, 2006). } \\
\text { - Integrative new identity (Battilana \& Dorado, 2010); 'bridging' } \\
\text { (Purdy \& Gray, 2009); attributing multiple different meanings to } \\
\text { practices (Zilber, 2000). }\end{array}$ \\
\hline
\end{tabular}




\subsubsection{Combining Strategies.}

An assumption within many of the underlying theoretical frameworks (Kraatz \& Block, 2008; Oliver, 1991) appears to be that organizations will implement a single dominant strategic process. That organizations cannot combine different strategies as a way of managing pluralism is not explicitly stated, but there is no mention of combinatorial approaches in the presentation of the frameworks. How the various strategies in the frameworks are combined and interrelate is, therefore, not discussed within these focal frameworks. It is argued (Binder, 2007, p. 551) that a focus on the search for "an organization's single response" has defined, and limited, understanding within the legitimacy literature.

There are exceptions regarding theorizing a more combinatorial picture within the broader legitimacy literature. For example, Dowling and Pfeffer (1975) outline how adaptation was combined with identifying an organization with prominent "legitimacy symbols" but they do not explore how more 'manipulative' strategies might be combined within that adaptive picture. Ashforth and Gibbs (1990) argue that symbolic and substantive strategies will be combined by organizations, and this has been explored empirically (Driscoll, 2006). They do not, however, suggest how or in what ways specific strategies will interact or be combined. Suchman (1995), meanwhile, acknowledges that organizations will likely seek multiple different types of legitimacy, which demands multiple different responses. The focus, though, remains on demarcating specific strategies not exploring their interaction. In their theoretical article Zimmerman and Zeitz (2002) explicitly outline that new ventures are likely to limit their agency intensive strategies with conformity in other areas and combine multiple strategies.

Exceptions are observable in an alternative body focused on rhetorical and discursive legitimacy strategy frameworks. These highlight the simultaneous implementation of multiple rhetorical and discourse strategies by an organization or groups of organizations, including within pluralism or settings characterized by conflict (Suddaby \& Greenwood, 2005; Vaara \& Monin, 2010; Vaara et al., 2006). However, this is not evident in the same way at the broader organization level which incorporates organizational practice (e.g., Kraatz \& Block, 2008). In particular, the broad tendency remains to apply the organizational level legitimacy strategy typologies, for example, Oliver's (1991), to classify an organization 
against a single response (e.g., Aaltonen \& Sivonen, 2009; Bigelow \& Stone, 1995; Deephouse, 1996; Goodstein, 1994; Ingram \& Simons, 1995; Westphal \& Zajac, 1995).

Within the empirical literature focused on pluralistic contexts specifically, there is a similar focus on singular strategic responses. Pache and Santos (2010) outline that the majority of empirical examples have focused on and explored idiosyncratic strategies and generally do not reflect back to broad strategy frameworks. The majority of studies in the review appear to focus on outlining a single strategy such as partial adaptation (D'Aunno et al., 1991); or failed contraction (Humphreys \& Brown, 2002). Elsbach and Sutton (1992) focus primarily on decoupling, albeit incorporating that strategy within a broader process model that includes impression management tactics in support of the decoupling process. Similarly, other studies which have found different strategies across a number of organizations have associated a single strategy with each organization rather than investigating more closely the potential of combinations of strategies (e.g., Purdy \& Gray, 2009). Part of the explanation may be that many studies have focused on specific practices such as hiring and socialization of staff (Battilana \& Dorado, 2010), stock repurchasing programs (Westphal \& Zajac, 2001), dealing with AIDs (Montgomery \& Oliver, 1996), or collaboration practices (Reay \& Hinings, 2009) rather than developing a holistic strategic picture at the organizational level which would highlight combinations.

Another aspect might be a growing distinction between studies of negotiation and transcension. One interpretation is that the literature is increasingly forming into two 'camps.' First, the implicit assumption made by Kraatz and Block (2008) regards the primacy of transcension as a way of managing pluralism. Other authors highlight the importance of an integrative identity in managing divergent logics (Battilana \& Dorado, 2010). By contrast, other studies have positioned their examples as explicitly non-transcentive, focused on the development of an "on-going and uneasy truce" or "pragmatic collaboration" as the means through which pluralism is managed (Glynn, 2002; Jarzabkowski et al., 2009a). The assumption that more integrative strategies are less desirable or likely is evident. For example, Reay and Hinings (2009) highlight the lack of an overarching hybrid 'logic' or shared identity in their study. They argue that negotiation through pragmatic collaboration may be more successful than such synergistic efforts. This distinction between studies of 
negotiation and transcension has perhaps overshadowed any discussion of the potential for simultaneous implementation of these by organizations.

Some studies do mention strategic approaches that appear to traverse Kraatz and Block's categories. However, they do not explicitly highlight or reflect on this fact or ground it within an understanding of simultaneous implementation by a single organization (e.g., Alexander, 1996; Aurini, 2006). Others take a longitudinal view which outlines multiple strategies pursued over time or in sequence, but not simultaneously (Jarzabkowski et al., 2009a; Sonpar et al., 2010). Another study outlined multiple responses to different demands being enabled through a broader compartmentalization strategy. For example, with different subunits exhibiting different relationships with different stakeholder demands (Binder, 2007). An example that can be reflected upon further is Reay and Hinings' (2009) study. While they ultimately present a central strategy of 'pragmatic collaboration' singularly, their discussion of this broad strategy does incorporate an element of compartmentalization as one of four "supporting mechanisms." This enabled the broad negotiation process of collaboration between stakeholders. Finally, Aurini (2006, p. 83) offers an example of pluralism providing a context wherein "garnering legitimacy is thus conceived as an active and multifaceted process that can include multiple avenues for mythmaking, coupling, and logic-of-confidence strategies." These examples provide a foundation for suggesting that organizations may combine multiple strategies, sometimes in ways that appear paradoxical, in their management of legitimacy amidst pluralism. Yet this remains an area that few studies have explicitly explored.

Overall, this review of the literature has focused attention on this research omission (Binder, 2007; Pache \& Santos, 2010) and results in a supplementary focus regarding: do organizations combine different legitimacy strategies in pluralistic contexts? And, if so, how do these strategies interrelate and how are combined by organizations?

\subsection{Summary: Chapter Two}

This chapter first introduced the concept of pluralism and provided a brief overview of the associated literature. The second section discussed legitimacy, largely based around the two broad traditions that comprise it: the 'strategic' and 'institutional' approaches. Definitions 
were outlined, the relationship between legitimacy theory and pluralism explored and a stakeholder-centric definition provided. Third, the specific intersection between legitimacy strategy and pluralism was reviewed. Foundational legitimacy strategy frameworks were summarized and the impact of pluralistic contexts on legitimacy strategy briefly outlined. Finally, a specific framework for understanding legitimacy strategy in pluralistic settings was provided and used to review the literature. This theoretical framework, along with the definition of pluralism and legitimacy developed here, will be taken forward as an analytical framework through which to explore the empirical domain of interest: organizations within NZ's science sector. 


\section{CHAPTER THREE}

\section{Methodology and Context: NZ's Science Sector}

The following quotations from media commentary about the New Zealand (NZ) science sector introduce the relationship between the empirical setting of my research and the concept of pluralism:

Scientists need to be more understanding about how the business marketplace works. We need quick solution to our current challenges within days, weeks or months, not within years. (Mario Wynands in Casinader, 2010)

Scientists are understandably growing weary of this approach. They point to many of the world's great scientific discoveries and the many years of research that preceded them. They claim, rightly, that many commercially successful applications of scientific discoveries were the result of serendipity; the product of true scientific exploration. (Britten \& Scott, 2009, p. 14)

These two perspectives provide an indication of some divergent stakeholder legitimacy demands that science organizations (the unit of analysis in this research) encounter.

The goal of this chapter is to provide an understanding and explanation of the research processes I engaged in. There are five main parts: a description of the ontological and epistemological positioning; the case study approach adopted and decisions concerning sector and organization selection; the empirical context of this study (NZ's science sector); and the data collection and analysis procedures followed. This methodology is summarized in Figure 3.1. 
Figure 3.1 Summary of research methodology

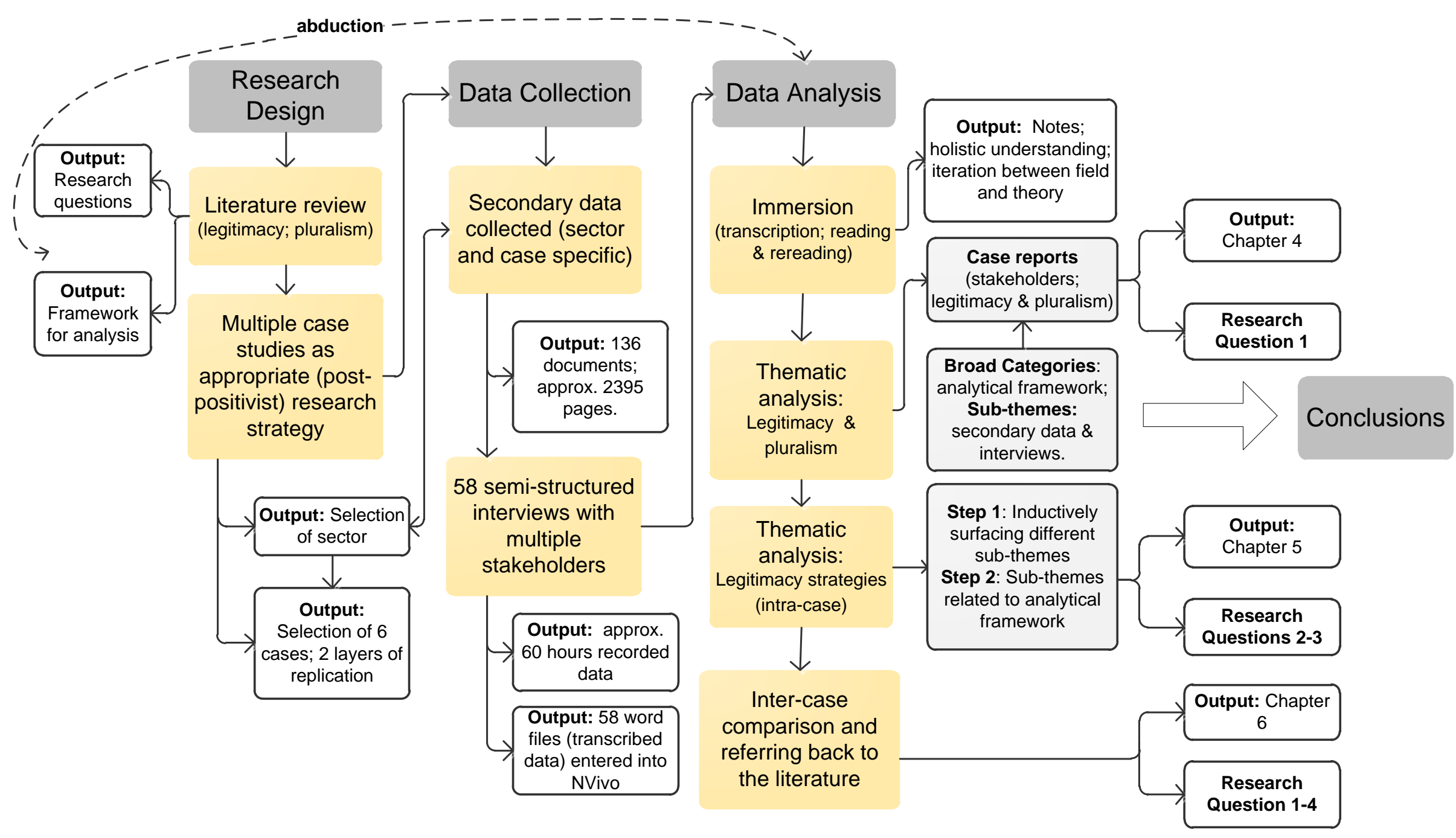




\subsection{Research Philosophy}

\subsubsection{Post-Positivism}

To explicate some of the underlying assumptions contained within my research questions two illustrative points are considered. First, I assumed a tentative ability to explore strategic regularities and patterns within my engagement with the empirical domain (Miles \& Huberman, 1994; Miller, 2000). An understanding and organization of the central strategies, based on the participant's perceptions, implemented by an organization was sought. Second, central to embracing pluralism, was a respect for and understanding of the multiple perspectives (or 'realities') of participants. This contrasts with a research approach of "simply judging them as true or false" (Hammersley, 2001, p. 45).

Post-positivism best illuminates the philosophical underpinnings reflected in these assumptions. Such a position offers a "space in-between" positivism and radical constructivism (Crotty, 1998; Hammersley, 2001; Patton, 2002a; Phillips \& Burbules, 2000). To illustrate my experience of post-positivism, I quote Miles and Huberman as they similarly position themselves:

The lines between epistemologies have become blurred...approaches like ours, which do away with correspondence theory (direct, objective knowledge of forms) and include phenomenological meaning, are hard to situate ( Miles \& Huberman, 1994, p. 5)

This difficulty relates to the balancing act such an position entails due to sitting between more definitively positioned traditions (Hammersley, 2001). Authors define post-positivism as a philosophy that seeks to address perceived "imbalances" within other paradigms; juggling, for example, the need for precision and richness (Guba, 1990; Phillips \& Burbules, 2000). The self-referential analogy is that this perhaps has semblance to the organizational experience of managing legitimacy within pluralism.

Post-positivism draws on social anthropology and is said to have had widespread influence within qualitative methodologies (Eriksson \& Kovalainen, 2008; Patton, 2002a; Tesch, 1990). This includes grounded theory (Glaser \& Strauss, 1967) and transcendental realism (Bhaskar, 1979, 1989; Danermark, Ekstrom, Jakobsen, \& Karlsson, 2002). Important here is its frequent association (e.g., Eriksson \& Kovalainen, 2008; Huberman \& Miles, 2001; Tesch, 
1990) with both the case study strategy (Eisenhardt, 1989; Yin, 2009) and Miles and Huberman' (1994) analytical approach adopted in this research.

As a philosophical framework, post-positivism addresses questions regarding both the nature of reality (ontology) and epistemological question regarding the nature of knowledge and the relationship between what can be known and the 'knower' (epistemology) (Ackroyd \& Fleetwood, 2000; Guba \& Lincoln, 1994) (Table 3.1). Post-positivism provides a 'subtle realist' position (Hammersley, 2001). It is:

Ontologically bold but epistemologically cautious (Outhwaite in Bhaskar, 1989, p. 186).

While maintaining a belief in the existence of mind-independent phenomena, postpositivism breaks from positivism in disputing our direct access to it. Instead, it shares with constructivist perspectives the belief that knowledge, including legitimacy in this case, is a human construction and contextually determined (Denzin \& Lincoln, 2005; Hammersley, 2001; Miles \& Huberman, 1994; Miller, 2000; Patton, 2002a; Reed, 2005; Sayer, 1992). Through drawing a distinction between beliefs and objective reality, post-positivism enables appreciation of the multiple "realities" or perceptions of participants (Creswell, 2007; Eriksson \& Kovalainen, 2008; Miller, 2000, p. 38; Phillips \& Burbules, 2000). This is something a focus on pluralism led me to embrace. Such a position is aligned with much of the institutional theory approach to legitimacy: objective reality is not denied but rather argued "to be shaped and understood by cognitive frames" (Alexander, 1996, p. 832; Scott, 2001).

Post-positivism also assumes that "we severely limit the scope of research" and our understanding of social phenomena if we exclude a research interest in the perspectives (including their values and interests) of participants. It is aligned with an focus on exploring the roots and motivating beliefs within organizations (Crotty, 1998; Phillips \& Burbules, 2000, p. 66). This is important in a study focused on the perceptions of desirability and appropriateness (i.e., legitimacy). Aligned with this is an openness to qualitative methods as a way of investigating 'deeper' social phenomena (Gray, 2009; Guba \& Lincoln, 1994).

Miles and Huberman (1994, p. 144) stipulate that:

The fallibilities of explanation of daily life are central to qualitative researchers: we must 
traffic in meanings, as well as actions; who must rely, in part, on the explanations that people give us; and who must live with the knowledge that because we, too, are "people" our own explanations are equally vulnerable.

This 'epistemologically cautious' position entails recognition that "evidence underdetermines theory." While empirical evidence serves as a constraining boundary for our beliefs, there remains room for alternative accounts and interpretations. This means it would be "sloppy" to "speak of 'the truth"' as if there were only one truth to be discovered about a particular research problem (Eriksson \& Kovalainen, 2008; Miller, 2000; Phillips \& Burbules, 2000, p. 38). Instead, post-positivism accepts there can be "multiple, noncontradictory and valid" descriptions and explanations regarding the phenomena of study (Hammersley, 1992, p. 55; Maxwell, 1992). This is a point of differentiation from positivism: post-positivism has an anti-foundational epistemology. It does not assume a secure foundation for beliefs and knowledge claims within the research process (Phillips \& Burbules, 2000).

Post-positivism also questions the possibility of objectivism, whereby 'known' (i.e., the theme of 'transcension') and 'knower' (i.e., me as the researcher) can be separated (Eriksson \& Kovalainen, 2008; Guba \& Lincoln, 1994; Maxwell, 1992; Miller, 2000). This less privileged position for "science" can be related to an increased regard within post-positivism for the voice of the participant: the perspective of participants is as important as any other (Creswell, 2007; Crotty, 1998; Phillips \& Burbules, 2000). A decreased faith in objectivity also relates to the point regarding the under-determination of theory by evidence: so-called disinterested observation takes place within the context of theory and is shaped by it. It is therefore "necessarily selective" (Crotty, 1998, p. 33; Miles \& Huberman, 1994; Phillips \& Burbules, 2000). The analytical approach is one of managing biases to determine that an appropriate theoretical lens is used based on the dataset at hand and to ensure the transformation of that framework as necessary. Objectivism, in this way, remains a regulative (albeit unattainable) ideal, something which I can seek a degree of but no more (Crotty, 1998; Phillips \& Burbules, 2000). We can talk in terms of tendencies and provisional descriptions rather than "conjunctions of events" (Bhaskar, 1979, p. 24). Such an assumption means, for example, that prediction lies outside the scope of this project. 
Nonetheless, judgmental relativism, the argument that all beliefs and explanations are equally valid, is rejected (Bhaskar, 1989, p. 24; Hammersley, 2001; Phillips \& Burbules, 2000). We can still talk about degrees of "epistemological gain" (Sayer, 2004, p. 8): recognition of the fallibility of knowledge does not mean all knowledge is equally fallible. Rational grounds for choosing between interpretations generally can be found (Miles \& Huberman, 1994; Sayer, 1992). Post-positivists use Dewey's (1938) substitution of truth with "warranted assertibility" to explain this (Phillips \& Burbules, 2000). For example, in surfacing what participants perceive to be the central strategies associated with particular organizations through interviews, secondary data can be used to increase understanding (i.e., epistemological gain) of those stakeholder perceptions. Post-positivism provides the qualitative researcher the methodological space for "guesswork, intuition and the following up of hunches" (Crotty, 1998, p. 33). However, it maintains that degrees of epistemological gain are achieved through adopting rigorous data collection and analytical methods (Dewey, 1938; Eriksson \& Kovalainen, 2008; Miles \& Huberman, 1994; Patton, 2002a; Phillips \& Burbules, 2000). As Miles and Huberman (1994, p. 277) argue: "the fact is that some accounts are better than others. Although we may acknowledge that 'getting it all right' is an unworkable aim, we should, as Wolcott (1990) suggests, try to 'not get it all wrong'" (also see: Maxwell, 1992). Hammersley's (1992) post-positivist 'mid-way' position regarding validity is perhaps illustrative. He outlines that an empirical account must be plausible and credible. As part of this, the amount and kind of evidence used in relation to a finding needs to be taken into account. In this sense plausibility is inherent in the relationship between an account and that of which it is intended to be an account (Maxwell, 1992). For example, whether a perception of a legitimacy strategy is widely or consistently held by participants is considered here to be part of building plausible findings that are reflections of my dataset and the 'reality' that it is a partial reflection of. This is contained in my display of the analysis to the reader (Chapter 5). 
Table 3.1 Post-positivism (Crotty, 1998; Patton, 2002a; Phillips \& Burbules, 2000).

\begin{tabular}{|c|c|}
\hline $\begin{array}{c}\text { Ontology } \\
\text { “what is the nature } \\
\text { of reality?” }\end{array}$ & $\begin{array}{l}\text { - Subtle realism: A mind-independent reality exists, but can only be partially rather } \\
\text { than fully accessed by a researcher. } \\
\text { - Reality as pluralistic and local': The "reality" that I have access to (through } \\
\text { participant perceptions) is instead contextual and is multiple: the focus is on } \\
\text { multiple participants perceptions. } \\
\text { - Not singular/universal reality/truth: I therefore cannot speak about "the truth" or a } \\
\text { "single reality" as something I have access to it. }\end{array}$ \\
\hline $\begin{array}{c}\text { "what is the nature } \\
\text { of the relationship } \\
\text { between the knower } \\
\text { and the known?" }\end{array}$ & $\begin{array}{l}\text { - Anti-foundationalist: A firm foundation for knowledge is rejected within a } \\
\text { epistemologically cautious position (empiricism and rationalism rejected). } \\
\text { - Epistemological gain sought, but objectivism unattainable: Objectivism and the } \\
\text { pursuit of knowledge remain regulatory ideals. I seek degrees of epistemological } \\
\text { gain and to limit bias. However, this does not mean I claim access to "truth" or } \\
\text { absolute objectivity: the theoretical frame applied here is only one possible lens. } \\
\text { However, it can still be shown to be a more or less 'warranted' one. } \\
\text { - Participant perceptions: This places the researcher in a less privileged position. The } \\
\text { perspective/experience of participants is as important as any other. Grounding my } \\
\text { research questions in participant perspectives also reflects epistemological caution. } \\
\text { Gaining knowledge through a correspondence with 'reality' beyond that perception } \\
\text { is not assumed. }\end{array}$ \\
\hline Methodology & $\begin{array}{l}\text { - Qualitative methods/multiple case studies: Post-positivism advocates conducting } \\
\text { inquiry in natural settings using more qualitative methods. Multiple case studies } \\
\text { (Yin, 2009) and the analytical method followed here (Huberman \& Miles, 1994) } \\
\text { have been associated with post-positivism. } \\
\text { - Exploring rather than predicting: There is value in findings that are not necessarily } \\
\text { predictive but seek to illuminate patterns and explanations. } \\
\text { - Triangulation as important in attaining degrees of epistemological gain (see Section } \\
\text { - Aligned with exploring legitimacy within pluralism: Issues of research focus } \\
\text { incorporates understanding of deeper structures (i.e., legitimacy, perceptions of } \\
\text { legitimacy strategies). Similarly, the methodological approach can be grounded in } \\
\text { the exploration of pluralism (e.g., multiple worldviews and associated legitimacy } \\
\text { demands). }\end{array}$ \\
\hline
\end{tabular}

\subsubsection{A Pragmatic Note}

An additional aspect of my research process is its pragmatic nature. Such an approach is associated within the methodology below (Miles \& Huberman, 1994; Patton, 2002a). Indeed, much of what Creswell (2009) identifies with a "pragmatic worldview" is aligned with postpositivism. This includes being open to both qualitative and quantitative research depending on the research questions. Both maintain a belief in realism as well as multiple (pluralistic) perceptions of that reality. Patton (2002b, p. 271) outlines that his pragmatic utilitarian stance is based on a method being "useful, practical and accurate." A concern for "what 
works" and the problem or research question is primary, and is what I mean by a "pragmatic approach' here (Creswell, 2007; Patton, 2002a; Saunders, Lewis, \& Thornhill, 2007). ${ }^{12}$ My research process can be defined as pragmatic to the extent that my experience of this research journey is one of commitment to the research question that originally sparked my interest. This is distinct from commitment "to any one system of philosophy and reality" (Creswell, 2009, p. 10). My primary reference point remained the research questions I had set out to explore, with pluralism and legitimacy being at the core of these.

\subsection{Research Design}

\subsubsection{Legitimacy Research and Qualitative Case Studies}

Much early understanding of organizational legitimacy was sought through statistical studies (e.g., Deephouse, 1996; Deephouse \& Carter, 2005; Elsbach, 1994; Ruef \& Scott, 1998). For example, the population ecology stream has been almost entirely dominated by quantitative methods and has not measured legitimacy directly (e.g., Carroll \& Hannan, 1989; Hannan \& Carroll, 1992; Hannan et al., 1995; Singh et al., 1986). There is also a tendency of much research to use proxies, such as the population density of particular organizational forms, rather than direct measures of legitimacy (Baum \& Oliver, 1992; Zucker, 1989). ${ }^{13}$ Quantitative articles that acknowledge a degree of pluralism in conceptualizing legitimacy follow a similar pattern of developing a complex theoretical picture before justifying its limitation to a few operationalized variables (e.g., Deephouse, 1996; Elsbach, 1994; Ruef \& Scott, 1998). For example, Deephouse and Carter (2005, p. 337) state that while legitimacy "is a complex, multidimensional concept linked to a variety of stakeholders...from a pragmatic perspective, we limit our research design to certain dimensions." Similarly, quantitative studies of legitimacy strategies within pluralistic settings tend to focus on a single type of strategy such as decoupling (Westphal \& Zajac, 2001), or specific examples of 'resistance' in relation to a specific practice such as downsizing

\footnotetext{
12 The full implications of a pragmatic approach to research is outlined within the philosophical tradition of 'pragmatism,' a paradigm distinct from post-positivism (see Cherryholmes, 1992; Crotty, 1998).

${ }^{13}$ The ability in qualitative interviews of being able ask participants directly regarding their perceptions of 'desirability and appropriateness' and the content of those assessments, namely, their legitimacy demands contrasts with this.
} 
(Greenwood et al., 2010). Potentially, such a focus on particular dimensions and stakeholders as well as general proxies of legitimacy at the field level has resulted in legitimacy research that does not fully account for pluralism.

At least partly in response to these limitations, researchers are increasingly turning to qualitative methods to study legitimation. Authors argue that legitimacy research should account for its complexity, multidimensionality, and multiple sources (Deephouse \& Suchman, 2008; Epstein \& Votaw, 1975; Pache \& Santos, 2010). Previous studies have indeed shown that qualitative case studies can offer holistic treatments of legitimacy that highlight pluralism and provide in-depth pictures of strategic processes at the organizational, rather than field, level (e.g., Battilana \& Dorado, 2010; Brown, 1995; Elsbach \& Sutton, 1992; Glynn, 2002; Vaara \& Monin, 2010). Reflecting on their own quantitative investigation into 'resistance' as a institutional response strategy, Marquis and Lounsbury (2007) suggest that qualitative studies that investigate actor's accounts of various legitimacy strategies would be beneficial. In sum, the ability of qualitative research to incorporate complexity (e.g., multiple perspectives) and holism (e.g., situating legitimacy within pluralism) is important, given the research agenda I have set myself (Becker, 1992; Creswell, 2007; Mabry, 2008; Orum, Feagin, \& Sjoberg, 1991; Stake, 1995).

In reflecting on qualitative studies exploring legitimation amidst pluralism two things are apparent. First, the majority of these studies are single case studies (e.g., Glynn, 2002). Some exceptions combine two cases within a single sector (Battilana \& Dorado, 2010; Elsbach \& Sutton, 1992). Other studies (e.g., Alexander, 1996; Reay \& Hinings, 2009) explore a range of organizations within a sector but do not take a case-based approach to reach understanding of strategies in individual organizations (an exception is Purdy \& Gray, 2009). That multi-case comparative research designs remain rare is argued with regards to the institutional entrepreneurship literature more broadly. For example, Battilana et al. (2009) argue that a sole focus of successful institutional entrepreneurs is linked to a focus in the literature premised on this focus on singular "successful" cases. Second, a characteristic of these studies is that they have either focused specifically on intra- (Jarzabkowski, et al., 2009a) or inter- (Reay \& Hinings, 2009) organizational dynamics and sources of legitimacy, rather than combining both. In particular, the employee level appears to be infrequently 
represented in previous studies at the intersection of pluralism and legitimacy. This suggests that the following may be a research design of particular value:

- Exploring the research problem through multiple case studies within a single sector with varying layers of replication (discussed further below); while

- Maintaining appreciation for the complexity and detail of each case ; and

- Incorporating both inter and intra organizational stakeholders as sources of legitimacy within that understanding.

Such a design will now be outlined.

\subsubsection{Multiple Case Studies}

Context counts and, where possible, should be given theoretical consideration. (Bamberger, 2008, p. 839)

Case studies are widely recognized as a distinct qualitative research strategy - differentiated, for example, from grounded theory, ethnography, and action research approaches (Creswell, 2007; Denzin \& Lincoln, 2005; Eriksson \& Kovalainen, 2008). Yin (2009, p. 13) defines a case study as an inquiry that: "investigates a contemporary phenomenon within its real life context; especially when the boundaries between the phenomenon and context are not clearly evident." This ability to incorporate context is widely accepted as a key justification for a case study research design (Eisenhardt, 1989; Eisenhardt \& Graebner, 2007; Hartley, 2004; Mabry, 2008; Orum et al., 1991) and, indeed, qualitative methods more broadly (Creswell, 2007; Denzin \& Lincoln, 2005; Patton, 2002a). A case study strategy enabled me to situate a phenomenon (i.e., legitimacy management) within a specific context (i.e., pluralism), something my research questions demanded. Also aligned with these questions, case studies are suited to answering how and why questions (Easton, 2000; Eisenhardt \& Graebner, 2007; Hussey \& Hussey, 1997; Yin, 2009). Such questions focused this research on probing deeper into the research problem.

A central rationale for this study is that the pluralistic case can refine, add understanding to and extend existing legitimacy frameworks. Importantly, case studies lend themselves to surfacing new theoretical interpretations and have the ability to elaborate on or revise existing theory. Processes previously ignored in the literature can be illustrated in a way that 
redraws generalizations to refine or modify existing theory (Dubois \& Gadde, 2002; Hussey \& Hussey, 1997; Ragin, 1992; Stake, 2005; Yin, 2009). This corresponds with the case study's strength in making theoretical generalizations as opposed to population generalizations (Yin, 2009).

A positivist argument levelled at case study research is its lack of statistical generalizability, i.e., external validity (O'Leary, 2004; Yin, 2009). Studying two particular organizations does not provide me with a foundation to generalize the resulting findings to all similar population cases. Findings are, however, generalizable to theoretical propositions. For example, here they are 'transferable' to Kraatz and Block's (2008) framework. This is a process Yin (2009) labels analytical generalization (also see Eisenhardt \& Graebner, 2007; Gobo, 2008; Huberman \& Miles, 2001; Stake, 1995). In moving beyond empiricism, postpositivism provides a foundation for valuing this form of generalizability (Crotty, 1998; Guba \& Lincoln, 1994; Phillips \& Burbules, 2000). Ackroyd (2004, p. 175) contrasts a subtle realist philosophy with positivism in this regard: "because research is theoretically based, realists reject the notion that case studies cannot be the basis for generalization" (Bergene, 2007; Harrison \& Easton, 2004). Such an interpretation of generalizability is aligned with the strength of case studies utility in generating or, as in this thesis, extending theoretical understanding.

Case studies can follow a single or multi-case design (Stake, 2005; Yin, 2009). My research goals contrasted with an 'intensive' case design where a key interest is the case itself. I had predefined goals of theoretical elaboration based on a theoretical framework. Such goals pointed to the desirability of a multiple case study design (Eriksson \& Kovalainen, 2008; Piekkari, Welch, \& Paavilainen, 2008; Yin, 2009). Further, from a post-positivist perspective of "epistemological gain" it is argued that multiple case studies enable greater corroboration of findings through enabling comparison and identification of idiosyncrasies (Eisenhardt, 1989; Eisenhardt \& Graebner, 2007; Yin, 2009). From such a perspective, comparison allows researchers to distinguish between constitutive and more accidental aspects of the empirical data and results in more robust findings (Danermark, et al., 2002; Phillips \& Burbules, 2000; Tsang \& Kai-Man, 1999; Yin, 2009). More simply, investigating multiple cases increased the likelihood that different aspects of the framework (Kraatz \& Block, 2008) might be highlighted. As Eisenhardt (1991, p.620) suggests: "different cases 
often emphasize complementary aspects of a phenomenon. By piecing together the individual patterns, the research can draw a more complete theoretical picture"

\subsubsection{Case Selection}

Understanding the organization (my unit of analysis) at the time of data collection became the case boundary. This case "bounding" offered parameters for participant selection, collection and treatment of secondary data, and framing of the interview questions. For example it excluded a primary interest in historical interviewees (such as past CEOs, for example) and sector-level individuals who had no direct connection to the cases at hand. However, as Miles and Huberman (1994) point out "the boundary is never quite as solid as a rationalist might hope" (p. 27). Most importantly strategic changes over time arose as important to understanding "current" strategic dynamics. Finally, this focus on organizations as the level of analysis draws from the foundations of my theoretical framework. Kraatz \& Block (2008, p. 246) argue that their framework is "an avowedly organization-centric perspective" as distinct from much institutional theory.

Analytical generalizability can be increased by the strategic, or (theoretically) purposive, selection of cases (Eisenhardt, 1989; Flyvbjerg, 2006; Patton, 2002a). This selection process is outlined as replication logic. Multiple cases are treated as discrete experiments that serve to replicate, contrast and extend the emerging theoretical explanation (Yin, 2009). Based on this logic two broad practical guidelines for case selection are provided.

First, a degree of similarity in the chosen cases is advocated so as to decrease the number of extraneous variables at play. Practically, this helped provide parameters to the complexity of the eventual dataset and analytical process. Choosing cases from within a single industry is suggested for this reason (Eisenhardt, 1989; Eisenhardt \& Graebner, 2007; Yin, 2009). This informed the decision to select NZ's science sector as the empirical boundary rather than including cases from diverse sectors.

Second, including a variety of cases operating under different conditions helps ensure the resulting theoretical generalizations are more robust through exploring the phenomena in a number of different settings (Eisenhardt \& Graebner, 2007; Yin, 2009). This guided my decision to choose different organizational form $s$ within NZ's science sector: high-tech start- 
ups (HTSUs), Crown Research Institutes (CRIs), and Centres of Research Excellence (CoREs) (Figure 3.2).

Figure 3.2 Research Design: Replicated and embedded

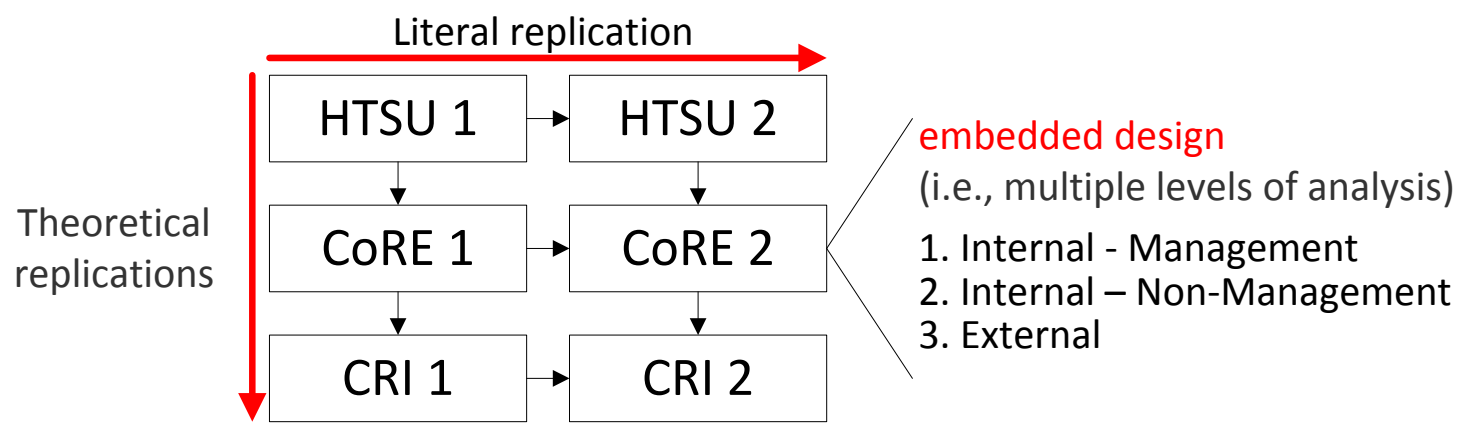

Yin's (2009) concepts of literal and theoretical replication were utilized to assist my case selection. Cases can be selected depending on whether they produce similar results (literal replication) or different results for predictable reasons (theoretical replication). Literal replication is achieved through duplicating the conditions of the original "experiment." This guided my decision to study two rather than one of each type of organization of a broadly similar type. Incorporating two similar organizations (rather than four, for instance) was considered to be pragmatic given my desire to also incorporate an additional layer of theoretical replication.

The basis for assuming a degree of literal replication between similar organizations is highlighted in Table 3.2. The central differences between the similar organizations are also highlighted so that the practical limitations of literal replication (no two organizations are exactly alike) are appreciated. 
Table 3.2 Case descriptions: Broad basis for replication ${ }^{14}$

\begin{tabular}{|c|c|c|c|}
\hline & CoRE $1 \& 2$ & CRI 1 \& 2 & HTSUs 1 \& 2 \\
\hline Type of organizations & $\begin{array}{l}\text { Non-profit collaborative } \\
\text { research networks }\end{array}$ & $\begin{array}{l}\text { Government owned } \\
\text { companies }\end{array}$ & Companies \\
\hline Age & 2002 & 1992 & Similar: $<10 \mathrm{yrs} ;>5 \mathrm{yrs}$ \\
\hline Revenue & $\begin{array}{l}\text { Similar: approx. } 20-40 \\
\text { million (over six years); } \\
\text { CoRE } 1 \text { larger }\end{array}$ & $\begin{array}{c}\text { Similar: }>\$ 50 \text { million } \\
\text { (annual) }\end{array}$ & $\begin{array}{l}\text { Similar: approx. \$1 } \\
\text { million (annual) }\end{array}$ \\
\hline Total Staff & $\begin{array}{c}\text { Similar: < } 50 \text { PIs; CoRE } 1 \\
\text { slightly larger }\end{array}$ & Similar: > 300 & Similar: $<12$ \\
\hline Funding Sources & $\begin{array}{l}\text { TEC administered CoRE } \\
\text { Fund; same funding } \\
\text { criteria }\end{array}$ & $\begin{array}{l}\text { Similar: core government } \\
\text { (MoRST); research grants } \\
\text { (FRST); clients. } \\
\text { Difference: CRI } 2 \text { has a } \\
\text { few larger key clients }\end{array}$ & $\begin{array}{l}\text { Similar: private investors; } \\
\text { government grants; } \\
\text { University (HTSU } 1 \text { only); } \\
\text { Shareholder CEO (HTSU } 2 \\
\text { only) }\end{array}$ \\
\hline $\begin{array}{l}\text { Relevant policy / } \\
\text { regulatory bodies }\end{array}$ & $\begin{array}{l}\text { Same; e.g., CoREs } \\
\text { selection framework. }\end{array}$ & $\begin{array}{c}\text { Same (e.g., CRI Act; } \\
\text { Shareholder' } \\
\text { expectations) }\end{array}$ & $\mathrm{n} / \mathrm{a}$ \\
\hline $\begin{array}{l}\text { Type \& domain of } \\
\text { science }\end{array}$ & $\begin{array}{l}\text { Same: basic research; } \\
\text { different science } \\
\text { domains }\end{array}$ & $\begin{array}{l}\text { Generally applied (but } \\
\text { also includes more basic } \\
\text { science); different } \\
\text { sectors/industries }\end{array}$ & $\begin{array}{l}\text { Similar domains; similarly } \\
\text { moved from basic to } \\
\text { commercialized } \\
\text { science/technology }\end{array}$ \\
\hline $\begin{array}{l}\text { Geographical } \\
\text { spread/focus }\end{array}$ & $\begin{array}{l}\text { Similar number of } \\
\text { partner organizations } \\
\text { including CRIs. Both with } \\
\text { international (academic) } \\
\text { linkages }\end{array}$ & $\begin{array}{l}\text { Similar number of sites } \\
\text { and degree of } \\
\text { geographical spread. } \\
\text { Both with international } \\
\text { linkages }\end{array}$ & $\begin{array}{c}\text { Similarly export focused. } \\
\text { Both with research teams } \\
\text { outside of the corporate } \\
\text { centre }\end{array}$ \\
\hline Role of scientists & $\begin{array}{l}\text { Scientists as leaders } \\
\text { (Directors) and members } \\
\text { (Investigators) }\end{array}$ & Employees. & $\begin{array}{l}\text { Scientist founders } \\
\text { original (HTSU 2) or } \\
\text { current (HTSU 1) } \\
\text { shareholders }\end{array}$ \\
\hline
\end{tabular}

Based on the logic of theoretical replication (Eisenhardt \& Graebner, 2007; Yin, 2009) it could be argued that a compelling design feature would be contrasting pluralistic cases with non-pluralistic cases. The rationale for not doing so was twofold. I was reluctant to divert my attention and limited resources away from a primary focus on the pluralistic context. Further, the legitimacy literature provided a foundation of non-pluralistic cases and general frameworks with which I could contrast my pluralistic cases (e.g., DiMaggio \& Powell, 1983; Dowling \& Pfeffer, 1975; Suchman, 1995). Accordingly, while I decided to vary the types of organizations I included in my study, I only selected organizations likely to experience pluralism. Put simply, the question guiding case selection was: "does this organization appear to be characterized by interesting dynamics indicative of pluralism?'

\footnotetext{
${ }^{14}$ Exact figures cannot be provided due to human ethics commitments regarding confidentiality. See Table 3.3 for glossary of abbreviations.
} 
Multiple divergent and salient stakeholder demands are said to have a relatively large effect on non-profit, governmental, and start-up organizations (Bryson, 1988; Jarzabkowski \& Fenton, 2006; Stone \& Brush, 1996). Therefore, I chose for-profits (high-tech start-up (HTSU)); government-owned companies (Crown Research Institutes (CRIs)); and public notfor-profit collaborative networks (Centres of Research Excellence (CoREs)). For example, start-up firms must satisfy a variety of stakeholders who have conflicting objectives: the goals of the founder, employees (including scientists in the case of high-tech organizations), suppliers, and venture capitalists or bankers may all be widely divergent and shift over time (Stone \& Brush, 1996). With regards to public sector and not-for-profit organizations it is pointed out that pluralistic tensions arise from competing demands such as a commercial orientation (increasingly demanded of such organizations) being managed at the same time as providing quality public service (Jarzabkowski \& Fenton, 2006). While presumptions regarding the intricacies of each case prior to entering the field were not possible, it was envisaged that these two layers of replication offered an explanatory foundation for exploring and understanding a number of potential findings. For example, whether different or similar strategies were perceived in relation to dissimilar or similar organizations can both be explored from this platform.

In addition to this discussion, Figure 3.3 demonstrates how case selection was also informed by the landscape of the NZ science system itself. A glossary related to this sector regarding the points relevant to this study is also provided (Table 3.3). 
Figure 3.3 NZ RS\&T system (at the time of data collection) (adapted from FRST, 2008). ${ }^{15}$

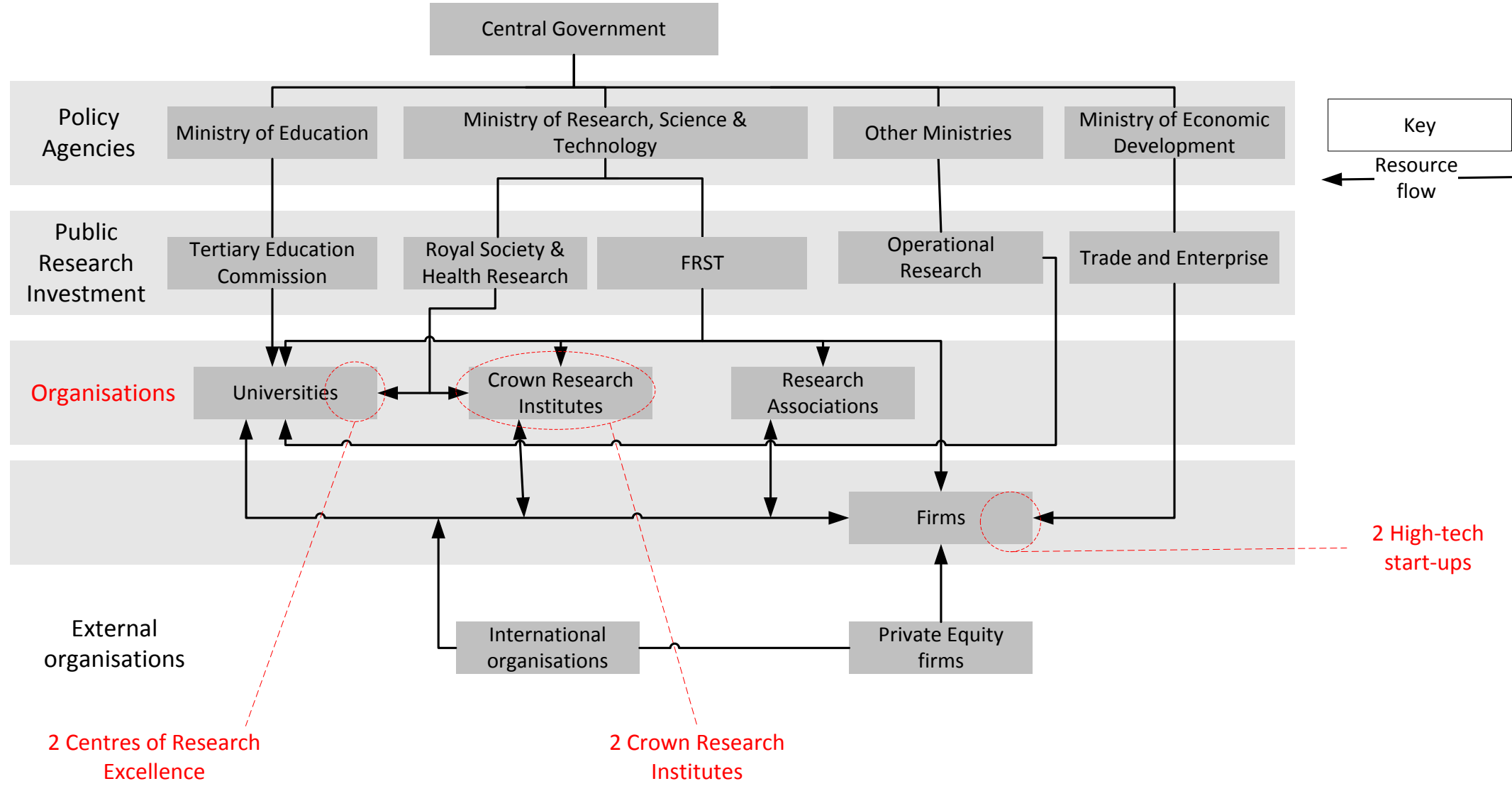

\footnotetext{
${ }^{15}$ There were four choices at the organisational level within the sector. Not including the fourth, research associations, was pragmatic. It involved determining the limits and manageability of the PhD project. Further, research associations were assessed as dealing with distinct issues to the ones encountered by the organizations included here. For example, with a few exceptions they did not necessarily deal with the political interface in the way the organizations included here (including, HTSTUs through government grants) did. Determining a degree of literal replication would also have been less possible between research associations. There is a huge variety regarding structure, funding and purpose. Consequently, while research associations are likely to face pluralism and interesting issues that future research could explore, for these reasons they are not included here.
} 
Table 3.3 Glossary: NZ Science Sector

\begin{tabular}{|c|c|}
\hline Terms/Acronyms & Explanation \\
\hline HTSUs & $\begin{array}{l}\text { High tech start ups: Private (i.e. prior to IPO or acquisition) SMEs (small medium } \\
\text { enterprises) with limited operating history engaged in research activity. }\end{array}$ \\
\hline CoREs & $\begin{array}{l}\text { Centres for Research Excellence: Seven CoREs were established in 2002, one in } \\
\text { established in } 2006 \text { (the CoRE re-funding round). One of the CoRE's funding } \\
\text { ceased in } 2006 \text { during the re-funding round. }\end{array}$ \\
\hline \multicolumn{2}{|c|}{ Other terms related to CoREs } \\
\hline Directors & Scientist managers/leaders of CoREs. \\
\hline Pls & Principal Investigators: Scientists who are receive funding as part of the CoRE. \\
\hline Als & $\begin{array}{l}\text { Associate Investigators: Scientists associated with the CoRE. May not receive } \\
\text { funding, but receive other benefits such as access to equipment. }\end{array}$ \\
\hline Outreach & $\begin{array}{l}\text { A descriptor of activities that CoREs engage in around disseminating knowledge } \\
\text { into the community. An example is "outreach" being used as a descriptor for } \\
\text { engagement with secondary schools or Maori (indigenous people of NZ). }\end{array}$ \\
\hline PBRF & $\begin{array}{l}\text { Performance Based Research Fund: Government funding received by tertiary } \\
\text { education organizations based on an assessment of research performance. } \\
\text { Academics are individually ranked as part of this. }\end{array}$ \\
\hline CRIS & $\begin{array}{l}\text { Crown Research Institutes: There are currently eight crown research institutes. } \\
\text { Ten were established in } 1992 \text { under the CRI } 2 \text { Act. One was disbanded (1993) and } \\
\text { two were joined through a merger (2008). }\end{array}$ \\
\hline \multicolumn{2}{|c|}{ Other terms related to CRIs } \\
\hline CRI Shareholders & $\begin{array}{l}\text { Minister of Research, Science and Technology [MoRST] and Minister of Finance } \\
\text { are the shareholders of CRIs. }\end{array}$ \\
\hline CRI Taskforce & $\begin{array}{l}\text { A Taskforce set up to review the CRI model; established October 2009; Report } \\
\text { released March } 2010 .\end{array}$ \\
\hline MoRST & $\begin{array}{l}\text { Ministry of Research, Science and Technology: Ministry responsible for policy for } \\
\text { NZ's science sector at the time of this study [since changed into Ministry of } \\
\text { Science and Innovation, est. Feb 2011]. }\end{array}$ \\
\hline $\begin{array}{l}\text { FRST / "the } \\
\text { Foundation" }\end{array}$ & $\begin{array}{l}\text { Foundation for Research, Science and Technology: Government funding agency in } \\
\text { sector at this time of this study. Funds research in Universities (CoREs); CRIs and } \\
\text { private sector companies [since subsumed within Ministry of Science and } \\
\text { Innovation, est. Feb 2011]. }\end{array}$ \\
\hline TEC & $\begin{array}{l}\text { Tertiary Education Commission: Entity focused on tertiary sector within broader } \\
\text { Ministry of Education. Funds and monitors CoREs. }\end{array}$ \\
\hline
\end{tabular}




\subsection{NZ's Science Sector: HTSUs, CRIs, and CoREs}

Pressures for relevance of scientific research, and in general, new linkages with, and interferences by the 'outside' world have opened up the earlier protected space for science (Rip 2004, p.32).

The term NZ's science sector refers to organizations within the policy umbrella of 'Research, Science and Technology' (RS\&T). The definition includes any organization conducting basic or applied research in the physical and biological sciences whether private, non-profit, or public (MoRST \& Statistics NZ, 2006). Central reasons for selecting this sector are: the relevance debate, dispersion of stakeholder power, and legitimacy issues related to funding and uncertainty. While these points do not preclude the selection of an alternative industry, they do present a theoretically informed rationale concerning why NZ's science sector was selected. These issues sit within a science system that has been transformed as part of wider neo-economic driven changes within NZ's public sector (Carter, 2005; Leitch \& Davenport, 2005; Simpson \& Craig, 1997). This transformation can be summarized as increased levels of monitoring of science organizations (i.e., diffused power) as well as the explicit introduction of additional objectives and legitimacy demands (Mallon et al., 2005). The sources of legitimacy demands within this domain can, therefore, be defined as increasingly multifaceted and powerful.

Research utilizing an institutional perspective has explored the intersection and associated conflict between 'academic' (i.e., science) and 'commercial' norms and logics (Vallas \& Kleinman, 2008). However, the dominant approach from an institutional perspective has focused on highlighting the institutionalization and legitimation of 'academic entrepreneurship' over time, rather than exploring the conflict inherent within these different logics (Colyvas \& Powell, 2006, 2007; Sampat \& Nelson, 2002). However, other research, not utilizing an institutional or legitimacy lens, has focused on the inherent tensions between the intersection between the domains for individual scientists (Mallon, Duberly, \& Cohen, 2005; Owen-Smith \& Powell, 2001) and public science organizations (Davenport \& Bibby, 2007; Powell, Owen-Smith, \& Colyvas, 2007) inherent in the coming together of these formally distinct spheres.

Another issue is that the strategies NZ science organizations have used to respond to their changed context have been understudied. A study providing brief sketches showing the 
different responses of four CRIs to the government reforms is a rare exception (Simpson, 2004). The selection of this context this research project helps address this research gap.

\subsubsection{The Relevance Debate: Divergent Objectives}

Scientists must now show that we, the people, will see a return for our invested dollars. And that return better come pretty quickly before we lose interest! (Britten \& Scott, 2009)

A rationale for choosing the NZ science sector was the tension highlighted by both the academic research and media commentary between the demands for "scientific discovery/excellence", "public good", and "commerciality" (Figure 3.4). Worldwide, authors have depicted a changing research, science and technology sector whereby additional requirements (such as societal and economic robustness) have joined the traditional one of scientific excellence (Cohen, Duberley, \& McAuley, 1999; Mars \& Lounsbury, 2009; Raine \& Beukman, 2002; Rip, 2004; Ziman, 1994). Colyvas and Powell (2006) outline that this transformation is a promising domain for research as it affected multiple levels of the sector (i.e., individuals, departments, and organizations) and multiple organizational forms (i.e., university, industry, and government sectors). For example, the literature, generally from a US university context, variably points to new institutionalized academic identities and practices (Colyvas \& Powell, 2006, 2007), but also provides warnings regarding what this means for universities with commercial objectives in tension with academic objectives (Owen-Smith \& Powell, 2003; Powell et al., 2007), and highlights the individual level tensions for university scientists (Owen-Smith \& Powell, 2001). 


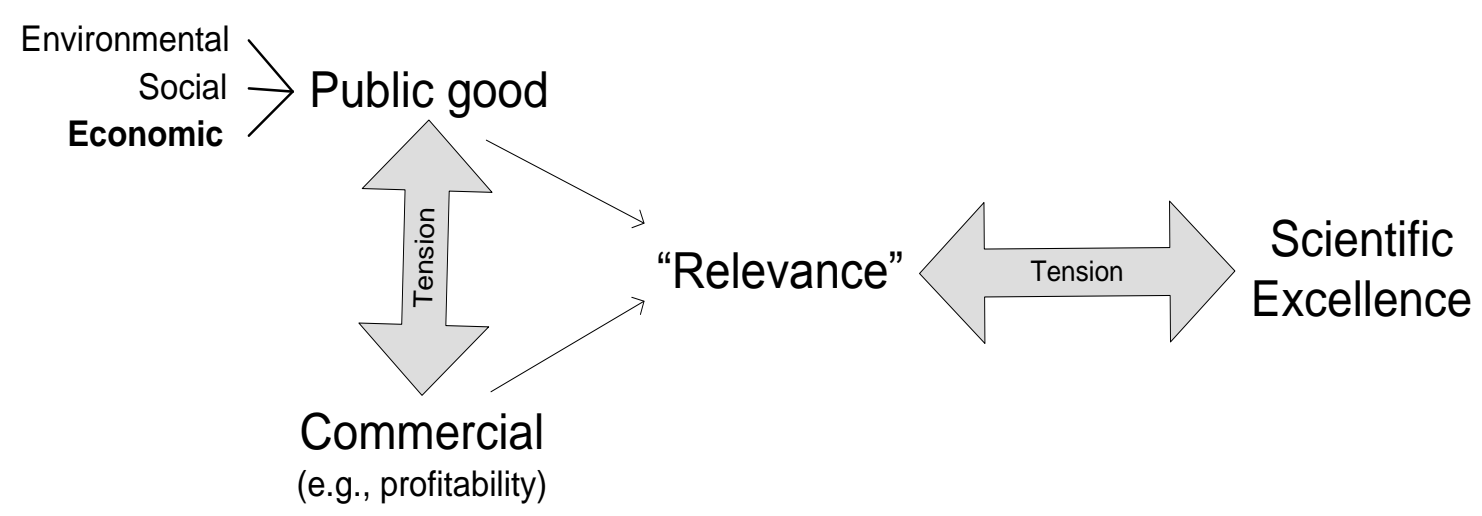

In NZ the creation in 1989 of the Foundation for Research, Science and Technology (FRST) signalled the beginning of the "deliberate marketization of science and innovation" (Leitch \& Davenport, 2005, p. 896). Most government scientists were previously employed as public servants in a number of core government departments. However, a commercialized model was formalized with the Crown Research Institute Act (1992) which channelled governmentfunded science into ten (although this quickly become nine) Crown Research Institutes (CRIs), each aligned to different economic sectors. This juxtaposed the traditional concern on "research for the good of the nation" (defined usually in economic, but also social, terms) with a new requirement of "financial viability." CRIs were required to operate as commercial entities under the Companies Act (Davenport \& Bibby, 2007; Edmeades, 2004, p.87).

From a focus on science itself and robust processes, following NZ's reforms in the 1980s "excellence" has increasingly been coupled with "relevance" (to users) based objectives and demands (Davenport, Leitch, \& Rip, 2003, p. 244; Leitch \& Davenport, 2005). This development can also be observed in NZ universities. An example is the introduction of Centres of Research Excellence (CoREs). The CoRE Fund was established in 2001 with the aim of producing strategically focused (i.e., relevant) as well as excellent tertiary-education based research (New Zealand Government, 2002; Taula, 2006; TEC, 2006, 2009). In sum, NZ's science system has shifted from being based solely on scientific merit to being based on more complex priorities.

These multiple demands have been experienced as tensions within the sector (Davenport, et al., 2003; Edmeades, 2004; Sommer, 2010). Authors highlight an "underlying struggle" as 
user relevance and science "vied for control" (Davenport et al., 2003, p. 247); "deep-seated philosophical conflicts" (Edmeades, 2004, p. 91); and that "the most critical issue that has faced the CRIs in recent years is the tension between their public good role and their commercial focus" (Davenport \& Bibby, 2007, p. 189). For example, it is argued that too much is expected from CRIs in juggling the tensions of the multiple objectives placed on them (Crown Research Institute Taskforce, 2010; Devine, 2003; Jordan \& Atkinson, 2003). More specific illustrations of such divergence are that science cannot be measured in the same way as other commercial or output focused activities, the short-term performance focus of the market model undermines the long-term focus of science excellence, and the tension between publishing and commercialization (Bridger, 2009; Easton, 1997; Edmeades, 2004; Revington, 2008; Simpson, 2004). As one report summarizes: "people cannot buy what they cannot imagine" (Arnold, 2005, p. 6).

While this tension between 'relevance' and 'scientific discovery/excellence' clearly affects CoREs and CRIs, this terrain must also frequently be navigated by start-ups. Such companies are frequently spun-out of universities or CRIs and rely on the scientific founders and their knowledge platforms due to their high-tech nature. These companies are frequently required to meet the needs of stakeholders with foci as potentially diverse as return on investment (e.g., private investors) and research funding and technological excellence (e.g., scientist founders). In this way they are said to be defined by interdependent stakeholders with conflicting interests (Djokovic \& Souitaris, 2008; Duberley, 2007). For example, academic or technological driven objectives are frequently associated with such companies (Meyer, 2003). This multi-stakeholder nature of start-ups will be discussed further below.

\subsubsection{Dispersion of Stakeholder Power}

The 'locus of innovation' is said to reside in a network of inter-organizational relationships (Powell et al., 1996) and research is becoming increasingly distributed (Pisano \& Verganti, 2008; Powell et al., 1996; Rip, 2004). The fast pace, high cost, and complex nature of technology development has led to the establishment of consortia, alliances, and other cooperative efforts (Davenport, Grimes, \& Davies, 1999). Indeed, studies suggest that the level of technological intensity is positively correlated with collaborative activity (Hagedoorn, 2002; Koza \& Lewin, 1998; Powell et al., 1996). Another example is the development of 
"post-modern universities" characterized by "overlaps and alliances with Centres (of excellence and relevance)...and various private organizations managing and performing research" (Rip, 2004, p. 159). Within such inter-organizational collaborative systems "multiple constituencies with conflicting demands exist (almost by definition), and no single organization directly controls all of the needed resources" (Stone \& Brush, 1996, p. 648). This diffuses power while increasing the likelihood that divergent objectives and loyalties exist within an organization.

The number of relevant stakeholders with the ability to make demands on science and research has increased since NZ's science reforms. Public funding of science is not only output focused but also more closely monitored by stakeholders external to the science providers themselves (Duberley, 2007; Ziman, 1994). As Davenport et al. (2003, p. 239) summarize, while much of the sector "used to be entirely in the hands of "science", the involvement of other stakeholders...has become important." Such diffusion of power away from the providers of science is recognized and often argued against by scientists. For example, it is illustrated in a recent survey of NZ university and CRI scientists with "a common complaint of scientists" being "outside interference in their quest to satisfy their intrigue with the search for truth and knowledge, their principal reason for becoming a scientist" (Sommer, 2010, p. 30).

Crown Research Institutes. Department of Science and Industrial Research, the main predecessor to CRIs, was previously both the primary provider of policy advice as well as being the sole controller of funding to its researchers (Davenport \& Bibby, 2007; Winsley \& Hammond, 1997). In this context, scientists had "the autonomy to determine both the means and ends" of their research (Simpson, 2004, p. 254). By contrast, currently "there are multiple lines of accountability that dilute the CRIs' sense of purpose and direction" (CRI Taskforce, 2010, p. 7). Similarly, the diffused power context of CRIs is indicated by government's power to determine the CRIs' direction, survival, and the level of return they are required to make (CCMAU \& The Treasury, 2007). The history of the CRIs is one of diffused power as the relevance of private companies and overseas revenue grew (Davenport \& Bibby, 2007; Davenport \& Leitch, 2005; Parker, 2002). A competitive funding system (Devine \& Webb, 2004) and the resulting variation in FRST funding for individual CRIs has caused issues with some CRIs losing significant income and consequently having to 
diversify their revenue sources (Davenport \& Bibby, 2007). This has increased the importance of 'clients' while the high dependence on government (policy and funding) remains.

Centres of Research Excellence. The establishment of CoREs is a specific example of the increasing drive towards collaboration, and accompanying power diffusion, within NZ's science sector. COREs are inter-institutional networks which, while hosted by a particular university, comprise a number of partner organizations (universities and CRIs) (Taula, 2006; Tertiary Education Commission (TEC), 2009). As with CRIs, they are dependent on assessments by external stakeholders for their funding and existence; their re-funding is not assured unless they meet the objectives set for them by external stakeholders (New Zealand Government, 2006b; TEC, 2009) .

High-tech start-ups. Compared to larger firms, start-ups are resource constrained and lack relative power within their stakeholder relations (Aldrich \& Fiol, 1994; Stone \& Brush, 1996). HTSUs, particularly, rely on scientific capability but usually do not have the resources to develop their own research. In comparison with other start-ups, high-tech start-ups face additional pressures due to the need to collaborate to fund high-cost R\&D and acquire knowledge (Knockaert, Lockett, Ucbasaran \& Clarysse, 2006; Pisano \& Verganti, 2008). That is, they counter their resource constraints somewhat through collaboration (Davenport et al., 1999). For example, research suggests that an entrepreneurial firm's rate of patenting (Shane \& Venkataraman, 2000), product innovation (George, Zahra, \& Wood, 2002), and foreign sales (Leiblein \& Reuer, 2004) are enhanced by strategic alliances. As Knockaert et al. (2006) summarize: HTSUs are typically resource-poor and rely on important external stakeholders to provide risk capital and technology (e.g., universities or other research institutes). HTSUs have, therefore, become increasingly exposed to a multi-stakeholder context.

Knowledge workers. Applicable to all science organizations is their dependence on knowledge workers. Parker (2002, p. 42) describes how when the first Chairman of the CRI Industrial Research Limited (IRL) addressed the CRI's staff (a workforce that included 150 PhDs) he noted that "it was the first company he'd been involved in where 'all the intellectual property goes home at night.'" In such organizations power is more diffused 
internally amongst the scientists who hold the intellectual property. In NZ, for example, there is concern regarding the ability of such workers to leave NZ and take their skills elsewhere if their demands are not met (Britten \& Scott, 2009). Three characteristics of high-tech workers are highlighted in the literature: high level of education, a strong preference for independence, and a professional orientation rather than an organizational focus (Roger, 2001). The 'science excellence' objective outlined above is likely tied in with the professional identity of important internal stakeholders within science organizations.

\subsubsection{Legitimacy: Funding and Uncertainty.}

Linked to the diffused power dimension, any organization that depends heavily on its relationships with stakeholders (whether government agencies, venture capitalists, alliance partners) is likely to emphasize legitimation strategies (Boyd, 2000). Resource dependence theory stipulates that autonomy has an important link to legitimacy (Dowling \& Pfeffer, 1975). Legitimacy is more important for organizations that depend heavily on social, resource, and political support (Brown, 1994; Parsons, 1960; Terreberry, 1968). This has been shown to be the case with CRIs, CoREs, and HTSUs in the discussion above.

NZ's funding culture vis-à-vis research, science and technology has become highly contractual and contestable. Monitoring and evaluations of legitimacy vis-à-vis specific organizations has increased within this low-trust system (Arnold, 2005; Davenport \& Bibby, 2007; Royal Society of New Zealand, 2008). In 2000 FRST introduced a narrative of 'disinvestment' where NZ\$26 million per annum of investment into the forestry sector (affecting for example the CRI Scion focused on this industry) was potentially in jeopardy (Davenport et al., 2003). Further, in the 2006 selection or refunding round, six of the existing CoREs were awarded further funding (two conditionally) while one existing CoRE was 'disinvested' in by the government (TEC, 2009). This illustrates that for both CRIs and CoREs positive evaluation is linked to their ability to attract and retain government funding, suggesting that legitimacy management is an important issue for these organizations. More broadly, the support and funding of science in NZ is not something that can be taken for granted (Britten \& Scott, 2009). This is demonstrated by those explicitly seeking to legitimate science as a "proper investment" rather than the historical perspective of it "as a cost to society" (Callaghan, 2009; Gorman, 2010; Royal Society of New Zealand, 2008; 
Williams, 2004). Indeed, Stone and Brush (1996) argue that not-for-profits and start-ups share a common lack of control over resource flows and, therefore, must meet external standards of legitimacy to attain them.

Aldrich and Fiol ask regarding start-ups: "with no external evidence, why should potential parties "trust" an entrepreneur's claims...given that an entrepreneur may be no more than an ill-fated fool?" (1994, p. 650). In this way, start-ups are faced with a 'liability of newness' associated with a legitimacy deficit (Lounsbury \& Glynn, 2001; Singh et al., 1986). Research shows that start-ups face legitimacy problems due to their newness and small size and corresponding relative lack of power over multiple stakeholder claims, and control over resource flows (Deephouse, 1996; Hannan \& Carroll, 1992; Ruef \& Scott, 1998; Singh et al., 1986; Stinchcombe, 1965; Stone \& Brush, 1996). New technology ventures in emerging industries are particularly difficult to evaluate: it is up to entrepreneurs to convince and continue to reassure stakeholders of their legitimacy (Deeds et al., 2004). In sum, for startups, achieving legitimacy is relatively more difficult whilst also being vital due to their resource-constrained nature (Elfring \& Hulsink, 2003; Parsons, 1960; Zimmerman \& Zeitz, 2002).

\subsection{Data Collection}

\subsubsection{Knowledge from Interview Data}

With my primary data being interview-based, I will briefly explicate my post-positivist view regarding it. King (2004a, p. 11) outlines the goal of interviews as to "see the research topic from the perspective of the interviewee." This aligned with my research questions. However, the basis of the critique of interview data has changed from traditional practical concerns regarding bias, inaccuracies, and impression management to basic scepticism about the capacity of interviews to provide representations "either of the self (i.e., perceptions) or of the world" (Hammersley, 2003, p. 119). Such radical critique suggests that no knowledge about reality "out there" can be obtained through interview (e.g., Atkinson \& Coffey, 2002; Dingwall, 1997; Potter, 2006; Silverman, 2006). The methodological options become avoiding interviews altogether or only analyzing them for what they can tell us about them 
as sites for discursive meaning-making (Hammersley, 2003; Hammersley \& Gomm, 2008; Miller \& Glassner, 2004).

The above critique undermines the ability of interviewers to study acts, meanings and experience in an organizational context. However, it is argued that such an approach may be over-zealous in sacrificing relevance for rigour (Holstein \& Gubrium, 2004). Post-positivism instead suggests that claims can be made (albeit tentative ones) about the "tendency of things" outside the interview itself (Bhaskar, 1979, p. 24; Phillips \& Burbules, 2000). I reiterate the 'anti-dualist' point made by Miller and Glassner (2004): the positivist view of the interview as an objective tool is not accepted, nor is the romantic view of seamless authenticity. I do not, however, discount the possibility of learning about the social world or, more accurately here, participants' perceptions of it outside the interview. As authors (Hammersley, 2003; Miller \& Glassner, 2004) suggest, that interview accounts are constructions does not mean that they cannot be accurate representations. To argue that an interview carries no reliable implications about events, attitudes, and perceptions outside the interview grants too much power to the interview context to shape those perceptions. Nonetheless, a level of caution in the use of interview material remains. To ignore warnings about the fraught nature of the link between interview data and reality would be complacent (Hammersley, 2003). The interviews, thus, are viewed as providing access to participants' perceptions of legitimacy strategies rather than being presented as uncomplicated access to "reality" (Marshall \& Rossman, 2006; Phillips \& Burbules, 2000). The main response suggested by post-positivism to building more (rather than less) warrantable representations of those perceptions is triangulation (Hammersley \& Gomm, 2008).

\subsubsection{Triangulation}

One way of increasing the plausibility of accounts is through triangulation: "the act of bringing more than one source of data to bear on a single point" (Marshall \& Rossman, 2006, p. 202). Denzin (1989) identified four forms of triangulation: across data sources (i.e., participants), methods (i.e., interview, observation, documents), theories, and among different investigators. Denzin's conception is widely accepted (Creswell \& Miller, 2000; Denzin \& Lincoln, 2005; Miles \& Huberman, 1994; Patton, 2002a) and is advocated by 
authors from multiple perspectives as an important aspect of case study research (Eisenhardt \& Graebner, 2007; Gerring, 2007; Mabry, 2008; Stake, 2005; Yin, 2009). Both data (multiple different participants) and method (for example both interviews and secondary data) triangulation are incorporated here.

Judgments regarding the plausibility of accounts inevitably involves a tentative subscription to the view that language is referential to a reality outside the text (Seale, 1999), an approach aligned with post-positivism (Hammersley, 2001; Phillips \& Burbules, 2000). Nonetheless, traditional conceptions of triangulation have been critiqued as assuming the existence of a single correct conception of a phenomenon (Flick, 1992; Silverman, 2006). This is partly circumvented here through the definition of triangulation being used. From the case study literature Stake $(1995$, p. 173) provides a useful definition of triangulation as "working to substantiate an interpretation or to clarify its different meanings." This has similarities with Cohen, Manion and Morrision's (2000, p. 112) definition of triangulation as an attempt to explore "the richness and complexity of human behaviour by studying it from more than one standpoint." Based on these definitions, triangulation will be used in the more 'traditional' sense (e.g., Eisenhardt \& Graebner, 2007) to gain a sense of the central things stakeholder's perceptions relate to (for example, a restructuring of an organization). This is what Stake (1995, p. 115) calls "confirmation of a single meaning." However, it is also used to increase understanding through the "search for additional interpretations" (Dubois \& Gadde, 2002; Stake, 1995, p. 115) in terms of surfacing stakeholder legitimacy demands and pluralism. For example, the multi-stakeholder approach (participant triangulation) to participant selection was central to this. Denzin (1989) explicitly states that his categories of triangulation are compatible with both uses.

\subsubsection{Accessing the Organizations}

The first step in data collection was selecting and gaining access to the case organizations. Secondary data assisted in case selection. Case-specific reading enabled initial assessments regarding the existence of pluralism and potentially interesting strategic dynamics observable within specific organization. Informal conversations with those knowledgeable in the sector were also important in gaining a sense of potential case organizations. 
There were eight CoREs to select from, six of which were science-based. All six of these organizations were assessed as potential options due to all appearing to experience pluralism (as discussed above). Pragmatic issues around ease of access then guided the order in which CoREs were approached. There were also eight potential CRIs to choose from, which similarly were assessed based on apparent pluralism and legitimacy strategies evident within the secondary data such as their annual reports. This list was reduced, through conversation with my supervisors, with regards to their openness to the research. In relation to the two CRIs eventually selected, potentially interesting strategies being used to manage divergent demands were evident both in the secondary data and apparent in discussions with those knowledgeable of the sector. One of the CRIs was also identified as dealing with some particularly interesting tensions between stakeholders. There were naturally a greater number of HTSUs to choose from. A list was assembled of start-ups that appeared to be dealing with pluralism, based on the secondary data and prior knowledge of individual cases. Prerequisites were that the HTSUs incorporated private investment, some university involvement (either as spin-outs or on-going collaboration), the involvement of scientist founders and technological intensity of the product offering. Two cases that fitted the pluralism criteria, my prior knowledge of one case, combined with views on their potential openness to being involved determined eventual selection. In sum, the selections were based on confirmation of pluralism (via secondary data); potentially interesting legitimacy dynamics being evident; and pragmatic issues regarding access (ease, openness, actual consent being granted).

From there, this study is typical of much business research in first seeking permission at the organizational level prior to interview-based data collection (Eriksson \& Kovalainen, 2008). I contacted the CEO or equivalent (i.e., CoRE Directors) via email requesting their participation. A formal letter of introduction was also mailed to them. This was followed by a positive response in all six cases. To manage the data collection process the organizations were contacted sequentially, although this did overlap. After gaining organizational access, I then contacted individual interview participants. 


\subsubsection{Interviewing and Interview Participants}

An aspect of my design was its "embedded" (Yin, 2009) nature. It involved multiple levels of analysis that included managers, employees, and external stakeholders (See: Figure 3.2; Table 3.6). This multi-stakeholder approach enabled the inclusion of diverse vantage points and hence a greater capacity to incorporate pluralism. This can be described as 'purposive' (or 'theoretical') sampling, with participants selected based on theoretical goals (O'Leary, 2004; Patton, 2002a). I entered each organization with an idea of who I wanted to interview based on prior understanding of each organization. This was determined by where the divergence and salient legitimacy demands were located. For example, there was no tension reported in the relationship between HTSUs and customers. In some cases, pragmatic restrictions also determined access. For example, in HTSU 1 employees were not interviewed at the request of the CEO. A refined understanding of the organizations through the initial interviews then helped determine who I needed to include. The stakeholders interviewed and degree of diversity in stakeholders accessed was largely similar across cases, with a slight exception with HTSU 1 for reasons regarding access.

Participants were emailed a copy of the information sheet (Appendix 1) prior to the interview. Along with the research agreement, this was the first thing discussed at each interview; with an emphasis on the human ethics procedures (Appendices 2 and 3). The processes through which I accessed participants varied between cases. With HTSU 2 and two CoREs I contacted participants directly and no restrictions were placed on that. With HTSU 1, participants were also contacted directly. However, who I could contact was limited at the CEO's request and excluded access to private investors and employees. Due to their larger internal structure, accessing individuals within the CRIs was more complex. In the case of CRI 1 no limitations were placed on who I could access but internal interviews were set up for me and names provided by an executive assistant. The research agreement and information sheet was passed on for me and participants were informed that their involvement was voluntary. I reiterated this with the individual participants when I then engaged with them directly. With CRI 2 the names and contact details of potential interviewees were provided and I contacted them directly with a participation request. In both CRIs the interview with their external clients was arranged for me by the CRI for practical reasons. 
Table 3.4 Summary of interview and participants ${ }^{16}$

HTSU 1

Access : Jun-Sep 2009

- CEO [1]

- Scientist founders [2-3]

- Board members [commercialization office] [45]

- University manager / shareholder [6]

\section{CRI 1}

Access: Sep 2009-Apr 2010

- CEO [14]

- 4 Managers [15-18]

- Scientist manager [middle management] [19]

- 3 Scientists [20-22]

- Board member [23]

- Client/CRI spin-off [24]
CoRE 1

Access : Sep-Dec 2009

- 3 Directors [35-37]

- Department/school manager [38]

- 3 PIs [39-41]

- $\mathrm{Al}$ [42]

- Board members [43-44]

- Administrative manager [45]

- University manager [46]

- PhD Student [47]

Total CoRE 1 interviews: 12 [one CORE 1 interviewee represented two position]

\section{CORE 2}

Access: Dec 2009 - Aug 2010

- 3 Directors [48-50]

- PIs [51]

- Al [52]

- Board member [53]

- Administrative manager [54]

- University manager [55]

Total CoRE 2 interviews: 8

Total HTSU 2 interviews: 7

Total CRI 2 interviews: 10

\section{External Stakeholders [ES]}

Access: Mar-Apr 2010

- 3 public sector senior managers: MoRST; FRST; TEC $[56,57,58]$

- 2 public sector observers of CRIs $[59,60]$

Total interviews: 58

- 1 public sector observers of CoREs [61]

- President of NZ scientific body [62]

- Venture capitalist [63]

Total external interviews: 8

Towards the end of data collection, interviews were conducted with individuals in the broader NZ science landscape. These are labelled external stakeholders in Table 3.4 above. These participants were contacted directly based on accessing the relevant government

\footnotetext{
${ }^{16}$ The total number of interviews (58) does not equal the number of interview subjects represented (63) as some interviewees held multiple roles and were interviewed in more than one capacity. This was particularly true of the external stakeholders. Three interviewees are represented twice in the above table while one interviewee is represented three times. The numbers are individual codes given to each interviewee and will be used in the presentation of findings.
} 
perspectives (i.e., TEC, FRST, MoRST) and on suggestions regarding relevant individuals made by my participants and others knowledgeable of the sector. These interviews were also used as a way to manage any perceived gaps regarding the stakeholder perspectives already gained. For example, I included the perspective of a venture capitalist who had not invested directly in any of the selected cases but nonetheless offered insight into the investor perspective of HTSUs more broadly.

A total of 58 semi-structured in-depth interviews were conducted. The average time per recorded interview was 61 minutes, equating to nearly 60 hours of interview data. This reflects my commitment to the stipulated hour timeline unless participants explicitly indicated otherwise. Three interviews were conducted via Skype for practical reasons regarding geographical location. The majority of the other interviews were conducted in private offices or meeting rooms, with nine conducted in semi-private spaces such as cafes. There was no obvious difference between these interviews, with two of the most 'frank' discussions occurring either via Skype or in a semi-communal space. I requested and was granted permission to record all interviews. I fully transcribed the interviews as well as writing notes during and after each interview. The exception was one of my final interviews where a technical fault corrupted the data. More comprehensive notes were written within a few hours of that particular interview when it was realized that this fault had occurred. $A$ few small snippets of direct quotation were also gained through close listening to the corrupted recording.

'Semi-structured' means that an interview guide was used to outline key themes and provided guiding questions but still allowed for flexibility and the opportunity to probe and improvise (Noaks \& Wincup, 2004; O'Leary, 2004; Patton, 2002a; Yin, 2009). The interview schedule was focused around three stages based on the conceptual framework (see Appendix 4). They sought insight into stakeholder perceptions concerning legitimacy, pluralisms' dimensions, and organizational-level legitimacy strategies. First, perceptions of legitimacy among stakeholders, using the terms 'desirable' and 'appropriate' (Suchman, 1995), rather than legitimacy directly, was focused on. Second, divergent objectives, and associated salient tensions, the organization encountered were explored. In gaining a sense of power diffusion, these first two steps also incorporated insight into the key stakeholders who were making legitimacy demands and held or prioritized divergent objectives. Finally, 
building on the pictures created in the first two stages, the strategies use to manage stakeholder legitimacy demands in this context were focused on.

\subsubsection{An Additional Note on Human Ethics}

The research was performed under the guidelines of Victoria University of Wellington's Human Ethics Committee (Appendices 2 and 3). Ethical concerns were incorporated throughout the practical decisions I made within this project. The most important decision I encountered regarded whether to intervene during the access process within one CRI. Individual participants were contacted on my behalf by an executive assistant. Given the practical benefits of letting their own internal process take place I instead made numerous stipulations regarding the ethical aspects of my study. The interviews with scientists within this CRI were some of the more relaxed, friendly, and frank that I conducted, which was important for me in personally reconciling this decision.

Regarding confidentiality, an additional layer of caution I felt to be important was keeping the identities of the cases confidential as well as those of my participants. Further, in the reporting of the quotations, a final level of differentiation was not made at the individual participant level. I refer to 'CRI 1, scientist', for example, generally rather than the more specific 'CRI 1, Scientist $A$ '. This means that individual 'voices' become a little more anonymous. The necessity of these steps was important given that the small size of NZ increases the difficulty of maintaining confidentiality (Tolich \& Davidson, 2003).

The above decisions meant that when accessing external stakeholders (such as a public sector manager) I did not make explicit the organizations that had been selected. We discussed specific organization types (i.e., CoREs) rather than explicitly identifying a particular organization (for example, CoRE 1) as the focus of the interview. For example, CoREs generally were discussed with some specific examples rather than referring to 'CoRE $1^{\prime}$ specifically. Maintaining confidentiality also meant that organization-specific secondary data could only be used in a way that did not undermine this confidentiality. This prevented direct quotations from this data source. 


\subsubsection{Secondary Data}

Secondary data were collected prior, during, and after the interviews. These data were used according to the literature which stipulates its strength in building up knowledge of case background and historical contexts. Entering each case site as an informed interviewer was important. It also relates to triangulation; that is, to corroborate and augment the themes emerging from the interview data (Marshall \& Rossman, 2006; Yin, 2009). An example of the spread sheet summary used to organize specific documents is provided below for two data sources related to CRI 1 (Table 3.5). The full summary provided in Table 3.6 is selective, indicating only the data that were most relevant rather than the full range of documentation engaged with (also see Section 3.3).

Table 3.5 Example of use of secondary data: CRI 1

\begin{tabular}{|c|c|c|c|c|}
\hline $\begin{array}{l}\text { Type of } \\
\text { data/code }\end{array}$ & $\begin{array}{l}\text { Informed case } \\
\text { selection? }\end{array}$ & $\begin{array}{l}\text { Existence of } \\
\text { multiple } \\
\text { objectives? }\end{array}$ & $\begin{array}{l}\text { Existence of } \\
\text { diffused power? }\end{array}$ & Notes: response strategy \\
\hline \multicolumn{5}{|l|}{ Example 1} \\
\hline $\begin{array}{l}\text { Type: Annual } \\
\text { report } \\
\text { Code applied } \\
\text { To document: } \\
\text { CRI } 1 \text { SD1 }\end{array}$ & $\begin{array}{l}\text { Yes: } \\
\text { collected prior } \\
\text { to data } \\
\text { collection. } \\
\text { September } \\
2009 \text { (received) }\end{array}$ & $\begin{array}{l}\text { Yes: } \\
\text { Commercial } \\
\text { and science. }\end{array}$ & $\begin{array}{l}\text { Yes: } \\
\text { staff (strong) and } \\
\text { stakeholder (tacit) } \\
\text { highlighted. }\end{array}$ & $\begin{array}{l}\text { 'Expanded objective' shown } \\
\text { to be recent rather than } \\
\text { historical strategy. (e.g., } \\
\text { focus on science and } \\
\text { financials but less obvious } \\
\text { "NZ" / public good focus). }\end{array}$ \\
\hline \multicolumn{5}{|l|}{ Example 2} \\
\hline $\begin{array}{l}\text { Type: Media } \\
\text { article } \\
\text { Code: CRI1 } \\
\text { SD31 }\end{array}$ & $\begin{array}{l}\text { No: } \\
\text { collected post- } \\
\text { case selection. }\end{array}$ & $\begin{array}{l}\text { Yes: } \\
\text { Science, } \\
\text { commercial, } \\
\text { public good. }\end{array}$ & $\begin{array}{l}\text { Yes: } \\
\text { Government/ } \\
\text { stakeholder; } \\
\text { customers and } \\
\text { staff. }\end{array}$ & $\begin{array}{l}\text { Highlights current } \\
\text { 'expanded objective' and } \\
\text { the associated more } \\
\text { "balanced" approach; } \\
\text { especially in comparison to } \\
\text { previous strategy. }\end{array}$ \\
\hline
\end{tabular}


Table 3.6 Summary of Secondary Data (with codes)

\begin{tabular}{|c|c|}
\hline $\begin{array}{l}\text { CoRE } 1 \\
\begin{array}{l}\text { - } 4 \text { reports [CoRE } 1 \text { SD1-4] } \\
\text { - } 14 \text { Newsletters [CoRE } 1 \text { SD5-18] } \\
\text { - } 2 \text { media articles [CoRE } 1 \text { SD 19-20] }\end{array}\end{array}$ & $\begin{array}{l}\text { CORE } 2 \\
\text { - } 8 \text { Annual reports: CoRE } 2 \text { SD 1-8 } \\
\text { - } 10 \text { Newsletters: CoRE } 2 \text { SD 9-19 }\end{array}$ \\
\hline Total documents: 20 Total pages:454 & Total documents: 19 Total pages:489 \\
\hline $\begin{array}{ll}\text { CRI } 1 \\
\text { - } & 17 \text { Annual reports [CRI 1, SD 1-17] } \\
\text { - } & \text { Select CRI } 1 \text { press releases [CRI 1, SD18-22] } \\
\text { - } & \text { Public presentation by CEO [23] } \\
\text { - } & \text { Statement of Corporate Intent [CRI1, SD 24] } \\
\text { - } & 6 \text { newsletters: oldest available [CRI 1, SD25-30]. } \\
\text { - } & 6 \text { newsletters: newest available [CRI 1, 31-36] } \\
\text { - } & 3 \text { relevant media articles [CRI 1, SD 37-39] }\end{array}$ & $\begin{array}{l}\text { CRI } 2 \\
\text { - } \quad \text { Annual reports [CRI 2, SD1-7]. } \\
\text { - } \quad \text { Statement of corporate intent [CRI 2, SD8]. } \\
\text { - } \text { Internal document [strategy] [CRI 2, SD9]. } \\
\text { - } 4 \text { (strategy specific) published articles, media etc } \\
\text { [CRI 2, SD 10-13]. }\end{array}$ \\
\hline Total documents: 39; Approximate pages: 731 & Total documents: 13; Approximate pages: 466 \\
\hline $\begin{array}{l}\text { CoREs generally } \\
\text { - } 6 \text { government press releases (Maharey, 2001, } \\
\text { 2003; New Zealand Government, 2002, 2006a, } \\
\text { 2006b, 2007). } \\
\text { - TEC website and related documents (e.g., re- } \\
\text { funding criteria): (Tertiary Education } \\
\text { Commission, 2006); http://www.tec.govt.nz }\end{array}$ & $\begin{array}{l}\text { CRIs generally } \\
\text { - CRI } 1 \text { Act (Crown Research Institute Act,1992 ). } \\
\text { - } \quad \text { Report: “Crown Research Institutes: Governance } \\
\text { \& Capability” (McKinlay Douglas Limited, 2002) } \\
\text { - } \quad \text { Report: “An appraisal of Crown Research } \\
\text { Institutes 1992-2002” (MoRST \& CCMAU,2003). } \\
\text { - CCMAU website and related documents, e.g., } \\
\text { CCMAU (2007). Information now accessible on: } \\
\text { www.comu.govt.nz); e.g., (CCMAU (Crown } \\
\text { Company Monitoring Advisory Unit) \& The } \\
\text { Treasury, 2007) } \\
\text { CRI Taskforce Report (CRI Taskforce, 2010). }\end{array}$ \\
\hline Total documents: 7; Approximate pages:17 & Total documents: 5; Approximate pages:178 \\
\hline $\begin{array}{l}\text { HTSU } 1 \\
\text { - } \quad 1 \text { Television media interview [HTSU 1, SD 1] } \\
\text { - } \quad 5 \text { media articles [HTSU 1, SD 2-7] } \\
\text { - } \quad 3 \text { Press releases (external) [HTSU 1, SD 8-10]. } \\
\text { - } \quad \text { Website [HTSU 1, SD 11] }\end{array}$ & 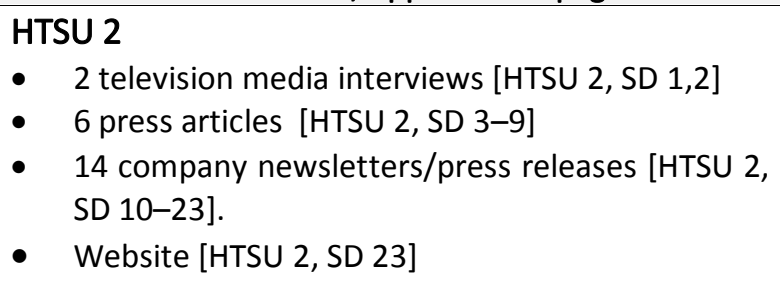 \\
\hline Total documents: 11 Total pages: 33 & Total documents: 23 Approximate pages: 31 \\
\hline
\end{tabular}

Additional secondary data [NZ RS\&T sector more broadly]

- Reviewed literature as laid out per section 3.3 both academic (e.g., Leitch \& Davenport, 2005) and media (e.g., Casinader, 2010; Fox, 2009)

- Additional main government documents utilized (Ministry of Research, Science and Technology, 2006, 2008).

- Surveys of NZ scientists (Sommer, 2010) 


\subsection{Data Analysis}

\subsubsection{Abductive Theoretical Extension}

The following quote is indicative of my analytical process:

We often use empirical evidence to articulate theories, to flesh them out, to ascertain their spatiotemporal limits and establish their scope conditions.... In short, ideas and evidence are mutually dependent; we transform evidence into results with the aid of ideas, and we make sense of theoretical ideas and elaborate them by linking them to empirical evidence. Cases figure prominently in both of these relationships (Ragin, 1992, p. 218).

This approach can be labelled abductive and, as Ragin (1992) suggests, is closely tied to the notion of "case study." Many authors argue that it is indeed a central feature differentiating case study from the tabula rasa of grounded theory or ethnography (e.g., Bergene, 2007; George \& Bennett, 2004; Miles \& Huberman, 1994; Yin, 2009). It is also associated with a post-positivist approach to qualitative analysis (Creswell, 2007; Järvensivu \& Törnroos, 2010), including Miles and Huberman's (1994) thematic analysis which informs my analytical approach here. Within such a process, theoretical frameworks are viewed as central to ordering qualitative data. This is particularly true for multi-case studies where themes are usually partly pre-defined to enable cross-case comparison and avoid data overload (Eriksson \& Kovalainen, 2008).

"Abduction" involves iterative movement between the theory and data (Dubois \& Gadde, 2002; Ketokivi \& Mantere, 2010; Van Maanen, Sorensen, \& Mitchell, 2007). It is said to offer a "middle ground" between induction and deduction, accepting existing theory as improving the theoretical strength of case analysis while simultaneously being less theory driven than deduction, which enables data-driven theory generation and refinement (Järvensivu \& Törnroos, 2010). This was aligned with the envisaged contribution in providing reflection back to Kraatz and Block's (2008) empirically unexplored theoretical framework. An abductive approach is argued to be particularly suited to such a focus on refining and extending existing theories (Dubois \& Gadde, 2002). Aligned with this abductive process, theory development defined this study's aims, rather than strictly inductive theory building sometimes associated with case studies (e.g., Eisenhardt \& Graebner, 2007; Woodside \& Wilson, 2003). 
The abductive process involved starting with a legitimacy strategy framework. For instance, Erkama and Vaara's (2010) example of abduction integrates previous rhetorical legitimacy strategy frameworks to provide theoretical insight. The framework illustrated in the literature review plays a similar role here. From this starting point the aim is to develop, refine, and extend that framework through the empirical data. What this meant for me practically was continuous attention to the balance between the theoretical constructs and the multifaceted voices of my participants. For example, I restarted my NVivo coding after I assessed early coding as being overly constrained by the framework's categories. Consequently, a degree of resolution lay in an effort to refrain from moving too quickly to theoretical categorization (Dubois \& Gadde, 2002). The incorporation of both "emic" overarching categories (e.g., transcension) and "epic" sub-categories based on the empirical data was also important as a way of managing the iterative analytical processes (Miles \& Huberman, 1994).

\subsubsection{Thematic Analysis}

Analysis was thematic and supported by NVivo (Boyatzis, 1998; Miles \& Huberman, 1994; Patton, 2002a). I drew on techniques outlined by Miles and Huberman concerning data reduction and presentation as important parts of the analytical process. As they state, categories are labels assigned to units of meaning made up of chunks of varying sizes, from words to paragraphs. Here, thematic categories were attached to data chunks ranging from sentences to paragraphs depending on the time participants spent conveying a particular topic or issue. NVivo's capacity as a coding tool is aligned with this process and enabled management and delineation of data along case, stakeholder, and thematic lines. Utilizing tabular displays to organize my data as part of that coding process helped refine my thinking and augmented and helped develop the NVivo coding rather than simply mirroring it. In direct response to the practical lessons contained in Miles and Huberman's (1994) approach I progressed from tables depicting lists to more effective two-by-two matrices and network diagrams (Crabtree \& Miller, 1999). Regarding the depiction of the strategies involved, I developed the analysis from intra-case conceptually oriented matrices and networks to similarly conceptually oriented inter-case displays. 
An understanding of the 'regularities' or core consistencies (Patton, 2002a) was important in arriving at themes (Boyatzis, 1998; Miles \& Huberman, 1994; Silverman, 2005). As Silverman states "counting techniques...can offer a means to survey the whole corpus of data ordinarily lost in intensive, qualitative research...the reader has a chance to gain a sense of the flavour of the data as a whole" (2006, p. 52). This was achieved in two ways: 1) the number of interviewees from which a particular theme was drawn and 2) the density with which these interviews discussed a theme (i.e., mentioned at one point in the interview versus six times) (Berg, 2004). This is aligned with a post-positive approach where regularities are not assumed to signify the existence of a particular phenomenon but do provide a reasonable indication (Yeung, 1997). Alongside this, a stakeholder-centric approach was maintained in line with a commitment to 'pluralism' and surfacing multiple stakeholder voices in relation to those 'frequencies' (Burgoyne, 1994).

The concept of pattern matching was also important. This is the juxtaposition of patterns surfaced from the empirical data with propositions contained within the theoretical framework (Miles \& Huberman, 1994; Trochim, 1989; Yin, 2009). My analysis was connected to a theoretical framework which contained implicit propositions regarding how organizations strategize in pluralistic settings (for example, differently to how they respond in non-pluralistic settings). The data were then "matched" to this framework. Here the original patterns contained in the framework were implicit rather than being explicitly predetermined as propositions in the way Yin (2009) appears to advocate. The eventual propositions, therefore, resulted out of the iteration between the framework and empirical data, as per abduction, rather than being predefined. Further, while pattern matching is frequently associated with surfacing causal explanations from qualitative data (Miles \& Huberman, 1994, Trochim, 1989; Yin, 2009), authors do recognize that the technique can be used within a more descriptive approach. The post-positivist approach adopted was that understanding causal relationships between variables was deemed to lie beyond the epistemological scope of this study.

Pattern matching is closely aligned with an approach to analysis centred on rival explanations (Miles \& Huberman, 1994; Trochim, 1989; Yin, 2009). For example, do some general traditional legitimacy frameworks (e.g., DiMaggio \& Powell, 1983) better explain legitimation in pluralistic contexts than the strategy framework developed here? Such rival 
explanations were implicitly investigated through these strategic categories being mutually exclusive; that is, if one explanation (e.g., more agency intensive responses) is valid then others cannot be (e.g., isomorphic acquiescence) (Yin, 2009). Prior to entering the field I was aware that surfacing any of these rival explanations that refuted the proposed theoretical framework would be as theoretically compelling a finding as any confirmation. In the end, however, my findings extend and refine the original framework rather than explicitly contradict it. However, post-positivism suggests that the researcher makes their biases explicit and this is done here with regards to the framework. It is only one possible interpretation of the data based on my theoretical positioning. The analysis nonetheless suggests that it is a 'warranted' one that led to increased insight of the dataset. Finally, rival explanations at the level of the sub-themes (within the framework itself) were investigated through exploring and presenting the less supported aspects of the framework within each case (see Chapter 5).

\subsubsection{Thematic Codes}

An analytical framework was developed out of the literature review: legitimacy strategies are embedded within contextual analysis of stakeholder legitimacy demands and pluralism.

I used a two-level scheme for thematic coding of the strategies. An "etic" level derived from a theoretical framework and a more specific "emic" level, which was "close to participants categories but nested in the etic codes" (Miles \& Huberman, 1994, p. 61; Patton, 2002a). This was guided by Constas' (1992) framework of category development. Additional texts regarding the development of categories and codes also informed this process and meant that I utilized definitions, surfaced in the literature review, as well as "templates" with respect to each emerging theme (Boyatzis, 1998; Miles \& Huberman, 1994). In dealing with these themes the issue of internal homogeneity (the extent to which the data in the theme "dovetail" or hold together in a meaningful way) and external heterogeneity (the extent to which differences between themes are bold and clear) were sought (Guba, 1978; Miles \& Huberman, 1994). For example, in differentiating 'negotiation' and 'transcension,' the degree to which the strategy was reported as entailing self-determination or transformation rather than adapting to legitimacy demands, differentiated the two categories. This differentiation was also supported through locating key words such as 'balance' and 
'compromise' (negotiation) found in the literature review. Table 3.7 introduces these central thematic categories.

Constas' (1992) framework enables representation of the 'time' particular categories were identified as well as where they came from (origin); how their inclusion was justified (verification); and the naming of the category (nominal). For example, the category "transcension" originated out of legitimacy literature (Kraatz \& Block, 2008); while the choice of name was chosen by the researcher rather than explicitly being labelled within the literature (investigator). I entered the field with the category 'transcension' already established in my theoretical framework. Table 3.8 shows the degree to which the broad categories were developed 'a priori' (e.g., 'negotiation') versus the sub-categories being developed 'a posteriori' (e.g., 'partial adaptation'). This is reflective of the abductive analytical process already discussed.

Table 3.7 Central thematic categories

\begin{tabular}{|c|c|c|c|}
\hline $\begin{array}{l}\text { Stakeholder } \\
\text { legitimacy }\end{array}$ & Pluralism & $\begin{array}{l}\text { Legitimacy } \\
\text { strategies }\end{array}$ & Sub-categories [strategies] ${ }^{17}$ \\
\hline $\begin{array}{l}\text { 1.Commerical } \\
\text { demands }\end{array}$ & $\begin{array}{l}\text { 4.Diffused power } \\
\text { Sub-category: } \\
4 a+/++ \text { perceived power } \\
\text { diffusion }\end{array}$ & 6. Transcension & $\begin{array}{l}\text { 6a Transformation } \\
\text { 6b Infusing organization with value } \\
\text { 6c Overarching objectives / } \\
\text { expanded vision }\end{array}$ \\
\hline $\begin{array}{l}\text { 2. Public good } \\
\text { demands }\end{array}$ & $\begin{array}{l}\text { 5.Divergent objectives } \\
\text { Sub-categories } \\
5 a+/++ \text { perceived } \\
\text { divergence } \\
5 b \text { Specific tension points }\end{array}$ & 7. Negotiation & $\begin{array}{l}\text { 7a Partial adaptation } \\
\text { 7b Active bargaining } \\
\text { 7c Inter-stakeholder understanding } \\
\text { /collaboration } \\
\text { 7d Democratic partnership }\end{array}$ \\
\hline \multirow[t]{2}{*}{$\begin{array}{l}\text { 3.Science } \\
\text { demands }\end{array}$} & & $\begin{array}{l}\text { 8.Compart- } \\
\text { mentalization }\end{array}$ & $\begin{array}{l}\text { 8a Bounded separation } \\
\text { 8b Separation }\end{array}$ \\
\hline & & 9. Contraction & $\begin{array}{l}\text { 9a Restructuring } \\
\text { 9b Pre-emptive contraction } \\
\text { 9c Singular focus / ignoring }\end{array}$ \\
\hline
\end{tabular}

\footnotetext{
${ }^{17}$ These categories reflect those outlined in Chapter 6; the case-specific descriptions of strategies (Chapter 5) are more various and are not included in this table.
} 
Table 3.8 Constas' (1992) categorization framework ${ }^{18}$

\begin{tabular}{|c|c|c|c|}
\hline \multirow{2}{*}{$\begin{array}{c}\text { Component of categorization } \\
\text { Origination } \\
\text { Where does the authority for } \\
\text { creating the categories reside? }\end{array}$} & \multicolumn{3}{|c|}{$\begin{array}{c}\text { Temporal Designation } \\
\text { At what point were categories specified? }\end{array}$} \\
\hline & $\begin{array}{l}\text { A priori } \\
\text { (before) }\end{array}$ & $\begin{array}{c}\text { A posterior } \\
\text { (after) }\end{array}$ & $\begin{array}{c}\text { Iterative } \\
\text { (continual) }\end{array}$ \\
\hline Participants & & $\begin{array}{l}4 a, 5 a, 5 b, 6 a, 6 b \\
6 c, 7 a, 7 b, 7 c, 7 d \\
8 a, 8 b, 9 a, 9 b, 9 c\end{array}$ & $1,2,3$ \\
\hline Literature & $4,5,6,7,8,9$ & & $\begin{array}{l}1,2,3,6 a, 6 b, 6 c, 7 a, 7 b, \\
7 c, 8 b, 9 a, 9 b, 9 c\end{array}$ \\
\hline \multicolumn{4}{|l|}{$\begin{array}{c}\text { Verification } \\
\text { On what grounds can one justify } \\
\text { a given category }\end{array}$} \\
\hline External - panel of experts. & $\begin{array}{l}\text { General framework } \\
\text { [legitimacy; pluralism; } \\
\text { strategies]. } \\
\text { [conferences] } \\
\text { 1-3 [discussions with } \\
\text { industry experts] }\end{array}$ & $\begin{array}{l}\text { 1, 2, 3, 4, 5, } 6 \text { (a- } \\
\text { c), } 7 \text { (a-d), 8, } 9 \text { (a- } \\
\text { c) [conferences] }\end{array}$ & $\begin{array}{l}\text { Entire framework and } \\
\text { categories [supervisors]. }\end{array}$ \\
\hline Rational - logic and reasoning. & $6,7,8,9$ & & \\
\hline $\begin{array}{l}\text { Referential (Literature) - existing } \\
\text { research. }\end{array}$ & $1,2,3,4,5,6,7,8,9$ & & $\begin{array}{l}6,6 b, 6 c, 7 a, 7 b, 7 c, 8 b \\
9 a, 9 b, 9 c\end{array}$ \\
\hline \multicolumn{4}{|l|}{$\begin{array}{c}\text { Nomination } \\
\text { What is the source of the name } \\
\text { used to describe a category }\end{array}$} \\
\hline Literature & $\begin{array}{l}1,2,3,4,5,6,7,8 \\
9\end{array}$ & & $6 b, 7 b, 7 c, 8 b, 9 a, 9 c$ \\
\hline Investigative (researcher) & $\begin{array}{l}6,7,9 \\
\text { [choice of exact } \\
\text { label] }\end{array}$ & $7 d, 8 a, 9 b$ & $6 a, 6 c, 7 a, 7 d$ \\
\hline
\end{tabular}

With regards to verification, three processes highlighted by Constas (1992) formed part of the analysis. First, the framework was based on rational grounds, one that relies on 'logic and reasoning' through the establishment of the appearance of logical connectedness. This was established in the literature review through explanation of the theoretical framework. Second, 'referential' verification is evident here: reference to the literature to justify the use of particular categories was central. Third, the external source of verification represents the use of "experts outside of the study" to verify the categories. Most directly, two interviews from different cases were independently analysed by my supervisor. Their interpretation of the text reflected the analysis I had similarly reached regarding those transcripts. Further,

\footnotetext{
${ }^{18}$ Constas' (1992) represents a number of different categorization options. Only those relevant to this project are included. The categories outlined above are those that were surfaced after the case-specific themes where reduced/incorporated within cross-case comparison (see Chapter 6).
} 
'peer debriefing' is said to assist in the validity of the findings (Creswell, 2009) and can be connected to this verification category. Several parts of the work here were presented at academic conferences and, thus, the analytical framing benefited from several rounds of peer review. A version of the developed theoretical framework as a way of investigating legitimation strategies amidst pluralism was presented at the 2009 Academy of Management Meeting (Chicago). A version of the same framework substantiated with case data from a study of a Steiner School was also presented at the EGOS (European Group for Organization Studies) Colloquium in Barcelona in 2009. Early analysis, using the analytical model based primarily on the first three cases, was presented at the EGOS in the paradox stream in Lisbon, 2010. Finally, a more developed analysis was peer-reviewed and accepted for the upcoming Academy of Management Meeting in San Antonio (2011).

\subsubsection{Phases in Analysis}

To provide further description I will briefly explain my analysis as consisting of five phases. These built on each other, although also overlapped in an iterative fashion. The first defining process within these phases is the movement from intra-case to inter-case analysis, a key element of multiple case study analysis (Eisenhardt \& Graebner, 2007; Miles \& Huberman, 1994; Stake, 2005; Yin, 2009). As Patton (2002a, p. 449) states, my first 'responsibility' as an analyser of qualitative text is to do 'justice' to each individual case. The second aspect contained within the phases of analysis was determined by my research questions. Developing understanding of a particular context (and the divergent legitimacy demands within it) before analyzing the organizational responses to this is one observable trend in many previous studies within the institutional and legitimacy literature ( Erkama \& Vaara, 2010; Jarzabkowski et al., 2009a; Reay \& Hinings, 2009; Suddaby \& Greenwood, 2005). Such an approach is mirrored here. The explication of stakeholder legitimacies and the associated pluralism forms phase two (Chapter 4), and the legitimacy strategies participants outline relates to phases 3 and 4 (Chapter 5).

The first phase was the least structured and had the goal of immersion in the interviews and interview data. I transcribed then read and reread each transcript to gain an understanding of each interview and reach a picture of the data as a whole (Marshall \& Rossman, 2006). During this phase I was not coding as such but rather identifying key ideas 
of interest. This is most aptly described as a process of "indexing." Seale (1999, p. 154) describes: "The early stages of coding are therefore more appropriately called 'indexing', acting as signposts to interesting bits of data, rather than representing some final argument about meaning."

Familiarity with my data increased throughout the analysis. I was increasingly able (at least to a degree) to hold a picture of my dataset as whole, despite the multi-case structure and number of interviews. As analysis progressed I could place a particular "data chunk" within its context of a whole interview, an organizational case, and my broad cross-case data-set. For example, the realization, towards the end of the analysis, of the distinction between perceptions of power diffusion between similar cases (e.g., CoRE 1 and CoRE 2) arose from understanding of the entire data set, not out of the activity of coding individual interviews or particular data segments. This phase also corresponds to widespread advice regarding qualitative analysis to not move too quickly to categorization (Miles \& Huberman, 1994; Patton, 2002a; Yin, 2009).

The second phase involved developing case reports for each organization's context (Eisenhardt, 1989; Stake, 1995, 2005; Yin, 2009). This contextual understanding focused on the basis of stakeholder assessments and associated demands regarding organizational desirability and appropriateness (Hybels, 1995; Suchman, 1995). This step highlights that an understanding of the central legitimacy themes (Erkama \& Vaara, 2010) was developed before exploring the strategies in relation to those. Suddaby and Greenwood's (2005) example of developing understanding of the 'institutional vocabularies' associated with stakeholders' different legitimacy criteria was also helpful. For example, the term "freedom" was usefully indicative of legitimacy assessments based on science-excellence; while "efficiency" tended to be indicative of commercially-based demands. Understanding of the perceptions of desirability and appropriateness built on the commercial, public good, and science excellence understanding explained in this chapter's discussion of the science sector as its starting point. 
This understanding was supplemented by stakeholder analysis (Burgoyne, 1994). This focused the analysis on who was making a particular legitimacy demand and who, conversely, was de-prioritizing it. ${ }^{19}$ This treatment of legitimacy is aligned with the stakeholder-centric definition (a focus on legitimacy sources rather than dimensions (Deephouse \& Suchman, 2008)) developed in this study. It resulted in "stakeholder legitimacy maps" which I developed through both network and matrix displays. The resulting display in Chapter 4 utilized examples already provided in institutional theory (Jarzabkowski et al., 2009a; Reay \& Hinings, 2005) regarding presenting the "belief systems" (both goals and values) within a given context, but supplemented it with an explicit stakeholder focus.

The dimensions of power and divergent objectives were explored directly to provide indepth understanding of the pluralism each organization was dealing with and confirm its existence. Diffused power was based primarily on a stakeholder analysis (Burgoyne, 1994): who were discussed as the salient stakeholders? Second, a diverse range of tension points were raised and described in different ways by interviewees. To help make sense of these, the analysis of objective divergence built on the analysis of stakeholder legitimacy demands to organize this multi-faceted discussion. I moved from within-case pictures of legitimacies and pluralism to writing these up as three descriptions based on HTSUs, CRIs, and CoREs (Chapter 4). This was enabled by the similarities between these cases and the tensions/legitimacies they faced. Bringing the cases together in three 'sets' yielded additional insights: there was a slight difference in how pluralism was perceived between organizations of a similar type. This phase provided a contextualization for the strategic themes, that is, linking situational conditions to the phenomenon of interest (i.e., legitimacy strategies) (Bamberger, 2008; Ketokivi \& Mantere, 2010).

The third phase involved developing an understanding of the legitimacy strategies implemented by each organization. This remains the central focus of the thesis. In the interviews and in the analysis the understanding of divergence legitimacy demands and pluralism laid the foundation for investigating the strategies that were implemented in

\footnotetext{
${ }^{19}$ Stakeholder analysis can be described as a focus on some of the stakeholders involved in a case and analysing data based on their perceptions or experiences in relation to the phenomena (Burgoyne, 1994).
} 
relation to that context. During the early stages of analysis the strategies within each specific case were analyzed without reference to the framework's broad categories or the other cases. Building the strategic sub-themes (e.g., surfacing perceptions of "expanded vision" as a strategy) was initially based on the case data rather than immediately focusing on the emic-level categories (i.e., transcension).

Attention to the internal homogeneity and external heterogeneity (Miles \& Huberman, 1994) of the strategic themes being revealed was maintained. These criteria helped reduce an initial long list of categories. Reduction in the number of themes was also assisted through attention to frequencies and sensitivity to the importance placed by participants on particular strategies. Finally, the connections between the strategies discussed was important (Boyatzis, 1998; O'Leary, 2004), with some being shown to be particularly interconnected. I followed the advice that it is permissible for the same data-rich chunks of my interviews to be assigned to more than one node (Miles \& Huberman, 1994; King, 2004b; Maykut \& Morehouse, 1994). A high degree of overlapping coding (whilst also ensuring there was enough difference identified to maintain their external heterogeneity) was one way these inter-connecting patterns were highlighted.

The fourth phase involved both cross-case comparison of the strategies and referring back to theory (Miles \& Huberman, 1994). First, the theoretical framework (Kraatz \& Block, 2008; Oliver, 1991; Pratt \& Foreman, 2000) was referred to as an explanatory and organizing device to make sense of the empirical data. This provided a framework for organizing and reporting the findings (Chapter 5 ) as well as enabling the similarities and differences between cases to be highlighted and communicated more effectively as I moved to intercase analysis (Chapter 6). Such an approach within thematic analysis has been described as "clustering" (Boyatzis, 1998; Coffey \& Atkinson, 1996; Miles \& Huberman, 1994), the organization of multiple themes into groups utilizing a higher-order or meta-theme. It was in this phase the pattern matching or "noting patterns" was most directly incorporated in my analysis (Miles \& Huberman, 1994; Yin, 2009). This was evident in the matching of the themes to the proposed strategic framework developed from the literature. This pattern matching confirmed aspects of but also added insight into and refined the original framework (Dubois \& Gadde, 2002). 
Next, cross-case comparison was engaged in and forms the basis of the 'Discussion' in Chapter 6. While engaging in this cross-case comparison a potentially important distinction contained in the data was developed and is reported in Chapter 5 in relation to each case. This related to differences between organizations in terms of the perceived success of the response strategies used. This assessment arose out of the stakeholders' own perceptions rather than any singular or externally imposed definition of success (which would contradict the pluralistic focus of this study). It was not something explicitly looked for but arose as I became aware of inter-case distinctions. The comparison was made between organizations of a similar type (e.g., HTSU 1 and 2) due to the variance between the organizational forms making broader comparisons of relative success more problematic. It relates to the point in time the interview was conducted rather than being a historical or future orientated assessment. A pictorial example of the above process and its relation to the NVivo coding is provided in Appendix 5.

The final phase was a more directly interpretive phase. I follow Wolcott's advice to differentiate this aspect of the analytical process as a separate chapter (Chapter 6) (Marshall \& Rossman, 2006; Wolcott, 1994). As Patton (2002a, p. 480) notes: "interpretation means attaching significance to what was found, making sense of the findings, offering explanations, drawing conclusions, extrapolating lessons, making inferences." This final step draws from but goes beyond the findings. It involved bringing together the different elements of the project (the literature, the context, and the strategies) and making inferences and seeking explanations within that (Miles \& Huberman, 1994). Particular patterns could be observed and reflected on to form propositions. This denotes a more abductive approach to pattern matching whereby a particular pattern originated out of the data and was then matched across cases rather than being predefined prior to entering the field.

\subsection{Summary: Chapter Three}

This chapter has outlined the philosophical (post-positivism) and contextual (NZ's pluralistic science sector) foundation for the empirical study. The practical steps engaged in, both in terms of data collection and analyses have been detailed. The different phases, and associated findings, in analysis and interpretation will now be outlined in the following three 
chapters. As the analytical framework suggests, a contextual understanding based on pluralism is developed before uncovering the legitimacy strategies. It also moves from analysis (Chapters 4 and 5) to the interpretation of those findings (Chapter 6). 


\section{Chapter Four}

\section{Findings: Contextual Descriptions}

To understand the behaviour of an organization, you must understand the context of that behaviour. (Pfeffer \& Salancik, 1978, p. 1)

This chapter contextualizes the six organizations in relation to the multiple legitimacy demands and pluralism within their contexts. It is divided into four sections. First, the stakeholder legitimacy demands encountered by the science organizations are outlined. Legitimacy demands were found to be related to commercial, science and public good based perceptions of desirability and appropriateness (section 4.1). Second, the pluralism (i.e., diffused power and divergence objectives) the organizations are faced with is discussed moving from CoREs (4.2) to CRIs (4.3) to HTSUs (4.4). The sequence adopted reflects the progression within these organizations from basic research (CoREs) to applied research focused on an industry sector (CRIs) to commercialized research (HTSUs). Multiple points of divergence were surfaced within each case and these were shown to exist both within the broad legitimacy demands (e.g., between long-term growth and short-term ROI) as well as between them (e.g., between legitimacy demands based on 'commercial' and 'public good' criteria).

High degrees of power diffusion and divergence were evident in all six cases. However, unexpected subtle differences were also found between similar organizational cases (for example CRI 1 and CRI 2). Perceptions of the degree of power diffusion and objective divergence are shown to differ slightly between organizations. This is summarized in the concluding section of this chapter.

\subsection{Stakeholder Legitimacy Demands}

From a pure commercial investor point of view...the first hurdle is 'this company has to be able to return thirty times our investment inside five to seven years'...it's pure financial (Investor, HTSU 2; commercial based legitimacy).

I just want to play in my sandpit with my toys (First Scientist Founder, HTSU 1; science based legitimacy).

I can say things like 'my research over the last [decades] has cost 600 hip replacements...or 120 herceptin breast cancer treatments, that's what it's cost - a lot of money. But, in two 
years (at the present rate) that will all be paid off in terms of [HTSU 1's] export sales. (Second Scientist Founder, HTSU 1; public-good based legitimacy).

The above quotations illustrate commercial, science and public good based perceptions of desirability and appropriateness respectively, using the HTSUs as an example. The primary focus was on the stakeholders and the basis of their assessments of CoRE, CRI, or HTSU desirability and appropriateness. This relates to the stakeholder-centric definition of legitimacy guiding this study. These stakeholder legitimacy demands varied slightly both in degree and form between the different types of organizations. However, they can all be framed as reflective of the "relevance debate" discussed in Chapter 3 (Figure 3.4).

Interviewees highlighted that CoREs faced demands based on relevance in a public good sense (i.e., contributing to national development both socially and economically) and science excellence (i.e., traditional academic indicators of legitimacy). As well as being reported within the interviews, these demands were regulated in the funding and reporting policy associated with the CoRE Fund. CRIs, meanwhile, were shown to face legitimacy demands based on contributing to NZ (public good), being at the forefront of science in order to provide that benefit, maintaining financial viability, and a mandated level of return on equity. These demands were communicated through the reported perceptions of desirability and appropriateness from various stakeholders and were reflected in legislation and policy. Finally, the two HTSUs were not driven solely by commercial demands (although this was central in both cases) but also around demands based on science (for example, technological excellence and ongoing R\&D) and public good (e.g., staying NZ based and contributing to its future prosperity). A summary is provided in Table 4.1. 
Table 4.1 Stakeholder legitimacy demands: Summary

\begin{tabular}{|c|c|c|c|}
\hline \multicolumn{2}{|c|}{$\begin{array}{c}\text { Stakeholder legitimacy demands } \\
\text { (assessments of desirability and appropriateness) }\end{array}$} & $\begin{array}{l}\text { Examples of associated practices } \\
\text { (means for pursuing legitimacy demands) }\end{array}$ & $\begin{array}{c}\text { Stakeholders making/prioritizing legitimacy } \\
\text { demands }\end{array}$ \\
\hline $\begin{array}{l}\text { Sub-categories \& key } \\
\text { words: } \\
\text { efficiency; value; } \\
\text { financial viability; } \\
\text { bottom-line; growth; } \\
\text { profit; ROI; costs; } \\
\text { budget; customers; } \\
\text { market. }\end{array}$ & $\begin{array}{l}\text { Representative data : } \\
\text { "We are trying to make a profit - } \\
\text { profit's not a dirty word. We have to } \\
\text { make the } 8 \text { or } 9 \text { percent." (CRI 1, } \\
\text { Manager). } \\
\text { "Dollars. First and foremost, and I've } \\
\text { talked about all those values and } \\
\text { excitement about the technology, but } \\
\text { it's got to be sales." (Scientist Founder, } \\
\text { HTSU 1). } \\
\text { "I'm here just to make a dollar for us." } \\
\text { (University Shareholder, HTSU 1). }\end{array}$ & $\begin{array}{l}\text { CRI examples: } \\
\text { - Spin-out companies to create revenue for } \\
\text { CRI. } \\
\text { - } \quad \text { Cut capabilities to meet prescribed level of } \\
\text { ROI. } \\
\text { - } \quad \text { Focus on monthly budgets and targets. } \\
\text { - } \quad \text { Search for alternative revenue streams. } \\
\text { - Charge clients market, or close to market, } \\
\text { rates. } \\
\text { HTSU examples: } \\
\text { - Everything secondary to growth/sales. } \\
\text { - Shareholder future return determines } \\
\text { current decision-making. } \\
\text { - Focused product offering targeting a } \\
\text { particular defined market segment. }\end{array}$ & 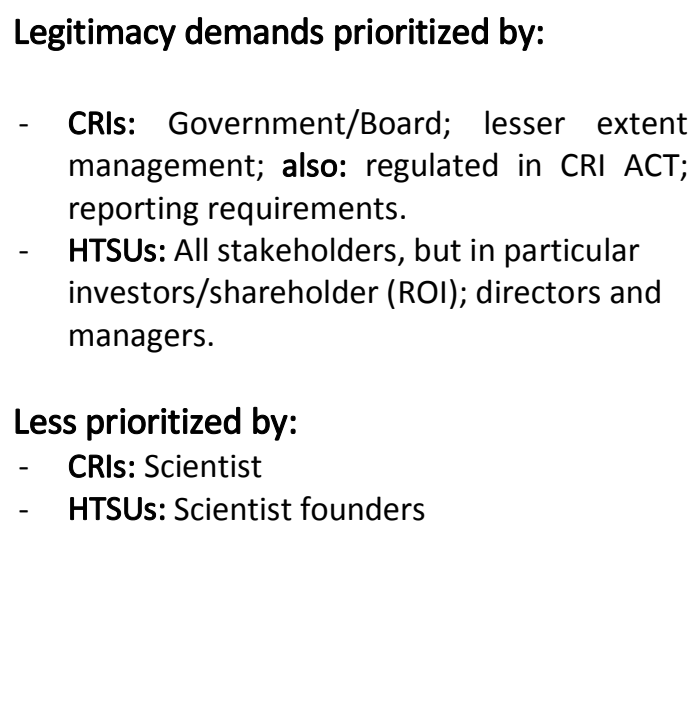 \\
\hline $\begin{array}{l}\text { Science Excellence } \\
\text { Sub-categories \& Key } \\
\text { words: } \\
\text { academia; new } \\
\text { knowledge; } \\
\text { publishing; freedom; } \\
\text { exploration; } \\
\text { technological / } \\
\text { scientific excellence; } \\
\text { PBRF (CoREs \& HTSU } \\
\text { 1); education (CoREs); }\end{array}$ & $\begin{array}{l}\text { Representative data : } \\
\text { "As a scientist you do want to be doing } \\
\text { research....that's really what makes } \\
\text { you tick...your self-esteem is very much } \\
\text { the last paper you wrote and your last } \\
\text { good idea. And if those start drying up } \\
\text { then you start losing your own sense of } \\
\text { self-worth." Director, CoRE } 1 . \\
\text { "That's what keeps you going as a } \\
\text { scientist. Coming up with new ideas }\end{array}$ & $\begin{array}{l}\text { CoRE examples: } \\
\text { - Provide freedom to follow ideas. } \\
\text { - } \text { Focus on publication, citations, PBRF } \\
\text { rankings as measures of success. } \\
\text { - } \text { No expectation of short-term outputs. } \\
\text { - Providing students with interesting } \\
\text { projects. } \\
\text { CRI examples: } \\
\text { - Build up and invest in research capability. } \\
\text { - Measure academic indicators such as } \\
\text { publications and conference presentations. }\end{array}$ & $\begin{array}{l}\text { Legitimacy demands prioritized by: } \\
\text { - All six organizations: Scientists; also: } \\
\text { regulated in CRI ACT \& CoRE legislation. } \\
\text { - CoREs: widely held by stakeholders (e.g., } \\
\text { partner organizations; government; TEC). } \\
\text { Less prioritized by: } \\
\text { - CoREs: Government (TEC; as well as more } \\
\text { broadly) and some CoRE leaders described } \\
\text { as increasingly focused on other indicators of } \\
\text { legitimacy. } \\
\text { - CRIs: Government and boards outlined as }\end{array}$ \\
\hline
\end{tabular}




collaboration (CoREs).


Public Good
Sub-categories \& Key
words:
prosperity; economy;
relevance; NZ/NZ Inc.;
environment/climate
change.
CoRE examples:
industry; outreach;
culture change;
education; end-users
CRI examples: industry
engagement; service;
clients; essential
infrastructure
HTSU examples:
employment; 'giving
back'; socially
significant; education
(HTSU 1); leading the
way.

and being able to follow interesting leads" (Scientist, CRI 2).

"I don't actually really like business...I am most comfortable when I am dabbling in the lab or designing something. I actually don't like the business world at all." (Scientist Founder, HTSU 2).

\section{Representative data}

"The message we're been getting [from government] in the last couple of years or so is community engagement...The outreach work we do is top of the pops for us at the moment. (Board Member, CoRE 2)

"Are they a research organization? They do research but their main purpose is about enhancing the socia wellbeing of the country by assisting [us]." (Client, CRI 2)

"[the CEO] has stated that we want to be a billion dollar company...we want to do something socially compelling ... and we want to stay ultimately with our roots in NZ." (Manager, HTSU 2)

"I want to be involved with bold initiatives that do great things for NZ and our ecosystem" (Investor, HTSU 2)
- Freedom to pursue scientifically interesting avenues not directly related to client needs.

\section{HTSU examples:}

- Focus on technological excellence and perfection.

- Focus on new ideas/products within broad product platforms.

- Build collaborative research partnerships.

- Maintain freedom to 'potter' / play in the 'sand pit.'

\section{CoRE examples}

- Perusing practices that contribute to NZ's economy (spin-outs; assisting industry).

- Increasing profile of science and creating 'culture change' through outreach activities; science communication.

- Contribute to NZ's social indictors (outreach with Maori and schools etc).

\section{CRI examples:}

- Delivering benefits to clients that contributes to NZ's economy or essential infrastructure.

- Activities that contribute to NZ's balance sheet not the CRI's balance sheet.

- Providing "free" /subsidised services.

\section{HTSU examples:}

- Growth contributing to NZ economy.

- Providing employment opportunities for young scientists.

- Showing other NZers it can be done.

- Giving back to NZ taxpayer. more directly interested in public good outcomes and financials; managers' conception of research linked to public good; clients interested in immediate output of science.

- HTSUs: Many stakeholders (e.g., Directors; investors; CEO (HTSU 1); two scientist employees (HTSU 2)) de-prioritized research based demands either explicitly or implicitly in relation to the commercial.

\section{Legitimacy demands prioritized by:}

CoREs: Government; some directors, PIs and boards; also: regulated in funding and reporting criteria; reporting.

- CRIs: All stakeholders define public good as central indicator of legitimacy, especially managers and scientists; also: regulated in CRI ACT.

- HTSUs: Varied between cases. Scientist founders (in particular HTSU 1); government and HTSU 2 CEO.

\section{Less prioritized by:}

- CoREs: PIs and some Directors.

- CRIs: Government and boards reported as prioritizing financial demands instead. Previous management regime in CRI 1 also outlined as prioritizing the financial.

HTSUs: CEO [HTSU 1]; investors/ shareholders; directors [HTSU 1]. Investors prioritized the commercial but also appreciated public good objectives. 


\subsection{CoREs: Pluralism}

\subsubsection{Diffused Power}

It comes back to this ironical thinking. Centres of Research Excellence. Think about what that means. Centre means in one place. We are not a centre, we are an anti-centre. (Director, CoRE 1)

The term 'anti-centre' is a reference to how power in the CoREs was not located centrally but rather diffused amongst multiple partner organizations and PIs (Principal Investigators). The stakeholders highlighted as defining the diffused power context are summarised in Table 4.2. While participants in both CoREs described organizational contexts defined by diffused power, the following overview also suggests that CoRE 2 participants perceived a slightly higher degree of power diffusion (++) than those in CoRE $1(+)$. 
Table 4.2 Summary of diffused power: CoREs

\section{Partner Organizations/ Universities}

Reported by: CoRE 1: 35-47; CoRE 2: 4955; ES (External Stakeholders): 58, 61.

- "The notion that [CORE 1] is independent when it is so deeply entangled with the institution can be hard to get your head around. Practically speaking there are substantial limits to their ability to exercise any real independence." (University Manager, CoRE 1)

- "The host institution wants to kill [CoRE 2's engagement with end-users] and won't let us sign agreements with [end-user], because we don't exist, we're not a legal entity." (Director, CoRE 2)

CoRE 1 - perceived slightly lower (+) level of power diffusion:

"[CoRE 1] is the CoRE that is most independent of its host." (University Manager, CoRE 1)

\section{Scientists}

Reported by: CoRE 1: 35-39; 43; 45; 47; CoRE 2: 48-51; 53-55; ES: 61.

- "The scientists are the important thing. They've got to be, they're the foundation." (CoRE 1, Administrative Manager)

- $\quad$ "It's never a directed thing...I would have been wasting my time [saying] to people: "I want you to do this"... Because that's [not] the way science works. You don't work in a directed way easily - not in a university environment anyway." (CORE 1, Director)

- $\quad$ "For a group of senior researchers .... controlled collaboration was not going to work. So we had to endeavour to get consensus among the whole set of investigators." (CoRE 2, Director)

\section{Government}

Reported by: CoRE 1: 35-43; 45; CoRE 2: 48-55; ES: 56; 58; 61.

- "I wouldn't say it's entirely political game but it [direction of CoRE 1] is driven very much around a sense of we've got a very limited amount of time to prove impact [to government...] And let's be blunt about why we are doing this. It is partly about the good of the country...but there is also an institutional aim there and that is that we want to see [CORE 1] go on." (Director, CORE 1)

- $\quad$ "You can start with TEC. They expect certain things out of all the CoREs. So you are dealing with the life of [CORE 2] at that level. And I do mean the word 'life' literally because at the end of the day if TEC isn't happy there isn't any money for [CoRE 2]." (Board member, CoRE 2)

CoRE 1 perceived slightly lower (+) level of power diffusion (especially: $35-37)$ :

"[TEC] are happy for us to provide the aspirations that we see best for ourselves and for us to report on those." (Director, CoRE 1) 
Partner organizations. The CoREs were both spread over multiple collaborating institutions (rather than being located within a single organization). They were also virtual entities nested within the infrastructure of, and dependent on, their partner organizations. This "host parasitic relationship" as an interviewee described it, was evident in all interviews with CoRE stakeholders:

For each CoRE to have its own independence and sense of governance and yet be hosted by a university is fraught with tensions...you've got this relationship which is difficult to define but both sides know they need it (Industry Observer)

A distinction between the organizations was that participants in CORE 2 appeared to perceive the power of the partner organizations, and in particular its host, to dictate CoRE decision making and practices to be particularly high. In CoRE 2, the host was perceived to be able to enforce ways of operating that CoRE 2 members were not comfortable with (e.g., especially interviews 49-50; 53; 54):

Our University does not trust us to be involved with it. So we've been completely removed from our involvement [...they] wanted to highjack that success for their own purposes (Director, CORE 2).

This was not the case in CORE 1 where stakeholders largely characterized the CoRE's relationship with its partner organizations as being mutually supportive. This was partly related to CoRE 1's perceived success, limiting some of the power diffusion away from them. For example, a Director recalls the first question a CRI CEO was asked by a visiting Minister: "why aren't you guys associated with [CORE 1]?" Nonetheless, to reiterate, both CoREs were perceived to be dependent on their host and partner organizations.

Scientists. Interviewees from both CoREs highlighted the diffused nature of the Institute's internal power dynamics in relation to their PIs:

I like to talk about it as a collective, a scientists' collective, rather than a heavily top-down driven activity. (Director, CORE 1 )

We saw ourselves [as], the scientists were leading the way and we were helping them. (Director, CoRE 2)

Through defining scientific excellence as central to the CoREs, participants recognized that this was held by, and dependent on, the Pls. 
Government. That CoREs were dependent on government was identified by the majority (21) of CORE stakeholders. For instance, just under half of the CoRE participants explicitly discussed the power of government to "cull" CoREs:

Whether [CoRE 2] should or shouldn't have gone and changed direction is just a pragmatic thing in that if you want the funding you have to respond to those signals. At a philosophical level it seems to be irrelevant...you have to respond to the people giving you the money [otherwise] you will lose your funding. (PI, CoRE 2)

CoRE 1's focus regarding meeting the government's requirements so as to be refunded was widely evident both in the interviews and secondary data. For example, it was a focus reflected in their newsletters. However, in comparison to CoRE 2, participants from CoRE 1 perceived government as largely benign. A degree of freedom to self-define was outlined (Table 4.2). By contrast, CoRE 2 participants perceived a more 'intense' relationship with TEC concerning for example being the "last funded" of the CoREs. The following quotations highlight this perception of particularly high power diffusion in CoRE 2:

Our primary stakeholder in many respects is TEC. I think our internal history has been one, been quite variable...So if I was TEC I would be suspect. But we talk to them regularly... we'll just keep working [on that]. (Director, CoRE 2)

[CoRE's are] whatever the Government want them to be. They call the rules. (PI, CoRE 2)

\subsubsection{Divergent Objectives}

All CoRE participants as well as external stakeholders outlined various points of divergence between the different objectives faced by CoREs. Three broad points of divergence were identified: 1) 'science excellence' and 'relevance', 2) 'science excellence' and 'economic development', and 3) tension concerning collaboration and competition (Figure 4.1). A brief discussion of divergence related to defining some of these broad objectives follows. A particularly high degree of perceived divergence between research excellence and other objectives was evident in CoRE 2:

It takes a certain amount of discipline to say 'you can only do this at the expense of what we're best at. We can do these other things well but what we're doing best is what we'd like to do.' (Director, CoRE 2)

An overall finding was that CORE 2 participants appeared to perceive a greater level of divergence $(++)$ than those in CORE $1(+)$. 


\section{Figure 4.1 Divergent objectives: CoREs}

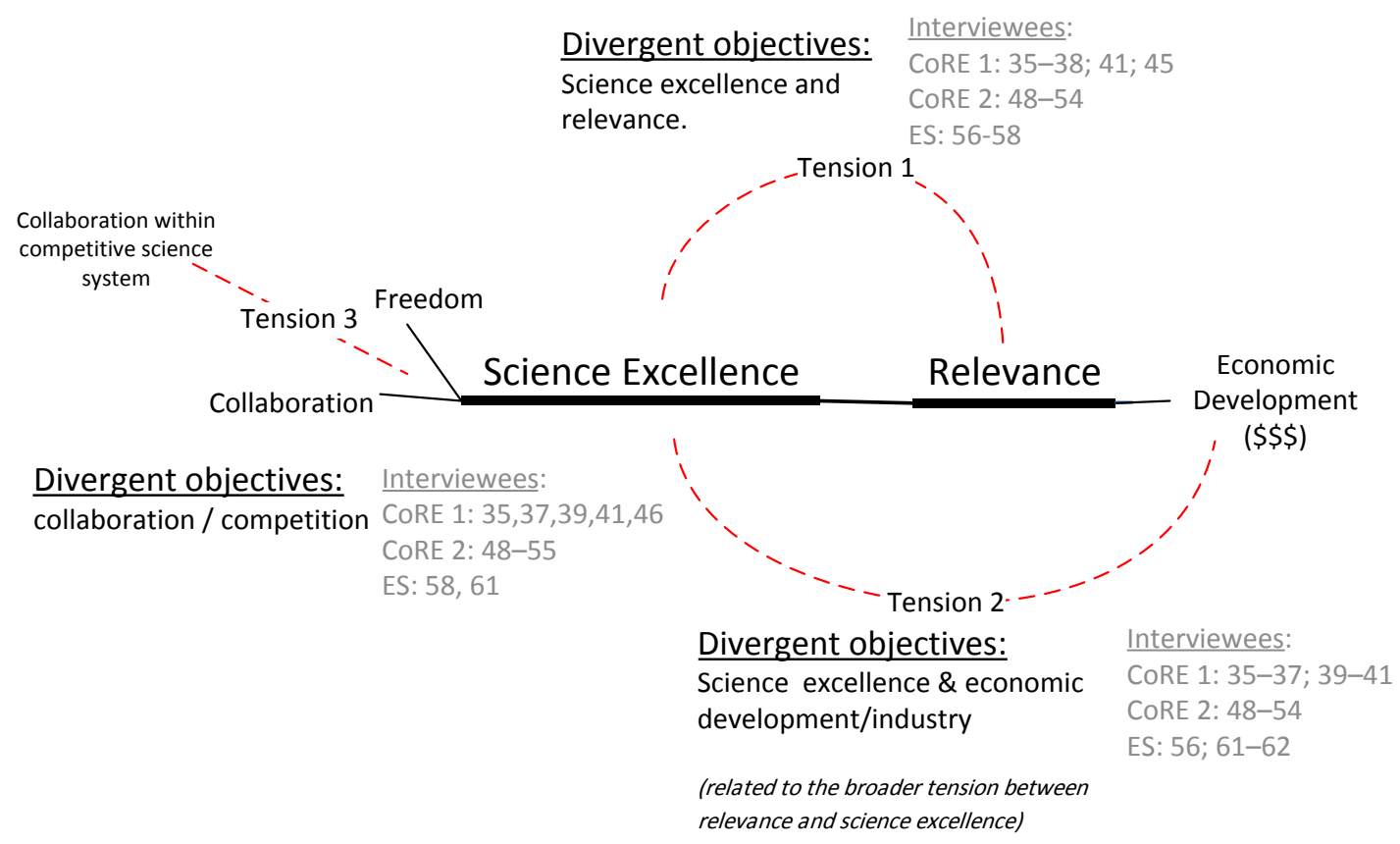

\section{Divergence 1: Science excellence and relevance.}

Research excellence in anything? Would an Old Norse Centre of Research Excellence be acceptable? I don't think so. That's one of the challenges that academics would hate but it's probably a political reality if there's going to be more money. (Public Sector Manager)

As the quote above illustrates, CoREs sit within a broad relevance-based discussion concerning the justification of spending public money on research. This tension can be described in three ways: a misalignment between research and short-term relevance; scientists thinking in new ways about their work; and anything outside science being perceived as a "sacrifice" or distracting from research.

The first aspect to this tension concerns demands for short-term outcomes:

It's like Queen Victoria going into somebody's lab...: "Mr. - whatever your name is - of what use is this?" And he said "Madam of what use is a baby?" The whole point is that you don't know until it is twenty years old whether it's going to be of any use. (Administrative Manager, CoRE 1)

For CoRE 2 this was explicitly linked to a vision to see CoREs as "free of these pressures" with regards to defining outcomes and relevance:

Our model was very much trying to help the researchers with good ideas follow on and accomplish ideas which were not easy to get done with just short-term funding. And also, 
would not appeal necessarily to short-term outside users...they were novel and they weren't appealing yet. (Director, CoRE 2).

This idea of "users" being perceived by some in CoRE 2 as detracting from scientific discovery was not expressed in CoRE 1.

Second, was the tension of "relevance" entailing a different mind-set from scientists. This divergence was perceived mainly in relation to CoRE 2. For example, the quotations below show a tension between a NZ (versus international) focus being divergent with research excellence:

We're probably losing ground internationally... the focus has been local. (AI, CoRE 2)

I thought of myself as a [particular type of scientist] not as a contributor to national development...[For example] most of our investigators would have spent most of their career without having to engage with Maori. And would find it a bother and a nuisance and not understand why it was important. (Director, CoRE 2)

This tension was also apparent in the perspective whereby anything outside of research was considered a sacrifice and detracting from the "excellence." This was evident in both CoREs:

To take on those jobs you give up your science. And you're sacrificing. (Director, CoRE 1).

A cynical side of me could say that it may have been a distraction at times. (Al, CoRE 2).

The Pls are focused on their research...Promotion doesn't come from being friendly to the local school. (Administrative manager, CoRE 2)

For CoRE 1 the broad tension between relevance and science was evident as shown in the quotations above and reflected by the number of interviewees who discussed it. However, in comparison to CoRE 2 it was largely perceived as less divergent and more manageable:

I see it as a critical obligation [outreach]...there's no point getting frustrated (PI, CoRE 1).

An example of this difference in perspective related to their treatment of the budget. That a proportion of the budget would be devoted to outreach, for example, was assumed in CoRE 1:

We've got a budget, we've got a large amount of money coming in. So let's make sure that we set aside a significant amount of money...not just to spend on science, or PhD students or whatever, but we use this to build that added dimension. (Director, CoRE 1). 
By comparison, in CoRE 2 the perception by those involved of higher divergence between these objectives was evident as this had been contested as detracting from the CoRE's raison d'être:

The tension point...is often around money. It is getting the approval to spend some money on maybe some Outreach activities. Because some of the investigators would think 'why are we spending the money on management? The money should just be spent on research.' (Administrative Manager, CoRE 2)

Some CoRE 2 scientists (both Directors and PIs) in this way considered funds not directly going into research to be wasted. This was not a sentiment evident in CORE 1.

Divergence 2: Science excellence and economic development.

CoREs have a very big struggle really. They have to, on the one hand, achieve academic excellence which is at a higher level than the average level for the universities. On the other hand they are perceived to have to meet economic targets...That's a really hard thing to manage...For example, [one CoRE] which has been hugely successful in the commercial space...their tension is that they feel they should achieve commercial success and keep going with that, but they might not get refunded because they've moved too far away from the research excellence criteria. (Industry Observer)

The tension between CoRE activity that leads to direct economic benefit for NZ, for instance spin-out companies, and science excellence is highlighted in the quote above. Differences between the academic 'world' of research excellence and the commercial 'world' of spinouts or engaging with industry was either explicitly outlined or implied by most interviewees (Figure 4.1 above). The ability claim a direct contribution to NZ economy was one way a CoRE can demonstrate its relevance. In terms of the relationship with Government, some argued that this was that most compelling way that CoRes could meet the demand for greater relevance. However, a tension related to the difficulty CoREs, and indeed science activity generally, had in demonstrating its economic contribution:

We can say...'Yes there is good evidence that it [research and science] matters for our economic future.' But when you step down and say "point me to the evidence." It's really really hard. In part investing in science and technology for our future is a leap of faith. (Public Sector Manager).

There was also divergence related to the broad cultures of science and industry that affected the CoREs' engagement in these areas: 
In the traditional academic sense business is the bad guys. Because there's different timelines, different cultures and all that sort of stuff and ideally from an academic view you want to funnel money back into blue sky research. (PhD Student, CoRE 1).

Further, the tension related to anything outside science being viewed as a sacrifice particularly applied to economic development:

Some of [our PIs] might want to just be left to concentrate on their basic research. And some of the external stakeholders and even ourselves sometimes we want to pull the industry development stuff. (Director, CoRE 1)

As a country we need to be stretched in our economic thinking...but in helping with that he's making use of knowledge he already knows...the challenge then is to keep that quest for excellence up. (Chairman, CoRE 1)

Interviewees also commented on the divergence between 'publishing' (upon which science careers are built) and commercial objectives.

For CoRE 2 the higher level of perceived divergence between these objectives was inherent within their assessment of the difficulty of meeting economically based relevance demands:

Even the [previous left-wing] Labour Government was pushing these buttons of more immediate economic return. And we will not measure up on that. (Director, CoRE 2)

In the area that we work in that [direct economic development] is unrealistic. (PI, CORE 2)

Indeed, only one CoRE 2 stakeholder perceived meeting this demand to be possible or desirable. This perspective can be contrasted with how the economic dimension was perceived in CoRE 1. A degree of commensurability is evident in the latter:

I think it's a really good tension. The basic science versus the let's get out of the lab and see what money we can make out of it. (Director, CoRE 1)

Consequently, CoRE 2 participants largely perceived the level of divergence to be comparatively higher.

Divergence 3: Collaboration and competition. There are two aspects to the divergence between collaboration and competition. It was raised as a point of divergence by 5 CoRE 1 but all eight CoRE 2 interviewees. There were also over twice as many instances of this tension being commented on in CORE 2 than in CORE 1. This is indicative of the degree of divergence between these objectives being perceived to be greater by CoRE $2(++)$ interviewees than those in CoRE $1(+)$. 
The first aspect of this tension was reflected at the individual level:

[Collaboration] is for some people bloody difficult. A lot of academics who have spent their whole lives doing the complete opposite...it's the academic model..."go ahead and do what you're interested in and do it very well." So a lot of people are very focused on being individuals and their individual goals. (PI, CORE 2).

A tension between "individual freedom" and research sitting within a collaborative system with a broadly defined research agenda is apparent. Divergence between 'collaboration' and 'competition' at the scientist level was, however, only outlined by two CoRE 2 interviewees.

There was greater evidence regarding the tension between competitive and collaborative goals at the inter-organizational level. The competitive RS\&T systems and "institutionallycentric" focus of their partner organizations sat alongside the CoRE's requirement to be collaborative. One example, outlined by four interviewees, was CoRE 2's host trying to retain as much of the financial benefits within its university as possible rather than adopting a more collaborative approach. The following anecdote is illustrative:

Whenever I used to see him [particular university manager] in the corridor he'd say: 'you're not handing [host's] money over to anybody else are you?'...And every time he made me swear hand on heart 'I promise you I haven't given any of the [host] returned money to anybody outside [the host], it's only benefiting [the host]'...Every time I'd see him he'd say "are you sure, are you sure?" (Administrative Manager, CoRE 2).

This was identified as a point of divergence by many interviewees, with some outlining that the CoREs had "in some ways... exacerbated it" (PI, CoRE 1). However, the level of divergence was perceived to be higher by CORE 2 interviewees. For example, in the above anecdote the university manager is directly intervening (and, thus, exacerbating the tension) based on a competitive-oriented objective. Such a dynamic was not outlined in relation to CORE 1.

Despite this, a concluding quote shows that this tension was evident in both CoREs:

The government talks as though it [collaboration] was trivially easy, but my performance objectives are not to make [CoRE 1 partner organization] a more productive place. It's to make [my university] a more productive place. I'm only interested in cooperating with [another organization] to the extent that it helps [my organization]. (University Manager, CoRE 1).

An additional point: divergent definitions of objectives. A final tension is not related to any one "legitimacy demand" in particular. Instead, it reflects that different stakeholders had 
divergent conceptions of how a particular CoRE should actualize each of its broadly conceived objectives. For example, in CoRE 1, while a PI explicitly focused on liking their educative role to explaining their economic 'relevance', a Director argued against relying on such an argument.

In CoRE 2 a tension regarding the definition of "outreach" was evident. A scientist highlights divergent definitions of what outreach meant within CORE 2:

The [CoRE] is far too focused on Outreach and...the wrong sort of Outreach, not on big ideas about "let's bring a conference here." And also it's missing the boat in terms of the advantage it can provide to the economy. (AI, CoRE 2)

Another tension concerned how CoRE 2 defined their science excellence. Again the Al outlined how, from his perspective, CoRE 2 was relinquishing their "greatest strategic asset" in terms of a particular capability. This suggests divergent perspectives regarding CoRE 2's scientific capabilities and focus and was commented on by four CoRE 2 participants. This again indicates that CoRE 2 dealt with more fundamental points of divergence regarding its definition of itself than CORE 1.

\subsection{CRIs: Pluralism}

\subsubsection{CRIs: Diffused Power}

CRIs' diffused power context was illustrated by the range of stakeholders identified as a) central to the CRI's operation (e.g., staff, government and clients) and/or b) whom the CRI had no choice but to respond to (e.g., government via regulation) (Table 4.3). A CRI 2 manager outlines the current lack of organizational autonomy when articulating a hope for CRI 2's future: "we just need flexibility from our two key stakeholders, which is our shareholder and our clients." Participants in both CRIs described contexts defined by diffused power. However, it was also found that CRI 2 participants perceived a slightly higher degree $(++)$ of power diffusion than those in CRI $1(+)$. 
Table 4.3 Diffused power: CRI Summary

\section{Government/Shareholder}

Reported by: CRI 1: 14,15; 17-24; CRI 2: 25-29; 32-33; ES (External Stakeholders): 54, 57;

60

- $\quad$ "We're sort of doing a dance with government. And we're such an addict. We are such a junkie. We just put our arm out for another fix every time it comes along.(Scientist, CRI 1)

- "Ultimately each CRI is dependent on the shareholder, represented by two shareholder Ministers as to whether they continue their existence or not." (Industry observer)

\section{Clients}

Reported by : CRI 1: 14-16; 18; 21; 23; CRI 2: 26-32; ES: 55; 57; 60; 61

- $\quad$ "The second bunch of people - and the most important at the end of the day - are our customers...They are our prime stakeholders. Without them, whatever government may say...we would not exist." (CRI 1, Manager)

- $\quad$ "We do what they [clients] want - we get paid to do what they want...then the contracts are managed through the course of the year to make sure that we're on track...and still doing what they want. And if they change what they want we vary - we stop doing something and start doing something else." (CRI 2, Manager)

\section{Scientist/staff}

Reported by: Implied by all CRI stakeholders.

- $\quad$ "Scientists are the engine room and the life of any scientific organisation." (CRI 1, Director)

- " If we lose capability in one area...we can't go out and replace that...they've gone through rigorous long-term training...if we lose them, we won't get them back." (CRI 2, Manager)

Counter-argument: CRI 1: 15, 21; CRI 2: 25; 28; 32; External stakeholder: 60

"Our people are worried about their jobs and whether there's going to be more cuts." CRI 2, CEO

- $\quad$ "The CEO of a CRI can walk down a research bench and say to you "Rebecca for the next ten years you are working on the dynamics of steel"... And like it or not, that's your job." (Industry Observer)

Government. The representative quotations in Table 4.3 indicate the importance of government as shareholder and CRI regulator:

The government wants 9 percent. So what's coming to dominate is the money. And to some extent the CRIs have to bite the bullet really. They've got to do what their masters tell them. (Scientist, CRI 2)

This quote is suggestive of how the shareholder was, at the time of the interviews, perceived to be dictating decision making in CRI 2. This reported immediate pressure meant that CRI 2 interviewees were particularly aware of government's ability to dictate their 
decision making and operations. They perceived themselves as currently being "driven rigidly by the almighty return on equity", in response to government's "inflexible" demands.

By contrast, in CRI 1 alongside broad acknowledgement of its dependence on government there was a perception of less direct and immediate exertion of power. A degree of selfdetermination with regards to delivering on government demands was outlined. For example, one scientist said they just needed to "tell [government] what our capabilities are." There was not the impression of being directly dictated to by government that was evident in CRI 2. By contrast, in CRI 2, government's requirement for a certain level of return was, at the time of the interviews, meaning that decisions were being implemented that internal stakeholders (both managers and scientists) did not agree with.

Clients. CRI 2 was "dominated" by some "big service contract[s]":

Sometimes they [large client] think we should just do as we're told...you've got to constantly be careful that you're not in a master/slave relationship. Where they've got the money and they just tell you what to do. (Manager, CRI 2).

For CRI 1, responding to and engaging with clients was identified by management as central to their purpose (Table 4.3). Client engagement was their current focus and defined as crucial. Nonetheless, a comparison can be made that CRI 1 clients were not outlined as being able to dictate the operation of the CRI as a whole, in the way CRI 2's large client did. Another example was how interviewees discussed CRI 1's capacity to select the clients it engaged with, whereas this was not outlined as a possibility for CRI 2. As an industry observer states of CRI 1:

I think it's probably shifted from a false sense of democracy: 'We will open our doors and be ready to service anybody.' We've got to have the political spine and support to tell businesses...that we will do stuff with people who are ready to work with us. (Industry Observer)

This distinction was also suggested by "clients" being over twice as densely coded in the case of CRI 2.

Scientists. Scientists were identified as the "engine room" of both CRIs. For example, CRI 2 managers discussed the danger of any potential downsizing. Nonetheless, it was also evident that managers retained the power to enforce redundancies, if required, and to 
determine the requirements of employment (Table 4.3). Further, as was pointed out (by two CRI interviewees) jobs for scientifically trained employees in NZ were not readily available. This made them less mobile than might otherwise be assumed of such highly qualified 'knowledge workers'. The evidence of diffused power internally, although evident, is, therefore, not quite as strong as the external diffusion of power in the case for both CRIs.

\subsubsection{Divergent Objectives: CRIs}

We're required to service industry. We're required to make a profit. We're required to do new scientific discovery. At the same time we're required to deliver commercial outcomes (Manager, CRI 2).

All CRI participants outlined the existence of divergent objectives. Four broad points of divergence were identified: 1) 'research' and 'making money'; 2) public good and financial performance; 3) research and public good; and 4) definitions of public good. The tensions in the CRIs appeared to be particularly centred around the commercial demands:

That we're supposed to return 9 percent is just nonsense. But that's just politics you see. That's what you get when you have a politician running an organisation like this. [Minister X] thinks he looks like the man asking for 9 percent - he just looks like a jerk! (Scientist, CRI 1).

An overall impression was that CRI 2 participants perceived the level of divergence between objectives to be higher (++) than did CRI 1 participants (+). For example, three managers in CRI 1 refuted the existence of divergence, either with regards to one of the tensions, or initially before then acknowledging examples of divergence. The following quote indicated the degree of commensurability perceived by some CRI 1 stakeholders:

I think the tensions exist until you actually start to analyse them. (Manager, CRI 1)

Such a perspective was not made explicit in CRI 2 . 
Figure 4.2 Divergence Objectives: CRIs

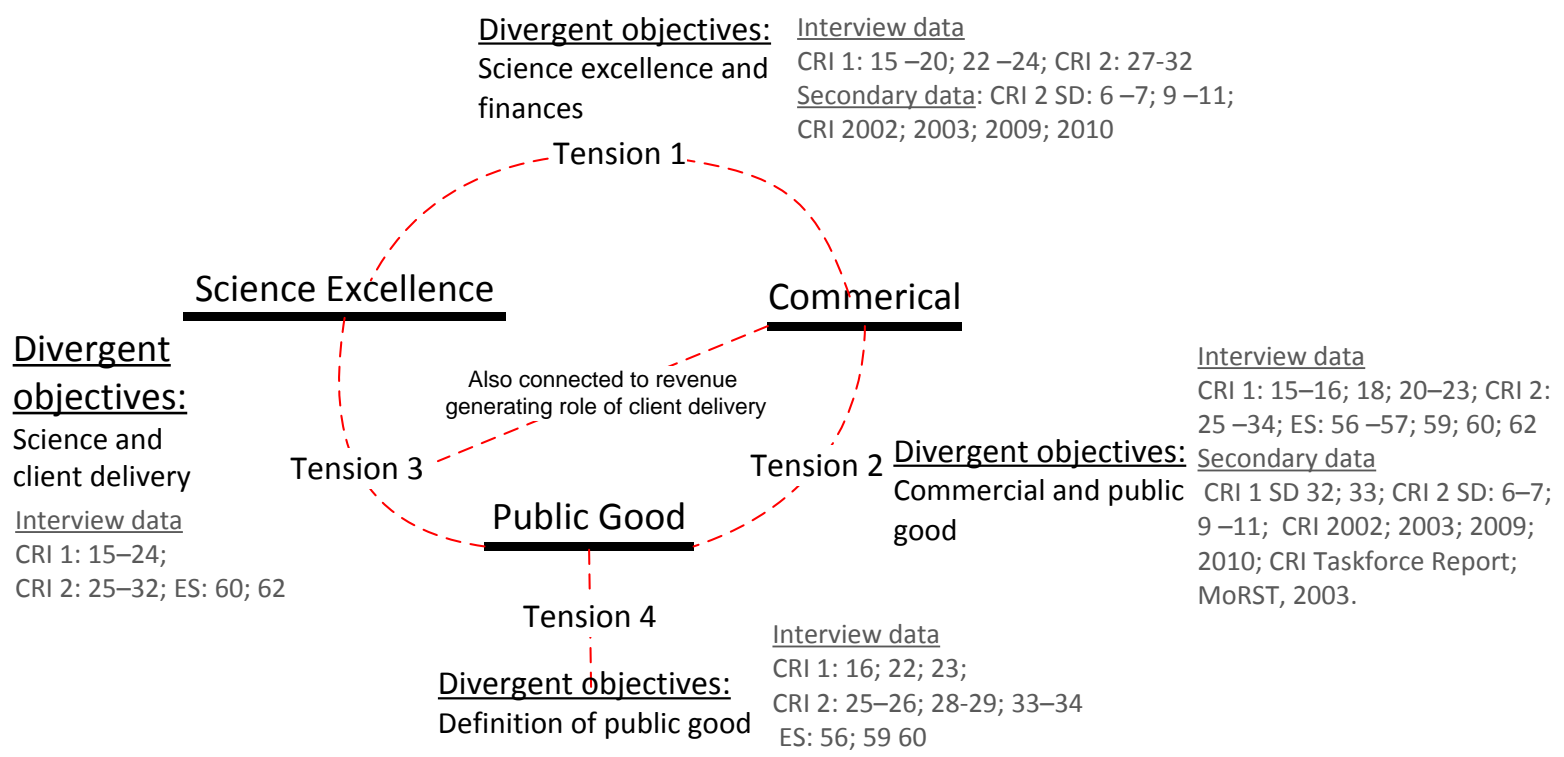

Divergence 1: Science excellence \& financial demands. A tension was the general difficulty regarding making money from science. This was highlighted by nine participants in CRI 1 and all CRI 2 interviewees:

Managing that complexity between that high-commercial return and the need to invest in long-term research, which you may not get a return from, is a complex problem. (Board Member, CRI 1)

That's our flagship programme...It takes ten to fifteen years of investment with no return during that time. (Scientist, CRI 1)

[My field of science] doesn't make money - it eats up the money. (Scientist, CRI 2)

A distinction can be made between the two cases regarding the perceived level of divergence. CRI 2 interviewees appeared to perceive the ability to fund research (rather than just delivering service outputs) without harming their bottom line to be relatively more difficult than those in CRI 1. The comparison is shown in the following:

We're in this bloody situation...there is a bit of an issue of developing a capability [via research] and making sure it gets paid for... you've got to find new money or you've got to stop doing something else. In which case what was the point really, if you're not expanding you're revenue base? (CRI 2, Manager)

We were able to do that [improve their finances] in parallel with a range of other activities such as improving our research and development outputs. (CRI 1, CEO) 
In comparison with $\mathrm{CRI} 1$, that research related activity "is not a revenue generating exercise", as one CRI 2 manager explained, appeared to be perceived as particularly divergent by CRI 2 interviewees.

\section{Divergence 2: Commercial and public good.}

You can't have a [disaster] event and go "oh right! How much is the client prepared to pay to help us maximise our profit." It just doesn't work. And the scientists...if we were trying to maximise our profit on that, it wouldn't go down that well in terms of their ethics. (Manager, CRI 2).

The following above highlights that CRIs cannot be focused on profit maximization in the way commercial companies can be due to its public good objective. The divergence was that this was coupled with objectives around profit and prescribed levels of ROI. This tension was recognized by all CRI interview participants. For example:

Our tension is 'how do we earn enough money from public good services?' (Manager, CRI 2).

[I]n the past people have seen a - it's not even two different ends of a spectrum because it's not even a spectrum the way people have seen it - it's been two different planets almost. 'This is the public good planet and this is the making money planet.' (Manager, CRI 1)

The references to "in the past" by the CRI 1 Manager above highlights that perceptions in CRI 1 were, compared with CRI 2, perhaps moving beyond seeing the two objectives as so highly divergent.

Within CRI 1 this tension was frequently described by participants as divergence between an internal versus external (NZ focus):

Ninety percent of the meeting is "you've got to meet your budget" "you've got to meet your budget" "you've got to meet your budget." Which is effectively internal. I think the management focus has been on meeting their own budget requirements. That doesn't create wealth for NZ. That's just about making sure they keep their own house in order so that the management can see a profit overall...[they] say: "you've got to make a profit" "you've got to make a profit." "Why didn't you make a profit?" (Scientist, CRI 1).

This was also outlined in the secondary data, for example: "It is not clear if a CRI's objective is to create value for itself, as a company, or to generate value for NZ) (Crown Research Institute Taskforce, 2010, p. 7).

In CRI 1, an example was not being able to assist some potential clients, which some defined as crucial from a public good standpoint, as they could not afford the CRI's services: 
The public good thing is something we really can't afford to do. (Scientist, CRI 1).

The same scientist continues: "so they come to us, they'll want us to do something but they're not expecting to pay for it." This issue of expectations of a free or subsidised service due to CRIs being government-owned while having to make a profit was raised by seven interviewees as a tension.

For CRI 2 the level of divergence between these objectives was experienced as being at crisis level at the time of the interviews. As a scientist started "there's a lot of panic around at the moment." The experience of the tension related to the inflexible demand (by the board/government) of a particular level of ROI meaning CRI 2 was contemplating cuts in capability and, hence, in public good:

The Board is driving the organization currently to deliver on financial outcomes rather than public good outcomes. Because if somebody took a step back and said "what's the best for the public of NZ as a whole?" It might be CRIs having a lesser return but maintaining capability for the future (Manager, CRI 2)

In response to the financial viability criterion one manager stated: "we've cut our infrastructure to the bare bone. We're now left that any other cuts will have to be in national capability." The tension was exacerbated by the expectation, already outlined, on the part of the clients that the CRI would "hold on" and subsidise the service due to its public good mandate.

This tension in CRI 2 was also reported in relation to the commitment of the scientists to their public good delivery affecting the CRI's bottom line:

Rather than deliver what they want we have a history of over-delivery. And that's where you get into trouble with our finances. Our scientists are so keen they tend to over rather than under deliver. So the client's actually getting more than what they are paying for (CEO, CRI 2) Consequently, both CRI 2's clients and scientists believed some services should be subsidised:

What I want [CRI 2] to do is take seriously the public good component of what it does so that we don't have to make a profit on every single thing that we do (Scientist, CRI 2).

To summarize, the tension between public good and financial demands was highlighted in both cases. However, it was perceived as particularly divergent by CRI 2 interviewees. The following quotations show the slight difference in perspective: 
The services being performed, by their nature, are public good...So you've got quasicommercial drivers on something in all other countries is seen to be free... that's always a challenge. (Manager, CRI 2)

Two or three years ago we would have been asked 'shouldn't you be providing that for free?' This [client] now recognises the potential value of that to them and is prepared to pay...there's also going to be short-term benefits for them. So it's only reasonable that they share the costs. (CEO, CRI 1)

Perhaps indicatively, for CRI 2 it was three times more densely coded than the other tensions and nearly twice as densely coded than for CRI 1.

\section{Divergence 3: Science and client delivery.}

You were expected to go and keep up to date and do research. Do things that were expected because you're a scientist. You should go on Friday afternoon to the library and read the journals. Well, if anyone around here started to go off on Friday afternoons to read the journals they'd get kicked up the bum. (Scientist, CRI 2).

The above quote reflects how in CRI 2 finding the space to do research clashed with the (revenue generating) client delivery work and pressure to be focused on delivering in this way. Another scientist highlights this tension from another perspective:

The only time I've got angry around here recently was when people were slagging off the [business development team]...Someone was opting to cut them adrift: "let's just be done with it and we'll just do science." Well no one's going to pay for it. You're just going to die slowly. You're like a rat bolting to get down the hole. There is no Elysian field where someone just dished out money for wonderful science out of the goodness of their heart. (CRI 1, Scientist)

All except one CRI interviewee confirmed the existence of this as a tension. Two external participants also spoke of this general divergence between client engagement and science. Issues related to time frames (immediate versus long-term) and inability to predefine scientific outcomes due to the nature of scientific discovery were highlighted:

My friend...used to say 'people expect an immediate result on something that has never been done before' - it makes it [engaging with industry] quite challenging. (Manager, CRI 1)

Tensions related to the demands for aspects of traditional science indicators such as publishing and new knowledge were painted as conflicting with client demands in both CRIs:

We are doing an awful lot of commercial work... it's almost turned...certain members of the team...into factory workers actually. It seems to have, for want of a better word, dumbed the team down quite a bit...finding that balance between dumbing down your scientists with 
the factory type commercial work...and managing to push those technological boundaries...is very difficult. (Scientist, CRI 1)

Clients don't pay us to write papers. They pay us to give them a service. (Manager, CRI 2)

The tension is between the science culture, which is essentially a university science culture around publication. And there's quite a broad-based desire amongst CRI scientists to participate in that culture rather than participate in the service culture of the application of science to their sector. And that tension manifests itself at management and board level. (CRI 2, Board Member)

A greater degree of difficulty was reported for CRI 2 regarding maintaining a research capability rather than simply focusing on the service. For example, interviewees perceived a larger amount of CRI 2's work to be incompatible with research excellence:

One of the problems we do have in this organisation is that a lot of the work we do is routine. (Scientist, CRI 2)

A perceived high degree of divergence between "research" and "service" in CRI 2 is also apparent in the introductory quote to this section. There the scientist reflects on a particular lack of space to focus on research within CRI 2. Interviewees in CRI 2 also talked about "research" and "client engagement" in a way that conveyed a clear distinction, and accompanying sense of divergence. For example:

Often you hear things from the CEO and you think "well that doesn't apply to me because I'm not service." And I think the different groups have different challenges and you don't necessarily understand service delivery people's issues and they don't necessarily understand research people's issues. (Scientist, CRI 2)

This level of distinction between 'service' and 'research' scientists was not as apparent in CRI 1.

\section{Divergence 4: Defining public good.}

You get these very extreme views of a customer or a group of customers - who are clients trying to determine what the science should be, which gets things screwed up. (Industry Observer)

A fourth tension was initially made explicit by three external stakeholders and then became apparent within the internal CRI interviews. There was tension identified between responding to immediate client need versus leading/pushing an industry sector, something described as having a more strategic picture of public good. For example, interviewees 
discussed CRIs having to push their conservative industry to develop versus just delivering what they wanted:

[particular CRI] has a very Jurassic industry in its thinking. It's just totally backward...But they've [CRI] been doing things that are challenging the sector...And that's challenging because the sector doesn't really want to know that. But for New Zealand's future we probably need people like [CRI 1] thinking like that. (Public Sector Manager)

For CRI 1 this divergence was reported as being manifested in clients demanding an immediate response to their individual needs:

You get a [small client $\mathrm{x}$ ] ringing up [CRI 1] and saying, in effect: "please take your world class research scientists off whatever stupid stuff they are working on at the moment. I want a new $[\mathrm{x}]$ designed. I want it by next week. You're taxpayer owned. I pay my taxes. Do it."...Actually the CRI...has assessed where NZ's needs are...has seen where NZ's needs might be tomorrow and said: "we are maintaining capability, and building capability and building products and services in this area. We cannot be doing this stuff over here just on a whim." They are not a service organisation to that extent. (Industry Observer)

This was also highlighted as a tension between a service focus versus building up larger research and IP platforms. The later may not be directly connected to a particular client's expressed needs.

With CRI 2, this divergence was articulated in the tension between new versus existing capabilities. Existing capabilities provided an expected service to pre-defined clients. The tension was how to fund research platforms that were (potentially) vital for those clients and NZ in the longer-term. As a CRI 2 manager explains "a different mind-set" exists between research and service delivery. "With service delivery you are driven by direct client needs." The tension for CRI 2 was maintaining their service delivery capability and focus while also finding the funds and space to extend beyond that:

[CRI 2's] tried to get out from underneath that [being dictated to by clients] by doing other research. But then of course people say "you're [supposed to be delivering in this particular area], why are you doing this other stuff?" So they have a bit of a trouble really. (Industry observer, CRI 2)

To reiterate, in CRI 2 they were fighting to avoid a "master/slave relationship" with their clients. By contrast, in CRI 1 there was wide recognition that: "You can't just say, 'go and help Joe Blogs fix his thing.' It's got to be much more mature than that." Consequently, divergence was again perceived to be particularly high for CRI 2 . 


\subsection{HTSUs: Pluralism}

There are multiple stakeholders with multiple requirements, expectations, and views of the company. Absolutely, we are a classic example of that and probably more so than most companies in NZ. (CEO, HTSU 1).

\subsubsection{Diffused Power}

The interviewees confirmed the existence of diffused power in the literature associated with HTSUs. Reliance on the providers of scientific capabilities and capital was highlighted:

At the moment [HTSU 1] is still being propped up by a lot of people who are just helping (Scientist, HTSU 1)

With regards to investment there was a difference between the more direct pressure from private investors and the more passive involvement on the part of government. The key stakeholders were the universities (HTSU 1); private investors, scientist founders, university collaborators (HTSU 2), and government, summarised in Table 4.4. 


\section{Table 4.4 Summary of diffused power: $\mathrm{HTSUs}^{20}$}

\section{Universities [HTSU 1 only]}

Reported by: all HTSU 1 interviewees

"If you get a...Vice-Chancellor...who doesn't understand commerce at all, then they will try and control the subsidiary company more." (HTSU 1, Director)

- "We still interact very strongly with the universities. There's a lot of information that flows backwards and forwards. There's a lot of time and effort and energy that still comes into the company from the university." (CEO, HTSU 1)

- $\quad$ Counter point $(11 ; 14):$ "I think it's got to the point...of being less beholden to the University....I think they are able to go their own way quite nicely." (Director, HTSU 1)

\section{Private Investors}

Reported by: all HTSU 1 \& 2 interviewees; also ES: 56,57, 63

"They are always trying to raise investment privately." (Director, HTSU 1 )

"At Christmas time it was really hard, there was just no money...and I pulled in about a quarter of a million bucks from existing investors...I said..."I'll give you a really great deal"...so one guy...he was happy then. And before that he was moaning because he was always the first to put up his money. 'We 'Okay I'll give you \$100,000.' Every few months another \$100,000." (CEO, HTSU 2)

- It's a big learning curve...you do begin to realise what different things cost us and how much investor money you need to survive this month or next month. (Scientist employee, HTSU 2).

\section{Scientists/Research groups}

Reported by: $1-6,7-13$.

- "The main constraint was a people constraint...[Scientist X] couldn't devote as much of his time as he should and they [HTSU 1] desperately needed material from [Scientist X], which only he could do." HTSU 1, Director.

- $\quad$ In terms of the inventors we deal with them every day... they can just turn up and say '[CEO] I've got this great idea we should do this' and it's like ' $\mathrm{No}^{\prime}$ '... [but] they've already started talking to one of the staff members and they're already half way through doing it and its like 'for god's sake.' HTSU 1, CEO.

- $\quad$ HTSU 2 Research collaborators as important $[7,8,10]$ or impactful [13]: "My next offshore trip is to [country $\mathrm{x}$, where an institution]...is doing some analysis on our technology to kind of cross-validate it with other technologies particularly the current world-standard...So this is a very important...meeting. We know the guys quite well and this is a relationship we've been developing for quite a long time." HTSU 2, Manager

- $\quad$ Counter-point HTSU 2: As employees scientists/scientist founders being able to be directed by managers and the issue of lack of opportunities for their skill set in NZ $(7 ; 12 ; 13)$.

\section{Government}

Reported by: HTSU 1: 12-14; 16; HTSU 2: 7-12.

"You've got to get into a position where you can tell the government to drop dead basically." HTSU 1 , Director, implying HTSU 1 is not yet in that position.

"The government was a huge player...initially they were probably the dominant extra party." HTSU 2, Founder

- $\quad$ “It's [government funding] still very important because at the moment...we don't make money, we don't come out of the red each month. So if you can get funding to update your website or send someone to a trade show... anything that pays for that is a bonus." (Scientist, HTSU 2).

\footnotetext{
${ }^{20}$ In both HTSUs customers, although central stakeholders, were not interviewed. This was partly due to customers simply being part of decision making as a component of the commercial focus rather than being explicitly discussed as applying a distinct demand on the company. Both HTSUs were also not forthcoming with potential customer interviewees. This table reflects both the structural differences and degree of access granted in each case. To summarise: HTSU 2 was not a spin-out and, therefore, unlike HTSU 1, does not involve a university stakeholder; access in HTSU 1 was restricted regarding employees and private investors; and, the CEO in HTSU 2 was also the dominant investor.
} 
Despite the power diffusion highlighted in both HTSUs, two points of difference regarding the providers of their science platform were evident. First, was the involvement (both in terms of science and as shareholder) of the university in HTSU 1. Second, was that the scientist founders were perceived as having a higher degree of autonomy in HTSU 1. For instance, one HTSU 1 scientist founder reiterated his ability to say: "hang on; we don't work for you [CEO]." This contrasts with a perception expressed in HTSU 2:

I told them [scientist-founders/employees] what to do. (CEO, HTSU 2)

With regards to investors, while there was not as large a distinction, there also appeared to be a perception in HTSU 2 that those shareholders could be managed and their input directed:

I think a lot of them are his [CEO's] friends... He has quite a good, very personal relationship with the shareholders. (Scientist employee, HTSU 2)

This difference in perspective was reflected in the boards. HTSU 1 had from the beginning a board the represented the university, scientists, shareholder, and private investor interests. By comparison, the board outlined on HTSU 2's website in 2011 consisted of a single member: the CEO. This perceived lack of power diffusion in this regard was reported as a concern by two HTSU 2 interviewees.

Accordingly, while both organizations operated in diffused power contexts they differed slightly in the degree to which this was reported on by participants. It was perceived to be higher in HTSU $1(++)$ than HTSU $2(+)$. In reflecting on both the scientists and investors, a quote from the HTSU 2 CEO summarises this distinction: "it's not a democracy...It's a little bit autocratic." Finally, despite this distinction, as Table 4.4 shows, in both cases power was highlighted as diffused. The following quote illustrates this:

It's been situation normal [for start-ups] where you have so many conflicting and divergent agendas...I think it's probably even more so in this particular organisation because we've had the on-going requirement for research. (Investor, HTSU 2)

\subsubsection{Divergent Objectives}

There was general confirmation of divergent objectives by all HTSU interviewees as well as four external stakeholders. The following is a reflection on the science/commerce divide: 
You've got a bunch of people on this side who say the worlds like this and a bunch of people on the other side who say the worlds like that ...its sort of different ways of thinking and looking at the world. (HTSU 1, CEO)

Three tensions were outlined. First, was a divergence between science and the commercial objectives, with science objectives remaining central due to their high-tech nature. Second, was tension between sales and any other demands which detract from those commerciallegitimacies (for example, a public good objective centred on contributing to NZ). Third, was divergence regarding the demand for ROI (Figure 4.3). In comparison with the two CoREs and CRIs, a distinction between the two HTSUs regarding perceived degree of divergence was not obvious.

Figure 4.3 Divergent objectives: HTSUs

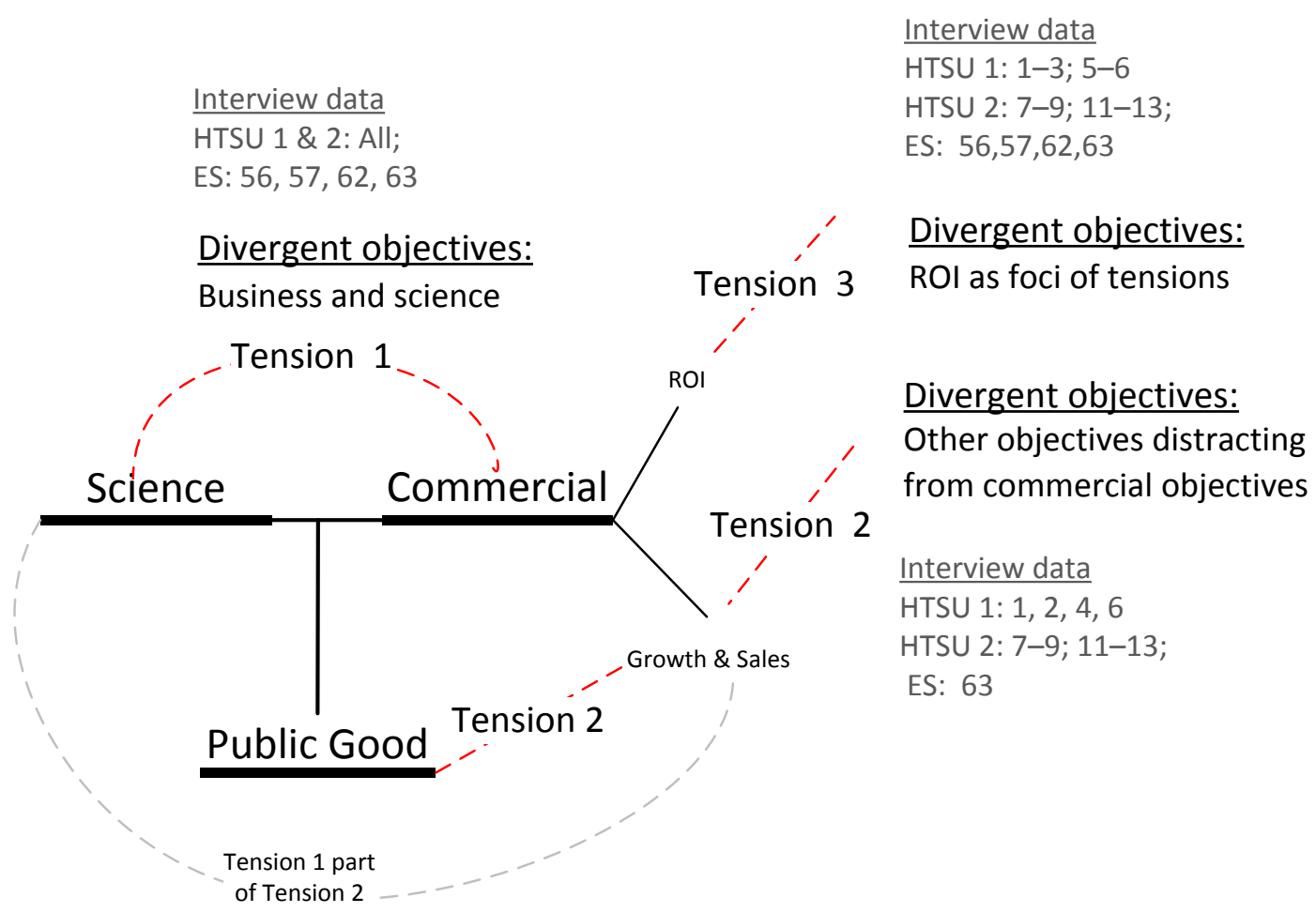

Divergence 1: Business and science excellence. The following illustrates the general divergence between 'science' and 'business':

I've been ridiculed by other pure scientists: 'oh you don't get your hands dirty' and all that sort of stuff. There's a real feeling out there that commercialisation's dirty: 'You don't go there. Us pure guys.' Those are the people who...get the prestigious stuff in this business [academia]...'Don't get your fingers dirty in the commercial stuff.' (Scientist, HTSU 1) 
Scientists tend to see business as dirty. Selling stuff it's actually sort of icky. (CEO, HTSU 1)

This was highlighted by all HTSU participants and four external stakeholders. External stakeholders tended to comment generally regarding the divergence between being focused on the technology (science) versus market relevance (commerce). For example, a venture capitalist argues that in technologically intensive companies those involved can believe:

'This is going to work because the science was so good.' They totally overlooked the fact that the product or service being offered was of no relevance whatsoever. So they did not understand the fundamentals of market and market connectedness. (Venture Capitalist)

Another manifestation of this tension was the divergence between creating new knowledge and refining and developing existing product offerings:

That tension is: 'Look you scientists want to make all these different products, but maybe we should kill that one and kill that one...Are you prepared to take the baby out the back and shoot it?' And we say 'oh no no.' Because we love what we're doing and want to try these things. So there's a tension there around the people like me and the people in my team who want to try new things...and the company saying 'We can't afford to do everything.' (Science Founder, HTSU 1)

This tension between business and the freedom to explore new scientifically interesting avenues was also reiterated by another HTSU 1 scientist founder. He emphasized the freedom to "play in my sandpit":

The big thing for me has been product handover. I design something...[but] I've got to hand this over so that it can be manufactured and everything has to be specified. And to me that's boring...it's not that exciting...so there's all these necessary evils that we have to do. (Scientist Founder, HTSU 1).

This was reiterated in HTSU 2 as the tension between the freedom to "potter" (in the words of two scientists) and being more directed in their research.

In HTSU 2 another tension regarded when to sell and what to "claim" regarding the product. Those with science-based objectives were perceived as more inclined to be conservative and wanting to perfect the technology before taking it to the market. One of the founder's outlines: "We've got a saying: "development's where the rubber meets the road. And marketing/[CEO] is where the rubber meets the sky." That science reputation was tied to being conservative and focused on technological perfection was outlined by four stakeholders: 
I'm almost pathologically attracted to risk...I claim we're going to do this. And then you've got to back it up. It's quite a high-risk personal position to take...you're credibility is on the line...Whereas your typical scientist is often quite conservative....Some of our founders were opposite to that. Hugely hugely worried about their reputations... [I] sell something on a 50:50 basis. If it's a 50:50 call about whether it's going to work or not you just keep moving along. Whereas for them, "no, no, no, you can't tell them that, we haven't proven that yet." Five years later you'd be broke. So to some extent I sell what I expect us to be like in three six months. (CEO, HTSU 2)

In the academic world, you really seriously need to understand and have all your 'i's' doted and ' $\mathrm{t}$ ' $\mathrm{s}$ ' crossed....and spend years proving every statement that you make. Whereas the commercial driver you want to make quite a song and dance about things and get a bit of a buzz going. So there's a real tensions. (Scientist Founder, HTSU 2)

More broadly, this was also expressed as a tension between "beauty" (technological perfection) on the one hand and commercial realities (selling the product now) on the other.

Another tension was outlined between commercial work and university indicators of research productivity and excellence:

People like [HTSU 1 scientist] would be hard pressed to produce very high-grade research publications working for [HTSU 1]. (Director, HTSU 1).

It's been a huge problem for me personally with PBRF, for example...as you try and commercialise you've got to keep your mouth shut...So I don't publish anything. (Scientist Founder, HTSU 1).

Further, the university manager interviewed, through not recognizing this divergence helped confirm this reported tension. His perspective was that if they were "good scientists" their HTSU work would still result in "publishing and other things that the university wants."

Two additional manifestations of this tension were raised explicitly by HTSU 2 participants. First, four interviewees outlined the tension of research as an expense that did not necessarily contribute directly to their commercial objectives:

It does tend to gobble up large volumes of money without an output that can necessarily be taken to market. (Manager, HTSU 2).

A further tension point of divergence by three interviewees concerned time. This was highlighted in terms of the HTSU 2's scientists and their collaborators:

Something at [university collaborator] was going to take six months and I said "shit, it's going to take two weeks." And in fact it has dribbled on for four to six weeks already...that's ridiculous. (CEO, HTSU 2) 
This exploration leads into, and indeed is part of, the broader tension that sees anything not directly connected to sales as a distraction.

\section{Divergence 2: Commercial and other objectives.}

Running a little business in a high-tech area where your market is principally outside NZ is hard enough.... without having other people impose other agendas...you can just do without. (HTSU 1, Director).

The interviewees outlined divergence between sales and anything not directly tied to this objective. The divergence already highlighted above between science and commerce is part of this tension. However, it also included public good type objectives as well as political motivations such as engaging with government. With the science-based objectives already outlined above, this second cluster of objectives will now be focused on. This was most explicitly evident within the interview with HTSU 1's CEO. The need to focus on "growth" and not being "distracted" by additional legitimacy demands was discussed, with "distracted" being used in this sense five times within the interview.

In HTSU 1, the CEO, directors, and university manager highlighted this tension regarding anything outside the commercial realm being potentially detracting. For example, a Director outlined how government-based objectives: "interfere and distract you from the business that you are supposed to be running and at the end of the day you've got to ask yourself "what the hell was all that about?" The CEO discussed how even going for a local award could be potentially distracting as it was not directly linked to sales:

"My initial reaction was "no"...why should we waste our time...when it's not really going to help us [in relation to export sales]." (CEO, HTSU 1)

For HTSU 2, the main example of additional objectives distracting from sales was highlighted in relation to their research collaborations. HTSU 2 participants either expressed frustration that they were not commercially oriented or indicated efforts to move beyond them and become more sales rather than partnership oriented:

The reality is if that [collaboration] does not translate into money in the door then it becomes a liability. (Scientist employee, HTSU 2)

Mirroring the discussion in HTSU 1, two HTSU 2 interviewees also outlined how involvement with government can be distracting: 
Some of the [government's] focus in terms of advancing NZ Inc. brands...you've got to do that to an extent to keep them happy. So there is a bit of wasted effort there. (Scientists Founder, HTSU 2)

HTSU 2's CEO also outlined that some stakeholders regarded his objective of remaining NZ owned and located as naive:

They [FRST] regard it as a little naïve. They think that you need the foreign partners to do any good... [And I think] we don't need to have them [foreign investors] controlling the company. (CEO, HTSU 2).

This is indicative of the perceived tension between public good/NZ focused objectives and a more purely commercial focus.

To conclude, an example of this tension between public good and commercial objectives is provided below by the university manager speaking as a HTSU 1 shareholder:

[Scientist founder] talks about those things [public good focus] but ...I have to be interested primarily in the benefits that the University can capture because we're not running a charity here...Because, it's not in my job description to make the government look good. I'm here just here to make a dollar for us (University Shareholder, HTSU 1)

This quote leads into the final tension focused around return on investment.

\section{Divergence 3: ROI as a source of tension.}

As you get seed or investment funding, once you get equity partners you start to get different tensions. There are lots and lots of examples of that. (Public Sector Manager)

Both the HTSUs had brought in private investors with ROI expectations. This, as the above quote indicates, brings in additional pressures. The ROI objective was perceived as a source of tension in three ways. First, a focus on ROI heightens the tensions already illustrated above through being the toughest litmus test of commercial success for an HTSU to achieve (e.g., in contrast to general indicators of growth). Second, some stakeholders saw it as opposed to other commercially oriented goals such as long-term growth. Third, it brought into focus different timelines and relationships to risk. An example was the reported divergence between a shorter-term ROI focus and the CEO's, still commercial, vision:

Their [Venture Capitalist's] primary goal is looking at an exit strategy...That isn't [CEO's] aspiration for the company. He wants to build a company that has value and keep it in NZ, not sell it offshore. So there's a fundamental philosophical difference between [CEO's] view...and the venture capital. (Manager, HTSU 2) 
This tension was discussed by five HTSU 1 and four HTSU 2 interviewees and four external stakeholders.

That the all-consuming nature of the ROI requirement can heighten tensions was discussed:

The big challenge with spin-off companies is typically the balance of the financial drivers...Typically the financial drivers on companies can be quite dramatic. Particularly if they have significant venture capital investment which is expecting their share price to hit key targets.... if you're a start-up company and you've got venture capitalist that's invested $\$ 250,000$ and you know that in a year's time your share price has to be worth $\$ 2.50$ so that they can get a return. Your share price is currently worth 90 cents. That's a huge driver to change the dynamics of the company. (Public Sector Manager).

The later stage the investor coming in...the more demanding they are for returns. And they don't care about wonderful science...So there's a big tension there. (Venture Capitalist).

The CEO in HTSU 1 provides a similar example of how the ROI criteria can be particularly hard to align with other objectives:

We have our very commercial shareholder who just basically invested cash...He would be thinking, 'why do I necessarily care about the reputation with FRST?' 'Why do I really care about all these other things that all the other directors and shareholder think is important?' If you are purely focused on ROI then a lot of the other stuff we do, the more intangible benefits don't really translate into benefits. (CEO, HTSU 1)

In both HTSUs interviewees distinguished between ROI and other commercial goals such as long-term growth, implicitly perceiving them as in tension:

You've got to be careful too because you can have investors which all they want to do is basically come in take everything and rip you off [Scientist Founder, HTSU 1]

Observable in the quotations above are the issues of risk and timelines that the ROI objective brings into focus:

There are the people who say 'I want to rapidly ramp up this business in two or three years time. I'm impatient'... Another approach might be to say: 'We really want to be here building up this company almost organically if you like. Within its own portfolio of products over many many years...we are determined to be safe.' In other words it's a question of risk. You go for the high risk, quick return, or do you go for the slightly lower risk longer term approach... it is another one of the central issues that we are continually in tension about. (HTSU 1, Scientist)

These issues around risk and timelines were discussed by nearly half of HTSU participants. 


\subsection{Summary: Chapter Four}

This chapter described the organizations through a focus on the theoretically informed phenomenon of interest: stakeholder legitimacy demands and pluralism. The two dimensions of pluralism: divergent objectives and diffused power were explored. The cases of a similar type dealt with similar forms of power diffusion and divergent objectives. Despite pluralism being evident in all organizations, subtle differences were also evident between similar cases (for example, CoRE 1 and CoRE 2). Participants perceived the degree of pluralism to be slightly higher (++) in some cases than in others (+) (Table 4.5$)$.

Table 4.5 Summary of pluralism

\begin{tabular}{|c|c|c|}
\hline Cases & Diffused power & Divergent objectives \\
\hline CORE 1 & $\begin{array}{c}+ \\
\text { perceived degree of diffusion. } \\
\text { perceived degree of diffusion }\end{array}$ & $\begin{array}{c}+ \\
\text { perceived degree of divergence } \\
\text { perceived degree of divergence. }\end{array}$ \\
\hline CRI 1 & $\begin{array}{c}+ \\
\text { perceived degree of diffusion. } \\
\text { perceived degree of diffusion }\end{array}$ & $\begin{array}{c}+ \\
\text { perceived degree of divergence } \\
\text { perceived degree of divergence. }\end{array}$ \\
\hline HTSU 2 & $\begin{array}{c}+ \\
\text { perceived degree of diffusion. } \\
\text { perceived degree of diffusion }\end{array}$ & $\begin{array}{c}\text { Similar } \\
\text { perceived degree of divergence }\end{array}$ \\
\hline
\end{tabular}

This provides the foundation for explicating the legitimacy strategies within each of the cases in relation to that pluralism. The contextual descriptions will returned to in the discussion as a way of further exploring certain 'legitimacy strategies' that were implemented in certain cases. 


\section{CHAPTER FIVE \\ Findings: Legitimacy Strategies and Pluralism}

Often you have totally different cultures between business and science. Where the success occurs is where...they dance and don't stand on each other toes. (Manager, CRI 1).

Given the primary focus of this thesis on legitimacy strategies, if Chapter 4 was described as setting the contextual scene, Chapter 5 is what the scene was being set for. It outlines the strategies each of the six cases implemented based on the perceptions of those involved. In reference to the introductory quote: I am exploring the dance these organizations engage in as they manage their legitimacy demands amidst pluralism.

Each of the six organizations are first addressed individually. The framework transcension, negotiation, compartmentalization, and contraction, provides categorization for the inductively derived sub-themes. Each section follows the same pattern: depiction of the main strategies, followed by briefly discussing any less prevalent strategic themes. Finally, before the section is concluded a concise overview of stakeholder assessments of the legitimacy strategies implemented is provided. The same order that was utilized for Chapter 4 is again followed here: science organizations focused on basic (CoREs), applied (CRIs), and commercialized (HTSUs) research.

\subsection{CoRE 1: Legitimacy Strategies}

The central 'strategic story' conveyed in CORE 1 was a combination of transcension and negotiation. These are represented in Figure 5.1 and will be discussed in turn, beginning with transcension due to its primacy in understanding the strategies. Of all the cases, CORE 1 will be shown to provide the most obvious example of an organization embracing both the divergent objectives (e.g., 'expanded vision' and 'expanding expectations') and diffused power ('democratic partnership' and 'entwining with the system') that defined its context. 
Figure 5.1 CoRE 1: Legitimacy strategies ${ }^{21}$

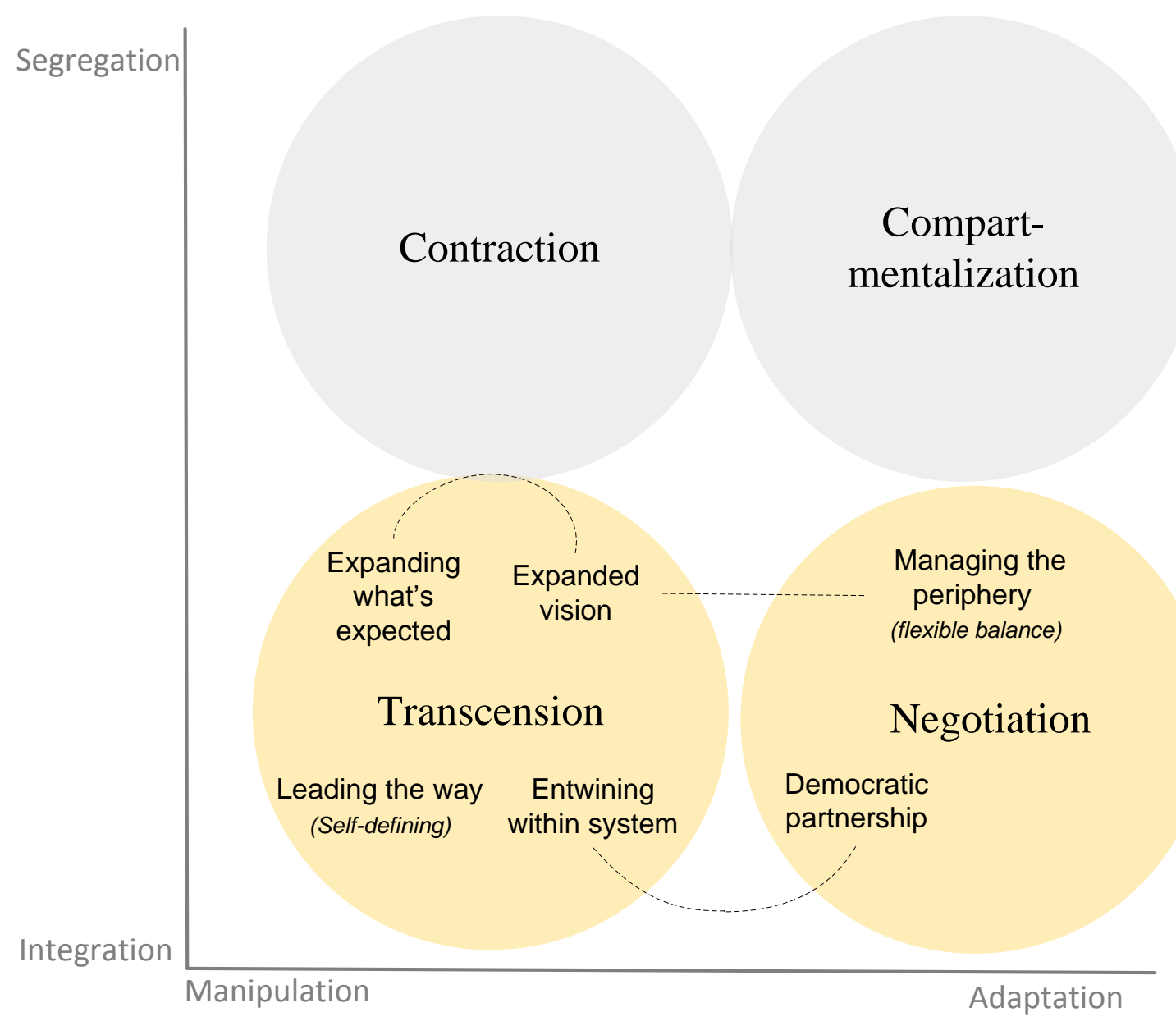

\subsubsection{Transcension}

Four CoRE 1 strategies can be defined in terms of high-degrees of agency (i.e., transformation of context and stakeholders) as well as integration (they were inclusive of multiple stakeholders legitimacy demands). The ability to 'rise above the tension' through these strategies involved moving beyond the traditional limits of their context (i.e., agency). While not the focus of the following discussion, their capacity to implement the following strategies and innovations can be understood in the enabling context of the increased funding that the formation of the CoREs entailed.

\section{Leading the way (self-defining).}

\footnotetext{
${ }^{21}$ Dashed lined in Figure 5.1 as well as in the similar figures for other 5 cases (Figures $5.2 ; 5.3 ; 5.6 ; 5.7 ; 5.8$ ) indicate strategies that appear particularly interconnected.
} 
They've blazed their own path in a way. (Chairman, CoRE 1)

Nearly all CoRE 1 participants, plus an additional 6 interviewees external to the organization identified the capacity of CoRE 1 to "blaze their own path." Participants described CORE 1 as leading the way and, in doing so; self-defining what a legitimate CoRE looked like. Internal reports as well as newsletters and a media article also provided examples of this strategy.

This strategy was connected to the CoREs being new entities:

TEC was feeling its way; they were learning too. We had the opportunity to drive the process in directions they felt comfortable with but where we were setting the agenda. Now that's because it was a new phenomenon. We were able to grab it by the throat and take it where we wanted to take it. (Director, CoRE 1)

This freedom continues into the present; another Director explains:

I don't think they [TEC] have a strong clear view of what a CORE should be. So to some extent our job is to try and develop that with them...it's a benign disinterest. (Director, CoRE 1)

This strategy was particularly evident in the interviews with the three directors and TEC manager.

CoRE 1 made the most of this opportunity to self-define through initiating innovative ideas and thinking. This meant it did not follow the direction set by others. For example, interviewees from the second CoRE included in this study instead reflect on CoRE 1 setting the format other CoREs were then required to follow:

To some extent, it's [government expectations] been influenced by the CoREs that have been the most successful [including CoRE 1]...So the rest of the CoREs are trying to follow their model. (PI, CoRE 2)

Indeed, being first and trying new things was seen as a defining aspect of CoRE 1 and an ongoing challenge:

The group was miles ahead of the game. That's a plus, but it's also a minus. The easiest thing in the world to do is to have a cup of tea. But the moment you have a cup of tea and let the world catch up with you you're doomed. So you have to keep reaching forward. (Chairman, CoRE 1)

This sense of momentum was perceived by participants as also important vis-à-vis CoRE 1 's relationships with its partner organizations: 
When the [RS\&T] Minister Mapp came for a visit to [partner CRI], one of the first things he asked was 'why aren't you guys associated with the [CoRE 1]?" Luckily our CEO was able to say "ah we are." So our partner institutions see a value in being associated with us (Director, CORE 1)

This was also important with regards to the relationship of internal participants with the CoRE. An example is explicitly connecting their identification with CoRE 1 to its strategy of leading the way:

[CoRE 1] first, [University] second. There's [CoRE 1] because they're pushing forwards. It was leading the way. (PhD Student, CoRE 1)

Another aspect in terms of this strategy of self-defining was highlighted as CoRE 1's focus on self-evaluation:

We're quite keen on measuring ourselves and understanding ourselves. We had this idea that we would be harder on ourselves than anyone looking in. So we'll be the harshest judge of our own performance. (Director, CoRE 1)

The freedom to self-define was seen as entailing an obligation to self-monitor their performance:

We have been entrusted and boy we better reward that trust. Show that that trust was worthy. (Director, CoRE 1)

For instance, individuals were asked to leave the CoRE if they were not producing at the required level of excellence. In all eight participants discussed CoRE 1's ability to define its own objectives as linked to its capacity to self-monitor in this way.

A final aspect of CoRE 1's ability to lead and self-define was discussed as lobbying with government more broadly (as opposed to simply within its relationship to TEC). For example:

Why back to Wellington? Because this is about political process....there's an element of politics here. It's about showing that there's impact...making that argument [to government] that individually as world-class research groups we have a certain amount of clout but put together in a network in a partnership like [CoRE 1] we have a huge amount of international clout. (Director, CoRE 1)

Being active at this policy level was mentioned by eight participants.

Expanded vision. Having expanded objectives beyond funding research excellence was central to how CoRE 1 saw themselves: 
I remember [the director] saying 'we've got to tick every one of these boxes'...the first set of criteria was pretty high and we set out to tick all the boxes. (Chairman, CoRE 1).

Part of this is saying 'okay excellent science is absolutely vital to what we do. But it's only part of the story. And in a way it's the least interesting part.' It's probably the hardest part to get right but the interesting part is the added value around that. So then it becomes things like culture change. (Director, CoRE 1)

A determination to "be the best" (again to quote the Chairman) was behind CoRE 1 leading the way (as above). However, it was also connected to CoRE 1 setting themselves an expanded set of objectives. The majority (ten of twelve) participants explicitly described CoRE 1 in this way: an expanded vision was part of what defined CoRE 1. Rather than involving an overarching singular objective as such, this involved the embracing of an expanded view of science and its role.

An expanded vision was accepted as central to CoRE 1 from the start:

There were very clear expectations of that from the time that [CoRE 1] was established. And I think that that certainty has been embraced by the PIs in the Institute...the rationale for the [CoRE 1] was that it would do these things...it was perfectly clear to us in constructing this bid that there had to be more than science excellence. (PI, CoRE 1)

This vision was personified and communicated in stories and in the individuals or names associated with the organization. At least 5 interviewees conveyed this:

The other driver was [famous scientist] himself who was an inspiration for many of us. His name is behind the [CORE]. [He] was an active communicator of science...So in a sense we saw the power of that kind of activity within science... We kind of had the sense of picking up his inspiration and ultimately his legacy. (Director, CoRE 1)

These objectives were reflected in how CoRE's funding and resources were managed:

We've got a large amount of money coming in. So let's make sure that we set aside a significant amount of money...to build that added dimension. (Director, CoRE 1)

It was also pointed out by six participants that the broadly defined and multi-faceted nature of this vision enabled those involved internally to have their own relationship to the fulfilment of these. For example:

There's certainly a difference in perspective. But there's generally a common goal to achieve good science in a NZ context, preferably but not necessarily of relevance to NZ. I think everyone, although they may put different emphases on it, on different aspects of it, would have those sort of general objectives. (Al, CoRE 1) 
This picture of flexibility with regards to the objectives outside of the science excellence "foundation" making up this vision will be outlined further below as a negotiation strategy.

\section{Expand what is expected (of scientists).}

Interviewer: So it's almost, because of what's given, expecting more [of your PIs]? Director: Yes, so we are a bit greedy that way. (Director, CoRE 1)

CoRE 1's capacity to lead the way and encompass an expanded vision was connected to a strategy of expanding what was expected of its PIs and scientists generally. 'Expecting more' from scientists was mentioned by 10 interviewees in relation to the CoRE's ability to meet multiple demands beyond science excellence. This involved connecting the expectations the CoRE had of the PIs to the expanded objectives:

We are not just a funding agency. We're going to change behaviours here. (Director, CoRE 1)

This ability to "expect more" and "change behaviours" was connected to the benefits and funding associated with being a PI of the CoRE:

Now [research] freedom comes at a cost. We ask them [PIs] all to - they actually have to do some voluntary service for us....we do have a requirement that they will commit to the broader objectives of [CoRE 1], which are around public communication, outreach, even in some of the industry engagement and they have to report on what they've done along those lines. (Director, CoRE 1)

We've written the rules and conditions for being a $\mathrm{PI}$ and we have a very stringent requirement for additional contribution beyond science...You don't get into this [CoRE] unless you buy into this vision and say "what are you going to do to help? What are you going to do for kids? What are you going to do about educating the public? What are you going to do about commercialization?"...The fact that you're a fabulous scientist that's nice but it's not enough." So we've formalized that more now. (Director, CoRE )

Other interviewees described this as a "tax" associated with the research funding a PI status provides.

This process was, however, identified as being more transformative than simply being a negotiated exchange for funding:

There was a change in mentality introduced with the creation of [CORE 1] in which people who were in their own isolated ivory towers...that has been transformed. (Scientist, CoRE 1) 
What the institute's doing is changing what it is to be an academic...And it's almost doing it from the inside in a positive way. (PhD student, CoRE 1)

This focus on transforming academic scientists suggests the strategy is one of transcension.

\section{Entwining within existing system.}

Let's own nothing and employ no one. ( Director, CoRE 1)

A strategy of becoming part of, rather than being distinct from or in competition with, the existing system was outlined as directed predominantly at the CoRE's partner organizations. It can be described as a strategy of embracing the diffused power context. Expanding on the introductory quote above, this strategy was outlined as manifested in decisions regarding the ownership structure:

The approach of the Institute that it employs no-one and owns nothing helped a great deal in terms of breaking down the barriers. (University Science Department Manager, CoRE 1)

We are going to be organisation that owns nothing and employs no one. What is the effect of that? It means you approach this in a different way. You say we are building a partnership here. That partnership comprises of institutions. The problem is that there have been institutional rivalries...There's naturally going to be suspicion. If we have a brilliant idea who owns the intellectual property? Not us. Who will own it? You [the universities] will own it...PI's in our [CORE] have employment contracts with [their various institutions]. None of that is going to be perturbed in the slightest. (Director, CoRE 1)

Lack of "ownership" was central to CoRE 1 being seen as entwined within and part of its partner organizations. This strategy of entwining itself within the existing system was outlined by 7 interviewees. While it was the least densely coded strategy it was also explicitly reiterated as a strategy in three secondary data documents.

An additional component of this strategy was developing ambiguous rather than clearly defined boundaries:

We are wanting to enmesh ourselves and entwine ourselves into the whole organ of the RS\&T environment. Because the more we are enmeshed in everything, the more successful I think we are as an Institute. We don't want to separate ourselves out and say "this is us and this is what we do and we're competing with everything else." We want to show how things can be done collaboratively and within all the other funding schemes and agencies within the system. (Director, CoRE 1) 
By far the strength of this [CORE] is that we are...not defined. We cross over a lot with the [particular department/school] because we work together....There's a blurry line and long may it stay blurry. Because immediately once you say "this is what you do. And there's the line" we're in trouble, because that's not how this [CoRE] works. (Administrative manager, CoRE 1)

Becoming part of rather than competing with the existing system enabled CoRE 1 to manage the demands of those stakeholders and help determine their relationship to them. The relationships were transformed from one of an external stakeholder (i.e., a partner organization) making demands on CoRE 1, to the partner being more likely to see its own success entwined in that of the CoRE's. This shifted the debate from being about institutional interests to a broader sense of shared ownership.

\subsubsection{Negotiation}

Two negotiation strategies were evident in CoRE 1 . The first involved partially adapting to some legitimacy demands. The second involved enabling multiple stakeholders to be represented in decision making. Both remained inclusive of multiple objectives but were more adaptive and less focused on transformation than the transcension strategies above.

Managing the periphery through maintaining a balance. In CoRE 1, science excellence was discussed by the participants as the centre around which the periphery (other legitimacy demands such as commercialization and outreach) was balanced. For example:

At the hard core of [CoRE 1] there is this matter of science quality. (Director, CoRE 1).

This managing of the periphery strategy also explicitly incorporated 'balance' as a central to enabling this. A balanced approach to the incorporation of additional demands helped avoid detracting from the CoRE's research excellence. This balance in relation to the "hard core" was also outlined as enabled by a flexible trial and error, rather than fixed or dogmatic, relationship to these additional demands. However, similarly, maintaining 'balance' reflects how incorporating these multiple objectives was accepted (as discussed above). This strategy was outlined within ten interviews.

Firstly, this strategy was explained in terms of maintaining a balance: avoiding imbalance in relation to the science foundation. This is highlighted below: 
[the Director] managed to give the different emphases the right proportion in the [CoRE]. Say "look we are not going to become an Institute of Management...we are not going to become an educational institution doing outreach all the time, we are not going to become a business generator with people spinning off companies every week. Our mission has got to be the science...The rest has to be there in its right proportion. I think that's the right approach. You don't want to be concentrating only on one topic. But you don't want to be doing everything because it's then unrealistic...But you have to do some of it in the right proportion. ( $\mathrm{PI}, \mathrm{CORE} 1)$

Where other CoREs have got into problems is where they have gone out and they've stretched the boundaries too far...long term the activity might have been to support excellence but....perhaps [it] did not require that excellence to be the key reason for why you are doing something. So that's quite important that we hold on to that. (Director, CoRE 1)

Partially adapting to rather than over-emphasizing demands beyond research excellence enabled this balance:

Asking people to think harder about what commercial applications might come from their work has been healthy enough...that hasn't been a problem. But because all these people are scientists first and foremost they haven't spent huge amounts of time chasing commercial applications as opposed to doing good science...it's dangerous for CoREs....to chase commercialisation too hard. (University manager, CoRE 1)

As long as that [CoRE activities outside research] takes up a reasonable amount of my time - say 25 percent of my time - then its fine ( $\mathrm{PI}$, CoRE 1 )

Second, important to enabling this capacity to balance the 'periphery' was having a flexible and "not defined" relationship to demands outside research excellence. Balance was contained in promulgating stories regarding many different activities that did not over-emphasize any one area of "relevance." This was observable in both the interviews and CoRE newsletters. Parity between these different activities geared at responding to the demand for relevance meant overemphasizing on any one element in relation to other objectives was avoided, for example, spin-outs or outreach with schools. This is connected to their approach of ticking "every one of these boxes." Through this multifaceted approach CoRE 1 could flexibly demonstrate its relationship to different non-science related demands as required:

We don't have formal objectives around engagement with industry. We don't say "we need at least ten people doing twenty visits with industry." We let some of those things fall where they lie. We did at the start, have a plan on having an [event] every two years. But that fell over...so we just let that go into a "happen naturally" mode. (Director, CoRE 1)

That's [emphasis on commercialization] waxed and waned...it was a strong focus of the 
original bid. Then followed the realisation that commercialization wasn't going to be straight forward. (University department manager, CoRE 1)

Different legitimacy demands (e.g., commercialization) were in this way flexibly incorporated in relation to the research foundation of the CoRE rather than dogmatically demanded. Importantly, this trial and error approach meant CoRE 1 was able to adapt its emphasis as the success or otherwise of different endeavours became evident. Further, at the PI level the CoRE's multifaceted and balanced approach to relevance based demands meant they could then find individual way of contributing. This enabled them to balance this in relation to their research and interests rather than it impacting negatively or being all-consuming at the individual level.

In summary, CoRE 1 incorporated a combination of elements indicative of negotiation here: a flexible balance developed through adapting partially to some legitimacy demands. This enabled different objectives to be incorporated in a way that did not adversely impact research excellence but instead moved around it.

\section{Democratic partnership: "Organ of democratic power."}

Where does the power lie? It's not the director. The Director's role is to provide leadership, not exercise power...You have to carry people with you by having this democratically elected group that actually made the decisions. (Director, CoRE 1)

Interviewees reflected on the use of democratic principles of representation and inclusion as exemplified in the quote above. This 'democratic partnership' was identified as a strategy by nine interviewees. It involved embracing the diffused nature of its stakeholder relationships and emphasized providing stakeholders with a voice and involvement in CoRE 1's decision making. It provided a space within which the different PIs and partner organizations involved could negotiate. It was consequently defined by an inclusive impulse (integration) as well as being responsive (rather than focus on selfautonomy or manipulation). As well as being reflected in representation-based structures, this strategy was also outlined in terms of foundational values of partnership and fairness that defined the CoRE:

The values of [CoRE 1] are: partnership, collegiality, equity, fairness, transparency. (Director, CoRE 1) 
These values were also explicitly reiterated in various reports and newsletters associated with the CoRE (Table 5.1). They are indicative of a sense of fairness enabling the give and take required for effective negotiation.

A focus on representation was outlined in relation to both the partner organization and PIs. The CoRE's board was built around balanced representation from the partner organizations and the CoRE's decision-making body was an elected body of Pls from different parts of the CoRE. These structural elements were confirmed in the CoRE's website. The effect of this representational structure in relation to the PIs was outlined:

Another thing is our [decision making body]. It's an elected body...and that manages the way we spend our money...The fact that it's elected and we try and maintain a balance between the different institutions and it's fairly transparent, by and large everyone gets an opportunity to be involved in it, and it lets people buy-in. It's a mechanism by which you feel connected. (Director, CoRE 1)

This connection between balanced representation at the board level and the ability to foster a greater feeling of connectedness to CORE 1 was also reported in relation to the partner organizations:

Having a representative at the board ensured that [my organization] at the management level has a continued interest. So I think it was a very positive thing. Otherwise...by now [my organization] might have said "are you making enough money from it. If not. Then that's not in our strategic interest." But being a true fully recognised member puts a different spin on it. (PI, CoRE 1)

This quote is indicative of the link (Figure 5.1) between this negotiation strategy and the transcentive strategy, outlined above, of the CoRE entwining itself within the system.

At the PI level, these democratic structures and practices fostered acceptance by internal participants of decisions made. As the Chairman outlines: "there's ownership by the group itself" even in the face of tough decision regarding, for example, asking some PIs to leave the CoRE. These decisions were negotiated by the group:

They [review panel] suggested..."look sooner or later you're going to have to say goodbye to people...Why don't you set up some kind of small group so that when the time comes it's not seen as being these bad guys [management] up there? (Chairman, CoRE 1)

Behind these democratic systems was an ethos of inclusiveness and fairness rather than being dominated by a single voice: 
[Our] governance board has representation from those major partner organisations. So there is a forum for those organisations to have their voices heard...[It] isn't controlled in a majority of one or any of the partners...it has to be consultative. (Director, CoRE 1).

Then there's the thing about the story telling. We'll be meticulous about when we are telling stories to give credit to everyone...And we make absolutely certain that [the host] is not dominating this....we make sure we tell a story about everyone so that no one story is missed out. (Director, CoRE 1)

Transparency and open communication was also important as a way of helping foster those values of inclusion and fairness central to this strategy:

I felt valued because people were communicating with me...In some ways because they were virtual and they realised that they would have this problem of engaging they focused on it and it became one of their best features. (PhD Student, CoRE 1)

CoRE 1 fostered underlying values that enabled an active forum of negotiation between multiple stakeholders. It was based on the ideas of balance representation this strategy entailed, something central to discussions of negotiation. This fostered a sense of fairness and assisted in breaking down strong distinctions of "them" and "us" between the CoRE and its stakeholders. In this way this negotiation strategy was strongly associated with the strategy of 'entwining within system' transcension strategy (Figure 5.1). This strategy, along with the other sub-themes surfaced, is depicted in Table 5.1. 
Table 5.1 CoRE 1 legitimacy strategies: Summary ${ }^{22}$

\begin{tabular}{|c|c|}
\hline Strategies & \\
\hline & $\begin{array}{l}\text { Summary of CoRE } 1 \text { data-set } \\
\text { Interviewees: } 35-47 ; \text { Transcribed data: } 722 \text { minutes } \\
\text { External stakeholders [ES]: } 56,58,61,62 . \\
\text { Secondary data [SD]: CoRE } 1 \text { SD } 1-19\end{array}$ \\
\hline \multicolumn{2}{|l|}{ Transcension } \\
\hline $\begin{array}{l}\text { Leading the way } \\
\text { (self-defining) }\end{array}$ & $\begin{array}{l}\text { Interviews: } 17 \text { interviewees }[35-37,39-45,47, \text { ES: } 56,58 \text {, } \\
\text { 61; CoRE } 2 \text { interviewees: } 48,51,54] \\
\text { Coding density: } 67 \text { separate data segments. } \\
\text { SD: CoRE } 1 \text { SD } 1-3,7,8,11,12,14,16 ; 19\end{array}$ \\
\hline Expanded vision & $\begin{array}{l}\text { Interviews: } 11 \text { interviewees [35-39; 41-43, 45, 47; ES: 58] } \\
\text { Coding density: } 49 \\
\text { SD: CoRE } 1 \text { SD 1,3, all newsletters (especially 10, 12-13, 20) }\end{array}$ \\
\hline $\begin{array}{l}\text { Expand what's expected } \\
\text { (of scientists) }\end{array}$ & $\begin{array}{l}\text { Interviewees: } 9 \text { interviewees [35-39, 41, 43, 45, 47] } \\
\text { Coding density: } 31\end{array}$ \\
\hline Entwining within system & $\begin{array}{l}\text { Interviews: } 7 \text { interviewees [35-40, 45]. } \\
\text { Coding density: } 19 \\
\text { SD: CoRE } 1 \text { SD } 1,3,13\end{array}$ \\
\hline \multicolumn{2}{|l|}{ Negotiation } \\
\hline $\begin{array}{l}\text { Managing the periphery } \\
\text { through maintaining balance }\end{array}$ & $\begin{array}{l}\text { Interviewees: } 10 \text { interviewees [ } 35-40,43,45,46 \text {; ES: } 62] \text {. } \\
\text { Coding density: } 46 \\
\text { SD: CoRE } 1 \text { SD } 8 \text {, } 17 \text {. Flexible balance also evident in } \\
\text { newsletters more widely. }\end{array}$ \\
\hline Democratic partnership & $\begin{array}{l}\text { Interviews: } 9 \text { interviewees }[35-38,41,43-45,47] \\
\text { Coding density: } 35 \\
\text { SD: CoRE } 1 \text { SD } 1-3,5,13,18 \text {, CoRE website. }\end{array}$ \\
\hline
\end{tabular}

\subsubsection{Less Prevalent Strategies}

Compartmentalization. A degree of compartmentalization was discussed in relation to a strategy of "expanded objectives." PIs were able to focus on particular things depending

\footnotetext{
${ }^{22}$ The numbers reflect the code given to each interview and secondary data document. The codes are provided in Tables 3.4 and 4.5 .
} 
on their own personal interests and strengths. This enabled a degree of segregation at the individual level:

That's the whole thing underpinning science: let people follow where they want to go...you can create that within the [CoRE]. Just let people do what they do best. But increase the metrics (PhD student, CoRE 1)

Six interviewees (across nine separate data segments) discussed this element of enabling PIs to isolate particular CoRE objectives.

Contraction. Contraction was not evident with the strategies centred on achieving multiple objectives and inclusion of multiple stakeholders. For example, even though the compartmentalization strategy above outlined that individuals can separate themselves from some legitimacy demands placed on the CoRE, such as commercialization, the requirement for PIs to contribute in some way beyond a contracted focus on science excellence remained.

\subsubsection{Assessments of Strategies and Legitimacies}

I really do look at how [CORE 1] handled things as a model for how we can manage relationships between the different players in the science sector. (Director, CoRE 1)

Exploring the assessment of the strategies engaged in CoRE 1 was relatively unproblematic: there was wide-spread recognition regarding the success of CoRE 1 generally and their legitimacy strategies specifically. This included external stakeholders and interviewees from CoRE 2. For example, participants in CoRE 2 referred to some CoRE 1 strategies, such as the expanded set of objectives, as ones they would like to emulate. Similarly, the secondary data used terms such as "exemplar."

Seven participants directly connected their positive assessments of CoRE 1 approach with its embracing of pluralism. For example:

It's almost that by setting itself these broad objectives that that was why people responded positively to it. (PhD student, CoRE 1)

Positive assessments were not solely focused on the transcension strategies. Explicitly positive comments, for example, regarding the democratic partnership strategy from PIs 
and directors, are evident in the relevant section above. Participants also outlined the success of the negotiation strategy of maintaining balance:

The balance we have achieved in [CoRE 1] at the moment looks to be pretty close to the ideal. I think that if you move too much into doing more outreach or trying to excel in areas that are not our - management areas and things like this - we would probably start spreading ourselves too thin. (Scientist, CoRE 1)

The closest any stakeholder came to expressing a less positive assessment regarding the strategies was the university manager who considered the democratic partnership strategy to sometimes be more problematic from the university host's perspective than if decision making had been more closely tied to the host. However, the university manager simultaneously acknowledged the benefits of this strategy more broadly.

\subsubsection{Summary: CoRE 1}

This discussion of CORE 1 has outlined multiple legitimacy strategies of transcension and negotiation. These strategies were assessed positively by stakeholders involved. CoRE 2 will now be outlined and provides a different strategic picture.

\subsection{CoRE 2: Legitimacy Strategies}

The strategic story of CORE 2 was told in a temporal fashion by the interviewees. This was evident to the degree that one interviewee differentiated the CoRE through two labels: "CoRE 2 - One" and "CoRE 2 - Two." Stage one is dominated by a 'contraction' strategy: focusing on and excelling at research excellence. Stage two is one of 'negotiation' as the CoRE reaches compromises with its stakeholders regarding meeting additional legitimacy demands. These strategies are represented in Figure 5.2 and will be discussed below adhering to the temporal sequence. Despite this shift in which

strategy was 'dominant', the two strategies also overlapped through aspects of both being evident during each phase. 
Figure 5.2 CoRE 2: legitimacy strategies

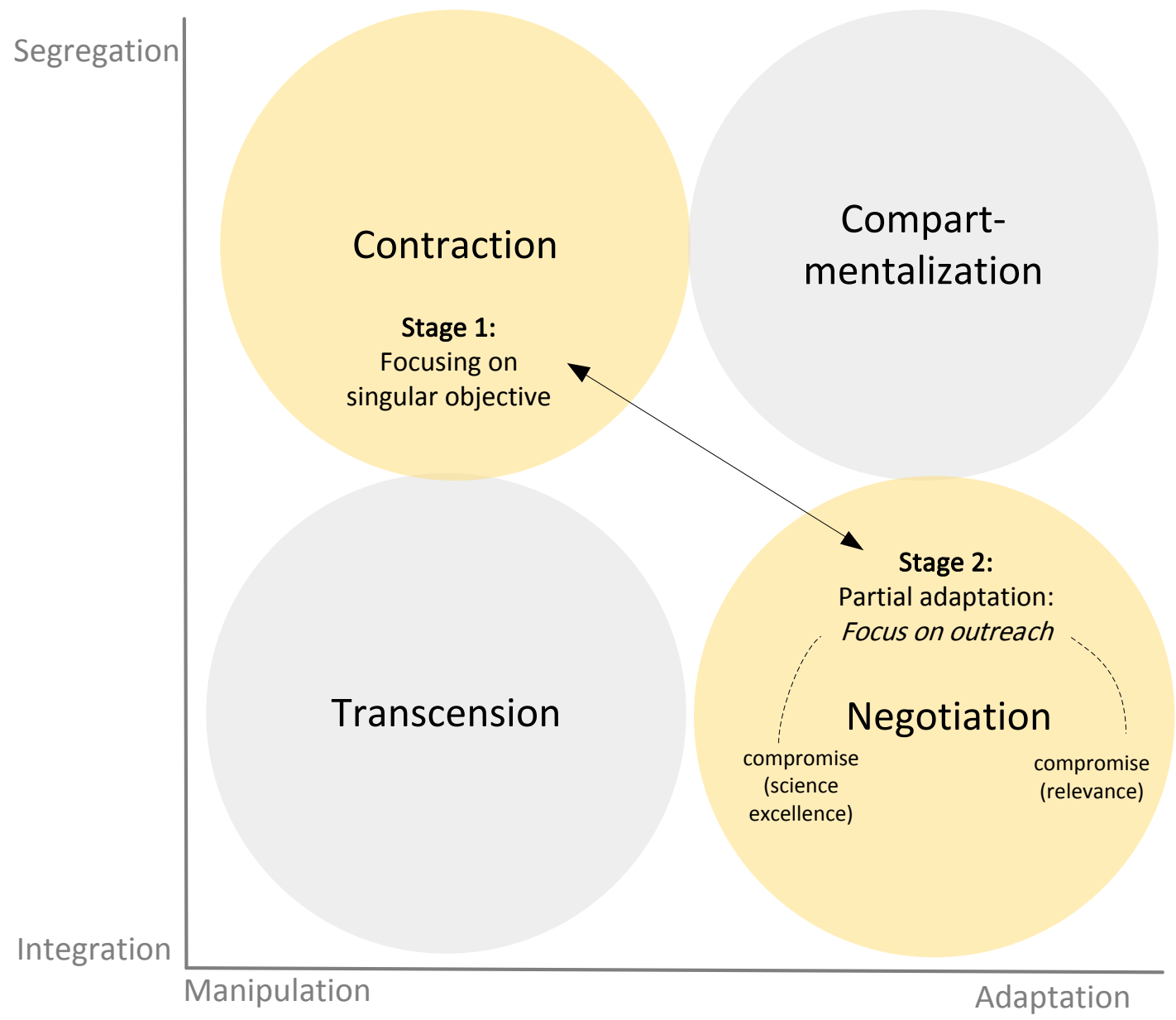

\subsubsection{Contraction}

\section{Stage 1: Focusing on singular objective.}

People just thought "bugger it." A lot of the time we get signals from the government that we should change this or change that and then they get reverted. So people do get a bit wary of "well there's this signal so we should do this fad or we should do that fad. (PI, CORE 2)

A strategy reported in CORE 2 was to focus on a single objective, while ignoring additional demands (e.g., outreach or industry engagement). This was highlighted by all CoRE 2 participants. This was also reflected in the secondary data where a strong focus on research excellence was exhibited early in the CoRE's history and additional objectives were only slowly introduced. For instance, in an early annual report the incorporation of additional objectives ("relevance") was explicitly argued against by the CoRE's then Chairman. This strategy is defined as contraction due to its focus on limiting pluralism. Ignoring stakeholders illustrates the lack of adaptation in this strategy. 
Participants portrayed this strategy as both a matter of misunderstanding the multiple legitimacy demands directed at CoREs and purposefully resisting these other legitimacy demands. This second point is expanded on:

We've attempted to just keep our heads down and just focus on the research because that was the primary thing. (Director, CoRE 2)

This was reflected in CoRE 2's initial budgets which were reported as focused primarily on research:

It (outreach) was a sell job. A lot of the work I did with [outreach activities] wasn't funded. There was no money coming from the CoRE. (Administrative Manager, CoRE 2)

I tried to partition the budget in such a way that the amount available for basic research was sacrosanct. (Director, CoRE 2)

Interviewees linked this strategy to assumptions that excelling to such a degree at "research excellence" would assist in the ability to maintain a unitary focus; for example:

So what they are doing is creating a reputation in one area that is inarguable on their strengths to bide time to build up their weaknesses. (Industry Observer)

This was made explicit by a Director who told the story of how they only decided to put in a CoRE 'bid' once they realised that science-based assessments of these applications would not be "thrown away" after "step 1" of the selection process. Instead, their strength in this regard was "carried forward" providing a buffer to assessments based on other objectives such as industry engagement (the second step in the selection process). He continues:

Then we knew we were in with a chance [when they saw the focus on excellence in the first selection round], because our work is aimed pretty much on the scientists finding really good ideas and trying to be effective. (Director, CoRE 2)

The perception that they were the most successful CoRE in terms of the research excellence objective (something reiterated by 5 interviewees) was connected to expectations that they would have capacity to marginalize government's other legitimacy demands. For example:

It [the requirement to meet other objectives at re-funding round] was a bit of a shock to the group within [CoRE 2] because the excellence of the science, it was just absolutely blinding. (CoRE 2, University Manager). 


\subsubsection{Catalyst to Change}

The university manager's point that CoRE 2 got " $a$ shock" regarding the re-funding round helps illustrate the transition into the negotiation strategy becoming dominant. Contraction in a context where government clarified its demands beyond science excellence and where other CoREs pursued multiple objectives became less sustainable. While the CoRE had initially resisted pressures, a change in strategy was eventually required through the crisis associated with their re-funding:

I think we were the next to be cut...our inability to respond to those changes was reflected in what happened to us...Ironically, in the beginning we were the most successful. But then by the time the six years came round [re-funding] we were second to last because we didn't respond. I think the directorship didn't see those signals coming. And even if they saw them coming didn't want to respond to them. They wanted to do what they wanted to do... [there was] really an inability to focus on anything other than what it was originally formulated as. (PI, CoRE 2).

CoRE 2's contraction strategy had focused them on a single legitimacy demand while not addressing the diffused power context they faced. The ability of external stakeholders to exert their legitimacy demands had not been mitigated. In this way the quote above highlights the catalyst to incorporating an additional strategic response of negotiation. As the PI continues: "whatever has happened [in terms of strategy] has been a crisis type thing."

Nonetheless, this additional strategy did not completely replace contraction efforts. An increased focus on negotiation was still conducted in combination with some Pls and Directors still pursuing a strategy of contraction. For example, this was evident in the interviews with two directors and reported in relation to some in the wider PI group.

\subsubsection{Negotiation}

\section{Stage 2: Partial adaptation.}

You only have to look at them [CoREs] to see that they are asking them to be all things to all people at all levels...And when you look at the dollars that were thrown at them in the very first place it's actually an unreasonable ask. So they will fail in some areas and be excellent in other areas. Being excellent: you can't be excellent across everything at all. You just can't. So you'll see some areas where they are not as good as they could be and others where they are superb. (Industry observer) 
The quote above illustrates the importance of negotiation for CoREs, fulfilling some demands partially rather than fully in an adaptive (rather than manipulative) relationship with external demands. In CoRE 2 this was engaged in internally through communicating the necessity with the PIs regarding compromising the sole focus on research excellence with the PIs. Second, partial adaptation took place with regard to external constituents with a negotiated compromise regarding the "relevance" based requirement taking place. As per the definition of negotiation, and in comparison to the contraction strategy above, this process was integrative in attempting to include, at least partially, all stakeholder demands.

These strategies are reflected in the increased resources and energy that were put into outreach, something which covers a large range of activities from engagement with schools, Maori and local organizations and groups, to science communication more generally. This was evident in the interviews and confirmed by the budgets displayed in CoRE 2's annual reports. While this strategy became more obvious within "stage 2" of the CoRE's strategic lifespan, negotiation regarding additional non-research related legitimacies were reported even while the dominant strategy was contraction. This is shown in the annual reports, for example, and shown in the following quote regarding the necessity of negotiation with regards to compromises within the budget:

Each year you prepare a budget which has all the money going to the investigators and the other things that have to be funded. There was quite a discussion around "why is that much going to Outreach?" and you would have to negotiate it with the entire investigator group. (Administrative manager, CoRE 2)

In short, while a primary focus on "contraction" and "negotiation" represent different phases in the organization, these also overlapped to a degree.

Compromising research excellence (internal stakeholders). The compromise reached within the CoRE was not so much explicit bargaining with the scientists involved but rather recognition that this was a necessity (linked to the CoRE's survival and crisis point) by those involved. These compromises were recognized as a reality that PIs had to accept if they wanted to continue to be part of the CoRE and receive the associated research benefits. This compromise was talked about in terms of an increased focus on a range of outreach activities by a PI: 
There's quite a compromise, some of the sort of outreach stuff we might have to do, some of the actual research we might do...it's not the sort of stuff that I would be particularly focused on normally. So you've got to make a compromise and say: "will I be part of this and involved with this perhaps as less of a focus...but there's still benefits to being there." (PI, CORE 2)

It's about focus. It's about "this CoRE started out this way. But it's going to end up this way. Do you still - one - want to be part of it? And two, can you still be part of it and do what you want to do? Can you recognise that there are these changing things and that you have to contribute to those? There were certainly people - I know - who left who said "I don't want to do that." (PI, CoRE 2)

In having "signed up for" the CoRE under the premise of a unitary emphasis, some scientists did decide that they could not compromise.

This strategy also involved prompting new conversations with Pls aimed at illustrating links to broader questions of relevance as a way of managing this compromise. " $A$ /l it needs is a wee bit of stimulus", a board member outlined:

The other issue or questions we've been [focused on], is scientists being aware...that outreach is critical for them...we're putting a lot of emphasis on that at the moment. (Board member)

This process was one of the CoRE communicating the necessity of new multi-objective compromised reality and linking this to flexible balance between performance measures rather than a sole focus on science. The experience of these changed performance measures are discussed below:

The focus has very much changed from [the beginning] in that it's become "we have to be seen to be doing something in society." And, the focus has almost just completely gone onto how we outreach onto society. By that it means: are we giving public talks, are we organizing school trips, are we engaging local [...] organizations and local Maori...And that's a sort of an attempt: "look at how we justify our existence." To me, and to most people, it's always been about science excellence. (AI, CoRE 2)

While this "compromise" was felt strongly by the scientists (as in the quote above), it was generally perceived as a partial adaption rather than dominance by objectives outside science excellence. Namely, the CoRE retained a science-centric vision of relevance:

You can't forget your main game [science excellence]...But I don't think it's unfair to expect us to go beyond sitting at our lab benches writing papers. (Director, CoRE 2)

This limiting of the relevance-based objectives is discussed further below. 


\section{Negotiating a restricted view of relevance.}

Most people would realise that in the area that we work in, that [sector transfer] is unrealistic ...The government has certain expectations of the CoRE, I think there are five of them. That is one of them. I don't think we would consider that we are very strong in that and we don't have to meet all of them. (PI, CORE 2)

As the above quote indicates, the type of objectives beyond science excellence that CoRE 2 was required to meet was to a degree restricted (i.e., partially responded to) by the CoRE. Combined with an increased focus on the government's objectives beyond research excellence (which has helped restore their relationship with government), CoRE 2 worked to negotiate a partial version of this. This was done through engagement with its government stakeholders.

A component of this strategy was fostering a better relationship with TEC through utilizing its more active engagement with outreach. CoRE 2 had become active in engaging with TEC around its fulfilment of their legitimacy demands:

[CORE 2 has] being going through some reorganisation....and [the director] rings me almost every two or three weeks to have a conversation about what they are doing. (TEC manager)

This increased direct engagement with TEC was also recognized by a director and board member.

Through this increased engagement with the legitimacy demands of government, CoRE 2 also actively sought to limit the conception of the form of 'relevance' that was expected. There was recognition that CoRE 2 was not going to contribute directly in an economic sense:

I'm not aware of too much drive for them in terms of the economic side of things. I think it's been much more awareness raising...a social driver. The social driver being getting young people inspired by the work that they're doing...It's about trying to achieve a sensible balance. (University manager, CoRE 2)

We don't have expectations of producing spin-off companies, that's just not what [we] do. (Director, CoRE 2)

From TEC's perspective they still felt that their demands had been responded to. For example: "they're going to develop an Outreach program...So that's something [...that] has developed over the last, best part of a year." However, they were happy with CoRE 2 
restricting the degree of that adaptation: "it's not high-tech commercialisation stuff." This was a continuation of the strategy of arguing away the "economic" observable in CoRE 2's earlier annual report (e.g., CoRE 2, SD 4).

That this strategy involved a potentially tenuous compromise that will need to be renegotiated in the future was also evident:

The...three pillars of the National Government...are the economy, society and the environment. And so the [CORE 2] decided that the environment, this is [CoRE 2, Phase Two] that the environment and social aspects are the areas which we may be able to gain the most traction. I of course think that's a mistake...fundamentally we miss out of the importance we can bring to the economy...that might be a problem later on... I think it's a big gap. (AI, CoRE 2).

I bet if you tried to get more money for CoREs now they would be right down that path of "show us how this is going to deliver in terms of economic impact for NZ. (Public Sector Manager).

The scientist above was, however, the only CoRE 2 interviewee who perceived this negotiated compromise as being inadequate in terms of meeting government's demands for relevance.This strategy and others outlined above are summarized in Table 5.2 . 
Table 5.2 CoRE 2 legitimacy strategies: Summary

\begin{tabular}{|c|c|}
\hline Strategies & \\
\hline & $\begin{array}{l}\text { Summary of CoRE } 2 \text { data-set } \\
\text { Interviewees: } 48-55 \text {; transcribed data } 516.5 \text { minutes. } \\
\text { External interviewees [ES]: 56; 58; } 61-62 \\
\text { Secondary data [SD]: CoRE } 2 \text { SD } 1-19\end{array}$ \\
\hline \multicolumn{2}{|l|}{ Contraction } \\
\hline $\begin{array}{l}\text { Focusing on singular } \\
\text { objective } \\
\text { (excelling at it) }\end{array}$ & $\begin{array}{l}\text { Interviewees: all participants [8]; ES: } 58,61,62 \\
\text { Coding density: } 66 \text { separate data segments. } \\
\text { Secondary data: Annual reports and newsletters confirm strong } \\
\text { initial focus on research [CoRE } 2 \text { SD } 1-5 ; 9-12 \text { ] }\end{array}$ \\
\hline \multicolumn{2}{|l|}{ Negotiation } \\
\hline $\begin{array}{c}\text { Partial Adaptation } \\
\text { (incorporating an outreach } \\
\text { focus) }\end{array}$ & Coding density total: 67 \\
\hline $\begin{array}{l}\text { Compromising research } \\
\text { excellence } \\
\text { (internal stakeholders) }\end{array}$ & $\begin{array}{l}\text { Interviewees: } 6 \text { interviewees }[48,51-55] \\
\text { Coding density: } 29 \\
\text { SD: CoRE } 2 \text { SD } 7-8 \text { outreach budgets; mention of additional } \\
\text { objectives in earlier reports [SD 36]; increased focus on } \\
\text { demonstrating relevance in newsletters [CoRE } 2 \text { SD 11-19]. }\end{array}$ \\
\hline $\begin{array}{l}\text { Negotiating a restricted view } \\
\text { of relevance } \\
\text { (external stakeholders) }\end{array}$ & $\begin{array}{l}\text { Interviewees: } 11 \text { interviewees [48-49, 51-55; ES: 56, 58, 61, } \\
62 \text { ]. } \\
\text { Coding density: } 42 \\
\text { SD: All [CoRE 2, SD 1-19]. Economic development/industry } \\
\text { either discounted; or not included. }\end{array}$ \\
\hline
\end{tabular}

\subsubsection{Less Prevalent Strategies}

Compartmentalization. There were isolated instances where compartmentalization was mentioned. However, it was not highlighted to the extent of being the central strategy. Two interviewees mentioned separating 'management' from 'research':

I went to the Directors...and said "look, you guys got funded for this because you have an excellent research background...You guys carry on with your research...I'll manage, you guys research. (Administrative manager, CoRE 2)

A university manager, meanwhile, described how CoRE 2 attempted to separate itself from the host, but this was a strategy that had not been realized:

Although the original intention...was to try and have it significantly isolated [i.e., 
separated] financially, in reality that hasn't occurred. (Director, CoRE 2)

Transcension. There was little evidence that CoRE 2 had been able to transcend the tensions between its stakeholder legitimacy demands. The following quote is indicative:

It's very hard to find somebody who can rise above all those personal agendas. (AI, CORE 2)

One isolated example was three participants providing an example of transcension in connection to the conferences and "big events" organized during phase 1 of CoRE 2. The following reflected a desire to move beyond current compromise in reference back to that recalled experience:

Whereas in [CoRE 2, phase 2] there's no big ideas like that [larger conference] about let's get out there and get this other thing happening...It's sort let's give some school talks, sort of do this, it's very...[CoRE 2] had some big thinking ideas and now it's got lots of piecemeal small thinking stuff. (AI, CoRE 2)

Similarly, a manager outlines an envisaged strategy for CoRE 2 as one of moving past negotiation:

You won't have to negotiate because the stakeholders believe in you...You stand on your own soap box and you tell them. (Administrative manager, CoRE 2)

These discussions of desired transcension suggest recognition of the current lack of such a strategy.

\subsubsection{Stakeholder Assessments of Legitimacy Strategies}

The above story leads into the overview of stakeholder assessment of the strategies provided in Table 5.3. A scientist provides an overview that illustrates the sharp distinction between how CoRE 2's strategies were perceived in comparison to CoRE 1 : "in terms patterns of behaviour I just see us repeating the same mistake over and over again." The overview in Table 5.3 shows that a mix of both positive and less positive (even negative) stakeholder assessments of CoRE 2's strategies. 


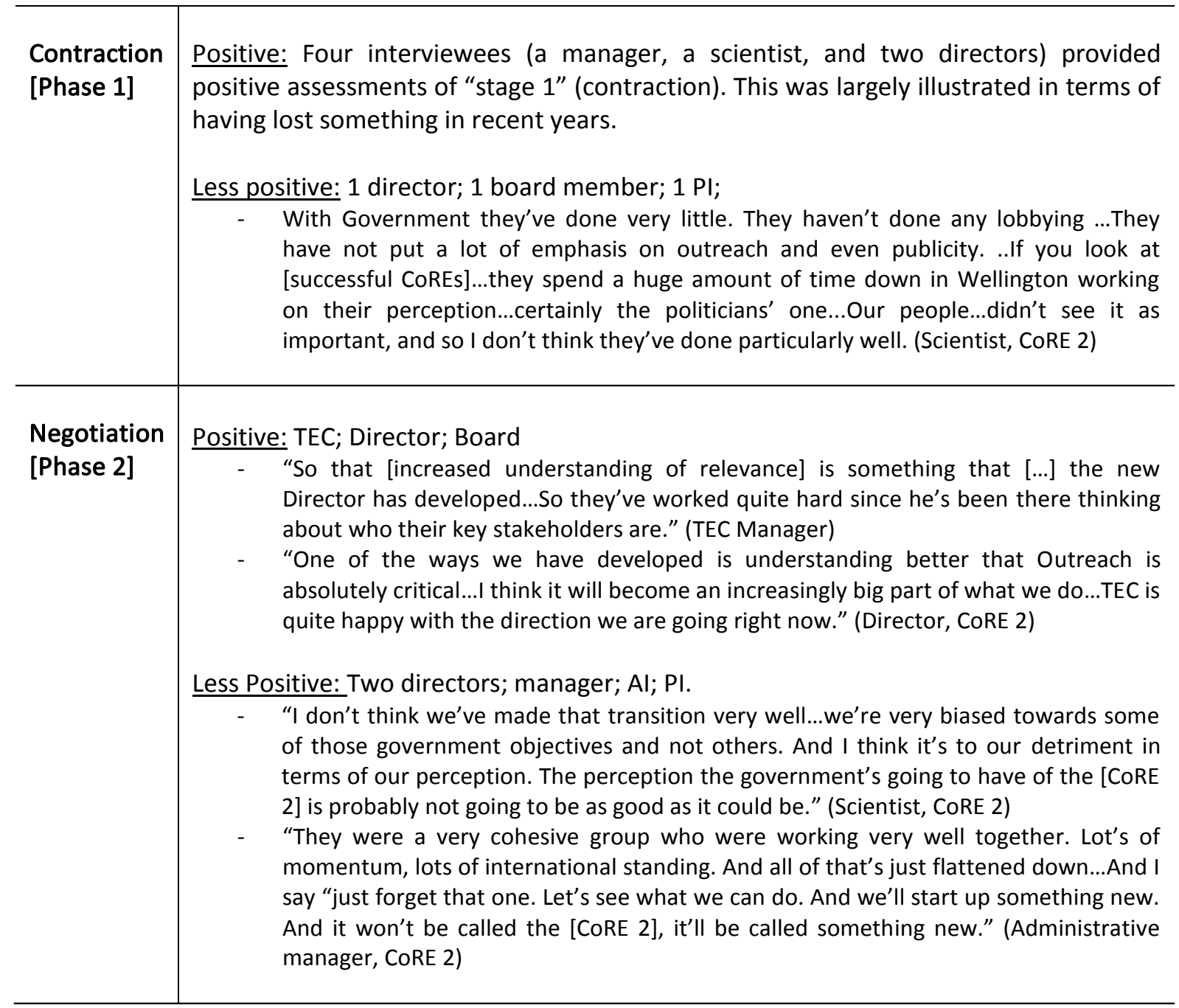

\subsubsection{Summary}

A final point of note regarding the above analysis is that not every tension identified as affecting CoRE 2 (Chapter 4) was addressed with strategic action. Specifically, a strategy directed at the divergence between collaboration and competition was not reported. This lack of strategic attention coincided with CORE 2 experiencing this tension comparatively more strongly. This perhaps hints at a lack of strategic focus exacerbating the perceived divergence between objectives. For example, CoRE 1 more actively managed the collaborative/competitive tension (Section 5.1), which may be linked to the divergence between these elements being perceived as lower in comparison to CoRE 2. 
Two main strategies of contraction and negotiation have been outlined in relation to CoRE 2. Stakeholders held varied assessments of these strategies, which contrasted with the broadly positive assessments outlined in relation to CoRE 1 . Having discussed the two CoREs, the strategies implemented by the CRIs will now be presented.

\subsection{CRI 1: Legitimacy Strategies}

It's all about this [participant indicates overarching 'why' in the diagram he had drawn]. Because you can easily disagree with the 'what' and 'how.' If you start down here "how we are going to do this is this?" "No - I disagree." You've got to get agreement at this [higher] level. So why are we doing this? To create wealth and prosperity for NZ. (Board member, CRI 1)

CRI 1's 'strategy story' was one of transcension and negotiation (Figure 5.3). The quote above illustrates this relationship between transcension (defining 'the why') and negotiation (flexibly navigating a balance concerning the 'what' and 'how'). The data are focused on CRI 1's strategies at the time of the interviews; however, a sense of moving forward (that is, leaving past strategies behind) was evident in the discussion of these current strategies. The reported past configuration of objectives by CRI 1 is used as part of understanding the current strategies. Transcension will be discussed first as the dominant strategy (based on coding density). 
Figure 5.3 Legitimacy Strategies: CRI 1

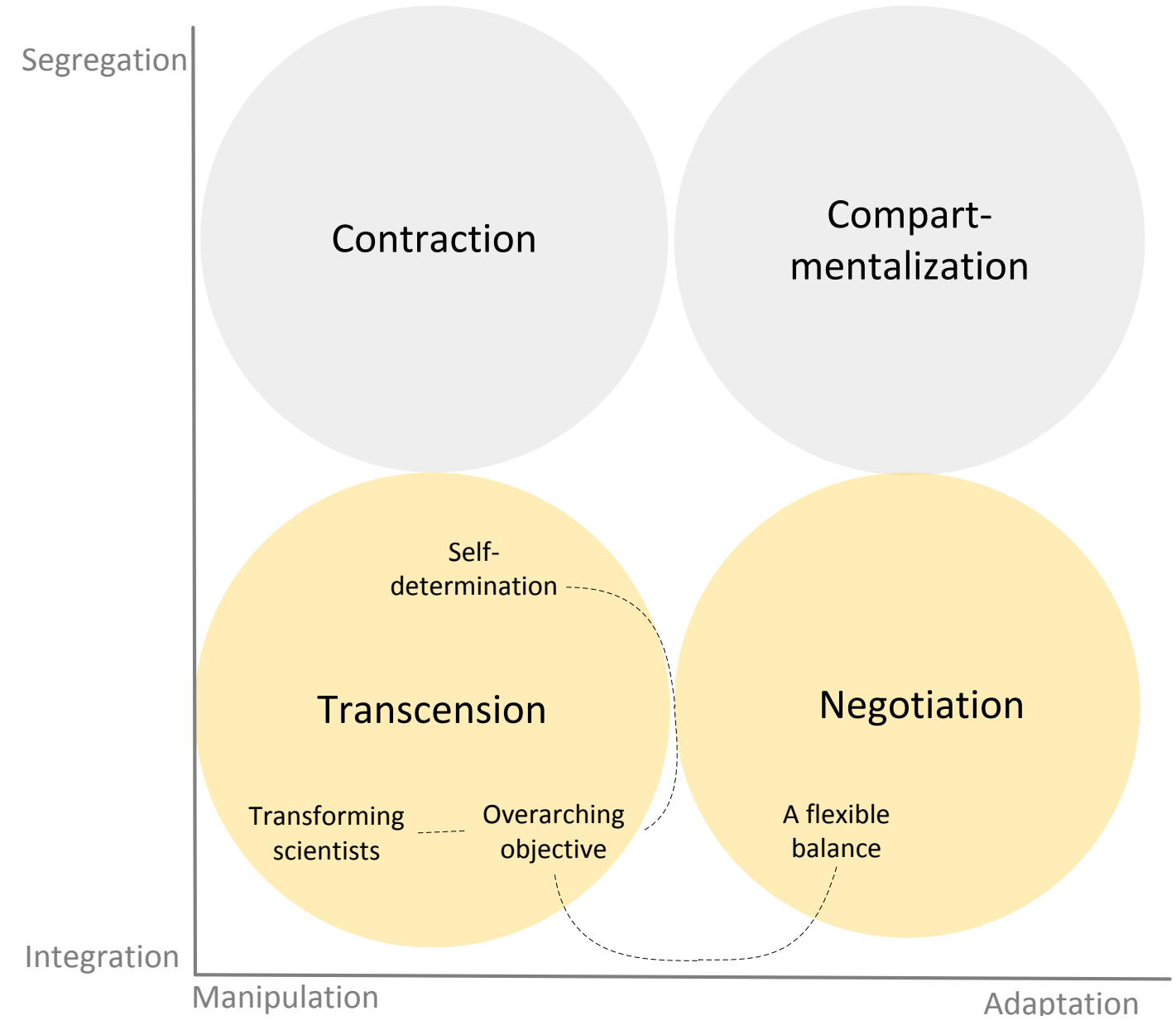

\subsubsection{Transcension}

In the case of [CRI 1] it is interesting that of late they have, not so much managed the tension but kind of diffused it.(Industry Observer).

Transcension was evident in CRI 1, as exemplified in the quote above. Three strategies were identified as rising above the divergent legitimacy demands. These represent transcension focused broadly on different stakeholders: the overarching purpose represented a change in understanding on the part of management; the selfdetermination strategy represents a focus on external stakeholders; while strategies termed as transforming scientists were, self-evidently, focused on that internal stakeholder group. All three strategies involved creatively expanding the possibilities inherent in their context and were in this way agency intensive (rather than being primarily adaption) as well as integrative. 


\section{Overarching objective: broadening and reconfiguring.}

I think the main one [strategy] is...to be focused [on]...putting this into NZ [and] creating wealth. That choice to do that. That's been a fundamental one - getting really clear about why we are here. (Board Member, CRI 1)

A CRI 1 strategy entailed reconfiguring the objectives of the CRI to create an overarching objective, or 'purpose' as it was frequently labelled by participants. This strategy of developing an overarching purpose can be viewed as the central CRI 1 strategy due to the density of coding associated with it (summarized in Table 5.4 at the end of this section). Although not explicitly agency intensive to the degree that the following two transcension strategies (transforming scientists and self-determination) are, this overarching purpose became central as part of shaping the legitimacy demands of stakeholders and the CRI's ability to find a degree of self-determination.

Previous configuration of objectives. Depicting this strategy is assisted by briefly outlining participants' perceptions of how CRI 1 management had previously configured its objectives. This understanding of the CRI's previous strategy draws from eight interviewees and secondary data. Below are indicative reflections:

There was a feeling at the time when we were going down this [commercialization] line that science was undervalued. (Scientist, CRI 1)

That was the mistake that some of the previous parties made. They focused all about making money for [CRI 1]. Until very recently the creating wealth for NZ has been forgotten or else paid the tiniest lip service. (Scientist, CRI 1)

The CEO similarly explains how a previous narrow focus was limiting though meaning: "an under-emphasis on the whole spectrum of technology transfer." As these quotations suggest, a generalized depiction was of financial viability being the central objective and commercialization being the means through which CRI 1 sought to achieve both its commercial and (perhaps less importantly) public good objectives. A change in strategy from this was associated with the failure of this approach: "We were bleeding money every month"; "when we were in the depths of our despair." CRI 1 moved beyond this more narrow focus to an expanded overarching objective and balanced approach. This generalized overview of CRI's 1 past strategy is outlined in Figure 5.4. 
Figure 5.4 CRI 1 past configuration of objectives

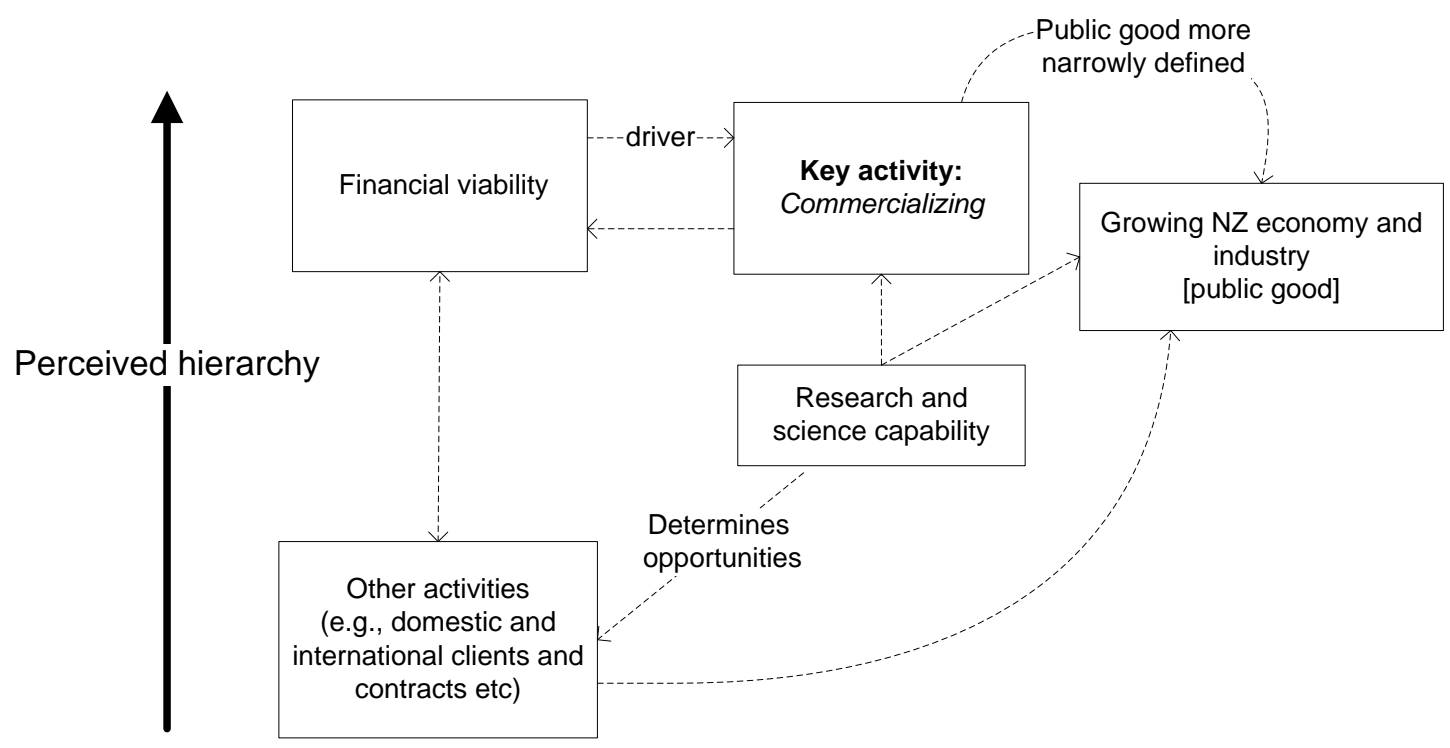

Current strategy: An overarching purpose. From this starting point the strategy participants described was one of reconfiguring objectives in relation to a clarified overarching purpose. A manager explains this in relation to the previous "commercialization" focus: "There will be occasions when we will create a spin-out business. But we will be keeping our eye on the main objective." Consensus regarding that "main objective" or "broader purpose" was evident; the following is indicative:

Focusing on what's important - and I think that's actually the thing, we are focused on what's important - delivering to NZ. (Manager, CRI 1)

As part of fulfilling that broader purpose, the CRI 1 focused on multiple things simultaneously. Through this understanding of the CRI's purpose, all other objectives (such as financial viability and research excellence) were described as working towards the same broad purpose:

Everything, these four or five things here, lead to that one thing at the end. (Manager, CRI 1)

Even when faced with financial concerns this strategy meant that the research-based objectives were not de-prioritized. It also enabled them to position the "financial viability" demand in relation to that purpose rather than it being an end in its own right: 
Whilst one of our objectives in accordance with the CRI Act is to provide a return to the shareholder on the equity that they have invested in the business, in doing so we also have to bear in mind that we are not doing it for the sake of [CRI 1] we are doing it for the sake of NZ. (Manager, CRI 1)

This strategy assisted in meeting the legitimacy demands of both internal and external stakeholders. For example, in comparison to a focus on the financials such a strategy was described in the following way:

It's [benefit to NZ] a much softer message to sell...[CRI 1 scientists] feel much more motivated to create wealth for NZ because that's what they came to do...the public good. (Scientist, CRI 1)

This broadened objective was also discussed in terms of the CRI's relationship with clients. Through no longer having commercialization as its prime focus, CRI 1 was less likely to be seen as a competitor by those potential clients.

The secondary data provided evidence in support of this strategic theme. First, with regards to annual reports, three earlier reports (CRI 1 SD 6-13) particularly highlighted an emphasis on commercialization. In one report, the CRI appeared to be depicting itself as a business incubator. This contrasted with more recent annual reports (CRI 1 SD 1417) that appear to present a broader and more multi-faceted focus. Second, a similar interpretation of the newsletters is possible: older newsletters appeared to exhibit a predominant emphasis on commercialization. For example, in one newsletter (CRI 1 SD 26) four of the five stories addressed this. More recent newsletters, by contrast, highlight a plethora of activities including commercialization but also science and research-level collaborations, different forms of industry sector engagement, and other forms of public good such as supporting key NZ infrastructure. Third, this was also evident in media articles (CRI 1 SD 37, 39), in which this movement from a previous focus on a sole objective (something which adversely affected other objectives) towards an expanded purpose was evident. Finally, this strategy was reiterated by the CEO in a public address (CRI 1 SD 23).

\section{Self-determination: Influencing stakeholder demands.}

[CEO's] trying to get those changes made at the policy level. (Scientist, CRI 1)

Part of what we try and do in the thought leadership area is set the contextual settings 
in which those individual discussions can take place. (CEO, CRI 1)

Another transcension strategy emphasised transforming the broader system that CRI 1 was part of. First, this involved efforts to prompt changes in the RS\&T system, both with industry and government. Second, it entailed utilizing the clarified purpose (as outlined above) to enable CRI 1 to self-determine the legitimacy demands stakeholders place on them. Both of these are evident in the CEO's quote above where he discusses CRI 1's engagement at the thought leadership level within NZ's science system and its ability to set its own boundaries with regards to stakeholder demands.

Changes in broader RS\&T context. Six participants (including two external stakeholders) mentioned CRI 1's focus on influencing the political system and ultimately creating changes within that:

[CEO] is a very good advocate for [CRI 1] because he goes out and - lobby's perhaps not the right word - but he's prepare to go out and talk to these people, talk about our capabilities and talk about these mixed signals or issues we have. Not just try and juggle them but come up with a solution about how we might perhaps align them. (Scientist, CRI 1)

Fostering this voice within the system frequently relied on one-on-one relationships and deliberate relationship building:

Our CEO talking to the CEO of the Foundation or MoRST, with the CEOs of our major clients. So [CRI 1] has done a lot of work...building those relationships and that rapport. (Manager, CRI 1)

As an example the CEO explained CRI 1's position in relation to the recent CRI Taskforce Report to the NZ government: "I think we've had a major influence in the thinking." He went on to describe that being active at this level had been a conscious strategy. This strategy was confirmed in a comment from an interviewee involved in the CRI Taskforce that: "They [CRI 1] were onto this before the CRI Taskforce came along." ${ }^{23}$ This strategy was similarly evident within the secondary data (Table 5.4).

A second aspect to influencing the system involved transforming the CRI's sector itself.

\footnotetext{
${ }^{23}$ To reiterate, the CRI Taskforce was a working group who produced a report and recommendations regarding NZ's CRIs which were subsequently adopted by government. The report was released at the end of the data collection period in this study.
} 
This was discussed by six participants; for example:

Has [strategic event] changed the landscape in terms of creating wealth for NZ? I like to think is has done a little bit. (Scientist, CRI 1)

What we tried to demonstrate [to NZ] there [with particular strategic event] also was that to achieve the type of innovation required for economic growth we've got to think more about larger projects. We've got to think more about larger impact. We've got to think more about larger opportunity. (CEO, CRI 1)

This strategy was about transforming CRI 1's sector and through that the sector's relationship to the $\mathrm{CRI}$ :

One of the problems... that the [sector] groups...that we are working with by OECD standards under invests in R\&D...we don't have a largish number of largish firms actually doing their own R\&D. So a lot of our thinking over the last couple of years has been around how we actually address that problem. If we can address that problem as a nation there will be more opportunity for [CRI 1] to expand its offering to [its sector] and so on. So some hallmark programme like [particular strategic event] have allowed us to demonstrate that yes there is a huge unmet demand by industry for R\&D...[that particular strategic event] has also ...forced [our customers] to start thinking...more about innovation...So there's been a range of activities like that. (CEO, CRI 1)

Another manager connected this strategy to a broad vision for NZ and the sector CRI 1 works in. The CRI 1 should implement strategies that helped create "a whole culture in NZ more broadly' around innovation. Additional understanding regarding this process was gained through the secondary data. In both press releases (CRI 1 SD 19 \& 20) and company newsletters (CRI 1 SD 34; 36), this strategy was described in terms of transforming the sector itself to become a more favourable context within which CRI 1 could fulfil its purpose and the multiple legitimacy demands placed on it.

\section{Clarified overarching objective used to determine parameters. An additional aspect to CRI}

1 seeking to self-define rather than simply responding to stakeholder demands was through its utilization of the clarity it has built around its overarching purpose. This was mentioned by five participants. Having defined its purpose, this could then be used to determine and create parameters for stakeholder legitimacy demands:

Things like core purpose statements are going to be particularly valuable as a means of encouraging dialogue and understanding across the full range of stakeholders [...] in the absence of a clearly stated core purpose statement it's very difficult to reconcile those [stakeholder] differences. (CEO, CRI 1) 
As he continued saying, through articulating their purpose CRI 1 should be able to "establish the boundaries in the relationship with those groups." Through the clarification of their purpose and capabilities with their stakeholders the potential was there for greater self-determination on the part of CRI 1:

It's defined in the CRI Act. There are no bones about it: we're here to transform NZ economically. We just have to decide for ourselves what capabilities that can best do that...So we really need to go to the stakeholders and say: 'this is what we are capable of. We really need some stable funding so that we can continue to do what we do best.' (Scientist, CRI 1)

Clarifying the overarching purpose was also discussed as meaning the CRI 1 remained committed to that regardless of external turbulence:

While policy may change, individual Ministers...you try and have a purpose and a vision I wouldn't say permanent as nothing is permanent - but a more enduring type of thing....we've done that for [CRI 1] I think relatively effectively... within the pressures that we get from these various things. (Manager, CRI 1)

It enabled a degree of self-determination and resistance and a way to justify this to stakeholders in relation to immediate external pressures.

\section{Transforming scientists: Engagement.}

So [CRI 1] in the last couple of years has spent a lot of energy in getting the scientists, particularly the leaders, commercially savvy - a lot of management investment in their training. And that has paid massive dividends. (Director, CRI 1).

The "engagement" subheading used to describe this strategy of transforming the CRI 1 scientists is represented in two ways. First, transforming scientists' relationship, or their level of 'engagement', with the CRI itself through improved communication and including them in decision making. This then fostered greater connection by staff with the broader purpose of CRI 1. Consequently, there was also increased connection by scientists to issues outside of science and specifically being able to engage with industry. This transformation of their role included educating scientists regarding business, was something referred to in the quote above. This strategy was discussed by eight participants including all CRI 1 scientists bar one.

The first aspect to this strategy focused on transforming the relationship scientists had with the organization itself. This entailed overcoming previous discontent and isolation, 
something reported as having existed in the past by interviewees and secondary data (e.g., CRI 1 SD 31). A manager outlined how the current management team: "has brought in this whole thing of empowerment. Where he [CEO] not only involves them but empowers them to make decisions." Two other interviewees make similar points:

We've invested a lot in the people... [staff] get on these courses and thinking "wow I can really do something here." It's been a significant investment...I know a chap working on [particular university strategy], and we showed him around and he said "there's something happening here." And he spoke about it and said "it's the attitude of the people." And it's positive. (Manager, CRI 1)

I really want others to have the same sort of belief in their potential in the organisation [that I have]. (Scientist, CRI 1)

As another scientist explained, the current (and recent) mandate from management of "If there's something that you think is a good idea, get off your arse and go and do it" was important in terms of his level of engagement with CRI 1. From the point of view of scientists, improved communication generally was also vital in increasing their engagement with CRI 1 goals:

I think first and foremost has been communication...when I'm saying communication here it's not one-way communication and I think that's the key thing. So the information is flowing but it flows in both directions. You have the opportunity to have your say. If you have an idea you don't just have to sit on it you can take it forward. (Scientist, CRI 1)

As well as engaging scientists with the organization itself (and hence its broader purpose) strategies had focused on transforming scientists' view of themselves to become aligned with contributing to NZ through industry engagement. The role of language in this was highlighted:

Quite often it's just a re-expression. Trying to develop some commonality around language. In a conversation, you might be using different words to say the same thing...We've done a lot of that...it's a capability of...being comfortable that we can talk about or projects in a board room, in a largely commercial context, at the same time as we can talk about it with some of our scientific peers at a scientific conference in a largely scientific context. And being able to manage those different contextual settings with the same people in the same conversation quite often. (CEO, CRI 1)

This entailed an educative dimension:

So that's [particular training] a way of...up-skilling me with a commercial view. While I have no interest in being a commercial manager at all I definitely need to talk the language. I've got to understand things. Think about the markets. (Scientist, CRI 1) 
With these scientists coming out of universities and so on, the doctorates, they've had no exposure to business generally and they just want to continue with their science. So one of the reasons we run these in-house programmes we do...they come away understanding business and understanding science. And once that's the case they start to link the two together. (Manager, CRI 1)

This strategy also involved transforming assumptions regarding what a CRI 1 scientist was; that is, the CRI 1 scientist was defined in relation to the organization's purpose:

For us that's around purpose and a clear understanding that at the end of the day we all choose to work in [CRI 1] because we want to make an impact. And we want to make an impact through working with [our sector] and that's at the core of our individual professionalism. (CEO, CRI 1).

Incorporating this picture of business literate CRI scientists at the recruitment phase was also highlighted as important:

I had this debate about recruitment...and I said, "if you're recruiting, when you decide their post-doc work's equally relevant, ask which one had the paper round. Take the one with the paper round. Someone who's shown a bit of business initiative at all." ...[but] don't stop there. Say "What is their drive?" Do they understand profit and loss? Do the understand the principles of Return on Investment?" (Scientist, CRI 1)

This image of a business-orientated CRI 1 scientist was made explicitly in one press release and newsletter.

\subsubsection{Negotiation}

A flexible balance. A final strategy focused on avoiding imbalance between legitimacy demands. This entailed flexibly adapting the degree of emphasis within that overall balanced approach as required at any point in time. This constant need to renegotiate emphases in response to the context is contained in the quotations below:

It's recognising that you have to manage the whole as a portfolio and at various time you have to make decisions around how much effort is put into each part of it. (CEO, CRI 1)

If recession hit us, which it hasn't in a big way, then our emphasis would probably more over to the financial side...So we've always got to have the four [objectives] together but the emphasis is going to move from one side of the spectrum to the other. (Manager, CRI 1)

Both integration (multiple demands being incorporated through balance) and adaptation (changing the emphasis in response to stakeholder demands) are observable. 
Eight CRI interviewees highlighted this strategy, as did one external observer. It was also reflected in the secondary data in the form of a public address by the CEO, media articles that explicitly highlighted the strategic importance of "balance", and newsletters that illustrated the greater balance achieved in recent years between objectives. A manager explains: "we... have managed to bring real balance to the organisation" with regards to decreasing the previous lack of balance focused on financial viability and commercialization. A board director similarly noted that previously "that pendulum had swung too far" and that key to their strategy was "swinging the balance back" because "any time you swing it you're going to get conflict...so you must have a balance at all times."

This strategy was not primarily focused on the overarching purpose (see above), but on the balance between the objectives defined as working towards the overarching "public good" purpose. For instance:

For example, a school has a motto...but often a vision and a set of values and a purpose are encapsulated in that motto. Do we change the motto every year? No. But we might have a different emphasis...it might be "okay guys you've got to get more commercial revenue." Or you might want to be creating more jobs. Or you might want to be having more publications. There might a subtly different emphasis in terms of the message. (Manager, CRI 1)

The negotiation strategy was in this way closely associated with the transcension strategy of "expanded purpose". Specifically it involves maintaining a degree of balance between underlying objectives so that whole was not "distorted" - as the CEO put it. Figure 5.5 illustrates the two components of this strategy: overall balance and flexibility of emphasis.

Figure 5.5 CRI 1: Negotiation strategy 


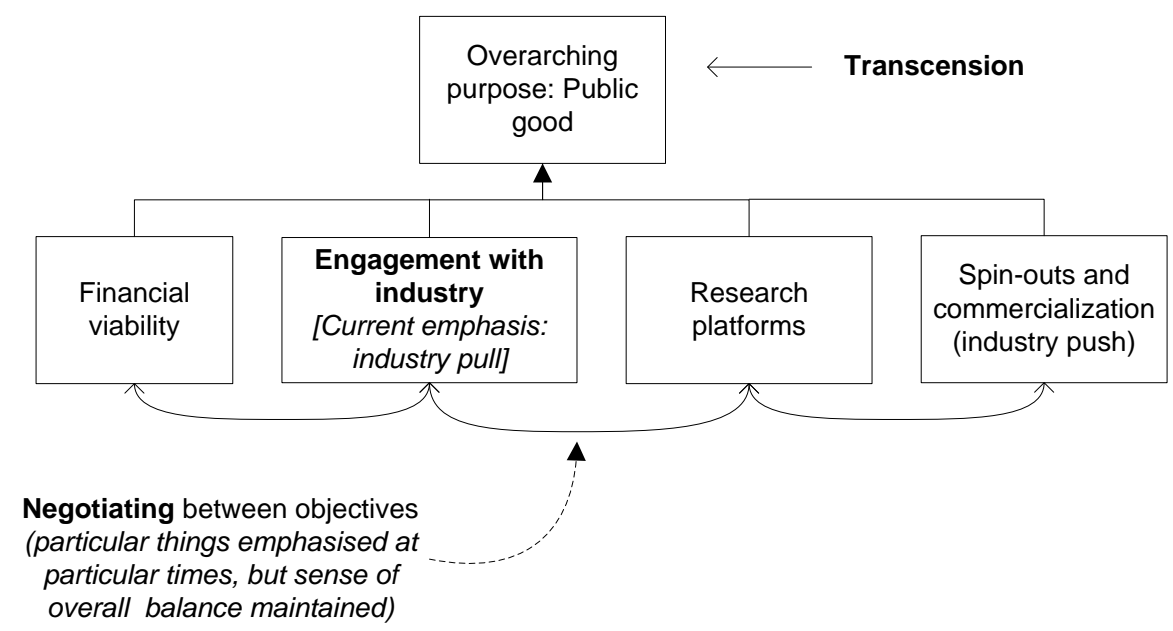

Achieving this balance involved decreasing the amount of emphasis on some objectives that had been overemphasised in the past. One example was in relation to the financial objective:

We still need to concentrate on financial stability. That doesn't mean making lots of money. That means making sufficient money to keep people happy. (Manager, CRI 1)

Similarly, a need for balance was expressed regarding being demand-led versus research-led. That this balance and degree of emphasis was constantly negotiated over time (rather than being resolved) was highlighted by three interviewees:

Turning down commercial work is...not a good look...there's a lot of team resources and equipment that has gone into that work over the last few months. And it's great...But on the other hand some of the other things may have suffered slightly because we haven't had the people. Some of the Foundation contracts for example...it's started to swing back, it's shifted, that commercial work is starting to die down a little bit...And now we're starting to focus [on the research-led projects more] a little bit more...it very difficult. (Scientist, CRI 1)

To summarise, the interviewees discussed how this balance was flexible over time as required in response to stakeholders and contextual shifts:

The balance subtly changes probably daily and certainly over time...you can place an emphasis on particular piece but your purpose and vision stay steady...you can move in a particular direction subtly. Because if you move totally in one direction you forget about the other things. I think [CRI 1] did that [in the past]... it forgot about science outputs. It forgot about engagement with [sector]...so we try and maybe emphasis that part of it but it's not seen as the sole purpose. (Manager, CRI 1) 
As such, articulating an expanded purpose was not the entire strategic story. Managing legitimacy demands in the CRI's pluralistic context also involved on-going negotiation regarding the multiple demands associated with that expanded purpose. 
Table 5.4 CRI 1 legitimacy Strategies: Summary

\begin{tabular}{c|l}
\hline Strategies & \multicolumn{1}{|c}{ Data sources } \\
\hline & $\begin{array}{l}\text { Summary of CRI 1 dataset } \\
\text { Interviewees: 14-24 Transcribed data: 624.5 minutes } \\
\text { External stakeholders [ES]: 56-57; 59-61 } \\
\text { Secondary data [SD]: CRI 1 SD 1-39 }\end{array}$ \\
\hline Transcension & \\
\hline $\begin{array}{c}\text { Overarching objective } \\
\text { (and reconfiguring } \\
\text { objectives) }\end{array}$ & $\begin{array}{l}\text { Interviewees: } 14 \text { interviewees [14-23; ES: 56, 57, 59, 60] } \\
\text { Coding density: 110 [separate data segments] } \\
\text { SD: CRI 1 SD 11-17, 25-36 [annual reports and newsletters]; } \\
\text { 23, 37, 39 [public address and media high lightening } \\
\text { broadening of focus] }\end{array}$ \\
\hline $\begin{array}{c}\text { Self-determination } \\
\text { Influencing change in the } \\
\text { broader system }\end{array}$ & $\begin{array}{l}\text { Interviewees: } 9 \text { interviewees [14, 15, 17, 19-21, 23; ES: 59; } \\
60] \\
\text { Coding density: 39 } \\
\text { SD: CRI 1 SD 19, 20, 31, 33 }\end{array}$ \\
\hline Transforming scientist & $\begin{array}{l}\text { Interviewees: 9interviewees [14-21, 23] } \\
\text { Coding density: 40 } \\
\text { SD: CRI 1 SD 17, 18, 33; }\end{array}$ \\
\hline Negotiation & $\begin{array}{l}\text { Coding density: 48 } \\
\text { SD: 23, 25-36, 39 }\end{array}$ \\
\hline Intexible balance &
\end{tabular}

\subsubsection{Less Prevalent Strategies}

Segregation. Compartmentalization was not obviously outlined by CRI 1 interviewees. Indeed, this was being explicitly discounted by the current integrative focus:

You talk about all being in the waka together paddling in the same direction. And I think that's a good analogy. (Manager, CRI 1)

The above quote and the strategies already outlined above instead highlight the strategic attention being one of bringing stakeholders together around an overarching purpose.

There was similarly little evidence of contraction. For example, the CEO discounted even having to "de-prioritize" any stakeholder demands, let alone deleting or marginalizing 
them. Difficulties concerning a CRI's ability to consider contraction will be touched on further in relation to CRI 2 below.

\subsubsection{Stakeholders Assessments of Strategies}

Overall, participants assessed the current strategies positively, usually in contrast with previous strategies. Such positive assessments were implied by interviewees frequently stipulating that the central issue was ensuring that these strategies were promulgated and actualized more fully. A manager provides an example: "I think it's really important that we continue to do what we are doing." A summary is provided in Table 5.5.

Table 5.5 CRI 1 stakeholder assessments

Transcension Assessed positively: 14-23; ES: 56, 57, 59, 60. Secondary data: compare media articles CRI 1 SD 37 (less positive assessment of previous strategy) with 39 (positive assessment of current strategies).

- "It's starting to happen... since [strategic event] it's been happening quite a bit. We just need to keep that momentum going actually." (Scientist, CRI 1).

- "They've been doing some great rethinking." (Public sector observer)

More tentative assessments although acknowledgement of being on the right track particularly evident with one manager and scientists $[15,19$, 20, 22].

- "We're heading in the right direction and that's great [But] personally, I don't think we've really sorted out the alternative revenue streams." (Scientist, CRI 1).

Negotiation Assessed positively: 14, 17, 18, 23, CRI 1 SD: 39. Data does not include explicit assessments for other stakeholders.

- "The scientists are going 'okay I can see the balance has come back.'” (Board member, CRI 1).

Assessed more critically by two scientists $(21,22)$.

- "I have a personal issue with that. It's not clear how we are supposed to interact with the university system. I think that's probably not an issue for [CEO] because he thinks, 'maybe we're not supposed to be there.'" (Scientist, CRI 1).

The clearest instance of a less than positive assessment were made by two scientists in relation to the negotiation strategies regarding finding balance between engagement and service delivery work. For example, a scientist who, while positive about the transcension strategies, communicated frustration with regards to the constant balancing between demands at the scientist level (i.e., negotiation): "I'm not sure we 
[our team] have been successful in doing that [balancing the service delivery work with research]." Further, while the overall the assessment of the current strategies can be summarised as positive some interviewees were more tentative than others regarding how far the CRI still had to go in terms of fully implementing those strategies. "We've got a long way to go" as one scientist stated.

\subsubsection{Summary: CRI 1}

The strategies perceived by interviewees to be implemented by CRI 1 were transcension and negotiation. The discussion here focused on describing the themes surfaced in relation to those strategies as well as providing an overview of how the main strategies were assessed by stakeholders. The same will now be done with CRI 2 .

\subsection{CRI 2: Legitimacy Strategies}

In times of [economic] contraction...you need to...make sure that any decision made for the short-term, the long-term ramifications are understood. (Manager, CRI 2).

The central strategy conveyed by CRI 2 interviewees was negotiation, that is, reaching compromises between legitimacy demands. As the manager's quote above suggests this involved compromising in the short-term to meet some legitimacy demands (i.e., financial) while attempting to limit the long-term effect of their ability to meet others (i.e., public good capability). At the time of the interviews, these negotiation efforts were heightened. The CEO explains that while: "[CRI 2] will always have services that are demanded by the government... they've reduced the envelope and we have to try and operate within that." These negotiation strategies are presented first (as the dominant strategy), followed by a discussion of compartmentalization (Figure 5.6). 
Figure 5.6 CRI 2: Legitimacy strategies

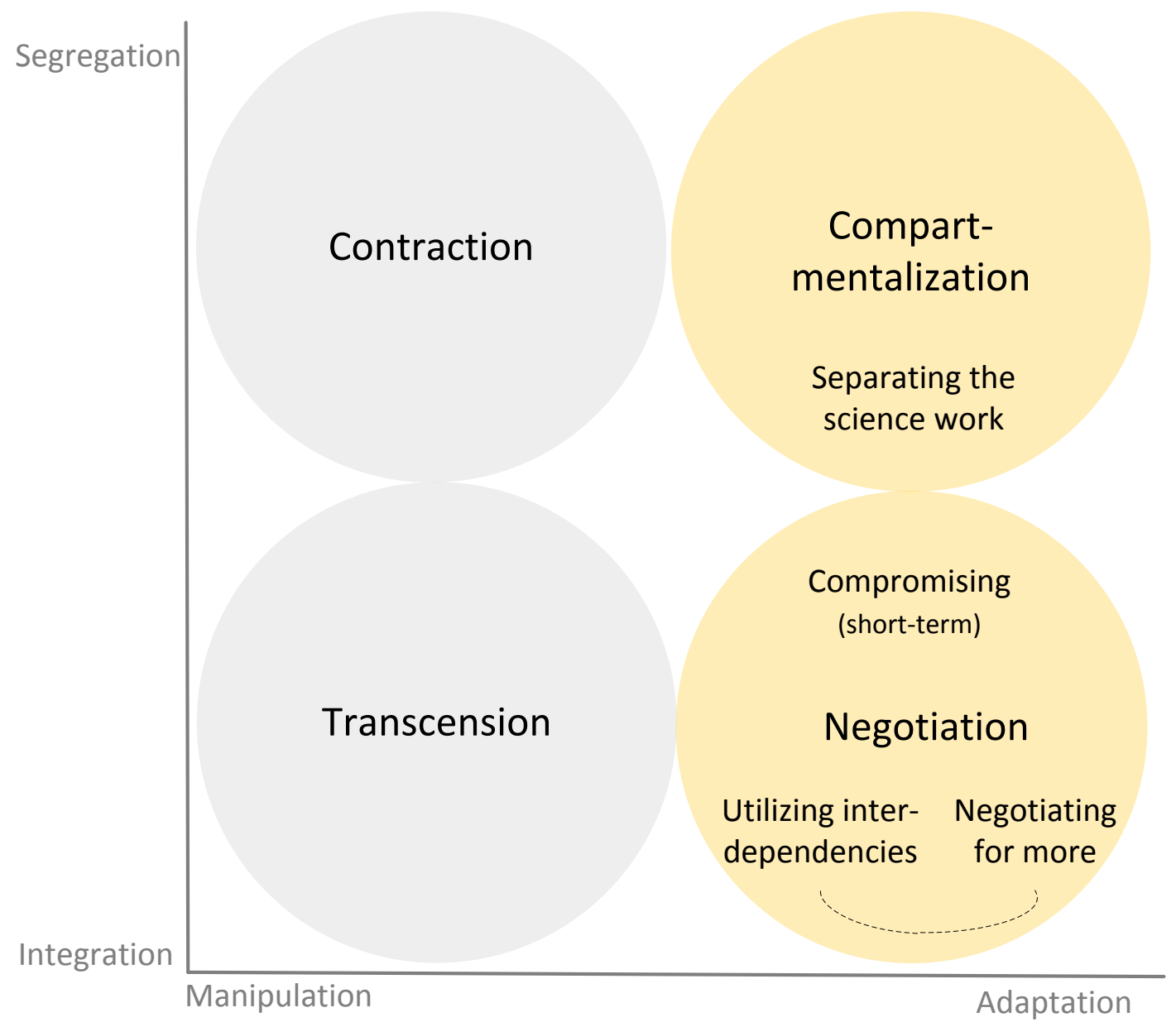

\subsubsection{Negotiation}

They're trying to negotiate a new...agreement [with clients] at the moment. But there's a lot of panic around. (Scientist, CRI 2)

The strategies here are integrative in nature, incorporating multiple objectives rather than trying to exclude or separate them. They were also characterized by an adaptive impulse, attempting to respond rather than attempting (or being able) to manipulate their demands or the CRI context.

Reaching compromises in the short-term. One negotiation strategy involved compromising on some legitimacy demands (either in the short term or in areas considered to be more peripheral) in order to meet other stakeholder legitimacy demands that were more immediate and measurable (i.e., financial indicators). This was illustrated by all ten CRI participants. It was conveyed as being enacted by CRI 
management, affecting CRI staff, and being in response to the actions and demands of their clients and board (representing the shareholding minister).

The degree of compromise required by CRI 2 regarding its public good (e.g., 'national capability') and research (e.g., 'conferences' and 'infrastructure') outputs had increased due to heightened pressure regarding meeting financial demands. A manager explains:

In the short term we've got some key decisions to make. Do we give a lower return to our shareholder in return for maintaining capability for the future? Or do we reduce our future capability by delivering short term for our shareholder? And it's very clear from the board and shareholder. They want an annual return. Not a return over three or five years. But that every single year there is a return. (Manager, CRI 2)

The secondary data confirm this picture of CRI 2's making compromises (in capability for example) as it sought to meet short-term legitimacy measures (CRI 2 SD: 7-12). Further, the "lack of flexibility" the manager refers to above was reflected in the secondary data. While some "non-financial" measures of legitimacy were compromised, the EBIT (earnings before interest and taxes) level achieved remained higher than forecasted in recent annual reports.

The scientists also discussed these strategies as being based on compromise rather than as indicating a rewriting of the company's commitment to service and science:

If they [scientists] feel that they're still understood, that [science is] still the main focus, then that's okay they can put up with the pressures of balancing. And they don't mind a little bit being taken out as long as the focus is still good science. (Scientist, CRI 2)

Alongside managing the tension between public good (service) and the commercial requirements was the "juggling" of resources connected to the long-term goal of CRI 2 of increasing its research focus. This was highlighted in the interviews with the CEO and one manager in particular as well as some annual reports. Increasing their research capability (something they defined as distinct from direct service provision) was frequently viewed as a process of balancing this vis-à-vis CRI's service provision role:

[CRI 2] has sort of systematically built its research capability. But because they are dominated by this big service contract, their expanding research capability is a bit of a juggling act. (Public sector manager) 
While increasing research was a strategy in the long term for CRI 2, in the short term, research was outlined as part of the compromise being made to meet demands for a financial return:

It feels from our perspective that research is getting smaller. That we're a bit of a pain in the butt. I know research is difficult and we're not making a profit and that's an issue for the company. Up until this year I've seen a lot of internal reinvestment, holding onto key researchers and developing new capabilities so that's been great. But that's all been put on hold as far as I'm aware. (Scientist, CRI 2)

Using the secondary data ( $C R I 2$, annual reports) to explore a few indicators of research productivity discussed by participants showed that in the shorter-term the number of conference papers presented had been reduced dramatically, while the number of academic publications remained stagnant and below target. This was explained as a trade-off being made to meet commercial requirements while maintaining a focus on service.

In summary, there was agreement that CRI 2's core purpose was public good; that is, the provision of vital services. Nonetheless, the easy-to-measure-and-understand nature of financial indicators of legitimacy meant that these objectives were currently dictating decision making and the compromises being made.

\section{Negotiating for more: Pushing back.}

So no one notices if [the public good outcome is not delivered to same degree]. No one notices for a couple of years...So the [clients] are hoping they can cut us this year, which they have done by $[\mathrm{x}]$ million dollars, and next year hold it at that level...So that's how they talk to me "[CEO] if you can just hold it for this year and next year, we'll guarantee we'll get more money the year after." But how can I do that? "You give us the money to hold the people." (CEO, CRI 2)

Interviewer: What's behind some of these tensions is the size of the pie [...]? Answer: Yes. Yes...Because everyone's trying to get their hands on a slice."(Scientist, CRI 2).

The above negotiation strategy concerned CRI 2 compromising internally. However, direct negotiation with external stakeholders was also evident and discussed by eight participants. There was a perception of previously being able to more effectively meet all legitimacy demands due to a context of growth. Connected to this assumption was a strategy whereby CRI 2 sought to negotiate for more from its stakeholders, or gain a larger "slice." This active and direct negotiation with stakeholders is demonstrated in the 
CEO's quote above,. This was done in two ways. First, it involved negotiating for more from their clients. Second, it involved negotiating for a more favourable ROI with government (or their board as the interpreter of the shareholder's demands). This more active negotiation can be summarised through the terminology used by two interviewees of "pushing back":

I've seen what is probably an unconscious management strategy, which is...to push back. If there is some sort of switch in support for us to push back. (Scientist, CRI 2)

The CEO's quote introducing this section shows that this strategy involved highlighting and educating clients about the result (i.e., loss in capability) of not assisting CRI 2. He continues:

That's our worry in the [particular client] area. That when [a social crisis ' $x$ '] comes, our surge capacity, which is what we call our standing army...we'll lose that by downsizing...So that is the way we warn our clients. That these cuts have consequences. Not immediately apparent, but when the [social crisis] comes it will be exposed. (CEO, CRI 2)

Through such warnings, CRI 2 was hoping to get more out of the contracts and thus avoid having to make further compromises:

At the moment money is everything and [CRI 2's] strategy is to try and get more money out of the [client]. The [client] strategy is not to let them. They're in a bit of a fix at the moment. (Scientist, CRI 2)

This strategy of stakeholders negotiating for more regarding their slice of the "pie" is again reiterated by the CEO and confirmed by the client:

It's human nature, you protect your own and, if you can, grab money. (CEO, CRI 2)

It's our job to keep costs down, get as much value but spend as little as possible. (Client, CRI 2)

A strategy of "pushing back" was also evident with regards to the relationship between CRI 2 management and board (and by extension government). In this case, it focused on arguing for a more favourable level of ROI in the short term. This remained both an actual and a hypothesised strategy for the future:

[It's] arbitrary profit at that. There is no real commercial background to the nine percent return. So that's a very key thing for us is our board going in to bat for us with the shareholder. Instead of accepting what the shareholder says and not pushing back. 
(Manager, CRI 2)

Actions already being put into place around this include trying to educate the board regarding the public good criterion:

We did some work with them [the board] around public good and I wrote a paper "what's public good?" They were quite keen to see if we could value, put a value on what our public good work is worth... Bloody hard, I did a couple of case studies but it's really difficult to put a dollar value on it. It's more of a narrative. (Manager, CRI 2)

Communication. Constant communication. Getting people to understand our position. That we are not just a research organisation. That we deliver in the public good area. We haven't evoked this but if we had a board of directors that was so inclined [we could argue] that although we only produced five percent there was a four percent social dividend. Which is really important and that makes up to nine percent. (CEO, CRI 2)

Finally, an additional point many interviewees discussed public good "crises" as being a way CRI 2 was able to gain more out of its service contracts and, thus, meet both its financial and public good objectives. Such events were characterized as points in time when the value of the public good delivered was explicit to everyone:

Where the two [public good and commercial demands] come together though is when we have [public good] drama. (Scientist, CRI 2)

Nonetheless, between external "events", the current strategy involved negotiating a more favourable "number" out of the client contracts and shareholder requirements.

\section{Utilizing interdependencies.}

They [CRI 2\} really are at the mercy of [clients]...So that's actually more of a relationship issue. (Public sector manager)

They strive to ensure that they are considered a partner. That it's not entirely a client/services provider relationship. And it is, but it's not...It's not a cold black and white you provide this, we'll provide that because there's a hell of a lot of discussion going on. (Client, CRI 2)

The strategic focus CRI 2 had put into its relationship building was another aspect to its being able to negotiate within its client relationship. Eight interviewees referred to strategies centred on fostering client relationships and building recognition of interdependencies on the part of both parties. Annual reports similarly indicated a strategic focus on long-term partnerships and trust. Indeed, the capacity to warn clients of the consequence of particular actions so as to ask for more (discussed above) is 
predicated on this strategy, hence the connection between the two depicted in Figure 5.6.

Building strong client relationships created the scope for CRI 2 to negotiate with those clients was central. For example:

The contracts we have with clients are essentially a two-way negotiation...it's a living relationship. We like to think of it as partnerships rather than just contractual relationships. It's very dependent on people though: people within [CRI 2] and people within the [client organizations]. One of the things that we struggle with is continuity of staff in [the client organizations]... a lot of the people we had had relationships are no longer there. So there are some new relationships...So we put a lot of energy into relationship building so we can have more of a partnership. (Manager, CRI 2)

This indicates fostering relationships was a constant and ongoing strategic issue for CRI 2. It was about constant communication with their clients to try and determine their needs while communicating their own: "through communication and relationship management is how we tend to do it"; "communication, constant communication." This involved reiterating the value of the service provided by the $C R I$ so that the client became aware of their reliance to the CRI:

It's not about marketing, it's not about sales marketing to our clients - it just doesn't work that way...We have to be very careful not to be self-serving in our promotion. We tend to focus on the capabilities and services that we provide, rather than "look how great we are." Because, it's more about our clients and them being successful. When they are successful, we are successful. It's more relationship - working with them. So we do a lot of publications, briefings and examples and case studies about the work that we're doing in support of [the clients] that we're working for. (Manager, CRI 2)

This degree of interaction between the CRI and its clients at multiple levels offered a safety net in terms of the relationships:

We've got CEO interaction, GM interaction and science interaction. There are interactions at all those levels, which forms the strength in the partnership. Because if someone falls out, if there's a bit of a disagreement, there's other layers of relationship in the organisation which can help sort it out. (Manager, CRI 2)

This focus on relationship building enabled two things. Not only was the CRI able to respond to any change in the need of their clients (and in so doing demonstrate and reiterate their value) but also create a sense of interdependence in the relationship, with clients increasingly appreciating the value of the CRI. The quotations below again 
outline both the constant communication as well as an understanding on the part of both the CRI and the client of these mutual dependencies:

I talk to [CRI 2] on a daily basis. And not because we have problems but because we simply work quite closely as a team...We talk about it being a partnership...because...we need that capability. We need to ensure that each of us is looking after the other to ensure that they're there in the future. So we work as a partnership. (Client, CRI 2)

I think of the situation with the laboratory in Auckland...and there has been very salutatory lessons for people in both sides of the relationship. One had been working for the other for many many years and a new kid came along and they thought 'why should we keep working for them, let's give it a shake up, let's use the market and competitive bidding.' Suddenly the contract was lost and someone else got the contract. And we all know that was a complete and utter disaster. So there are vulnerabilities on both sides of that relationship. (Scientist, CRI 2)

The CEO provides an example of this strategy reaping the intended result:

It's a matter of the closeness of that relationship, which you've got to put a lot of effort into, that allowed us, that the [client] went into bat for us with [government] to say "it's stupid tendering this stuff out ....why do we go through the process, why not have a basis where they are the sole source provider?" (CEO, CRI 2)

This process of building interdependencies rested on a long history on the part of the CRI of public good delivery. The client explicitly acknowledges this in speaking of their relationship: "[CRI 2] has provided that service to [us] for a hundred odd years." $\mathrm{He}$ continues:

By using [CRI 2]...with their long reputation there's an acceptance that they've been a long time and do a good job...If you start doing it on price, yes you'd probably get [service] cheaper...Will they have credibility? Will their staff have credibility? And you're going to be testing that every time...why would you do that? (Client, CRI 2)

To conclude, that relationship building was an on-going strategy is indicative of the constant give and take of negotiation rather than the agency-intensive ability to rise above these tensions. For example:

There's also been tensions...sometimes [our clients] think we should just do as we're told. And we think we can add value by having more of a discussion with them...you've got to constantly be careful that you're not in a master/slave relationship. We're they've got the money and they just tell you what to do. We feel that we can add a lot more value by being more of a partner than that. (Manager, CRI 2)

As this indicates, negotiating through the deliberate building of a close relationship and utilizing interdependencies was sometimes difficult for CRI 2 due to the 
interdependence was asymmetric. While there was a degree of recognized interdependence on the part of the clients, CRI 2's degree of dependence on its clients was greater. This connects to the observation in Chapter 4 of the perception of CRI 2's dependence on its clients (diffused power) being particularly high.

\subsubsection{Compartmentalization}

\section{Separating science work from financial/managerial concerns.}

You hear about other things, but the managers above us do quite a good job of saying "don't worry about that, your job is to do the science." (Scientist, CRI 2)

Within CRI 2 strategies focused on separating the science/service work and the management/commercial elements were evident. Six CRI 2 interviewees provided illustrations of this strategy (Table 5.6). One secondary data source also outlined the perception that the CRI 2 scientists tended to separate themselves from the CRI management and its commercial focus (CRI 2 SD 13). As the quote above indicates, this was a strategy engaged in by the scientist but also enabled, to a degree, by the managers.

Compartmentalization was discussed in terms of the active separation by scientists of their "public good" service work from the commercial and financial demands of the company. An anecdote was provided illustrating how scientists were able to find ways to separate their work from the commercial element of the CRI so as not to compromise public good delivery:

We've got a lot more accountants now...They'll tell you: if we're not making money why are we doing it?...There's all sorts of things that go on around that. [One particular service] is probably the best example. We've pulled out of [that particular service]...[CRI 2] said "...It doesn't add up so chop - we don't do it"...[however] I can tell you now the [clients] will call up "we need someone to do this [service], the [other provider] haven't done it properly." So we say "we can't do [that service] but if you say it's [another kind of service] we will send one of our [specialist scientists] and they can look at the [other thing] too." Or in one case one of the [scientist] went down and did a [service] for a cream bun. "I'll come down and have a look. But you provide some cream buns at lunch time. And [CRI 2] doesn't need to know." (Scientist, CRI 2)

This ability for scientists to decouple their work from the CRI's commercial demands was also recognized by the CEO: 
Our scientists have a very strong work ethic in terms of delivery...Despite what I say 'You haven't got funds to do that anymore, so you can't do it.' They do it. (CEO, CRI 2)

Other interviewees did not explicitly describe this strategy. However, through highlighting the level of identification between the scientists and their clients they helped explain this process. The strategy of compartmentalization regarding scientists and the commercial concerns of the CRI was in this way shown to be related to scientists' strong identification with external clients:

What gets added into the [CRI 2] situation is that our scientists and technicians have this immediate and very intimate relationship with the people they work with. So the relationship between the [scientists] and the [client] is very intimate...They are sort of twins. So their identity, their identification with those issues is very close with the client. (Scientist, CRI 2).

The client outlined how he deliberately fostered this strategy when explaining his current focus on "closing the loop" further between the client and the scientists providing the service.

Compartmentalization was also observable internally with regards to research demands.

CRI 2, through seeking to build up its research capability, had created within its structure small pockets with a sole focus on research. This function was separated from the wider pressures being placed on the CRI:

In the organization we've got a role - a principal scientist role - and these are internationally recognised scientists ...All they want to do is science. So we have given them a career path that means they can stay in science, they don't have to be a manager...So I guess that's one tangible way of showing [our commitment to research]. (Manager, CRI 2)

While only a small part of their structure, this compartmentalization was identified as important in building their research capability. ${ }^{24}$

To conclude, this strategy can be summarised as a separation, between scientists and the "corporate" level of CRI 2. This was associated with scientists' desire to focus on their work whether primarily defined as service delivery or research. The scientists had

\footnotetext{
${ }^{24}$ With regards to this strategy it was the doing of research not the type of research that was being separated from the other elements from the CRI. What research was conducted remained closely connected to the service that CRI 2 provided.
} 
the expectation that the commercial legitimacies are dealt with elsewhere and this was frequently fulfilled:

There's a comment someone made to me a couple of weeks ago: "managers are paid the big bucks to sort out those issues. We're paid the crap to do the science." We're not paid very well...so why should we have to worry about that kind of stuff? (Scientist, CRI 2)

To be honest with the team around here people are interested in what we're doing here...When it comes to... "[the management team] has considered the new five plan" they don't care. They're [a particular kind of] scientist. They want to be to get out there and [do the work]. (Scientist, CRI 2)

This strategy, as well as the others, is summarised in Table 5.6. 
Table 5.6 CRI 2 legitimacy strategies: Summary

\begin{tabular}{|c|c|}
\hline Strategies & Data sources \\
\hline & $\begin{array}{l}\text { Summary of CRI } 2 \text { dataset } \\
\text { Interviewees:25-33 Transcribed data: } 587 \text { minutes } \\
\text { External stakeholders [ES]: 56,57, 59,60 } \\
\text { Secondary data [SD]: CRI } 2 \text { SD } 1-12\end{array}$ \\
\hline \multicolumn{2}{|l|}{ Negotiation } \\
\hline $\begin{array}{l}\text { Compromising } \\
\text { (in the short-term) }\end{array}$ & $\begin{array}{l}\text { Interviewees: All CRI } 2 \text { participants (ten) } \\
\text { Coding density: } 50 \text { [separate data segments]: } \\
\text { SD: More recent annual reports and media articles [CRI } 2 \text { SD } \\
\text { 4-12]. }\end{array}$ \\
\hline Negotiating for "more" & $\begin{array}{l}\text { Interviewees: } 8 \text { interviewees [25, 26, 28, 29, 4143; ES: } 57 \\
\text { Coding density: } 31\end{array}$ \\
\hline $\begin{array}{l}\text { Utilizing interdependencies } \\
\text { Negotiating in the context of } \\
\text { close relationships }\end{array}$ & $\begin{array}{l}\text { Interviews: } 8 \text { interviewees [25-29, 31, 32; ES: } 56] \\
\text { Coding density: } 32 \\
\text { SD: CR } 2 \text { SD 3-6 }\end{array}$ \\
\hline \multicolumn{2}{|l|}{ Compartmentalization } \\
\hline $\begin{array}{l}\text { Separating science work from } \\
\text { financial/managerial } \\
\text { concerns. }\end{array}$ & $\begin{array}{l}\text { Interviewees: } 6 \text { interviewees }[25,26,29-31,33] \\
\text { Coding density: } 34 \\
\text { SD: CoRE } 2 \text { SD } 13 .\end{array}$ \\
\hline
\end{tabular}

\subsubsection{Less Prevalent Strategies}

Transcension. The analysis above suggests a degree to which CRI 2 had not transcended the tensions between its legitimacy demands. Instead they negotiated and renegotiated with stakeholders regarding them. The following quote provides further illustration:

We'd love to get away from the dollars and cents part of the relationship but we know that's not completely possible. (Manager, CRI 2)

One area of potential future transcension was an envisaged move to diversify (i.e., transform their context) to enable it to more successfully fulfil multiple demands. Five stakeholders in nine separate data segments discuss this and it was also observable in the secondary data (i.e., the most recent annual reports) as desirable future strategy. 
However, this remained a response driven by financial considerations: "truth to tell... the reason for us being more diversified... is purely driven by financials, we've been driven by financial concerns rather than altruistic ones." Consequently, this 'future' strategy could potentially be characterized as not rising above the current framing of tension between the financial and public good. For example, one scientist explicitly disagreed with this strategy for that reason.

Contraction. While stakeholders outlined a de-prioritization of non-commercial legitimacies in the short-term (negotiation strategy above) this was not described as a process of contraction, marginalizing public good and research objectives of the CRI. Instead, those legitimacies were codified in law (CRI Act, 1992) as well as in all stakeholders' perceptions of a legitimate CRI. Similarly, any (potential or actual) staff layoffs were not focused on deleting that stakeholder group or their legitimacy demands. Again, this instead is indicative of the negotiation process of compromising a little in one area (potential/actual slight reduction in staff) to meet demands in another (ROI). In sum, no strong evidence of contraction was found within the data-set.

\subsubsection{Stakeholder Assessments of Strategies}

I'd like to see a change in the model...But at the moment [CRI 2] and [client] are both looking for the right strategy. (Scientist, CRI 2)

A summary of participant perceptions of the different legitimacy strategies is provided in Table 5.7. A degree of frustration was expressed by some interviewees regarding the current negotiation strategy as suggested in the above quote. Many participants can be classified as desiring a deeper strategic solution than the one currently described. Indeed, one scientist depicted the strategies classified above as negotiation as a lack of strategy: "I don't think there's been any [strategy]." Conversely, there was, however, a general acceptance of the need for compromise, including amongst scientists (even while expressing a degree of concern around over-compromising):

We're gone through always knowing... my generation of scientists, that's just expected [compromise]. Because that's just how it is. (Scientist, CRI 2) 
Finally, however, the general discussion (six participants) regarding the need for new (more transcentive) strategies provides an indirect indication that current strategies responses were assessed as less than satisfactory.

\section{Table 5.7 Perceptions of legitimacy strategies}

\begin{tabular}{|c|c|}
\hline Negotiation & $\begin{array}{l}\text { Degree of concern/frustration at the current response }(26,28-32) \text { or as } \\
\text { something that is difficult }(25,28) ; \mathrm{ES} \text { : CRI } 2 \text { as struggling: } 56,57,59 \text {. } \\
\text { - "I've had a lot of good experiences at [CRI 2] that's what makes me so frustrated } \\
\text { with what is happening at the moment. It's all turning to custard!" (Scientist, CRI } \\
\text { 2) } \\
\text { - "Personally I see patterns in that regard... just doing what's familiar. Or more of a } \\
\text { protective stance rather than a development-mental stance." (Scientist, CRI 2) }\end{array}$ \\
\hline $\begin{array}{l}\text { Compart- } \\
\text { mentalization }\end{array}$ & $\begin{array}{l}\text { Scientists and one manager describe this strategy as a good thing and } \\
\text { something they want more of }(26,30,31) \text {. } \\
\text { - "Here they do very much say 'you're a scientists, do your science' which is good" } \\
\text { (Scientist, CRI 2). } \\
\text { CEO expressed concern regarding the separation between scientists and } \\
\text { commercial legitimacies (25). }\end{array}$ \\
\hline
\end{tabular}

\subsubsection{Summary}

CRI 2 has been found to implement negotiation coupled with compartmentalization. A final point regarding CRI 2 was that the timing of the engagement with the organization was potentially particularly important in this case. CRI 2 appeared to be only recently experiencing a heightening of the tensions, a 'crisis', between their multiple legitimacy demands. The strategies discussed here perhaps represent a moment in time where the $\mathrm{CRI}$ is recognizing the need for a transition to other strategies in the face of increasingly tough compromises being required as part of their current approach.

\subsection{HTSU 1: Legitimacy Strategies}

The strategies identified with regards to HTSU 1 involved interconnected transcension and negotiation and negotiation and compartmentalization. For example, an overarching objective (transcension) enabled negotiation regarding "things around the outside" (managing the periphery in Figure 5.7). A temporal element was not evident with interviews focused on current strategies and no differentiation being made by 
interviewees regarding past strategies. Each strategy will be discussed in turn, beginning with transcension as the most frequently discussed strategy.

Figure 5.7 HTSU 1: Legitimacy strategies

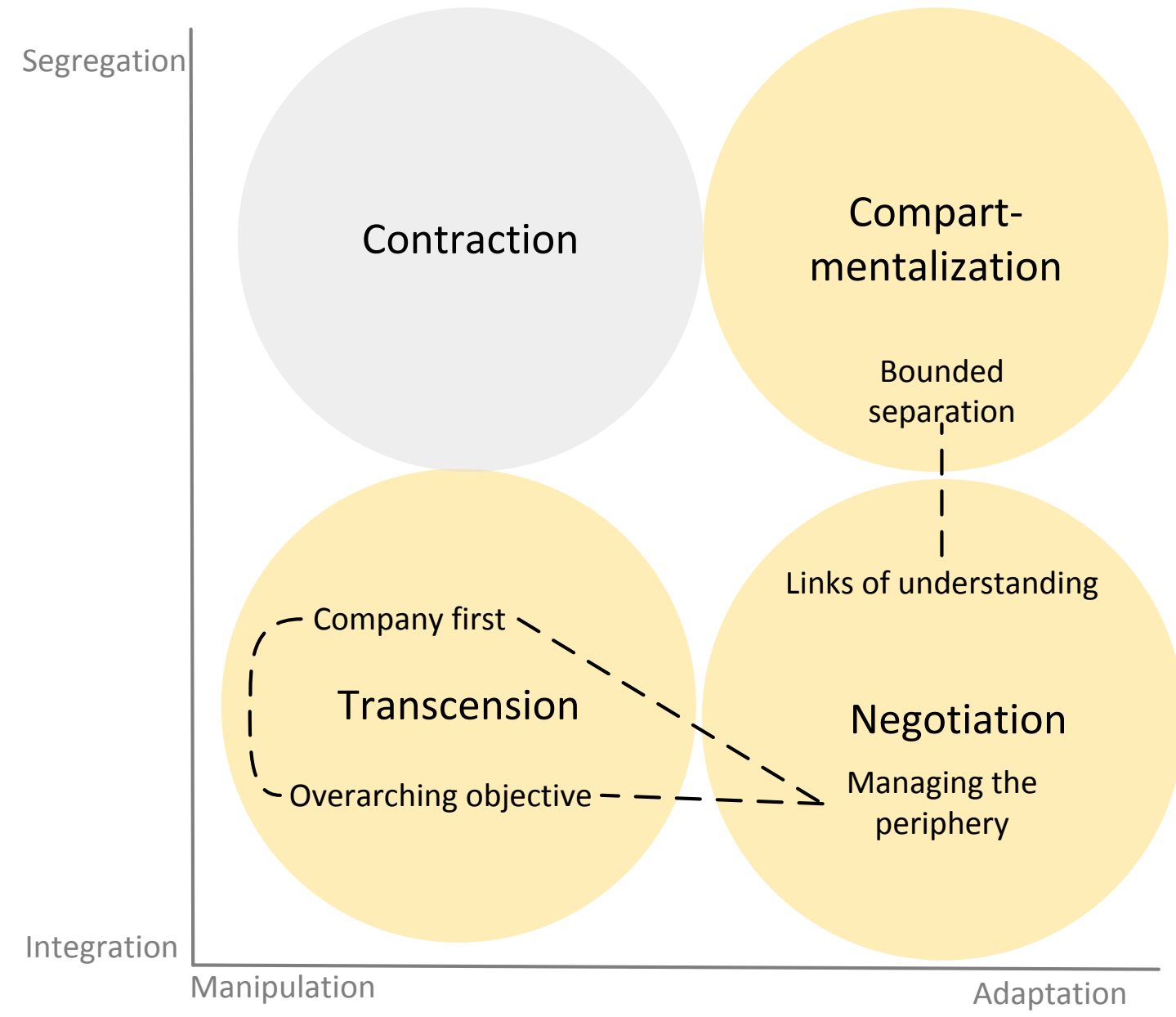

\subsubsection{Transcension}

Two strategies transcended the tensions at play by defining an overarching objective or through HTSU 1 being able to tap into stakeholders putting the wellbeing of the company before some of their legitimacy demands. The strategies were integrative in bringing all the stakeholders, and their demands, together. Both strategies were manipulative rather than adaptive; it was the needs of the company (not the stakeholders) that was largely able to shape decision making (focused around the overarching objective).

Overarching objective. The strategy that was immediately apparent within the interviews was the use of the overarching objective, expressed as growth or value creation. All 
HSTU 1 interviews helped build an understanding of this strategy and it was also evident in the secondary data. The CEO explains:

The common thread for me is about growth and the value of the company...there is a very clear need to have growth and value and nobody would disagree with that one as the key platform on which the company is built. (CEO, HTSU 1).

There was consistency amongst stakeholders regarding their focus on this overarching objective, as evident in the CEO's quote. The overarching objective was also consistently promulgated over time. For example, a scientist founder outlines that it was critical for HTSU 1 to be: "always fixed on the sales. And again / think that's something that all of us in the company have got to espouse and articulate. And I think that happens."

Different stakeholders were able to connect multiple legitimacy demands to this broad objective, even those that perhaps appeared less commercially oriented. A venture capitalist not involved directly in HTSU 1 outlined this as being something strategically useful that HTSU 1 had with its overarching objective:

People need to find a home in the words, the phrases that are used. (Venture Capitalist). For example, the scientist founders broadened the focus of "growth" beyond the company to the "NZ context" and public good:

That's [financial reward] not really what's driving us. The investors are obviously looking at that and correctly so. But for us the mark of success is that we grow the company - as I've said we start from that point. But the real pride is having done that it's the effect on all those other factors, particularly in the NZ economy. (Scientist Founder, HTSU 1).

There is a very clear need to have growth and value and nobody would disagree with that one as the key platform on which the company is built. What they will do is add different ones around the outside. (CEO, HTSU 1)

Another illustration of the potential for different relationships with this overarching objective was the narrower relationship to growth defined in return on investment terms. This was typified in the interview with the university shareholder and was reported as defining the relationship between HTSU 2 and its private investors.

Connected to this overarching objective encompassing multiple legitimacy demands was that "growth" remained defined in broad and ambiguous rather than precise terms. As a director outlines, a "rock solid customer base" had not yet been found. One of the 
founders suggests that this was perhaps helpful with regards to the company's relationship with its science teams as the broad "ecosystem...that diversity [of products] is what's motivating a lot of us [those in HTSU 1's science teams] anyway." As such, not knowing "quite where we are going" enabled an expanded vision of both the products and growth potential.

An additional aspect to this strategy was that for the directors it was taken as given that growing the value of the company was the objective the company was focused on. However, they had less involvement (compared with the CEO, for example) with the other stakeholders' legitimacy demands. This was potentially why the argument that this was a way to manage other stakeholder legitimacies (i.e., public good) was not as apparent for them. They discussed it more as the central objective rather than as an overarching one.

Another characteristic defining this strategy was its future-focused component. The objective was essentially a vision for the future:

Our strategy is that in five years time we want to be ten times as big as we are this year - so we will be a 10 million dollar company, in terms of sales, in five years time and five years after that 100 million dollar company and then eventually we are going to beat Fisher and Paykel Healthcare ${ }^{25}$ - that's the dream. That's the benchmark...Now that's an awfully big ask but you've got to have bold visions and goals. (Scientist founder, HTSU 1)

This was most evident in the interviews with the CEO and two scientists but also discussed by a Director in relation to managing the ROI objective of the investors. Shifting the focus of some stakeholders from the current situation to the future where their legitimacies would be more firmly fulfilled is discussed further as part of their managing the periphery strategy.

\section{Company first.}

[I've been involved] right from the beginning and very much sort of intertwined. So...it's just part of me really now. (Scientist founder, HTSU 1)

A strategy of putting the company first was articulated by four (of the six) interviewees. This involved the company being put before stakeholders' own specific interests and

\footnotetext{
${ }^{25} \mathrm{~A}$ large and successful NZ technology company.
} 
through this rising above some immediate stakeholder legitimacy demands. This was implicit throughout the CEO's interview where decisions and actions were frequently discussed in relation to the litmus test of what was in "the best interest of HTSU 1." The definition of "benefit" and "best interest" was connected to the overarching objective discussed above, which is the basis for linking the two strategies in Figure 5.7.

Two interviewees provided the example of this strategy occurring at the board level:

As a director for HTSU 1 my prime responsibility is to HTSU $1 . .$. am not there to make HTSU 1 do anything on behalf of the university [i.e., the shareholder]. (Director, HTSU 1)

Because the board understand the plan and where we are going, does that mean all of the shareholders understand and buy into that? Not necessarily so, because the [...board's] task is to do what is in the best interests of the company not what is in the best interest of the shareholders. (CEO, HTSU 1)

This strategy was expressed by the scientist founders. First, it became apparent that the scientists did in fact put the company ahead of their own personal interests, an example being in relation to publication. To reiterate:

The work he does for [HTSU 1] is extremely applied. And not particularly publishable. So [Scientist X] is sacrificing his PBRF rating to support HTSU 1 . And he's not the only one. (Director, HTSU 1)

However, the company was able to tap into the stakeholders' feeling they were involved in something fundamentally worthwhile to transcend this and ensure the ongoing commitment of its science stakeholders:

We see that we are trying to build something much bigger than ourselves. (Scientist founder, HTSU 1)

This was connected to the picture of the NZ context that stakeholders had linked with the company's overarching objective and the broader significance of their work:

We're driven by 'let's show how it can be done' - almost like a nationalistic thing...But it's that kind of pride factor that is behind it and an agreement that we are going to make this work and that no egos are going to get in the way of this. And for all of the complexity around the competing institutional rivalries, personal ambitious or whatever, in the case of this thing it's bigger than us - it's something more important. (Scientist founder, HTSU 1)

You write a paper and maybe five people read it. Here we are selling hundreds and hundreds of items now. And millions dollars of technology. It is significant. (Scientist founder, HTSU 1) 
This ability to put the company first was also connected to the excitement and pride particularly around the HTSU's sales and growth:

I'm just running on hype basically. Because you've got to because I'm getting knocked in other areas. (Scientist founder, HTSU 1)

This was also reflected in the secondary data (e.g., HTSU 1, SD 1).

Finally, one scientist outlined the level of personal identification with and investment in HTSU 1 as explaining this strategy. This was most evident in the description of HTSU 1 as a "baby":

As I said right at the beginning [of this interview] it's like this baby that screams and you've got to be there for it. And you have to choose whether to be in it or walk away. So I decided to be in it because I can't let go! (Scientist, HTSU 1)

An implication was that some of the divergence was effectively transferred from the organizational (HTSU 1) level to that of the individual. Putting the company first involved some stakeholders not connecting some legitimacy demands (and associated tensions) they themselves dealt with (e.g., publishing their science related to their all-consuming work for HTSU 1) to HTSU 1 as to do so was felt to be damaging for the company.

\subsubsection{Negotiation}

Two strategies involved partial adaption with regards to less central objectives and increasing inter-stakeholder linkages and understanding. These strategies entailed less of a focus than the strategies above on self-defining and more of an adaptive impulse. However, they were similarly integrative as multiple demands were responded to simultaneously through these strategies.

\section{Managing the periphery.}

The way I deal with this is to keep things focused on the growth and value part and I do let some of these things splat onto the ground...in a sense a lot of the strategy...is we just ignore it and sort of get on with it and hope people forget about it and that they don't sort of resent it and the danger for me is that if you start getting people talking about it...then you're picking at a scab that might have only just healed over...I don't want to create problems by picking over old scabs. (CEO, HTSU 1)

The above quote illustrates that the overarching objective did not completely transcend the tensions associated with divergent legitimacy demands. Any 'resolution' in relation 
to the overarching objective remained tentative. This meant on-going management of more peripheral demands. This was done through partially, rather than fully, responding to them as the CEO's quote suggests. Discussed by four (of the six) HTSU 1 interviewees, but most explicitly by the CEO, these strategies were enacted in relation to the overarching objective.

Negotiation was engaged in "around the outside," to quote the CEO. The overarching objective assisted decision making regarding the additional non-commercial demands on the company:

The thing that ensures that [HTSU 1] works is that there is a clear strategic objective that everybody has agreed on...if you start digressing away, well the argument is that we've all agreed on the strategic goal [and] you need to come back into line and start behaving in a way that supports our pursuit of it. (Director, HTSU 1)

"Less compatible" demands were negotiated on a case by case basis and partially responded to:

Sometimes it's about letting some balls fall splat on the ground; trying to catch enough on the fringes to keep people happy without distracting from the core thing. You make everybody a little bit unhappy a little bit of the time. Make sure everybody has some happiness some of the time so that everyone feels they get a little bit of attention...but try and...it back towards the core focus and not let it drift off into too many sidetracks too often. Is that a genuine strategy? (CEO, HTSU 1)

There's all these other sort of objectives that the stakeholders put in there. Some of them are more compatible with growth than other ones....Some of them are just "no we are not going to do that." So those are the ones that tend to hit the ground first...other ones you say we are not going to do it ten times we will do it once. (CEO, HTSU 1)

As the quotations indicate there was continued engagement with those additional legitimacy demands rather than complete marginalization of them. The scientists, for example, felt that they communicated their science and public good based demands to those with a more commercial focus:

We scientists sort of try and say - because what motivates us is this bigger context in which we work - can we find some way to make all this work for all of us? (Scientist founder, HTSU 1)

This can be classified as negotiation strategy as all stakeholders were actively involved in this prioritization: "it has to be dollars" as one scientist said of the basis for the 
company's legitimacy. However, they prioritized this whilst maintaining a link to additional objectives and asserting that within the company. For example, one of the founders outlined their capacity to say "wait a minute - we're not working for you [HTSU 1]. We're working for the University' to assert their simultaneous need to focus on their science objectives.

An additional point is linked to the already discussed future-focused nature of the overarching objective. Some stakeholders accepted the compromise regarding certain of their demands in the short term through envisaging a future where they no longer had to do so. This was reported in relation to both the investors regarding their ROI as well as the scientists. For example, a scientist-founder connected the image of responding to a "crying baby" in the present with a picture of the child having one day "growing up" and "leaving home":

It [HTSU 1] takes a lot of my time. Maybe I want to go and do something different. And start looking at some new technologies. I'm a science and engineering person. I just want to go back into my sandpit and play again. And see what else I can see. (Scientist founder, HTSU 1)

In this way a future that was different from the current, more compromised, reality can be suggested as behind the capacity to de-prioritize some of their demands in the short term.

Inter-stakeholder links of understanding. A fourth strategy was outlined as creating links between stakeholders through fostering understanding and respect. Two scientist outline these links of understanding and respect respectively:

You've got to have enough knowledge. [The CEO] knows enough about what we are doing, we know a bit what he's doing so we can communicate. It's about creating these terms that we can all understand really. We understand when he says certain things and he understands when we say certain things. (Scientist founder, HTSU 1)

First of all it is about respect for each other. It's about generosity, acknowledging the contributions of everyone. (Scientist founder, HTSU 1).

Five interviewees identified inter-stakeholder understanding and respect as important in managing HTSU 1's legitimacy with multiple stakeholders.

The CEO summarises this as the ability to "help different stakeholders understand 
what's important to the other stakeholder." He continues:

What you're trying to do is communicate over the top of the wall backwards and forwards. Because you've got a bunch of people on this side who say the world's like this and a bunch of people on the other side who say the world's like that...it's sort of different ways of thinking and looking at the world. So what you try and do is stand on top of the wall and say "hey" what's it like over there and over the other side of the wall it's like this." So you try and give them glimpses of the other side. (CEO, HTSU 1)

Fostering respect for the different roles within the organization was identified as part of creating these links of understanding:

It's a matter of almost mutual respect and trust. Which is to say: 'well the scientists know what they are doing'...And that attitude needs to go in the other way as well. Yes the scientists know what they are doing and they can get on with it but so too do the other professionals doing other steps in this process. (Director, HTSU 1)

They (scientists) are saying "I'm not really interested in the stuff up there I really want to get this technology...you know that's what matters." That does matter and it's getting the board to respect that too. It's me educating the board saying "wait a minute here" this person who you see as not being so keen on business is actually one of the key individuals in the company because what's in his head is so vital. We're only good because of what he's got. (Scientist founder, HTSU 1)

An example of how this inter-stakeholder understanding was generated was the constant communication between the research groups and the company. Three interviewees highlighted these frequent meetings as being important in managing the tension between 'commerce' and 'science.' Another example was utilizing hybrid individuals to help span the commercial/science "divide":

That I'm on the board also and can see governance perspective of this and try and convey the values of governance to people who are really interested in [particular science area] or whatever. (Scientist founder, HTSU 1)

However, fostering these links of understanding did not entail transformation of scientists into business people:

You want some great scientists who just focus on the science...[but] you don't want to let them to all huddle up in a little group where all they are thinking about is the technology and forgetting that at the end of the day someone needs to buy this and it needs to be valuable to them. (CEO, HTSU 1)

This quote indicates the link between negotiation and the bounded compartmentalization strategy which will now be outlined. 


\subsubsection{Compartmentalization}

\section{Bounded separation.}

Most companies will very quickly want to distance themselves from the university because future investors don't like the idea that you have free-wheeling academics controlling the intellectual property. (Venture capitalist)

Maintaining a degree of separation between stakeholders was a final strategy discussed. This separation entailed structural elements (i.e., separation between the company and the university foundation) as well as entailing the general capacity for stakeholders to separate objectives and focus on one of them rather than others.

The following quotations expand on the venture capitalists' point above regarding structural separation from the university and technical foundation:

Probably the most important thing was forming the company outside of the university...I think if you are trying to do this kind of exercise giving the company a couple of rooms in the university to operate out of would almost be a death sentence...it's almost impossible to get the commercial discipline and focus into the organisation. (CEO, HTSU 1)

You have to have that separation. Otherwise you get bum decisions...or no decisions. (Director, HTSU 1)

However, this compartmentalization remained 'bounded' or restricted, as reflected in the sub-theme's label:

Don't go so far that you alienate your technical links... so if we'd gone and sited ourselves [far away] and had a purely commercial interface with the world it would have almost alienated our scientists...you choose carefully how far away from the scientists to bring it. (CEO, HTSU 1)

Compartmentalization was implemented in connection with the development of interstakeholder respect and understanding. This enabled the different stakeholders to get on with their own part of the organizational whole while restricting the degree of separation:

I'm not a management or a business type person, but I know enough to do those right elements...[but] you become totally useless if you try and do everything....and you've just got to trust that each person is going to do their part. (Scientist founder, HTSU 1)

This suggests that compartmentalization was not simply beneficial for the company vis- 
à-vis its commercial legitimacy demands but also the science-based demands of the scientists. The structural separation enabled the scientists to remain focused on science rather than being totally dictated to by the commercially oriented demands of the company:

My role is helping [HTSU 1] stay at the leading edge of technology. I'm not interested in the business side of things as such. That's not my area, I'm not interested. (Scientist founder, HTSU 1)

This was also important from the university manager's points of view. Through "not working on the pure business side of it" this separation enabled the scientists to continue to meet their science legitimacy demands dominant within the university context.

In summary, this strategy entailed different stakeholders focusing separately on different legitimacy demands while simultaneously keeping that segregation to a bounded level. This strategy and the others already outlined are outlined in Table 5.8. 
Table 5.8 Summary of main strategies: HTSU 1

\begin{tabular}{|c|c|}
\hline Strategies & Data sources \\
\hline & $\begin{array}{l}\text { Total HTSU } 1 \text { dataset } \\
\text { Interviewees: } 1-6 \text { Transcribed data: } 363 \text { minutes } \\
\text { External stakeholders [ES]: } 63 \\
\text { Secondary data [SD]: HTSU 1, SD 1-11 }\end{array}$ \\
\hline \multicolumn{2}{|l|}{ Transcension } \\
\hline Overarching objective & $\begin{array}{l}\text { Interviews: } 7 \text { interviewees [1-5; ES: 63] } \\
\text { Coding density: } 52 \\
\text { Secondary data: HTSU } 1 \text { SD 1, 5-7 }\end{array}$ \\
\hline Putting the company first & $\begin{array}{l}\text { Interviews: } 4 \text { interviewees }[1-3 ; 5] \\
\text { Coding density: } 39 \\
\text { Secondary data: HTSU } 1 \text { SD } 1\end{array}$ \\
\hline \multicolumn{2}{|l|}{ Negotiation } \\
\hline Managing the periphery & $\begin{array}{l}\text { Interviews: } 4 \text { interviewees }[1-3,5] \\
\text { Coding density: } 27\end{array}$ \\
\hline Links of understanding & $\begin{array}{l}\text { Interviews: } 5 \text { interviewees }[1-3,5,6] \\
\text { Coding density: } 33\end{array}$ \\
\hline \multicolumn{2}{|l|}{ Compartmentalization } \\
\hline Bounded separation & $\begin{array}{l}\text { Interviews:7 interviewees [1-6; ES: } 63 \text { ] } \\
\text { Coding density: } 27 \\
\text { Secondary data: Website [structural element of strategy] }\end{array}$ \\
\hline
\end{tabular}

\subsubsection{Less Prevalent Strategy}

Contraction. An alternative potential explanation of "contraction" was considered in relation to HTSU 1. Is the overarching objective more accurately defined as a process of contraction vis-à-vis the commercial objective of "growth"? Grounds for such an interpretation were contained in the interviews with the directors who at times appeared not to see how HTSU 1 was dealing with stakeholder legitimacies outside of the commercial. However, this was addressed as part of their solely commercially focused relationship to the overarching objectives. By contrast, coding this as contraction would have contradicted other interviews. It would have not explained the picture of active on-going management of non-commercial legitimacies outlined by the 
CEO and the additional legitimacy demands held by the scientist founders (for example, in relation to research and public good). The CEO's comment regarding the importance of not "alienating the technical links" was indicative. Consequently, a "focus" on commercial objectives was central as suggested by all interviewees. However, this commercial focus was attainable through transcension rather than contraction. This simultaneously enabled space for stakeholders to relate multiple legitimacy demands to that objective rather than it being contraction.

Finally, there were implicit assumptions evident in all interviewees that contraction may be a desirable strategy for the future, although not achievable yet. This was evident in the scientist's quote, outlined above, regarding seeing the future as meaning decreased involvement on his part and him returning to his "sand-pit" to "play." This suggests, though, that contraction was not yet a current strategy.

\subsubsection{Stakeholder Assessment of Strategies}

If you put all that together you say 'well this is quite virtuous'... I mean there are no losers out of this. (Scientist founder, HTSU 1)

No explicitly negative assessments regarding the strategies utilized were outlined by the participants (in contrast to HTSU 2 below). The three instances that came closest to being a negative assessment were: 1 ) the reflection by one of the other scientist founders that he was being "knocked in other areas" (although he associated this with the university system not HTSU 1); and 2) the university manager not being completely positive with how the research group related to the organization and also being explicitly wary of a public good objective. However, a scientist founder statement that: "I'm not saying that there aren't tensions there but they are managed" sums up the perception of the legitimacy strategies being utilized. This was reiterated by one of the directors: "None [tensions] that are unmanaged...and HTSU 1 wouldn't be on the path that it is going if the differences weren't being managed." The overall assessment of HTSU 1's legitimacy strategies by stakeholders, thus, appears to be positive. 


\subsubsection{Summary: HTSU 1}

In HTSU 1, interconnected transcension and negotiation strategies on the one hand and negotiation and compartmentalization on the other hand were observed. Generally, positive assessments of these strategies were evident.

\subsection{HTSU 2: Legitimacy strategies}

With the absolute objective of achieving financial outcomes - sales. (HTSU 2, Manager)

Sales were outlined as the primary current focus for HTSU 2, a sentiment illustrated in the above quote. There were, however, different strategies originating from this common starting point: on the one hand utilizing a broad transcendant "vision", and on the other hand a desire for a tightly contracted vision based on sales to a specific market segment.

The strategies discussed by HTSU 2 interviewees incorporate a temporal dimension and this is represented in Figure 5.8. A transcension strategy of promulgating an expanded vision had been utilized throughout the company's history. This was accompanied by a contraction strategy of avoiding investors who were perceived as potentially misaligned with such a strategy. Another contraction process had been enacted during the company's past; specifically, restructuring to become more commercially oriented. Finally, a more recent strategy, and one also projected by some interviewees as a vision for the future, was further contraction around a focused (rather than broad) vision.

The evolution of these strategies (for example, the need to further implement contraction) was at least partly related to crisis-like decision points concerning the company's cash flow. Such 'crisis' points are indicated in the quotation below:

We had to take redundancies because it was a real down time and he [CEO] explained it, put it up on the table: "here's our money, here's our cash flow in and out." And we just can't survive. (Scientist employee, HTSU 2)

It wouldn't have survived without it [the 'restructuring' strategy]. That was a survival step. (Investor, HTSU 2)

However, this evolution was also linked to a picture of natural transitions associated with HTSUs moving from basic to commercialized science. 


\section{Figure 5.8 HTSU 2: Legitimacy strategies}

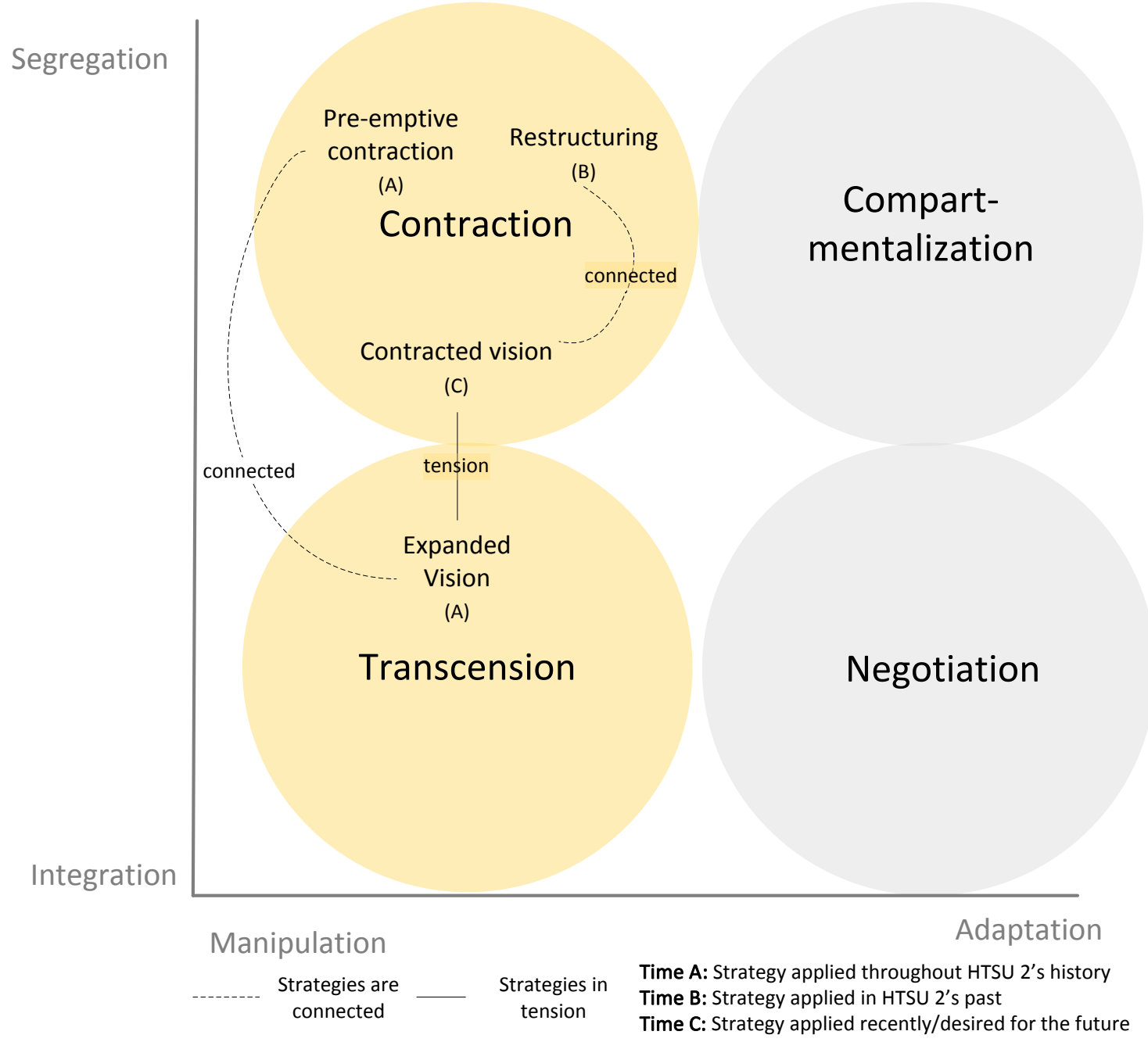

\subsubsection{Transcension}

\section{Expanded vision.}

It has a number of aspects to it other than just making money. We have three overarching objectives. One is to become a large profitable company...The second one is we really want to maintain a base in NZ...we want the heart of it to be here. And the third thing is that we all have an ambition to be part of major science breakthrough....t could be in [socially significant area one], some [socially significant area two] thing whatever. That's outside the money-making thing, we want to have that as well...why do people want to do this sort of thing? You see someone like Bill Gates throwing all his money at the grand challenge for global health - malaria and so on...money's great he's made lots of it, but he wants to do more than that. (CEO, HTSU 2)

The CEO's quote above exemplified the two aspects of this strategy: 1) a vision that incorporated being involved with a significant scientific discovery, being NZ based, and becoming a "billion dollar company"; and 2) a broad rather than defined conception of 
the market. This vision is reiterated by various participants as well as in the secondary data. It was largely implemented by the CEO and was directed at all stakeholders involved rather than being focused on a particular stakeholder or tension.

The intent of this strategy was to rise above the tensions between specific and immediate stakeholder legitimacy demands to create integration around that expanded vision. For example:

So what we do and how we do it is important. That doesn't mean we're naive about making money, because I think actually it drives us to make more... People think it's one or the other...I see it as actually a more sustainable way to make money... [T] hey [various stakeholders] see that I'm not just in it to make my own quick buck. Therefore I get away with a lot that I wouldn't get away with if you were just in it for the money. (CEO, HTSU 2)

The investor provides another example, explicitly linking HTSU 2's expanded vision with his decision to invest in it:

I've developed a phrase that unfortunately applies to...let's say 85 percent of companies I've encountered, and they're ghost ships. They have no heart. They have no purpose that is motivational...to me as a person I'm attracted to people and organisations with a mission to create something that's important. I'll give a hell of a lot more in that context than a company that is simply distributing profit to shareholders. (Investor, HTSU 2)

A broad vision for the company also allowed them to be flexible about their exact direction (i.e., target market) at different points in time. A manager explains:

The evolution of a small enterprise, is an unbelievable minute by minute dynamic process...you take the analogy of a sport like windsurfing, the lighter the wind and the more you try and stay still, the more likely you are to fall off...it works because you're constantly moving...constantly adjusting...running a small business, a start-up is very much like that...getting there could take you any number of different routes...that we might at some point be heading this way is pretty much immaterial provided that you're not stupid about it [and where you are heading]. (Manager, HTSU 2)

Three other interviewees similarly outlined that being NZ based (which was a clear part of the CEO's vision) was an additional motivating factor:

We are purely a NZ-based, NZ-owned company...It's us conquering the world almost...I think people are amazed "oh - this tiny little science company can be a competitor to an American company that's been in existence for twenty years. (Scientist employee, HTSU 2)

This strategy was partially enabled by an expanded vision of HTSU 2's market. For example, the founder links the expanded vision in the form of "[CEO] wants this to be a 
billion dollar company' to the practical implication of a broadly defined market. Such a vision entails capturing "the entire market, ...[developing] your own distribution channels, your own market brand, fighting those existing incumbents." The CEO and manager consequently remained "relaxed" about defining an exact direction or focus for the company:

We're still very, very heavily R\&D based. And we will be for a very, very long time. Because we have a platform technology, so it can be applied across lots and lots of different areas and each one has its own research challenges. (Manager, HTSU 2)

In all, various potential users and different broad market segments were highlighted, including within the secondary data.

A final point is the temporal one depicted in Figure 5.8 whereby this strategy had been in play throughout the company's lifespan:

Early on we did articulate some quite high values for [HTSU 2]: "We want to create a...[product] that could be used [to combat social issue]...there were some quite highideals. That is quite attractive to me...I think it wasn't particular well founded, it was never grounded scientifically, but I like those sort of ideals for a company. (Scientist Founder, HTSU 2)

As the company developed, however, contraction was reported as being enacted alongside this expanded vision.

\subsubsection{Contraction}

Interviewer: 'Just to summarise...you've managed these stakeholder relationships quite carefully in order to give you flexibility to do things.'

HTSU 2 CEO: 'Dead right. Maintain the control.' (CEO, HTSU 2).

Strategies aimed at reducing the stakeholder legitimacy demands that HTSU 2 was required to respond to were observed in two ways: 1) restructuring existing stakeholder relationships, and 2) pre-emptive avoidance of pluralism inducing new stakeholders. Continuing the line of thought contained in the quote above, the CEO notes the impetus behind these strategies:

We joke here: "it's not a democracy." So that's a little bit of the way we operate. It's a little bit autocratic...I've got more and more autocratic because l've seen how much time and energy we've wasted going down wrong tracks... [w] hereas when I first started with the founders I was quite happy to let them bubble along and it was only when it came to a crisis point that I realised that that didn't work. (CEO, HTSU 2). 
As these quotations indicate the intent was a reduction in the degree of power diffusion and, thus, the number of divergent objectives that company was required to manage. These strategies can be classified as manipulative (i.e., seeking to "manage" their context and stakeholders rather than adapt to them) as well as segregative (i.e., seeking to exclude particular stakeholders and their associated legitimacy demands).

\section{Restructuring internal stakeholders.}

How have I seen them [start-ups generally] manage those tensions? Most effectively when they bring in intermediaries early on...getting owner inventors to let go is probably one of the challenges world-wide. (External stakeholder)

As the references above suggests, the restructuring focused on the scientist founders, and occurred partly in response to the "crisis point" outlined by the CEO. All the HTSU 2 participants linked the founders being bought out (either to take up new roles in the company as employees/consultants or finish their association with the company completely) to the management of multiple legitimacy demands. That the restructuring enabled a focus on the commercial is reiterated in the HTSU 2 secondary data. It was also highlighted by external stakeholders (as in the quote above) as an important strategy for start-ups generally in managing tensions.

The following quotations outline this strategy. They also highlight that the rationale was to enable a more contracted focus on the commercial:

The first guys that were the discoverers, they are very much pure scientists: just play round and potter and see what discoveries they can make. But it needed someone with a sales/product development background to take it from this merely lab discovery to something you could sell and make money from. (Scientist, HTSU 2).

It's a painful death actually. It was a violent caesarean. I don't think it was a natural process. Because I don't think it is in anybody's nature, innately we do not like losing power...And some people who made very significant contributions to [HTSU 2's] beginnings are no longer here... There was nothing natural about it at all. I think it was ruthless but necessary. (Scientist Founder, HTSU 2).

The reference to the strategy being "necessary" in the above quote highlights that this contraction was perceived to part of the natural development of a company. This assisted the company in navigating that phase with (at least some) of those founders remaining partly involved: 
Right at the outset with the scientists I said: "look there's going to come a point in time where you're not suited to this organization. There's going to come a point in time where your skills and points of view, while they are fantastically suited to this early stage of things, will not always be suited"...before we really started out I didn't want any of them involved unless they agreed with that...we all knew from the outset that was inevitably what was going to happen. People haven't liked some aspects of how it happened, but everybody...acknowledges that...at the higher level...[it] played out the way that we initially knew that it would play out. (Scientist founder, HTSU 2).

This developmental picture of a start-up meant that some individuals with the scientific capability were able to understand and accept their changed position in the company, with the scientist founders interviewed being examples. Nonetheless, their reduction in decision-making power was evident as was the fact that others were now completely uninvolved:

He [scientist founder] gets upset with us because we...just don't acknowledge him...we don't want to deal with him...he's now held himself up as one of the founders of [HTSU 2]. From our point of view he was the one who nearly killed us. (CEO, HTSU 2).

Pre-emptive contraction. In addition to implementing structural changes to reduce the pluralism being experienced, another strategy reduced pluralism through actively avoiding particular demands by pre-emptively restricting the involvement of new stakeholders. In HTSU 2 this concerned potential investors and shareholders. This strategy was viewed as enabling a less diffused power context to be maintained and additional legitimacy demands, or "horrendous conditions" as the CEO describes them, to be avoided:

The drivers are quite different. I'm not very complimentary of $V C^{\prime} s$ - in fact I think they're a bunch of clowns... Their whole modus operandi is to herd all the investee companies all together and they then all circle around them like a bunch of predators ...And therefore the investee company is largely forced to accept the terms. It's not the money that's the problem, it's the terms that go with the money. Some of those terms are truly onerous and nobody in their right mind should sign up to them. (CEO, HTSU 2)

This strategy was noted by six (of the seven) HTSU 2 participants. It was also reflected in the secondary data, for example, HTSU 2's website (2010-2011) showed that their board consisted only of the CEO. The CEO also explained this strategy in the media as enabling him to maintain control.

The manager and two scientist employees largely reiterated the CEO's position: 
We've avoided the venture capital market because...of the degree of control [i.e., diffused power] and the nature of the framework [i.e., legitimacy demands] they want to put around the business doesn't fit with our view of that business. By that I mean often their primary goal is looking at an exit strategy...That isn't [CEO's] aspiration for the company. He wants to build a company that has value and keep it in NZ, not sell it offshore. So there's a fundamental philosophical difference between [the CEO's] view and what he wants to achieve as the owner of the company and the venture capitalists. (Manager, HTSU 2)

The ability of HTSU 2 to utilize this strategy of pre-emptively avoiding additional stakeholder demands was connected to what was outlined as the HTSU's unique resource in the CEO. The CEO was skilled at raising private investment, giving the company a strategic option that many other high-tech start-ups do not have. This point was made by three interviewees:

[HTSU 2's CEO] has been very successful in a very hard environment over the last couple of years in raising private shareholding input. So avoiding the need for venture capital by tapping into private investment, which of course is different. It means he retains control of the company, control of the direction and sort of potential end-game of the company...[by contrast] you do hear some horror stories of really neat NZ inventions being taken in a direction that the inventors didn't want to go, but actually they didn't have a choice because it was either that or die. (Manager, HTSU 2)

In pursuing this strategy HTSU 2 appeared to gain shareholders aligned with the broader vision (beyond ROI and commercial success) of the CEO. He reflected on this, stating: "you have in some cases some reasonably wealthy shareholders who also feel motivated by those issues." The CEO had explicitly sought out such individuals. This was also reflected by the HTSU 2 investor who contrasted his ability to have a relationship to this broader vision in his role as a private investor but that this was distinct from the narrower ROI criteria he applies when investing on behalf of an investment fund. For this reason this strategy is connected in Figure 5.8 to the desired expanded vision for the HTSU 2. Related to this was that through avoiding international investors they were able to maintain their overarching goal of being based in NZ and owned by NZers:

My argument: if I bring foreign money in, the company's going to go offshore. So I've resisted getting a lot of foreign [involvement]...from my point of view it doesn't fulfil my objective of a well-managed, well controlled company in NZ, owned in NZ, if I bring in a load of offshore money. Offshore people in the end will pull it offshore...The expressed expectation from FRST was foreign investment. And I'll say actually that's...wrong for what we want to do. (CEO, HTSU 2)

Contracted vision. Another strategy outlined by participants was that of moving towards further contraction. There were aspects to this strategy that were currently being 
implemented. However, it was frequently depicted more as something that participants saw as defining the company's future:

We've got to get to the point now where we stop trying to be all things to all people and get really really focused...that means there's a whole bunch of stuff we leave behind." (Scientist employee, HTSU 2)

This strategy of moving towards a more contracted vision is reflected in two ways, the desire for a solitary emphasis on the commercial legitimacies and the need to focus further on a specific market with regards to sales. This was summarized by a scientist employee as: "we need to get boring!"

The first aspect of this tension was the desire to primarily emphasise the commercial, particularly sales, rather than some of the more scientifically oriented legitimacies. An example was, as an employee phrased it, acting like "a research organization" rather than a commercial entity:

We have all these collaborations. That's great...But the reality is if that not does translate into money in the door then it becomes a liability actually. (Scientist employee, HTSU 2)

Another employee similarly argued that their collaborations were not always aligned with their commercial objectives but outlined that the company was already moving away from these towards a more contracted sales focus for that reason. The CEO also explains:

We're now saying we can't just be endless analysing stuff for other people... "we are a small company. We can't fund your research"... it's been a learning process for all of us, me included. (CEO, HTSU 2)

The secondary data however illustrated a degree of lasting focus on collaborations, suggesting there was perhaps still scope for further focus, as some interviewees suggested. For example, the website continues to highlight over twenty collaborations and a focus on collaborators (as opposed to customers) was evident in various media interviews (HTSU 2 SD 2, 3, 5, 6) and newsletters and press releases (HTSU 2 SD 9-13, 17-21).

A future, more specific, focus concerning to whom they were selling (i.e., a more clearly defined market) was noted by five interviewees as important strategically: 
It seems that our marketing is a bit hit and miss....[CEO] goes and sees a whole lot of people and suddenly says "I want to be able to do this." The next thing we get told is that we need to do this. But it's like "you've just meet ten people at a conference and that's suddenly our whole new direction?" (Scientist employee, HTSU 2)

It think a desirable [HTSU 2]...knows it's place in the world, knows what it is about...is focused and knows where it's going and can articulate that clearly and is not kneejerking from one potential market to another potential market.(Scientist founder, HTSU 2)

Another founder discussed how focusing and "not capturing the entire market" and becoming a "100 million dollar company", rather than a billion dollar one, was potentially a more desirable (and less risky) strategy, yet was not aligned with the expanded vision currently being promulgated. An employee also stated:

Because the [product] is applicable to such a range of [customers]... it's quite hard...we're trying to actually be a bit specific that way. So yes it's going to limit sales but it's going to make our sales more defined: what our sales markets are. I think in the short term, in terms of meeting investor requirements and building up the product and our sales and validation, it doesn't matter if we reduce our market. (Scientist employee, HTSU 2)

Steps towards a contracted vision for HTSU 2 was undertaken at the same time as the expanded vision. However, it was also a vision for the strategic future of HTSU 2 that in some ways contrasted with the expanded vision, for example, an argument was evident between a narrowly defined versus broadly defined market.

Table 5.9 HTSU 2 legitimacy strategies: summary

\begin{tabular}{|c|c|}
\hline Strategies & Data sources \\
\hline & $\begin{array}{l}\text { Summary of HTSU } 2 \text { dataset } \\
\text { Interviewees: 7-13; Transcribed data: } 464.5 \text { minutes } \\
\text { External stakeholders [ES]: 56, 57, 62, } 63 \\
\text { Secondary data [SD]: HTSU } 2 \text { SD 1-14 }\end{array}$ \\
\hline \multicolumn{2}{|l|}{ Transcension } \\
\hline Expanded vision & $\begin{array}{l}\text { Interviews: All HTSU } 2 \text { interviewees [7] } \\
\text { Coding density: } 35 \text { separate data segments, } \\
\text { SD: HTSU } 2 \text { SD 2, 4, 7, 8, 9, 13, website. }\end{array}$ \\
\hline \multicolumn{2}{|l|}{ Contraction } \\
\hline Restructuring & $\begin{array}{l}\text { Interviews: All HTSU } 2 \text { interviewees. } \\
\text { ES: general discussion of strategy as frequently necessary } \\
{[56,57,63] .} \\
\text { Coding density: } 32\end{array}$ \\
\hline
\end{tabular}


SD: HTSU 2 SD 2, 4, 7, website.

\begin{tabular}{c|l}
\hline & SD: HTSU 2 SD 2, 4, 7, website. \\
\hline Pre-emptive contraction & $\begin{array}{l}\text { Interviews: } 6 \text { interviewees }[7,8,10-13] \\
\text { Coding density: } 23 \\
\text { SD: HTSU } 2 \text { SD: 8, 6, website. }\end{array}$ \\
\hline $\begin{array}{c}\text { Contracted vision } \\
\text { (moving towards/desired) }\end{array}$ & $\begin{array}{l}\text { Interviews: } 9 \text { interviewees [7-13; ES: 62, 63]. } \\
\text { Coding density: 41 } \\
\text { SD: HTSU 2 SD 6; 8; 9; website. }\end{array}$ \\
\hline
\end{tabular}




\subsubsection{Less Prevalent Strategies}

Compartmentalization. As a consequence of the contraction strategy, the scientist founders were able to separate themselves from the commercial legitimacies and focus on the science. This was reflected in three interviews whereby the point that some scientists were able to operate separately from the corporate hub of the company was made. This was supported by a geographical separation of a particular "science team" and the commercial hub of the company. Nonetheless, this remained an implication of one of the main strategies rather than a defining process for the company.

An additional example relates to a particular interpretation of the research collaborations which HTSU 2 engaged in. Collaborations were a way the company could continue to access research capabilities and validation of the product while at the same time separating this activity from the core of the business:

That's [collaborator] the place to do that stuff. Those guys have the capability and the capacity to do blue skies type research... What we can't do is fund that blue skies research. The point of the partnership is that we are in partnership with people who can. So when you add all the contributions together you get a great project. (Manager, HTSU 2).

Evidence of this connection was made in four separate data segments by three interviewees and remains more of a minor strategy than something heavily emphasised. It was, however, also mentioned in an article describing HTSU 2's collaborations as enabling the company to continue to engage in research whilst ensuring this was done separately from the company's more commercial focus.

Negotiation. Negotiation was evident in relation to the ROI requirement and the investors involved. This was illustrated by two interviewees in three separate instances. One of the founders reflected on the importance of negotiating with investors during the early stages of HTSU 2, regarding the company's initial technology focus. The HTSU 2 investor provided a similar account of the importance of negotiating with shareholders in this way: "it's vital that you sit down with your shareholders and you articulate the period of investment and the period of return and that they're on board with that." However, analysis revealed small isolated instances of negotiation rather than its emerging as a central strategy. 


\subsubsection{Stakeholder Assessments of Strategies}

Different assessments regarding the strategies being utilized to manage HTSU 2's legitimacy in its pluralistic setting were evident (Table 5.10). More and less positive assessments of the implemented strategies are both evident. This is largely in relation to the tension between a contracted versus focused vision, with three interviewees in particular expressing a need to move beyond the current expanded vision. On the whole, contraction was assessed as something that was necessary and part of the company's development.

Table 5.10 Assessment of strategies: HTSU 2

\begin{tabular}{|c|c|}
\hline Strategies & Stakeholder assessment \\
\hline \multicolumn{2}{|l|}{ Transcension } \\
\hline $\begin{array}{l}\text { Expanded } \\
\text { vision }\end{array}$ & $\begin{array}{l}\text { Participants did assess the broader NZ focus of the company positively. CEO } \\
\text { appears to be driving this strategy, though recognized that some stakeholder } \\
\text { thought it was 'naive.' Some interviewees expressed concern around the lack } \\
\text { of focus in terms of particular market segments and the need to further focus } \\
\text { on sales }(9-13,62,63) \text { : } \\
\text { - "I thought they [HTSU 2] looked pretty academic." (External observer; implicit } \\
\text { critisim) } \\
\text { - "My belief is that we really need to get focused... we've had a very much scatter- } \\
\text { gun approach. So we go to a conference meet a whole bunch of people and react to } \\
\text { them coming to us." (Scientist employee) }\end{array}$ \\
\hline \multicolumn{2}{|l|}{ Contraction } \\
\hline Restructuring & $\begin{array}{l}\text { The general assessment is one of this being a necessity. Those who were } \\
\text { reported as assessing this strategy negatively are those who have been fully } \\
\text { contracted from the company. Their assessment therefore did not impact the } \\
\text { company anymore. }\end{array}$ \\
\hline $\begin{array}{l}\text { Pre-emptive } \\
\text { contraction }\end{array}$ & $\begin{array}{l}\text { General agreement regarding the CEO's perspective of this being a good thing } \\
\text { reiterated by the manager and two scientist employees. However, one of the } \\
\text { founders provides a more negative assessment (below) while the investor also } \\
\text { expressed concern regarding this strategy. } \\
\text { - "It would have been better for [HTSU 2] to have actually had people, investment, } \\
\text { come in a year ago that said "we want a seat on the board." I think that actually } \\
\text { some decisions that have been made because it's been a bit of a dictatorship have } \\
\text { not been the right decision...So I don't agree with that at all." (Scientist founder, } \\
\text { HTSU 2) }\end{array}$ \\
\hline $\begin{array}{c}\text { Contracted } \\
\text { vision }\end{array}$ & $\begin{array}{l}\text { Agreement regarding the need for further contraction (concerning a major } \\
\text { focus on sales rather than collaborations for example) was expressed by all } \\
\text { interviewees. Some interviewees viewed that further focus regarding the } \\
\text { target market was necessary, while the CEO and manager did not really }\end{array}$ \\
\hline
\end{tabular}




\subsubsection{Summary: HTSU 2}

The central story expressed with regards to HTSU 2 was transcension and contraction. Contraction was focused on managing scientist founders and (potential) venture capitalists. However, these contraction strategies had not focused on moving the company to a sole emphasis on a singular objective. For instance, the strategy of preemptively discounting a particular kind of investor (contraction) supported, at least partly, the broad vision of the company. Currently, the issue appeared to be the desire for an increasingly contracted focus (in terms of the commercial), potentially at the expense of this expanded vision.

\subsection{Summary: Chapter Five}

This chapter has considered the question of what strategies organizations are perceived as implementing to manage legitimacy demands in pluralistic contexts. It has highlighted that these organizations used a number of strategies simultaneously. This suggests that potential understanding regarding not only the individual strategies but combinations of strategies can be drawn from these findings. Four cases have been shown to have experienced crisis-like events in their histories and associated changes, or potential changes in the case of CRI 2, in strategies. By contrast, CoRE 1 and HTSU 1 were reported to have utilized similar strategies throughout their history and reported no such periods of crisis. Finally, it was shown that the strategies utilized by three cases (CoRE 1, CRI 1, and HTSU 1) were associated with largely positive stakeholder assessments, while this was not as apparent for the other three organizations included in this study.

The result of Chapter 5 is six distinct case-based stories organized similarly to enable cross-case comparison. Such cross-case comparison is the focus of Chapter Six. 


\section{CHAPTER SIX}

\section{Discussion: Theoretical Implications}

This chapter highlights the implications of the findings for the legitimacy literature. Intercase comparison and iteration between the empirical and theoretical domains are engaged in. First, the case-specific strategic pictures are brought together. This also involves comparing the empirical data with the legitimacy literature. Second, the contextual analysis (Chapter 4) is used to increase understanding of these legitimacy strategies. Third, a temporal picture of the six case studies is provided. Finally, the combinations of strategies are outlined as a central implication.

\subsection{Inter-Case Comparison of Legitimacy Strategies}

\subsubsection{An Overview}

A summary of the strategies within the six cases is depicted in Figure 6.1. This introduces the inter-case comparison. The organizations are clustered to highlight the similar strategies pursued by three organizations of different types (i.e., CoRE 1; CRI 1; HTSU 1). These organizations were found to implement transcension and negotiation. An additional rationale behind the clustering of these three organizations was that the stakeholder assessments of their strategies were more positive than in the other three cases (see: Chapter 5 above; Table 6.2 below). The second cluster shows that the other organizations implemented three individual strategy combinations. HTSU 2 was characterized by transcension and contraction. CoRE 2 similarly implemented a contraction strategy but combined it with negotiation. Finally, CRI 2 combined negotiation and compartmentalization. 
Figure 6.1 Summary of main strategies: 6 Cases

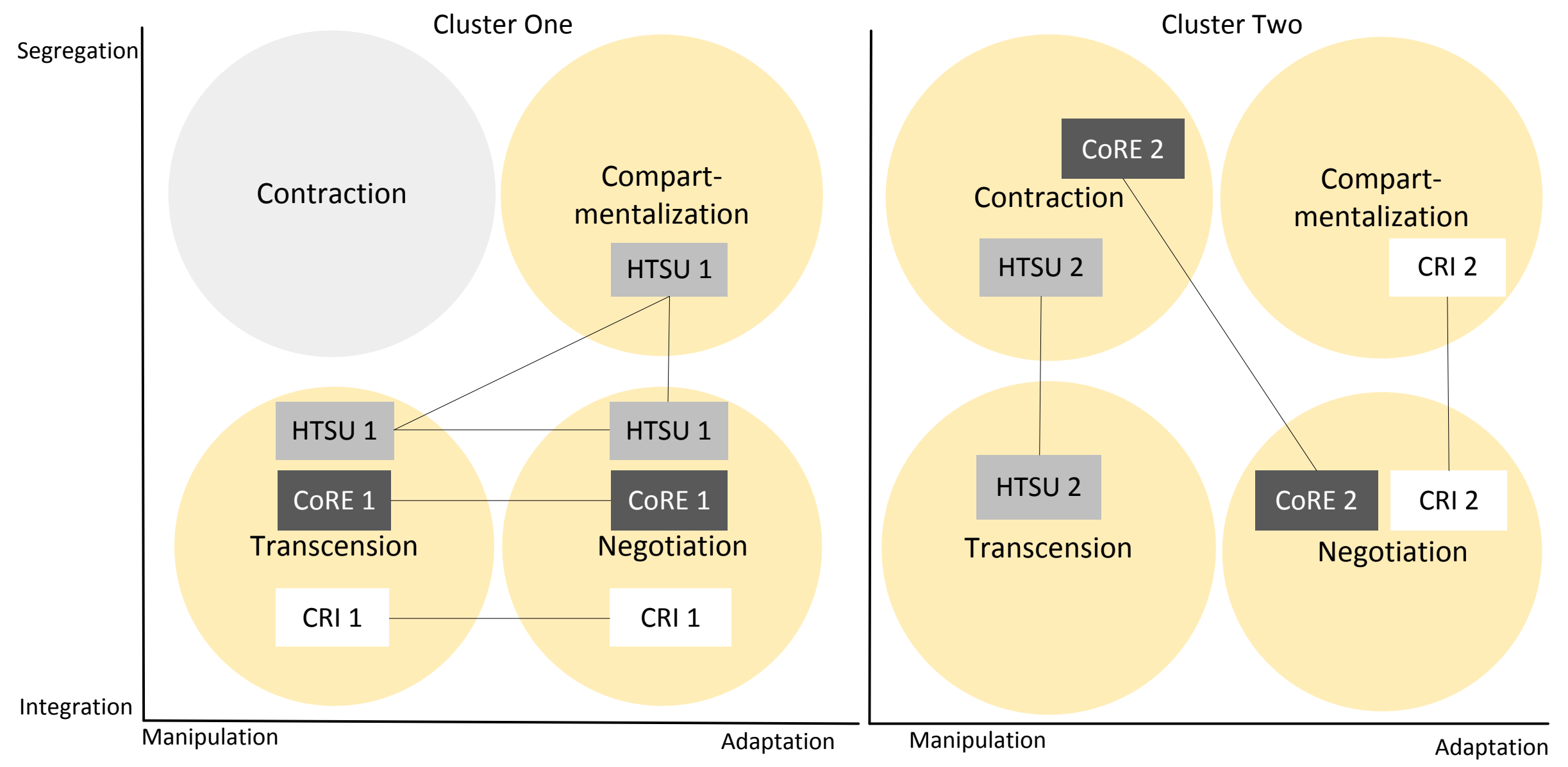




\subsubsection{The Legitimacy Strategy Framework}

Having provided this overview (Figure 6.1) the sub-themes will now be compared. The wide array of strategies surfaced is outlined in Table 6.1 and suggests support for the focal framework (Kraatz \& Block, 2008). Each of the surfaced strategies will now be considered, moving from more (transcension and negotiation) to less (compartmentalization and contraction) integrative approaches. This sequence reflects the prevalence of these more integrative strategies within the findings. 
Table 6.1 Summary of Legitimacy Strategies

\begin{tabular}{|c|c|c|}
\hline \multicolumn{2}{|c|}{$\begin{array}{l}\text { Legitimacy strategies } \\
\text { [perceived by participants] }\end{array}$} & Cases \\
\hline \multirow[t]{8}{*}{ Transcension } & \multirow{4}{*}{$\begin{array}{l}\text { Overarching objective / } \\
\text { expanded vision }\end{array}$} & $\begin{array}{l}\text { CoRE 1: 'Expanded vision'; connected to } \\
\text { 'expand what's expected.' }\end{array}$ \\
\hline & & CRI 1:'Overarching objective.' \\
\hline & & HTSU 1:'Overarching objective' \\
\hline & & HTSU 2: 'Expanded vision' \\
\hline & \multirow[t]{2}{*}{ Infusing with value } & $\begin{array}{l}\text { CoRE: 'Entwining within system'; Aspects of: } \\
\text { 'Leading the way'; and 'democratic } \\
\text { partnership." }\end{array}$ \\
\hline & & HTSU 1:'Putting the company first.' \\
\hline & \multirow{2}{*}{$\begin{array}{l}\text { Transformation } \\
\text { (creative enactment) }\end{array}$} & $\begin{array}{l}\text { CoRE 1: 'leading the way'; 'expand what's } \\
\text { expected' [linked to expanded vision]. }\end{array}$ \\
\hline & & $\begin{array}{l}\text { CRI 1: 'Self-determination"; 'Transforming } \\
\text { scientists.' [Linked to overarching objective]. }\end{array}$ \\
\hline \multirow{10}{*}{ Negotiation } & Democratic principles & CoRE 1: 'Democratic partnership.' \\
\hline & \multirow{2}{*}{$\begin{array}{l}\text { Collaborative } \\
\text { understanding }\end{array}$} & CRI 2: 'Utilizing interdependencies.' \\
\hline & & HTSU 1: 'Links of understanding.' \\
\hline & \multirow[t]{2}{*}{ Sense of balance } & CoRE 1: 'Maintaining balance' \\
\hline & & CRI 1: 'A flexible balance.' \\
\hline & \multirow{4}{*}{$\begin{array}{l}\text { Partial adaptation } \\
\text { (managing the periphery; } \\
\text { compromising) }\end{array}$} & CoRE 1: 'Managing the periphery.' \\
\hline & & HTSU 1: 'Managing the periphery.' \\
\hline & & CoRE 2: 'Compromising”' \\
\hline & & CRI 2: 'Compromising.' \\
\hline & Active bargaining & CRI 2: “Negotiating for more." \\
\hline \multirow{2}{*}{$\begin{array}{l}\text { Comparment- } \\
\text { alization }\end{array}$} & Bounded separation & HTSU 1: 'balanced separation' \\
\hline & Separation & $\begin{array}{l}\text { CRI 2: Separating science work from } \\
\text { financial/managerial concerns. }\end{array}$ \\
\hline \multirow{4}{*}{ Contraction } & \multirow{2}{*}{$\begin{array}{l}\text { Focusing on singular } \\
\text { objective }\end{array}$} & CoRE 2: 'Focusing on singular objective.' \\
\hline & & HTSU 2: 'Contracted vision' \\
\hline & $\begin{array}{l}\text { Restructuring stakeholder } \\
\text { power relation }\end{array}$ & HTSU 2: 'Restructuring' \\
\hline & Pre-emptive contraction & HTSU 2: 'Pre-emptive contraction.' \\
\hline
\end{tabular}


Transcension. Three transcension strategies were noted across four cases (Table 6.1). Such agency-intensive legitimation is widely recognized as being under-investigated within the legitimacy literature (Fligstein, 1997; Kitchener, 2002; Kraatz \& Block, 2008) (Chapter 2). That a wide range of transension strategies were contained in the findings helps address this omission.

The first strategic sub-theme was the use of an overarching objective/expanded vision to integrate various legitimacy demands. This varied depending on whether interviewees described an overarching objective (CRI 1 and HTSU 1) or an expanded vision made up of a collection of objectives (CORE 1 and HTSU 2). For instance, HTSU 1 was focused around "growth" as an objective that multiple stakeholders could relate to, albeit in different ways. HTSU 2, by contrast, articulated multiple objectives which formed a multifaceted vision. Despite both having an integrative impulse, the degree of integration differed. With an overarching objective, multiple legitimacy demands were brought together in relation to a single objective (Pratt \& Foreman, 2000). For example, CRI 1 reconfigured the legitimacy demands placed on it to clarify a public good 'purpose' that all other objectives worked towards. A less synergistic strategy would be closely joining two or more objectives together, to provide an encompassing vision, but not expressing that as a single objective (Pratt \& Foreman, 2000). This was evident in the case of CoRE 1: the 'research' and 'relevance' based legitimacy demands were brought together in a multifaceted expanded vision as opposed to a single overarching objective being evident. The concepts of a "synergy rhetoric" in the pluralism literature (Jarzabkowski \& Sillince, 2007) and that of an overarching frame and the ability to link contradictory objectives to it in the paradox literature (Lewis, 2000; Smith \& Tushman, 2005) are aligned with these examples. The findings here consequently indicate that constructing an integrating vision is potentially important as a way of strategizing for legitimacy within pluralism. This contrasts with other studies which imply that such an approach is unlikely or less desirable than others (Jarzabkowski et al., 2009a; Reay \& Hinings, 2009).

A second transcension strategy is transformation, a strategy the entails the ability to selfdefine (Kraatz \& Block, 2008). This encompasses dynamics that aimed to transform both internal and external stakeholders in CORE 1 and CRI 1. These were examples of "creative enactment": organizations seeking to expand the possibilities inherent in their context 
(Alexander, 1996). For instance, CRI 1 sought to expand the potential inherent within their context through transforming industry's relationship to research within NZ. The intent was to create an environment that enabled them to more easily meet both the demands for financial viability and public good delivery simultaneously. Interviewees reported a strategic focus on influencing the thinking in the Government's 'CRI Taskforce Report' to seek a degree of resolution regarding the tensions faced by CRIs. This indicated that CRI 1 was also engaged in transformation efforts vis-à-vis Government. CoRE 1 meanwhile seized the opportunity to self-define what a CoRE was supposed to be. Through leading the way they were able to flexibly embrace multiple legitimacy demands from multiple stakeholders in a 'self-directed' fashion that best suited them. These findings suggest that some organizations are able to self-define or transform the relevant legitimacy criteria upon which they are assessed (Ashforth \& Gibbs, 1990; Dowling \& Pfeffer, 1975; Kraatz \& Block, 2008; Oliver, 1991) as a way of managing their legitimacy within pluralistic contexts.

In both CORE 1 and CRI 1 transformation was also directed internally. These strategies focused on changing what it means to be a scientist. An example was specific socialization and educative activities seeking to enable CRI scientists to be more business aware. Another was utilizing the benefits PIs derived from CoRE funding to enable the CoRE to expect more from those scientists as a "tax" on that research funding. This involved "changing what it is to be an academic" as one interview describe it. Parallels can be drawn to Battilana and Dorado's (2010) depiction of socialization and training programs seeking to transform employees into hybrid individuals. While the concept of 'creative enactment' is usually applied in relation to the external environment and stakeholders (Alexander, 1996), this suggests that approaches that extend a context beyond its standard limits can also be focused internally. Here the importance of those internal stakeholders to the organization meant that they were a strategic focus. This suggests a distinction between these findings and the pre-occupation with external stakeholders within much of the legitimacy literature (Pache \& Santos, 2010; Stryker, 2000).

A third transcension strategy can be more directly linked with the concept of "infusing the organization with value" (Kraatz \& Block, 2008; Selznick, 1957). This was observed in CoRE 1 and HTSU 1. For example, in the case of HTSU 1 the identification of the scientist founders with the organizations was indicative: 
[HTSU 1] is like this baby that screams and you've got to be there for it...I can't let go!...its part of me and that's it. (Scientist, HTSU 1)

Viewing the start-up as infused with value provides an explanation for HTSU 1's strategy of the companies needs being put first by stakeholders, even when in conflict with some of their individual demands. In CoRE 1, a strategy of entwining themselves within their external environment to break down distinctions between them and external stakeholders was evident. For example, they blurred the boundaries between them and their partner organizations through not owning anything. 'Ownership' instead was located within the existing university system rather than the CORE competing for it. The CoRE consequently positioned itself as part of, rather than separate from, its external stakeholders. Selznick (1992, p. 234) provides the foundation for interpreting 'value infusion' in this way, arguing that it is not solely 'psychological' but also evident in the establishment of strong ties and alliances. While this was the most obvious example in CoRE 1, aspects of their other strategies such as 'leading the way' and embracing ideals of democratic inclusion were associated with high degrees of identification with the CORE by PIs and partner organizations beyond the research funds received. Hence, these were also indicative of value infusion. As Kraatz and Block (2008) suggest, through these strategies CoRE 1 and HTSU 1 were viewed as 'theirs' by their diverse stakeholders. They were therefore able to retain freedom and continued support even in the face of specific decisions that conflicted with more 'parochial' legitimacy demands. This understanding of "infusion with value" as a legitimacy strategy amidst pluralism extends previous research as it has been previously not been addressed by the literature.

Negotiation. The analysis also highlights the importance of negotiation: strategies focused around reaching compromise and balance through mutual adjustment between stakeholders (Kraatz \& Block, 2008; Lindblom, 1965). Four negotiation strategies were evident across five of the organizations.

A strategy of partial adaption was perceived in four cases (Table 6.1) and involved adapting to multiple stakeholder requirements partially (D'Aunno et al., 1991). First, a strategy of managing the periphery was evident in CORE 1 and HTSU 1. Partial adaption to legitimacy demands defined collectively as less central, but still recognized as important to particular stakeholders, was reported by interviewees. For instance, in HTSU 1 a central objective was 
agreed upon (i.e., growth). However, "around the edges" different stakeholders did add additional demands. These more 'peripheral' demands were then variably adapted to, in order to give everyone "enough happiness." The balance devised in CoRE 1 (discussed further below) was meanwhile centred on ensuring additional demands where incorporated in a partial way that did not compromise their "hard core" of science excellence. A similar dynamic was reflected within CoRE 2, where they sought to limit the effect of some legitimacy demands (for relevance) on their primary research excellence focus. These examples are illustrative of D'Aunno et al.'s (1991) point that organizations adopt a degree of hierarchy in managing pluralism demands. A link between these findings and studies that show how organizations adapt at the margins while simultaneously seeking to protect what is considered most 'sacred' can be inferred (e.g., Alexander, 1996; D'Aunno et al., 1991; Glynn, 2002).

A second partial adaptation dynamic was compromise. In contrast to 'managing the periphery' above, this was more indicative of 'partisan mutual adjustment' than negotiation in relation to an overarching or prioritized objective (Jarzabkowski et al., 2009a; Lindblom, 1965). CRI 2 and CoRE 2 provide examples of a trade-off with regards to one legitimacy demand in order to meet others. For example, CRI 2 compromised its research outputs to fulfil short-term financial demands. Similarly, in CoRE 2 a singular research excellence focus was compromised to meet stakeholder's relevance-based demands. However, they also simultaneously compromised with external stakeholders regarding the need to demonstrate direct contribution to the economy. These findings support the argument that strategizing amidst pluralism frequently does not result in "resolution" but rather compromises by stakeholders who, grudgingly, recognize its necessity (Jarzabkowski, et al., 2009a; Kraatz \& Block, 2008; Reay \& Hinings, 2009).

A closely related approach was an explicit emphasis on maintaining a flexible balance. This was evident in CORE 1 and CRI 1 where they focused on avoiding becoming imbalanced with regards to any of their objectives. This entailed maintaining broad and flexible parity between demands. Unlike the strategy above (CoRE 2; CRI 2) this balance was not explicitly associated with one legitimacy demand requiring compromises in another, but with divergent objectives being achieved if balanced correctly. For example, in CRI 1, preventing any objective from dominating was viewed as part of ensuring that all objectives supported 
the CRI's defined overarching purpose. This last point is indicative of the relationship between negotiation and transcension that was evident in some cases. For CoRE 1, this strategy was about balancing multiple demands to ensure that additional demands did not detract from the maintenance of their research excellence. This balance was therefore part of CORE 1's strategy of managing the periphery (i.e., non-research excellence objectives) outlined above. This strategy remains distinct from the managing the periphery outlined in HTSU 1 which was about managing imbalance rather than avoiding it. This finding of balance is reflected in the theoretical frameworks this study has drawn from (Kraatz \& Block, 2008; Oliver, 1991).

Collaborative understanding entailed developing collaborations through inter-stakeholder understanding and recognition of interdependencies (Reay \& Hinings, 2009). This was evident in two cases. In HTSU 1 a strategy highlighting the links between and importance of different stakeholders to each other was evident. This was depicted as fostering 'respect' and 'understanding' between the commercially and scientifically focused stakeholders. This has similarities to Pratt and Foreman's (2000, p.32) aggregation strategy and its focus on "forging links." In CRI 2 a strategy involved building mutual recognition of (and then strategically utilizing) the interdependence within their relationship with their clients to create a collaborative dynamic. This then enabled those stakeholders' demands to be negotiated. Recognition of interdependencies between stakeholders has previously been shown to be a way of negotiating pluralism (Jarzabkowski, et al., 2009a), and highlighted as having the potential to result in pragmatic collaborations (Reay \& Hinings, 2009). However, despite such isolated empirical examples, this collaborative finding contrasts with the assumption of competition and conflict apparent in the majority of research (e.g., Glynn, 2000; Oliver, 1991; Sonpar et al., 2010).

Two final strategies were evident in CRI 2 and CoRE 1. First, a negotiation strategy in CRI 2 can be differentiated through incorporating more explicit bargaining element (Lindblom, 1965; Oliver, 1991). CRI 2 sought to negotiate for more (either money or a reduced ROI requirement) from particular stakeholders to enable CRI 2 to meet their multiple demands. An example was alerting clients to the consequences if they were not mindful of CRI 2's dilemmas. Second, a distinct negotiation strategy was evident in CoRE 1. They utilized 'democratic principles' as a way of reaching solutions accepted by multiple stakeholders. 
This ensured a sense of representation and inclusion in decision-making among stakeholders. Consequently, even when some elements of the CoRE were less aligned with a particular stakeholder's demands, a sense of 'parity' (Oliver, 1991) and fairness was maintained. This strategy included structural elements such as a democratically elected decision making body where issues could be debated and multiple perspectives represented. Such a strategy does not appear to have been previously noted in the literature.

Compartmentalization. Compartmentalization was not as prevalent as transcension or negotiation. Nonetheless, two compartmentalization strategies were found and support the use of 'separation' as a way of managing pluralistic legitimacy demands (Kraatz \& Block, 2008; Meyer \& Rowan, 1977; Pratt \& Foreman, 2000).

Bounded compartmentalization was evident in HTSU 1. This entailed separating stakeholders and/or legitimacy demands, but simultaneously limiting the degree of this segregation. In HTSU 1 segregation was evident in decisions regarding the structure of the organization that ensured separation between the company and its academic foundation. Segregation was also evident at the individual level where a degree of separation from the organization enabled individuals to focus on a single objective such as technological excellence. HTSU 1 suggests a slight adaptation of 'pure' compartmetnalization described in the literature (Kraatz \& Block, 2008; Praat \& Foreman, 2000). In HTSU 1 this separation was bounded in its close association with the negotiation strategy of developing linked of understanding between stakeholders. This placed limits on that segregation. This finding of combining strategies (e.g., compartmentalization and negotiation) will be returned to in greater depth in Section 6.4 .

In CRI 2 a strategy focused on separating the science work (both in terms of 'research' and 'service') from commercial legitimacy demands was described by interviewees. One example was CRI scientists deliberately separating their service delivery from managerial overview and the CRI's commercial demands (Meyer \& Rowan, 1977). This is an example of decoupling occurring intra-organizationally, between scientists and managers in this case. This differs from the dominant treatment of this strategy as a way of managing external legitimacy demands amidst pluralism (e.g., Elsbach \& Sutton, 1992). Separation of research from the service work in the organization and managers shielding scientists from the CRI's 
commercial pressures were also evident. As a scientist mentioned, CRI 2 scientists appreciated being told: "your job is to do the science."

Contraction. Two case studies utilized contraction (Figure 6.1), with three strategies used to reduce pluralism.

CoRE 2 implemented a strategy of focusing on a singular objective (research excellence) through ignoring other demands (Kraatz \& Block, 2008; Oliver, 1991). For example, they initially did not put any resources towards outreach activities or connecting to end-users, something which government (as the funding stakeholder) demanded. The assumption was that their singular focus would enable them to excel to such a degree vis-à-vis their science that other demands would not affect them. Focus through contraction was also observable in HTSU 2 where many stakeholders desired a focused tightly defined sales goal. Contraction is frequently depicted as a unsuccessful strategy for pluralism contexts (e.g., Humphreys \& Brown, 2002; Kraatz \& Block, 2008; Sonpar, et al., 2010). This was observable in CoRE 2 where the diffused power nature of their context meant they were not able to 'escape' (Oliver, 1991; Suchman, 1995) the additional stakeholder demands. Stakeholder reaction to CoRE 2's lack of attention to some legitimacy demands prompted a shift in their strategy.

HTSU 2 exhibited two other forms of contraction. Pre-emptive contraction entailed intentionally attempting to avoid particular stakeholders and their demands. In HTSU 2's case, venture capital was avoided to limit power diffusion away from management and the introduction of additional demands. Second, contraction through restructuring stakeholder power dynamics occurred. Here the original scientist founders were bought out to enable a more commercial focus in HTSU 2. Both of these strategies mirror emphases in the resource dependence literature concerning an organization's ability to 'select' or 'escape' its context to choose more homogenous one (Dowling \& Pfeffer, 1975; Oliver, 1991; Suchman, 1995). HTSU 2 also provides a contrast with the literature's argument that contraction is usually undesirable (Kraatz \& Block, 2008; Smith \& Lewis, 2011). Instead, in HTSU 2 there was no evidence of the suggested escalation of conflict usually associated with contraction (Jarzabkowski et al., 2009a). In this way it offers a distinct perspective to the negative one commonly promulgated. 


\subsubsection{Reflecting on the Framework}

The focal legitimacy strategy framework (Kraatz \& Block, 2008) has not previously been empirically explored. Indeed, a summary of the literature is that empirical studies have tended to focus on idiosyncratic strategic responses rather than referring back to or constructing broader frameworks such as Kraatz and Block's (Pache \& Santos, 2010). The findings here suggest support for the use of the framework to gain understanding into legitimation in pluralistic contexts.

In contrast to much of the underlying assumptions within legitimacy theory (Ashforth \& Gibbs, 1990; DiMaggio \& Powell, 1983; Dowling \& Pfeffer, 1975; Suchman, 1995), simple acquiescence to stakeholder demands provided little explanation regarding the legitimacy strategies implemented here. For instance, transcension has been less frequently investigated as a legitimacy strategy. However, the findings suggest that organizations in pluralistic settings are likely to utilize agency-intensive strategies. This study consequently provides a contribution regarding our understanding of agency-intensive legitimation (e.g., Alexander, 1996; Kraatz \& Block, 2008). In comparison, the empirical development of acquiescence or isomorphism (Deephouse, 1996; Galaskiewicz \& Wasserman, 1989; Tolbert \& Zucker, 1983), decoupling (Hirsch \& Bermiss, 2009; MacLean \& Behnam, 2010; Westphal \& Zajac, 2001) and even negotiation (D'Aunno et al., 1991; Glynn, 2002) has previously been more extensive.

Two additional examples of how the empirical findings add insight are worth reiterating. First, was the finding of democratic partnership as a negotiation strategy. This has not previously been suggested in the literature. Second, increased insight into contraction was provided through examples of it as enabling in one case (HTSU 2), while less positive in another (CORE 2). As suggested above, this more multi-faceted perspective is distinct from the largely negative portrayal of contraction in the literature.

That organizations appear likely to combine multiple strategies is evident in the findings. Before focusing on this point in greater depth, additional understanding of the specific strategies will first be sought through linking them with aspects of the pluralistic context. 


\subsection{Legitimacy Strategies and Perceptions of Pluralism}

Suchman (1995) indicated the question of whether particular contextual conditions are particularly suited to particular legitimacy strategies as an area for future legitimacy research. This question is equally applicable for pluralistic contexts. Within pluralistic settings, why might one legitimacy strategy, rather than another, be implemented?

Due to the focus on pluralism of this thesis, the understanding developed here of the organizational context centred on diffused power and divergence. All six cases were found to experience pluralism. However, participants in some cases (e.g., CoRE 2) were shown to perceive higher degrees of divergence and/or power diffusion than those in the comparable organizations of similar type (e.g., CoRE 1). This distinction is represented by ++ (higher perceived power diffusion and/or objective divergence) and + (less high, although still within pluralism "quadrant") in Figure 6.2 and Table 6.2.

Patterns between these distinctions (Chapter 4) and the strategies implemented by the different organizations (Chapter 5) were then examined. Despite two organizations dealing with broadly similar tensions and power dynamics (e.g., the two CRIs) different strategies were implemented by these organizations. Indeed, a common pattern in strategic approach was observed across three organizations of a different type (e.g., CoRE 1, CRI 1, HTSU 1). Differences in how the dimensions of pluralism were perceived in each case emerged as one way of understanding this. As will become evident below, the performance aspect of these strategies, something explored through stakeholder assessments, also appears helpful in interpreting these associations. This is, therefore, also included in Table 6.2. 
Table 6.2 Legitimacy strategies, context, and stakeholder assessments

\begin{tabular}{|c|c|c|c|c|c|}
\hline $\begin{array}{l}\text { Case } \\
\text { Study }\end{array}$ & $\begin{array}{l}\text { Strategies utilized } \\
\text { (Chapter 5) }\end{array}$ & $\begin{array}{l}\text { Strategies explicitly } \\
\text { excluded } \\
\text { (Chapter 5) }\end{array}$ & $\begin{array}{l}\text { Perceived degree of } \\
\text { diffused power } \\
\text { (Chapter 4) }\end{array}$ & $\begin{array}{l}\text { Perceived degree of } \\
\text { divergence } \\
\text { (Chapter } 4 \text { ) }\end{array}$ & $\begin{array}{c}\text { Stakeholder assessments of main } \\
\text { strategies success } \\
\text { (Chapter } 5 \text { ) }\end{array}$ \\
\hline CoRE 1 & $\begin{array}{c}\text { Transcension; } \\
\text { Negotiation }\end{array}$ & Contraction & 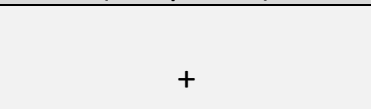 & ${ }^{2}$ & 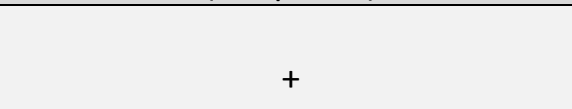 \\
\hline CORE 2 & $\begin{array}{l}\text { Contraction } \\
\text { Negotiation }\end{array}$ & Transcension & ++ & ++ & $+/-$ \\
\hline CRI 2 & $\begin{array}{c}\text { Negotiation } \\
\text { Compartmentalization }\end{array}$ & Contraction & ++ & ++ & $+/-$ \\
\hline HTSU 1 & $\begin{array}{c}\text { Transcension } \\
\text { Negotiation } \\
\text { Compartmentalization }\end{array}$ & None & ++ & $\begin{array}{l}\text { No clear distinction } \\
\text { evident between two } \\
\text { cases }\end{array}$ & + \\
\hline
\end{tabular}


Figure 6.2 Dimensions of pluralism and strategies

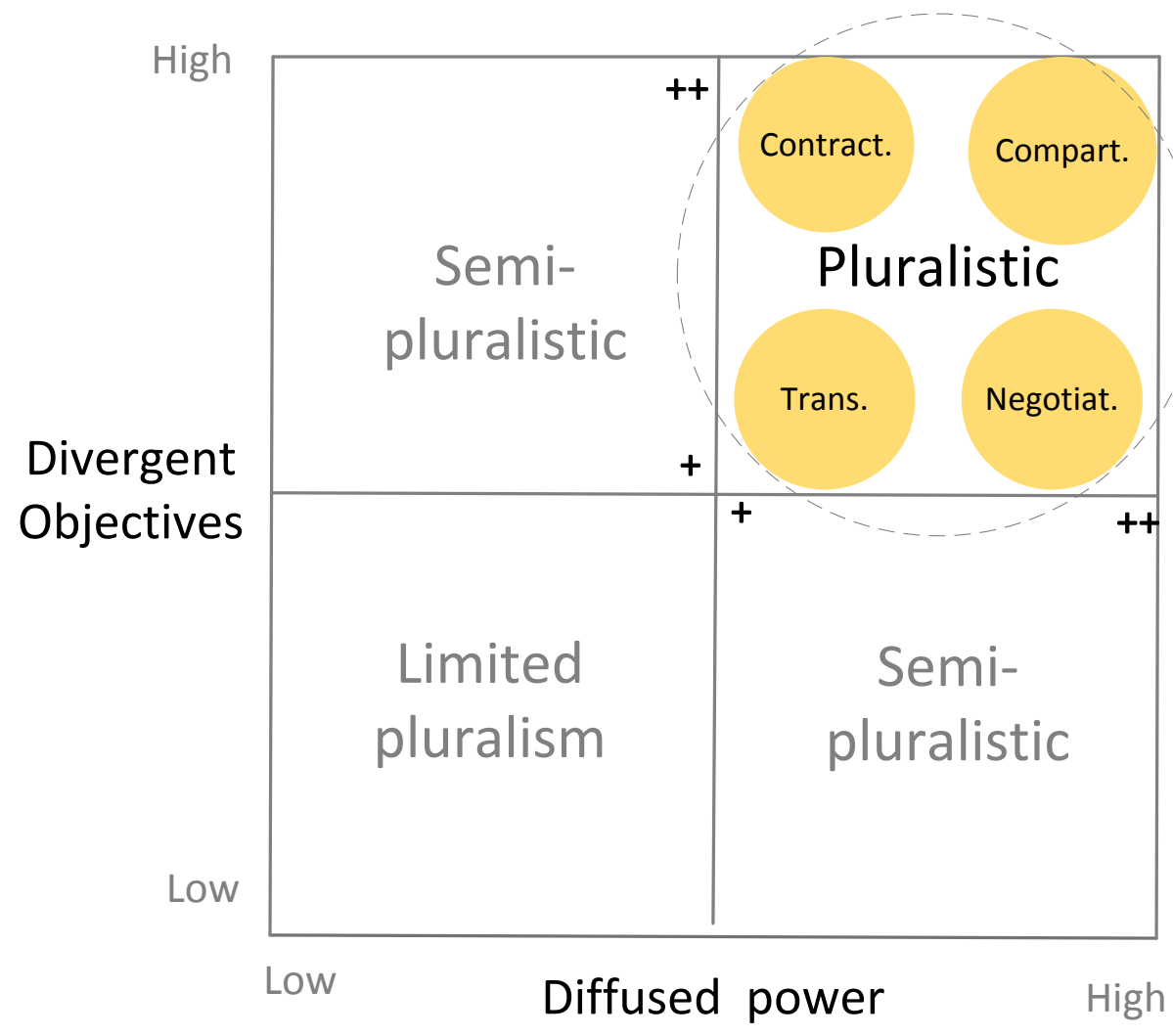

Pache and Santos (2010) outline the need for increased understanding into when individual strategies may or may not be applied to a pluralistic setting. The only insight available is the broad one that acquiescence is unlikely (Oliver, 1991). The development here adds to this through focusing specifically on the dimensions of pluralism. The value of this is increased insight into when organizations facing "similar conflicting demands may experience them differently and, in turn, mobilize different responses" (Pache \& Santos, 2010, p. 459). Pache and Santos cite George et al.'s (2006) cognitive perspective and their argument that patterns of isomorphism depend on whether change is perceived as a threat or opportunity. While a specifically cognitive analysis was not adopted here, the distinctions in internal stakeholders' perceptions regarding divergence and power diffusion can be connected to this research agenda. A further rationale for a focus on 'perceptions' was its alignment with post-positivism. Such a position focused this study on interviewee perceptions and is tentative about the ability of interview data to enable correspondence with reality beyond those perceptions (Phillips \& Burbules, 2000). 
Four propositions will now be developed as a basis for further investigation. They suggest associations between differences in perceptions of divergence and power diffusion and the resultant strategies. They also incorporate an assumption concerning time and assessments of success. For instance, an organization can implement strategies that are less aligned with its contextual dynamics. However, this will be argued to be often linked with less positive stakeholder assessments. One consequent interpretation is that over time either the strategy or the perceptions are likely to change in line with the theorizing here. For example, CRI 2 was currently looking for a new approach while its perceptions of higher (++) degrees of divergence being, according to the proposition below, were misaligned with its implemented negotiation strategy.

\subsubsection{Contraction and Perceptions of Pluralism}

A link between divergence being perceived as particularly high (++) and the implementation of a contraction strategy is proposed. In the case of CoRE 2, the perceived divergence was found to be comparatively higher. For example, one director explained how: "everything else you do works against excellence. You pour money into other things you take it away from excellence." This partly explains why CoRE 2, despite being aware of the variety of legitimacy demands, initially still chose to focus on only one of them. Conversely, both cases (CORE 1, CRI 1) that were classified with relatively lower degrees of perceived divergence (+) explicitly discounted contraction as a strategy.

Pratt and Foreman (2000) theorize that low-synergy responses such as 'deletion' are more likely when the degree of compatibility is particularly high. The greater the degree of divergence, the less feasible integration is thought to be. Oliver (1991) likewise suggests that a high degree of divergence between internal and external demands increases the likelihood of strategies of defiance as well as avoidance through "escape." Oliver's argument has been explored empirically with varying degrees of support. However, the single measures of 'objective congruence' used in those studies cannot be said to be fully incorporative of pluralism (Goodstein, 1994; Ingram \& Simons, 1995).

Second, a link between perceptions of a lower degree of power diffusion $(+)$ and the likelihood of a contraction strategy is proposed. HTSU 2 suggests such a connection. For 
example, the CEO outlines that much of the product innovation came from him rather than the scientist founders. A link is suggested here between that perception, which entails an assumption of a lower degree of diffuse power, and contraction with regards to those scientist founders. This link between comparatively lower perceptions of power diffusion and contraction was further supported by the cases which did not utilize contraction. For example, in HTSU 1, they explicitly linked their dependence (++ power diffusion) on "technical links" to a lack of contraction. Further, their discussion of any future movement towards contraction was linked to a scenario where this reliance had reduced $(+)$.

In CoRE 2, the perceived degree of power diffusion was outlined to be higher $(++)$, which appears to be inconsistent with this association. However, the fact that contraction attempts failed in their case can be connected to government enforcing their position as funder and evaluator of CoREs. Perceptions of higher $(++)$ degree of diffused power potentially grew as part of this and led to contraction being seen as less viable than it initially had been. Other strategies that reflected this were consequently pursued. As such, while the interview data do not allow full insight into the existence of a temporal shift in perceptions, CoRE 2 is potentially an example where feedback from the environment changed perceptions. Negative feedback, and associated action, from external stakeholders likely prompted the perception of power diffusion to increase $(++)$ and a negotiation strategy then becoming dominant in line with that change. One potential explanation is of initial perceptions of lower power diffusion (+) being linked to contraction during "Phase One" of the CoRE prior to this change in perception.

Contraction being associated with a lower degree of power diffusion can also be inferred from the literature. Oliver (1991) indicates that the lower the dependence on 'institutional constituents', the greater likelihood of defiance strategies. An association between low degrees of 'institutional pressure', in relation to internal 'countervailing power', and defiance strategies has been similarly illustrated empirically (Goodstein, 1994; Ingram \& Simons, 1995). Pratt and Foreman (2000) also link 'deletion' strategies to contexts when the 'identity' being deleted is not associated with powerful stakeholders. Jarzabkowski et al.'s (2009a) study can also be interpreted as providing an example where stakeholders' ceasing their attempts at marginalization were connected to growing recognition of their mutual dependence on other stakeholders and logics. This can be inferred as indicative of increased 
perceptions of power diffusion (++) by those involved resulting in contraction becoming abandoned.

Based on these insights it is suggested that:

Proposition 1: Contraction is more likely to be implemented when 1) stakeholders' objectives are perceived to be incommensurable (++); and 2) when the level of power diffusion is perceived to be lower (+).

\subsubsection{Compartmentalization and Perceptions of Pluralism}

CRI 2 interviewees perceived higher $(++)$ power diffusion and higher divergence (++) between objectives. In this case, the perceived degree of divergence between the "commercial" and "public good" demands can be associated with CRI 2's compartmentalization strategy. The strategy of scientists decoupling aspects of their service delivery is associated with perceptions that the CRI's commercial objectives explicitly stood in the way of their public good work (i.e., were highly divergent). Likewise, that the CRI separated aspects of its research capabilities and service work can be associated with relatively higher perceived divergence between those two activities. For example, they had distinct 'research' and 'service' scientists, indicating that a strong distinction between the two was made. Furthermore, in CRI 2 those dictating the various legitimacy demands (e.g., government and clients) were perceived as too powerful to ignore or directly manipulate that is, particularly high (++) power diffusion. This suggests that the heavy emphasis by powerful clients on service was part of what led the CRI to compartmentalize its research components.

HTSU 1 also suggests a link between compartmentalization and perception of higher diffused power (++) and higher objective divergence (++). A distinction regarding relatively higher or lower divergence was not possible between the HTSUs. Nonetheless, the need to separate HTSU 1's commercial operations from its "academic" scientific foundation was related to the perceived degree of divergence between those objectives. For example, the divergence was such that the "commercial" was perceived as needing to be protected through this compartmentalization. It was also, however, outlined that HTSU 1 could not alienate the providers of the science capabilities through marginalizing them or not giving them "some happiness" (i.e., contraction) (power diffusion: ++). Consequently, the more 
adaptive compartmentalization strategy enabled them to keep those stakeholders on board. This compares with HTSU 2's contraction strategy and associated perceptions of relatively lower power diffusion (+).

Oliver (1991) and Pratt and Foreman (2000) provide similar perspectives. For example, in Pratt and Foreman discuss the compartmentalization of identities as a strategy more likely in situations where the "compatibility...of the identities is low" (i.e., level of divergence) and "support by powerful stakeholders for" (p. 26) a particular identity is high. Oliver outlines that strategies of avoidance (which include decoupling) are more likely in contexts of higher dependence on constituents than defiance and manipulation strategies. Elsbach and Sutton's (1992, p. 710) case studies can be inferred as an example of this association. In their studies the level of divergence between constituent demands was so high that illegitimacy with one group legitimated it with another. However, at the same time "survival and effectiveness" of those organizations depended on engagement with both groups. Decoupling was the consequent organizational response.

Based on these insights it is suggested that:

Proposition 2: Compartmentalization is more likely to be implemented when 1) stakeholders' objectives are perceived to be incommensurable (++); and 2) when the degree of power diffusion is higher $(++) .{ }^{26}$

As with all of these propositions, the above association does not exclude moderating factors. For instance, a high degree of scrutiny is said to make compartmentalization amidst pluralism difficult (Ashforth \& Gibbs, 1991; Krratz \& Block, 2008). Compartmentalization strategies are argued to be premised on an ability to decrease the visibility of particular activities and, thus, buffer the organization from scrutiny (Meyer \& Rowan, 1977; Oliver, 1991; Westphal \& Zajac, 1995). This offers an explanation for why CoRE 2, despite higher perceptions of divergence and power diffusion, did not implement compartmentalization. The reported increased scrutiny by government in response to CoRE 2 reaching a "crisis"

\footnotetext{
${ }^{26}$ This proposition and discussion concern compartmentalization generally as opposed to decoupling specifically. Discussions of decoupling have related more to power imbalance and the split between substantive (linked with powerful stakeholders) and symbolic (linked with less powerful stakeholder) action rather than the overall level of perceived power diffusion (George, et al., 2006; Westphal \& Zajac, 2001).
} 
point may have made compartmentalization (for example, separating the responses for internal and external stakeholders) less viable.

\subsubsection{Negotiation and Perceptions of Pluralism}

With a majority of organizations implementing negotiation strategies, proposing a pattern vis-à-vis particular perceptions was less immediately obvious. However, through drawing on both the empirical data and the literature an association between negotiation and the dimensions of pluralism can still be argued.

A link between perceptions of higher degrees of power diffusion (++) and negotiation was evident in CORE 2, CRI 2, and HTSU 1. In these organizations perceptions of a relatively higher degree of power diffusion can be connected to the use of negotiation to adapt to, balance, and accommodate multiple demands. For example, increased awareness regarding the power of government in CoRE 2 was connected to negotiation (rather than contraction) becoming the dominant response. Another example was in HTSU 1: a link can be suggested between the perceived importance of the scientists and the CEO engaging in negotiation "to keep everyone happy at least some of the time." This was despite his expressed preference for a more singular focus. Negotiating a compromise and bargaining in CRI 2 was similarly indicative of being "caught between" powerful stakeholders. This required more adaptive responses, rather than ignoring or manipulating them being viable.

This link can also be inferred within the literature. Oliver (1991) outlines that 'compromise' is more likely (than 'manipulation' or 'defiance') in contexts where dependence on institutional constituents is high (Goodstein, 1994; Ingram \& Simons, 1995). Pratt and Foreman (2000) similarly argue that aggregation (forging links) is more likely in situations where powerful stakeholders support multiple identities. Empirical examples connecting negotiation strategies to recognized mutual dependence amongst stakeholders have also been noted (e.g., Jarzabkowski et al., 2009a; Reay \& Hinings, 2009).

In addition, negotiation was observed in association with lower perceived diffused power in two organizations (CORE 1 and CRI 1). Negotiation in these organizations can be partly explained by their simultaneous utilisation of transcension strategies that also made the most of that greater degree of perceived potential agency, that is, the degree of power 
diffusion being perceived as relatively lower $(+)$. This suggests that also thinking about these strategies in a combinatorial way is important, something addressed further below.

A link between negotiation and perceptions of lower degree of divergence (+) helps explain the utilization of negotiation by CoRE 1 and CRI 1 outlined above. In CRI 1, the strategy of striving for balance between objectives, rather than one particular demand being dominant, was connected to those objectives being perceived as somewhat commensurable. For instance, financial viability and research worked together towards the fulfilment of CRI 1's purpose if balanced. Likewise, in CORE 1 the strategy of 'democratic partnerships' was linked to perceptions that collaboration within a competitive system was possible. This contrasts with a situation where competition and collaboration were viewed as largely incommensurable, a perspective that was more apparent in CoRE 2.

Successful negotiation is associated with a capacity to demonstrate connections and negotiate compromises. This is dependent on a perception of partial commensurability. This point is implied by Pratt and Foreman (2000) who connect higher degrees of identity compatibility with 'aggregation' responses. Oliver (1991) similarly suggests that "compromise" strategies are most likely when there is moderate consistency between organizational goals and institutional pressures. Pache and Santos (2010) argue that compromise is less likely when there is conflict over goals rather than means, the former being indicative of more serious divergence than conflict over means. For example, Reay and Hinings (2009) show that 'pragmatic collaboration' was assisted by two stakeholders, driven by divergent logics, realising a degree of commensurability.

Again, some of the findings in the case studies lie outside this suggested association. CoRE 2 and CRI 2 implemented negotiation strategies despite higher perceived levels of divergence. However, a potential pattern in this regard is that engaging in negotiation in association with perceived high divergence is also linked with less positive assessments by stakeholders. A degree of perceived commensurability between objectives appears to play a role in determining a stakeholder's positive experience of negotiation and one can assume that positive assessments of a strategy make it more likely to persist in the long term. This suggests that either their strategic approach or their perceptions of the degree of divergence is likely to change over time. For example, CRI 2 was at the time of the 
interviews looking for a "new" strategy in the face of dissatisfaction with the current strategic approach. It is also partly explained by how negotiation was combined with other strategies (discussed further below). Both CoRE 2 and CRI 2 combined negotiation with segregative strategies which have been proposed above to be associated with these higher perceptions of divergence.

Encapsulating the above discussion, it is suggested that:

Proposition 3: Negotiation is more likely to be implemented when 1) stakeholders' objectives are perceived to be partially commensurable (+), and 2 ) when the degree of power diffusion is higher (++).

\subsubsection{Transcension and Perceptions of Pluralism}

Lower perceived diffusion of power $(+)$ can be connected to CoRE 1 and CRI 1's ability to adopt agency-intensive strategies. In CoRE 1 the perception of a degree of autonomy vis-àvis TEC can be associated with their strategy of 'leading the way.' This strategy was explicitly discussed in relation to perceptions of a degree of autonomy existing within its relationship with government. Similarly, CRI 1's more transformative efforts in relation to its context can be associated with perceptions of not being completely dictated to by external stakeholders (government and clients). By comparison, CRI 2 interviewees described a lack of autonomy in relation to their external stakeholders as preventing them from implementing transcension instead of their current negotiation strategy. Finally, internally in both CoRE 1 and CRI 1, the ability to transform scientists was connected to perceptions concerning power. For example, CoRE 1's utilized the research benefits and funding it provided to PIs as a way of transforming what it meant to be an academic. In CoRE 2's case the benefits of being a PI were not able to be used in this way, with interviewees reporting comparatively little such benefits. Consequently, CoRE 2 had less ability to transform PI behaviour in that way.

With the HTSUs a connection between the level of diffused power and transcension was also apparent. HTSU 2's ability to follow an expanded vision, a vision that emanated from the organization's managers, was connected to the perception of power being relatively less diffused (+). For example, investors and their demand for ROI were important but perceived as manageable. It was not necessarily something that dominated HTSU 2's decision making 
and demanded they have a narrow ROI focused vision. For instance there was not clear nonmanagerial voice on the board. By contrast, in HTSU 1 the implementation of negotiation in combination with transcension is perhaps indicative of the higher perceived power diffusion $(++)$. This provides a contrast with HTSU 2 sole focus on more agency-intensive strategies.

The connection between transcension and perception of comparatively lower perceived power diffusion (+) can be also inferred from the literature. For example, Alexander's (1996, p. 830) transcension strategy of "creative enactment" entails the ability to perceive "a universe of possibilities." In the example provided the power of external stakeholders was recognized yet not perceived as necessarily overly constraining. Similarly, Oliver (1991) describes "manipulation" strategies (e.g., 'transformation' in Table 6.1) as more likely in contexts where dependence on "institutional constituents" is lower.

An association between transcension and perceptions of a degree of commensurability is also suggested. This link was evident in CoRE 1 and CR1 1 . The following examples are illustrative:

- In CRI 1 a degree of commensurability $(+)$ can be linked to the strategy of an overarching purpose, with many objectives seen as working towards the same thing. Similarly, such perceived compatibility was behind the efforts to create business literate scientists.

- Lower perceived divergence was behind CoRE 1's strategy of an expanded vision. Rather than incommensurable, its various objectives were viewed as working together to define what the CoRE was and did (i.e., 'expanded vision').

- A clear distinction between start-ups regarding perceptions of divergence was unable to be made. However, in HTSU 2 the CEO outlined how there was a degree of compatibility between "science" and "business." He also outlined that incorporating "public good" objectives was a more sustainable way of doing business. As the expanded vision the company promulgated incorporated these three elements, such perceptions of compatibility can be connected to this strategy.

This association is supported by Pratt and Foreman (2000) who connect more integrative strategies to situations where degrees of compatibility exist. An example provided in the 
broader pluralism literature is Jarzabkowski and Sillince's (2007) concept of a "synergy rhetoric", connected to use of an overarching objective here. This "constructs a context in which multiple activities are compatible and mutually supportive" (p. 1646). It can be inferred that it is consequently built on the simultaneous impression and construction of a degree of compatibility between demands.

This discussion is represented in the following:

Proposition 4: Transcension is more likely to be implemented when 1) stakeholders' objectives are perceived to be partially commensurable (+); and 2) when the degree of power diffusion is lower (+).

In reflecting on Proposition 4, it is worth noting that these perceptions of the degree of diffusion and divergence (+) seem to be linked to an acceptance of pluralism rather than a denial or attempt to curtail it (Kraatz \& Block, 2008). For example, in CoRE 1, the recognition of the opportunity to self-define went hand-in-hand with efforts to democratically include all stakeholders (i.e., PIs, university partners and government). As Kraatz and Block (2008, p. 252) note, the interrelationship between "acceptance of irreversible commitments" to stakeholders and autonomy (the perceived ability to make "reciprocal claims" on those stakeholders) are interconnected.

\subsubsection{Summary: Propositions 1-4}

The four propositions and related theoretical extension are depicted in Figure 6.3. Also contained in the framework is Proposition 5 which relates to the combinations of strategies: the focus of the final section of this chapter (6.3).

The level of perceived power diffusion and divergence has been shown to have explanatory value in understanding why different strategies were pursued by different organizations. Such propositions can be connected to a conceptualization of the environment as enacted. The idea that organizational contexts can be perceived as partly created through 'attentional processes' and resulting action is illustrative (Alexander, 1996; Pfeffer \& Salancik, 1978; Smircich \& Stubbart, 1985). A potential framing is that organizations reinforce perceptions of different contextual characteristics (in this case degree of power diffusion and divergence) through their actions. In so doing, they partly create that context. 
However, it is also recognized that there are limitations to enactment (Jauch \& Kraft, 1986; Smircich \& Stubbart, 1985). This interaction between enactment possibilities and constraints within the "objective environment" (Pfeffer \& Salanik, 1978) is not fully resolved or incorporated in the theoretical development here. However, it is envisaged that the two interact in explaining these propositions. For example, CoRE 2 was constrained from successfully enacting, through contraction, the low power diffusion context they perhaps initially perceived. This could be interpreted as a case where performance was "affected by parts of the environment [initially] not noticed or heeded" (Pfeffer \& Salancik, 1978, p. 79).

Figure 6.3 Managing legitimacy demands in pluralistic contexts: Propositions 1-5

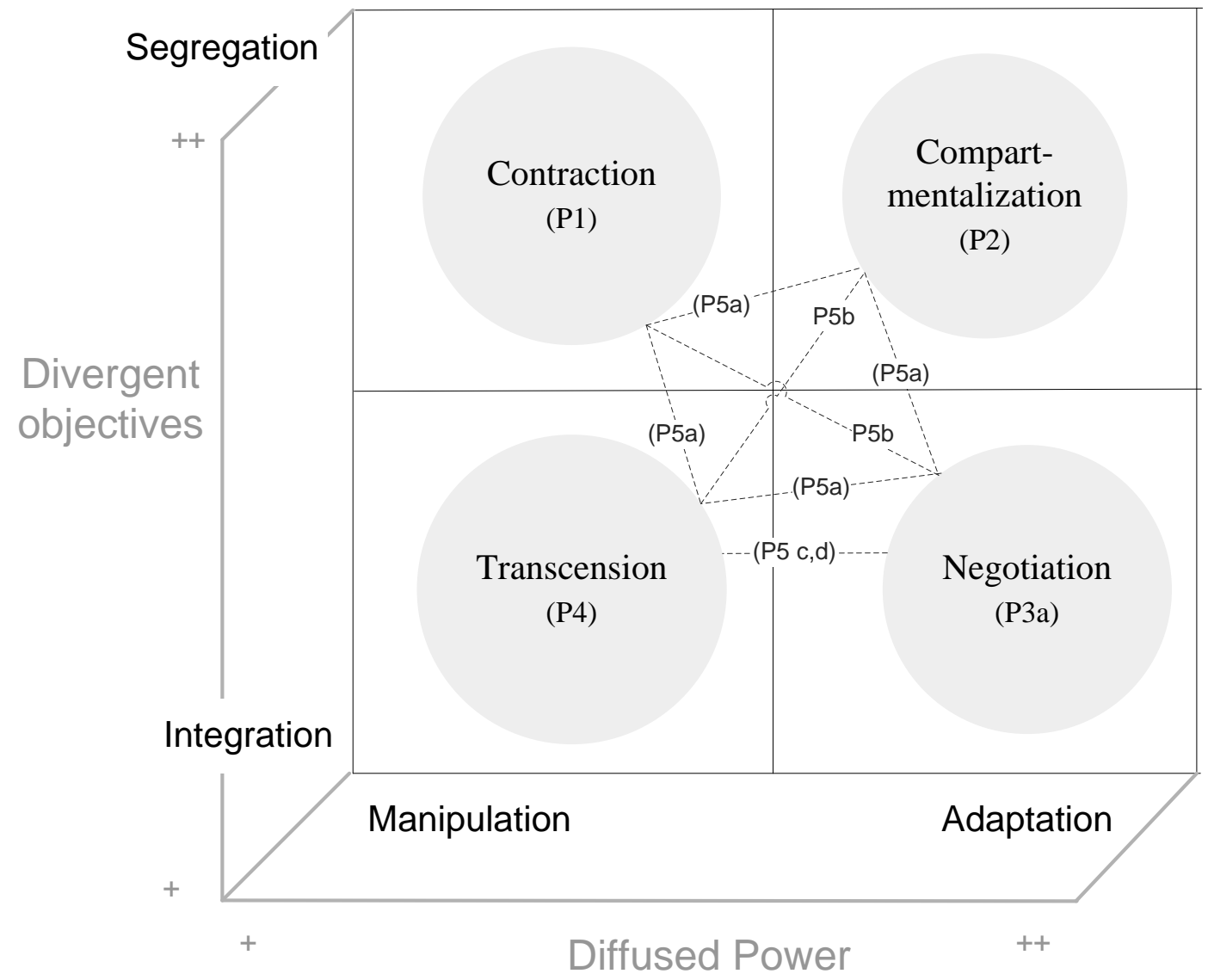

6.3. Highlighting the Temporal Story

A temporal understanding of the strategies can also be gleaned from the findings. While a process perspective was not the primary level of analysis, a degree of insight into the question of how organizations strategize over time (Jarzabkowski et al., 2009a) resulted from the data. Legitimation takes place and responds to contexts that are changing and 
developing (Sonpar et al., 2010). Static representations are acknowledged as providing a somewhat limited understanding.

Two broad temporal patterns were evident. First, in CoRE 1 and HTSU 1 there were no reported changes in their strategic approach over time. Second, the four other cases all reported experiences of crisis at some point. For these organizations this was associated with a rethinking of their strategic approach. For example, one CRI 1 manager outlined how "It was basically bleeding to death" before their change in strategy. A temporal summary is depicted in Figure 6.4.

Figure 6.4 Temporal picture of strategies
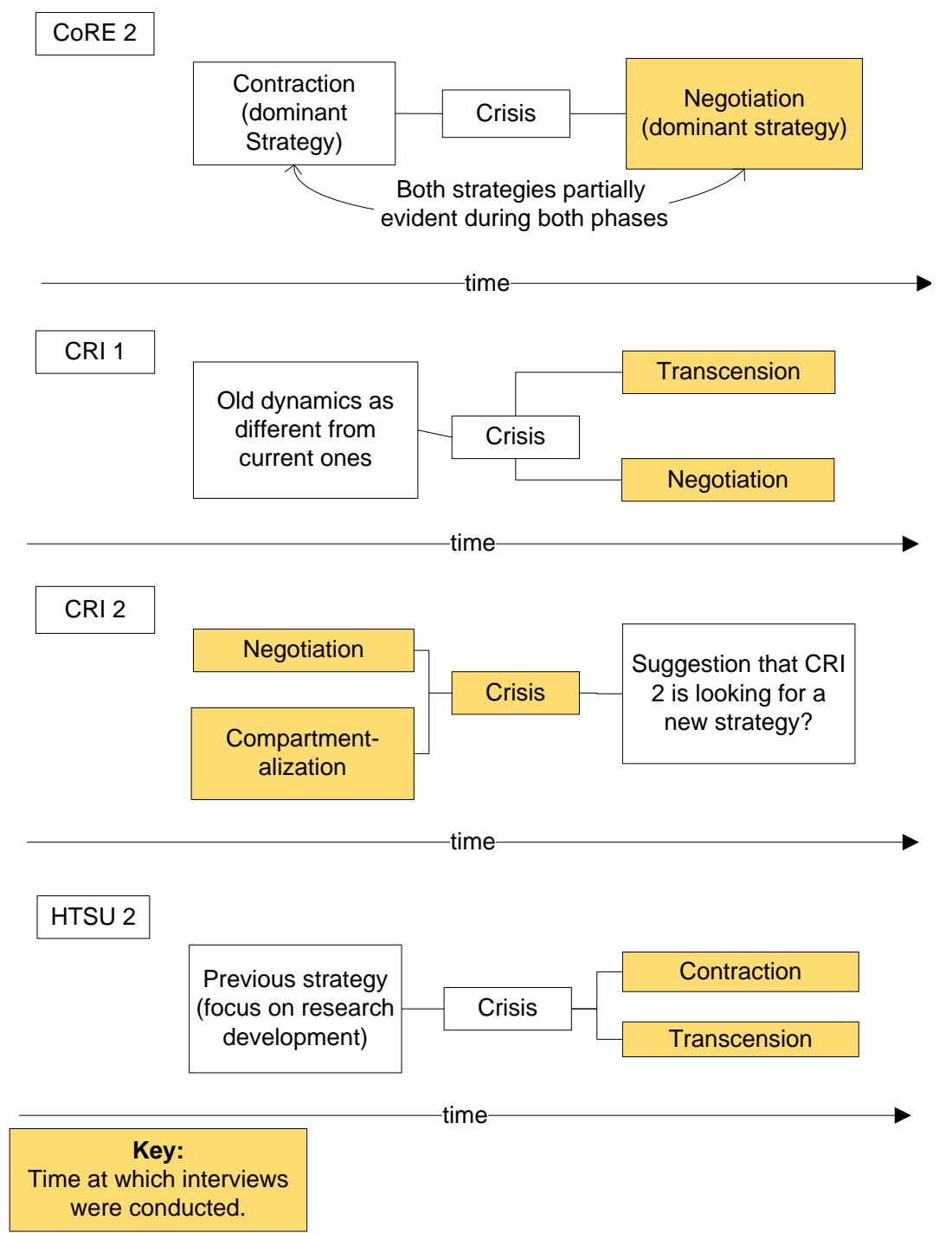

The research design did not always enable a complete understanding of past strategies. It nonetheless was made it apparent that changes in strategy had occurred (CoRE 2, CRI 1, 
HTSU 2) or that a crisis was prompting a potential rethinking of current strategies (CRI 2). As a temporal story, the case of CoRE 2 is similar to the one outlined by Sonpar et al. (2010) where contraction led to activism on the part of the contracted party. This resulted in the recognition of the need for negotiation.

The potentially obvious point that the management of pluralism is a dynamic process is highlighted in Figure 6.4. This supports research efforts that provide process frameworks of legitimacy strategies. Overall, it highlighted an iterative approach to addressing stakeholder demands in response to, for example, crises. While the cases were temporally bounded to focus on strategies currently at play, the empirical data provided the insight that an understanding of those strategies was inseparable from the broader temporal picture.

In addition, however, it appears that strategies are also to a degree entrenched, something described in the strategy literature as inertia (Miller \& Chen, 1994). To reiterate, accompanying much of the strategic change were crisis-like events. Crisis appears to be a required prompt for significant changes in strategic approaches to pluralism (Seo \& Creed, 2002). For example, while a change in strategic approach was evident in CoRE 2, some interviewees continued to promulgate the initial contraction strategy. This was despite it being largely recognized as unviable.

Population ecology authors highlight structural inertia in explaining this. Characteristics at time of founding can become imprinted and resistant to change (Hannan \& Freeman, 1984; Stinchcombe, 1965). However, this point regarding the path-dependency of legitimacy strategies themselves is something on which previous legitiamcy research has largely been silent. The tension between consistency and conformity Kraatz and Block (2008) raise (Section 2.3.2) with regards to legitimacy strategies amidst pluralism is put forward as potentially explanatory. Not only are organizations expected to symbolize their conformity with prevailing beliefs (e.g., DiMaggio \& Powell, 1983), but they must also "evidence crosstemporal consistency in their words and deed" (Kraatz \& Block, 2008, p. 248). For example, a commitment to a singular focus on science excellence on the part of CoRE 2 (consistency) interacts with their negotiation of additional demands (conformity). It is, therefore, suggested that legitimation over time can be understood as a reflection of the 
consistency/conformity tension that Kraatz and Block outlined as characterizing legitimacy strategies amidst pluralism.

\subsection{Combinations of Legitimacy Strategies}

A combinatorial approach to legitimation was apparent in the overview provided at the beginning of this chapter (Figure 6.1). A central finding is that organizations amidst pluralistic implement multiple strategies simultaneously. This includes combinations that are seemingly paradoxical, for example, simultaneously implementing integration (transcension) and segregation (contraction) as exemplified in HTSU 2.

Binder (2007, p. 551) connects legitimacy research's 'oversight' regarding organizational agency to institutional theories focus on the search for "an organization's single response to the environment." Binder focused on how a strategy of compartmentalization (Kraatz \& Block, 2008) enabled separate subunits to focus on different demands and, thus, exhibit distinct strategies. The findings here address this identified preoccupation with single strategies through looking at how different strategies are combined in the absence of such overarching sub-unit segmentation. Understanding legitimacy strategies in pluralistic contexts is enabled through showing how strategies interrelate and are combined by organizations simultaneously.

To reiterate, Pache \& Santos (2010) point out that studies addressing the question of strategizing for legitimacy in pluralistic settings have focused on the identification and exploration of single idiosyncratic strategies. For example, Elsbach and Sutton (1992) investigate decoupling as a means for managing divergent legitimacy demands (although they do link decoupling to various impression management techniques). Battilana and Dorado (2010) similarly focus on particular practices (hiring and training) and relate that to either a strategy of integrative vision or identity in two organizations respectively. Other authors (Jarzabkowski et al., 2009a; Sonpar et al., 2010) outline variations in strategies over time but do not focus on how different strategies (as defined by the framework here) are implemented simultaneously.

Pluralism and tensions are frequently argued as not fully resolvable (Jarzabkowski et al., 2009a; Lewis, 2000; Smith \& Lewis, 2011). Even when a strategy that exhibits characteristics 
of transcension is observed, it is unlikely that complete resolution is achieved. This means ongoing strategies of negotiation or compartmentalization are likely. For example, in HTSU 1 there was discussion regarding how stakeholders were integrated around a picture of growth (transcension). Despite this, negotiation around the periphery was still required.

Pluralism has been shown here to go beyond duality to incorporate a multiplicity of tensions (Smith \& Lewis, 2011). All six organizations were facing multiple embedded tensions rather than a single defining point of divergence. This provides more understanding regarding the use of multiple strategies in pluralistic contexts: multiple strategies may be needed to target different tensions or stakeholders. This is perhaps clearest in CoRE 2. A specific strategy that addressed the tension between competition and collaboration was not apparent in this case. This was an exception: in the other five organizations, strategies directly or indirectly targeting all points of divergence were evident. A possible assessment is that CoRE 2 suffered through its lack of a multi-faceted strategic approach in this regard. Interviewees assessed the organization's strategies negatively and expressed frustration with respect to the unaddressed tension between competition and collaboration.

Pluralistic contexts are consequently proposed to frequently demand a combination of strategies:

Proposition 5a: In pluralistic contexts, combinations of strategies are more likely to be implemented than a single dominant strategy by organizations.

This combinatorial approach to legitimation complicates the picture of the suggested broad strategies themselves. For instance, "partisan mutual adjustment" is theorized as coordination "without a dominant common purpose" (Jarzabkowski et al., 2009a; Lindblom, 1965, p. 3). Rather than 'pure' reflection of this negotiation strategy, some organization cases here showed stakeholders adjusting to each other in relation to an overarching objective. Negotiation in this sense was, for example, evident in HTSU 1's managing the periphery strategy or the balance engaged in by CRI 1 in relation to an overarching purpose. As this suggests, the conceptualization of transcension as an 'ideal option' that mitigates legitimacy problems (Kraatz \& Block, 2008) is also not the complete picture. Instead, organizations engage in strategies that 'integrate or somehow transcend' some legitimacy demands while simultaneously being engaged in on-going partial adaptation and balancing. 
In this way, the overlap between these strategies may, therefore, be relatively frequent, and theoretical elaboration highlighting this is important. Another example of theoretical refinement being required to reflect the combinatorial findings, regards 'bounded compartmentalization.' This was evident in HTSU 1 where, due to its close association with negotiation, the degree of segregation was limited.

This more complex picture is indicative of the argument that "contradictions" in legitimacy criteria offer opportunities for multiplicity, creativity, and agency with regards to legitimacy strategies (Aurini, 2006). For example, in HTSU 2 contraction was incorporated in some areas (e.g., with regards to venture capitalists) alongside other, even paradoxical, strategies (e.g., an expansive vision). This, perhaps surprising, combination of strategies is partly explanatory of the more positive picture of contraction presented in the cases here. Contraction was not necessarily reported as a dominant approach that markedly reduced pluralism (e.g., Kraatz \& Block, 2008), but rather as a strategy that partially reduced pluralism in particular areas in combination with other strategies that simultaneously embrace aspects of plurality.

Figure 6.5 Alternative depiction of framework (Proposition 5)

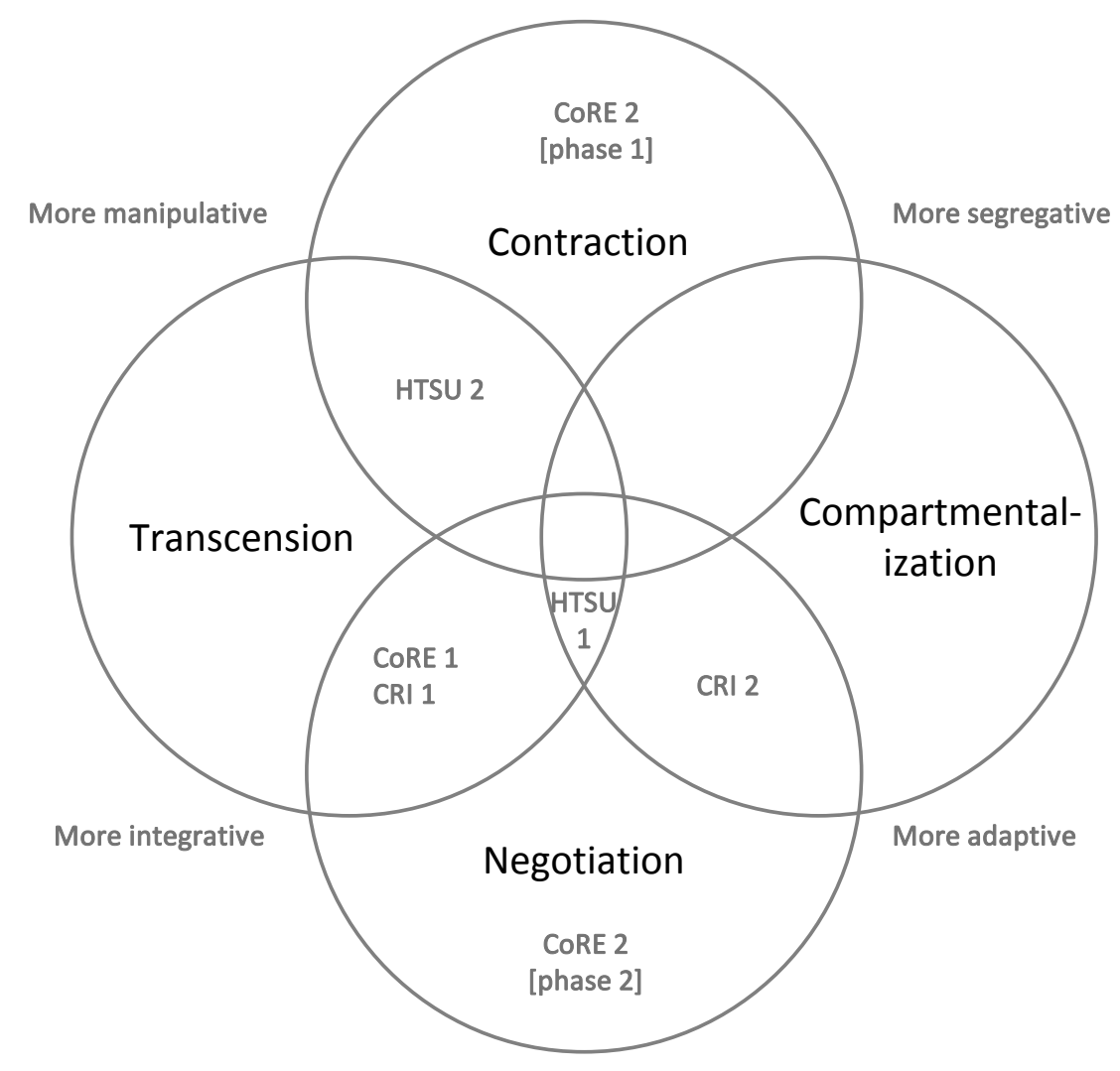


The consequent result of these observations is additional development (Dubois \& Gadde, 2002) of the framework. This is conveyed in Figure 6.5.

That particular combinations between strategies are more common is also illustrated in Figure 6.5. It is suggested here that it is more likely for strategies to be combined when they share a degree of commonality along one of the framework's dimensions (i.e., integration or agency) (Oliver, 1991; Pratt \& Foreman, 2000). For example, transcension and negotiation are both more integrative and are therefore proposed as more likely used in tandem than contraction and negotiation which differ both in their degree of agency and integration. This suggests contraction/negotiation and transcension/compartmentalization are less likely than other combinations.

The findings here support this theorization. Only one case provides a counter-example. This instance of combining contraction/negotiation by CORE 2 was, however, also associated with less favourable stakeholder assessments. Indeed, exploring whether there is a performance dimension to this proposition ( $5 b$ below) would be potentially illuminating. While organizations can in practice combine any of the strategies, perhaps such counterexamples are likely to result in less positive assessments; as was the case in CoRE 2. Similarly, CoRE 2 reflects examples in the literature (e.g., Sonpar, et al., 2010) through the relationships between its strategies being partly temporal in nature. While elements of the two strategies were shown to overlap, CoRE 2 can be described as shifting from a dominant contraction strategy to negotiation being the predominant approach. This contrasts to the more obvious simultaneous implementation of strategies in the other five organizations.

Based on the above discussion, while organizations can combine any strategies, the argument is that some combination will be more likely:

Proposition 5b: Combinations of strategies that share either a common level of integration or agency are more likely to be implemented than combinations that do not.

One particular combination of strategies stands out within the dataset as the most common: transcension and negotiation (CORE 1, CRI 1, HTSU 1). Moreover, it is those three cases that combine transcension and negotiation that are associated with more positive stakeholder assessments of their strategies. In contrast, CORE 2, CRI 2, and HTSU 2 are linked with more varied assessments (Table 6.2). 
An element of transcension appears to be important in explaining this association with perceptions of success. The findings suggest that when not combined with a degree of transcension, negotiation strategies are more likely to be assessed as a frustrating process of compromise and ongoing renegotiation. For example, in CRI 2 negotiation was characterized by some interviewees as a lack of strategy; in CoRE 2 negotiation was characterized by some as detrimental compromises, with the CoRE "becoming less desirable."

However, transcension does not provide the full answer; a direct association between transcension specifically and more positive assessment was also not evident. For example, the transcension is specifically associated with less positive assessments by some HTSU 2 interviewees. Another illustrative example is in HTSU 1 where the supplementary dynamics of managing the periphery and creating links of understanding were central. For example, actively managing the periphery was important in enabling the transcension strategy of an overarching objective to be something around which multiple stakeholders were integrated. Without this ongoing partial adaptation, the overarching objective could have increasingly represented a contracted sales focus. It is the combination of integrative strategies that appear to stimulate more favourable stakeholder assessments.

This can be summarized into the following two propositions:

Proposition 5c: Organizations are more likely to combine integrative strategies (transcension and negotiation) than implement other possible combinations of strategies.

Proposition 5d: Integrative combinations are more likely to be associated with broadly positive stakeholder assessments than other possible combinations of strategies.

This finding of organizations successfully combining transcension with negotiation differs from Battilana and Dorado's (2010) conclusion that identity synthesis is the only sustainable way to manage conflicting logics. Instead, it seems here that organizations frequently combine a broad overarching vision with ongoing partial adaptation and compromise regarding stakeholder demands. Simultaneously, it contradicts an assumption that the development of more transcensive strategies is unlikely or even unhelpful in such contexts and that negotiation will instead be apparent (e.g., Fiol et al., 2009; Jarzabkowski et al., 2009a; Reay \& Hinings, 2009). For example, the concept of 'partisan mutual adjustment' 
explicitly excludes any form of overarching integrative vision or objective (Lindblom, 1965). Instead, the findings highlight the importance of the relationship between these two strategies.

\subsection{Summary: Chapter Six}

The theoretical implications of this thesis have been highlighted as four-fold. First, increased understanding of the specific strategies in play was sought. Insight into infrequently studied strategies (such as transcension) has been provided, as has support regarding the utility of Kraatz and Block (2008) conceptualization. Second, the analysis of the pluralistic contexts (Chapter 4) and the strategies the organizations employed (Chapter 5) were brought together in Section 6.2. This enabled propositions regarding why particular strategies may or may not be implemented by organizations. Third, a temporal perspective is provided. The findings in this regard were explained as a potential reflection of the tension between the simultaneous need for consistency and conformity (Kraatz \& Block, 2008). Overall, it highlighted an iterative approach to addressing stakeholder demands, which evolved in response to crisis. Finally, the issue of strategic combinations is highlighted as central to understanding legitimation amidst pluralism. The implications of these findings will be further reflected upon in the concluding chapter. 


\title{
CHAPTER SEVEN
}

\section{Conclusion: Creative Chances at the Clashing Point}

\begin{abstract}
The clashing point of two subjects, two disciplines, two cultures - of two galaxies, so far as that goes - ought to produce creative chances. (Snow, 1959, p. 16)

So that's very radical. Again it's ironic - turning things around. And that's shocking. But we are going to do that. We are going to do shocking things. And there's value in that: it's grasping that bigger picture. (Director, CoRE 1)
\end{abstract}

The inclusion of pluralism means "one arrives at a less tidy, less idealized, but nevertheless truer and more realistic picture of our social condition" (Rescher, 1993, p. 189). Within the organization literature this same point is made by Glynn et al. (2000, p. 726$)$ who argue that although pluralism "can make demands on our models", its inclusion enables increased accuracy and nuance. It has been proposed here that incorporating pluralism into our understanding of legitimacy strategies offers such benefits to the legitimacy literature. To return to Snow's (1959) quote, the findings here highlight that 'creative chances' do indeed exist for organizations amidst pluralism (Aurini, 2006; Kraatz \& Block, 2008). An example was seen in CoRE 1 whose 'strategic enactment' (Alexander, 1996) and embracing of pluralism is highlighted in the quote above.

The story promulgated is one of active organizational agency as part of legitimation. Organizational actors respond strategically to "construct, change and enforce...expectations" (Covaleski \& Dirsmith, 1988, p. 562) as they manage divergent perceptions of desirability and appropriateness from multiple sources. However, we lack indepth understanding of agency-intensive legitimation at the organizational level; particularly, within pluralism (Kraatz \& Block, 2008; Pache \& Santos, 2010; Reay \& Hinings, 2009). This thesis offers a contribution as part of the growing body of research seeking to rectify this imbalance. In particular, insight into how organizations combine, sometimes paradoxical, strategies extends the existing framework and related literature (Binder, 2007; Pache \& Santos, 2010). While the underlying framework (Figure 2.4) enabled insight into the empirical data, the organization cases appear unconfined by the 'lines' that initially differentiated the four strategic categories. Theoretical development in Chapter 6 
consequently softened the demarcations between these legitimacy strategies to more explicitly account for combinatorial approaches.

How do organizations manage their legitimacies in pluralistic contexts? This question has been recognized as remaining both under theorized and under empirically investigated (Kraatz \& Block, 2008; Lounsbury, 2007; Pache \& Santos, 2010; Reay \& Hinings, 2009) (Chapter 2). This thesis sought to address this issue through exploring legitimacy within the pluralistic context of New Zealand's (NZ) science sector. Using a multi-case study design and thematic analysis, the research explored the application of an analytical framework. This focused on contextualization (legitimacy demands and the dimensions of pluralism) and legitimacy strategies (Kraatz \& Block, 2008). The findings then described the pluralism each organizations encountered (Chapter 4) and the legitimacy strategies perceived as implemented by each organization amidst such contexts (Chapter 5 ). The discussion that followed explored the theoretical implications of those findings through bringing together these different aspects of the thesis. This concluding chapter further outlines the particular contribution to legitimacy theory. First the specific findings and their relationship to our understanding of legitimacy strategies is highlighted, as is their connection to the research questions outlined in the introduction. Second, the broader contribution, to what Alexander (1996) labels 'strategic institutional theory', stakeholder theory, paradox literature and literature focused on managing science organizations are outlined. Implications for practice will be suggested before I canvass avenues for future research about which this thesis leaves me enthusiastic.

\subsection{Research Questions, Findings, and Contribution}

\subsubsection{Contribution: Specific Findings and Research Questions}

A central contribution made is theoretical elaboration at the intersection of pluralism and legitimacy strategy frameworks and theory. The connection between this and the research questions guiding this study are summarized in Figure 7.1. 
Figure 7.1 Research questions and findings: A summary

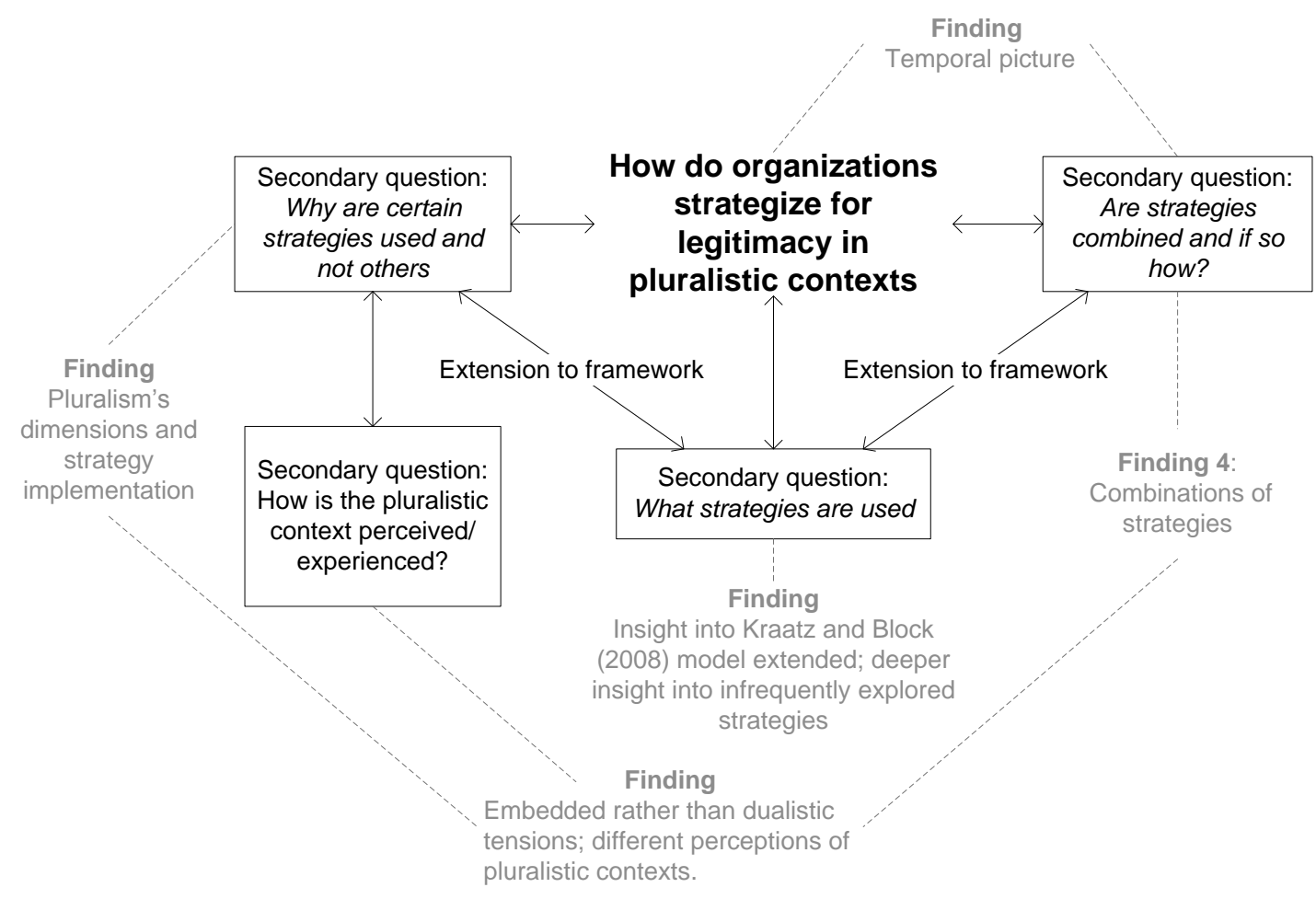

Understanding into the framework and specific legitimacy strategies. This increased insight is connected to the specific sub-questions of what strategies are used by organizations in pluralistic settings. Kraatz and Block's (2008) framework has not previously been directly in empirical studies of legitimation. For example, Pache and Santos (2010, p. 457) characterize the literature as "a few empirical studies have identified idiosyncratic responses to conflicting institutional pressures for conformity...without proposing a more general framework."

Transcension as a strategy has been infrequently explored within legitimacy literature. Historically, the underlying assumption in legitimacy theory has been that less agencyintensive strategies, such as of isomorphism or decoupling, will be more frequently and easily utilized (Ashforth \& Gibbs, 1990; DiMaggio \& Powell, 1983; Meyer \& Rowan, 1977; Suchman, 1995). The findings here address this omission through highlighting agency intensive dynamics such as 'infusing with value' (Kraatz \& Block, 2008; Selznick, 1957) and 'creative enactment' (Alexander, 1996). The fact that transcension strategies were 
uncovered in various cases consequently helps address this broad imbalance in the literature. I would suggest that pluralism indeed provides an opportunity to explore strategies that are less central in homogenous contexts where acquiescence is proposed to be more characteristic (Oliver, 1991). The findings also provide a different perspective to viewing transcension within pluralistic settings as unlikely, in comparison to ongoing negotiation and the development of 'grudging' or 'pragmatic' truces (e.g., Jarzabkowski et al., 2009a; Reay \& Hinings, 2009).

Negotiation was also confirmed as central to understanding strategizing in pluralistic contexts. This suggests that negotiation concepts such as mutual adjustment (Jarzabkowski, et al., 2009a) and partial adaptation (D'Aunno et al., 1991) as well as the proposition that organizations are able to transcend pluralism (Kraatz \& Block, 2008) are both explanatory. Understood singularly, neither emerged as centrally prominent. This contrasts with different literature that has been reviewed (see Chapter 2) as outlining one of these strategies as either more likely (e.g., Jarzabkowski, et al., 2009a) or ideal (e.g., Battilana \& Dorado, 2010; Reay \& Hinings, 2009). Finally, the idea of 'democracy' was raised as a particularly novel negotiation strategy. Such democratic processes have not previously been discussed as a legitimacy strategy.

Increased theoretical insight into segregative strategies was also gained. Understanding of compartmentalization was extended through the finding of 'bounded compartmentalization' (discussed further as part of combinatorial approach to legitimation below). Highlighting compartmentalization as a way of managing divergent legitimacy demands between internal stakeholders (managers and scientists) is also novel. The concept has usually been instead used to explore the management of distinct external demands versus internal demands (e.g., Elsbach \& Sutton, 1992; Meyer \& Rowan, 1977).

Increased insight into contraction also moved beyond the wide-spread discounting of this strategy within the literature (Humphreys \& Brown, 2002; Sonpar et al., 2010). Contraction was indeed shown in one case (CORE 2) to be associated with a risk of negative reinforcing cycles as proposed by the paradox literature (Lewis, 2000). However, the contrasting perspective that contraction processes can be usefully applied as a focusing mechanism in 
pluralistic contexts was apparent in HTSU 2. This is something that has been infrequently argued from a pluralism perspective.

To summarize, support for Kraatz and Block's (2008) framework is provided; it is shown to offer understanding into how organizations strategize for legitimacy amidst pluralism. The following discussion, however, has the intention of extending and refining the theoretical picture with which this research began.

Organizations combining legitimacy strategies. Another specific contribution relates to the question of how strategies are combined in pluralistic contexts. It is argued that organizations in pluralistic contexts will likely implement multiple, sometimes seemingly paradoxical, strategies simultaneously. The "paradox lens" is outlined in this thesis as a body of literature closely related to, but distinct from, the context-focused nature of pluralism. This strand of research may be a particularly useful in understanding this combinatorial finding. Smith et al. (2010, p. 450) use the term 'paradoxical strategy' to define multiple strategies that are contradictory yet interrelated. This term is indicative of the combinatorial approach adopted by some organizations here. Implementing strategies in combination was shown to affect how the strategies themselves were conceptualized. For example, the close association between negotiation and compartmentalization in HTSU 1 led to a restricted form of compartmentalization. Consequently, the initial representation of distinct strategies (Figure 2.4) was refined to reflect this understanding (Figure 6.5). In highlighting this combinatorial approach, I suggest that part of the legacy of underutilizing a pluralism perspective within legitimacy research is assumptions around strategy implementation that are also homogenizing. For example, the underlying frameworks do not explore the idea of combining strategies as part of the presentation of the array of legitimacy strategies (e.g., Oliver, 1991; Kraatz \& Block, 2008). As the literature review highlighted, these assumptions have been upheld through empirical concentration on uncovering single 'idiosyncratic' responses (Binder, 2007; Pache \& Santos, 2010).

Finally, this study found what appears to be particularly important strategic combination. The interrelationship between transcension and negotiation is suggested as likely to be associated with positive stakeholder assessments. Consequently, while the idea of patterns within legitimacy strategies highlights the degree of strategic innovativeness that can be 
pursued by organizations, performance-based limitations to strategic combinations were also suggested. The findings suggest that while organizations can paradoxically combine any strategies within the framework, some strategic combinations are likely to be more successful (and likely) than others.

The 'transcension'/'negotiation' dichotomy. The idea of combinatorial strategic implementation moves beyond a distinction observable in the literature. The different pictures emerging of legitimacy strategies reflect a difference between authors highlighting transcension (Kraatz \& Block, 2008; Selznick, 1957) and negotiation strategies (Jarzabkowski et al., 2009a; Lindblom, 1965; Reay \& Hinings, 2009) as either more likely or desirable. Here I suggest that insights such as 'infusing with value' (transcension) and 'mutual adjustment' (negotiation) can instead be used simultaneously to understand legitimation in pluralistic settings. This differs from these strategies being considered as opposing, or even sharply distinct, strategic options.

This research consequently contrasts with the argument that 'to be sustainable...an organization needs to create a common organizational identity...such an identity prevents the formation of subgroup identities within the organization" (Battilana \& Dorado, 2010, p. 1420). That organizations can be sustainable in pluralistic settings without this absolute degree of synergic resolution is instead proposed (Pratt \& Foreman, 2000). However, the findings also differ from previous research that has highlighted grudging mutual adjustment between stakeholders or operating amidst an "uneasy truce" through "non-trust collaboration" (Jarzabkowski, et al., 2009a; Reay \& Hinings, 2009). Here, in contrast, enhanced ability for organizations to transcend pluralism was observed than such previous studies suggest.

Legitimacy strategy and pluralism's dimensions: proposed associations. A connection between perceptions of pluralism's dimensions and strategies likely to be utilized by an organization is proposed. For example, a particular strategy (e.g., transcension) is proposed as more likely to be implemented in association with particular perceptions of pluralism (e.g., a degree of perceived commensurability between objectives rather than complete incommensurability). A suggested framing of this is one of 'enactment' (Alexander, 1996; Dowling \& Pfeffer 1975; Smircich \& Stubbart, 1985). A conceptualization is suggested of 
perceptions of pluralism guiding strategic implementation, which in turn perhaps 'enacts' those particular pluralism dynamics. This is explored further in section 7.3 as an avenue for future research. The understanding this offers regarding why some strategies are perhaps implemented by different organizations contributes to a recognized research gap regarding legitimacy strategies generally (Suchman, 1995) and in pluralistic contexts specifically (Pache \& Santos, 2010). In this thesis connecting the focal framework (Figure 2.4) to the dimensions of pluralism is offered as a theoretical extension.

Both strategic dynamism and inertia. The importance of understanding strategizing over time was also highlighted. While the research design did not focus around longitudinal data as other studies have, some insight was still gained (Jarzabkowski et al., 2009a; Reay \& Hinings, 2009; Sonpar et al., 2010). An element of inertia vis-à-vis strategic implementation was found, something not explicitly highlighted in previous research taking a longitudinal approach. The suggestion is that organizations seek to balance the need to be both responsive and consistent over time in their legitimacy strategies (Kraatz \& Block, 2008). This partly explains why resistance to or difficulty implementing a completely new legitimacy strategic approach was observable. In particular, shifts in strategy appeared to be associated with major events: the four cases that reported changes in their strategies also reported "crisis" triggers. This is another potential interpretation of the analogy of the "clashing point" and the creative chances therein (Snow, 1959). The 'crisis points' spurred new, potentially creative, strategies (Alexander, 1996). For instance, it was suggested that being faced with a crisis (at the time of the interviews) was connected with CRI 2's current search for new strategies that transcended some of their pluralism.

Additional notes on contribution: methodology and literature review. This study appears to be rare in exploring legitimacy strategies in pluralistic contexts through a multiple casestudy design. The majority of other published studies exploring this research problem have tended to utilize single organization cases (e.g., Binder, 2007; Brown, 1995; Glynn, 2002; Humphreys \& Brown, 2002). Other studies have incorporated multiple organizations within a broad sector without incorporating cross-case comparison (Alexander, 1996; Aurini, 2006; D'Aunno, et al., 1991; Reay \& Hinings, 2009). Exceptions include Elsbach and Sutton's (1992) case of decoupling in pluralistic contexts which compared the similar strategic dynamics of two social movement organizations. Battilana and Dorado's (2010) study also incorporated 
cross-case comparison of two cases and described different strategies from the same sector. This study adds to these through its replication of different organization types within a single sector. Through studying six organizations within a sector that incorporates both similar and different structures and contextual characteristics, the cross-case comparative aspect of this study was particularly enabled. The number of organizations incorporated (i.e., more than two) was also behind the wider array of strategic stories surfaced here, something that proved useful in "fleshing out" the framework (Eisenhardt, 1991). That this study incorporates both internal and external stakeholders, including employees or equivalent, within a single study was also important in moving towards a fuller account of pluralism. Other studies that have included a focus on internal sources of pluralism have tended to focus mostly on the managerial voice (Battilana \& Dorado, 2010; Jarzabkowski et al., 2009a).

Two contributions related to the literature review can also be summarized. First, an adaptation of a broadly utilized multi-dimensional definition of legitimacy was provided (Suchman, 1995). This adaptation involved grounding the definition of legitimacy in multiple stakeholder perceptions and assumptions. This was a shift from a conceptualization of "generalized legitimacy" to explicitly highlighting multiple legitimacies. This definition is put forward as a useful one for those seeking to explore legitimacies in pluralistic settings. It represents an explicit differentiation from the "monolithic tendencies" (Jarzabkowski et al., 2009a, p. 284; Lounsbury, 2007) that have defined aspects of legitimacy research. Second, structuring the relevant literature review around the focal framework is novel. These studies have infrequently been brought together or positioned in relation to an overarching legitimacy strategy framework. The organization of this literature is tied to the particular conceptualization adopted here and, therefore, remains partial as only one possible representation of the conversation (Philips \& Burbules, 2000). However, the hope is that a useful platform of understanding has been provided for future research.

\subsubsection{Additional Broader Contributions}

Strategic institutional theory. This research positions itself based on the permeability of the strategic and institutional strands of legitimacy theory (Kraatz \& Block, 2008; Oliver, 1991; Suchman, 1995). It consequently contributes to a strand of research labelled "strategic 
institutional theory" (Alexander, 1996). Legitimation is depicted as a process involving organizational agency and insights from both institutional and strategic strands of legitimacy theory are incorporated (Kraatz \& Block, 2008; Oliver, 1991). As Alexander (1996) suggests, the separation of so-called 'institutional' and 'technical' environments was an unnecessary restriction (also see Ruef \& Scott, 1998; Wilkinson, 1996). Understanding stakeholder legitimacy strategies depended on both an appreciation of resource flows (e.g., CoRE funding depended on government evaluation of their legitimacy) and the institutionalized values and norms (e.g., those associated with an academic conception of research excellence). As Kraatz and Block (2008) suggest, this more "strategic" approach to understanding legitimacy, as something that incorporates agency at the organizational level, is one the can profitably draw from older strands of institutional theory (Selznick, 1957).

This positioning follows the example set by Kraatz and Block of separating the "neoinstitutional research endeavour" from their specific organizational-centric contribution. They argue that their framework at the organizational level is distinct from the broader 'organizational institutionalism' project and label this: 'institutional organizationalism.' It is to this specific area of legitimacy theory where this thesis also contributes. Indeed, many authors from within institutional theory call for such an approach. For example:

The overwhelming majority of [institutional] studies now take for granted that the organizational field or environment is the level of analysis. Other levels of analysis have rarely been considered. For example, few studies treat the organization as the level of analysis (Greenwood, et al., 2008, p. 45).

This study can, therefore, be seen as part of a growing literature focused on addressing this imbalance through seeking understanding of legitimation at the organizational level. While not directly an institutional study of legitimacy, this is aligned with the expressed wish from within institutional theory for its future to include further application of its insights to multiple levels, topics and settings (Greenwood et al., 2008).

As already suggested, this research also contributes to the broad research gap regarding institutional theory's "limited theory of action" (Covaleski \& Dirsmith, 1988; Fligstein, 1997, p. 397; Kraatz \& Block, 2008). This has been described as the "proconformance bias" that underpins this theoretical approach to legitimacy (Kitchener, 2002, p. 411). In this sense, this thesis can be connected to the "institutional work" research agenda which has been 
similarly focused on addressing this. Institutional work provides a framework for understanding how individuals and organizations create, maintain, and disrupt institutions rather than simply conforming to them (Lawrence \& Suddaby, 2006, p. 215). As with this thesis it drew from Oliver's (1991) institutional response framework. The institutional work framework was, however, not directly incorporated here for a number of reasons. First, Kraatz and Block's (2008) theorization was found to be more specifically focused on the issue of 'legitimacy strategies' within pluralism. Second, Kraatz and Block's framework enabled the incorporation of a broader array of strategies, for example, including escaping and restructuring resource dependencies (Pfeffer \& Salancik, 1978; Suchman, 1995). This contrasts with institutional work that has a more restricted and tightly defined focus on institutions. However, a link between the exploration of legitimacy strategies and institutional work is evident. Both enable conceptualization of organizations as simultaneously constrained by, and exhibiting agency in response to, legitimacy demands (Lawrence, et al., 2009, p. 1).

This thesis helps address the omission that Jarzabkowski et al. (2009) similarly identify: research in the institutional work area has rarely addressed how conflicting institutions coexist. Instead, the picture has usually been that of a new 'created' institution replacing or reframing an existing one. In this way institutional work involved in managing pluralistic institutions or sources of legitimacy remains understudied; the findings here help attend to this gap. For example, the combinatorial finding suggests that research looks at how organizations amidst pluralism may engage in 'creation', 'maintenance', and 'disruption' work simultaneously.

Dimensions of pluralism and institutional logics. As outlined in the literature review, institutional logics have been a central mechanism for the incorporation of a more pluralistic understanding of legitimacy within institutional theory (e.g., Battilana \& Dorado, 2010; Reay \& Hinings, 2009). Such logics are theorized as broad templates for action, for example, the 'capitalist system' and 'religion' (Friedland \& Alford, 1991). While an explicitly institutional logics theoretical frame was not adopted here, a similar understanding of legitimacy demands based on 'science excellence' 'public good', and 'commercial' demands was surfaced. However, in reaching understanding of the complexity that organizations were dealing with, including multiple embedded tensions, explicitly incorporating the 
dimensions of pluralism was integral. The dimensions of "diffused power" and "divergence" perhaps offered a more fine-grained and nuanced approach to surfacing pluralism at the organizational level. For example, multiple different and overlapping points of divergence associated with the legitimacy demands were described (Chapter Four). This enabled attention to points of divergence originating from within what could have been classified as a broad "logic." Similarly, focusing analysis on 'stakeholder legitimacy demands' rather than adopting an explicitly 'institutional logics' analysis was helpful. For example, this enabled insight into dynamics such as a single stakeholder (for example, government through regulation) making multiple divergent demands and simultaneously prioritizing one of them. This was the case, for instance, with the CRIs.

It could be argued that understanding pluralism at the organizational level, rather than the field level benefits from this more detailed assessment of the tensions affecting particular organizations. This contextualization of the cases in the more specific dimension of pluralism (Denis et al., 2007), rather than the broad logics at play, appears to be a novel approach within legitimacy literature.

Stakeholder theory. The connection between legitimacy strategies amidst pluralism and stakeholder theory has been raised theoretically (Kraatz \& Block, 2008; Pache \& Santos, 2010) and increasingly utilized empirically (Driscoll \& Crombie, 2001; Sonpar et al., 2010). A stakeholder-focused conceptualization of legitimacy here was central to an understanding of pluralism.

This thesis offers support for stakeholder theory's broad proposition that attending to multiple demands is positive both in a performance and a normative sense (Donaldson \& Preston, 1995; Laplume, Sonpar, \& Litz, 2008; Sonpar et al., 2010). For example, CoRE 1's embracing of multiple stakeholder objectives was explicitly linked by interviewees to positive stakeholder assessments of the organization. As Pache and Santos (2010) suggest, an approach that explores both perceptions of conflict and perceptions of the importance of various stakeholders would build natural bridges to the stakeholder theory literature (Freeman, 1984; Mitchell, Agle \& Wood, 1997). While stakeholder theory holds that divergent salient stakeholder demands confront organizations and should be responded to (Sonpar et al., 2010), it is argued that it has not adequately explored the strategies 
organization engage in to achieve this (Kraatz \& Block, 2008). In particular, stakeholder theory stipulates that organizations will respond differently to different stakeholders depending on their salience (e.g., Friedman \& Miles, 2002; Mendelow, 1991; Mitchell et al., 1997). This point is incorporated in this study through the diffused power dimension. However, as Laplume et al.'s (2008) review shows, while various idiosyncratic strategies for managing stakeholders have been proposed by stakeholder theory (e.g., 'looking to Islamic texts' (Beekun \& Badawi, 2005) or using mediation (Lampe, 2001)), a meta-frame is absent. The framework here perhaps provides one and it could be utilized and extended by those adopting a stakeholder theory perspective.

This research also shares the implicit objective of stakeholder theory vis-à-vis providing a different picture to that of "shareholder hegemony" (Sundaram \& Inkpen, 2004) dominant within modern corporations (Kraatz \& Block, 2008; Pfeffer, 2009; Selznick, 1996). As Laplume et al. (2008, p. 1153) explain:

Stakeholder theory is also controversial because it questions the conventional assumption that pursuit of profits is the preeminent management concern, which Jensen $(2002$, p. 237) calls the "single-value objective" of a corporation.

I have analyzed companies (HTSUs) and public organizations that have multiple-value objectives including, but not reducable to, that "single-value objective" Jensen refers to above. The application of this framework to a wider variety of corporate contexts, the typical focus of stakeholder theory, will be useful for furthering this theory. In particular, the framework provides an avenue for stakeholder theory to more directly address the question of how shareholders might be managed if they are, as stakeholder theory suggests, "deposed from their preferred status" (Kraatz \& Block, 2008, p. 264).

The paradox lens. As stated in the literature review (Section 2.1) a plethora of studies within the broader pluralism field are focused on 'paradox.' Some of these have included a focus on 'coping' strategies (e.g., Poole \& Van de Ven, 1989; Smith et al., 2010; Werner \& Baxter, 1994). These studies usually explore a single specific tension such as that between exploitation and exploration (e.g., Andriopoulos \& Lewis, 2009; O'Reilly \& Tushman, 2004; Smith et al., 2010; Smith \& Tushman, 2005). This study necessarily limited an in-depth review of the literature to the specific issue of legitimacy strategies. However, this broader paradox research agenda can be reflected on. Smith and Lewis (2011) acknowledge that 
much of the paradox literature, including their own extensive review, has focused on dualities. This is distinct from the embedded array of tensions that pluralism usually denotes. This thesis is, consequently, a rarer example explicitly focused on understanding the management of multiple embedded tensions.

Managing science organizations. This research also contributes to understanding the challenges of knowledge-intensive organizations and technology management more broadly. Specifically, within both institutional theory and the pluralistic literature generally, greater attention has been paid to the tensions with in cultural (Alexander, 1996; Glynn, 2000; Glynn, 2002), education (Jarzabkowski \& Sillince, 2007; Meyer et al., 1987), and healthcare (D'Aunno et al., 1991; Denis et al., 2010; Reay \& Hinings, 2005; Sonpar et al., 2010) than to science organizations. This thesis consequently adds to studies that focused on the challenges of organizations faced with conflicting demands in the modern science context (Colyvas, 2007; Colyvas \& Powell, 2006, 2007). In particular, research highlighting how such organizations have managed this pluralism remains rare. The above studies instead utilize an institutional perspective to explore the institutionalization of new "hybrid" models rather than focusing on the divergent legitimacy demands involved. This study also adds insight to the body of work seeking to conceptualize changes within NZ's science sector (e.g., Davenport et al., 2003; Devine, 2003; Leitch \& Davenport, 2005). It extends such work through increasing understanding of how these changes, and associated tensions, have been managed at the organizational level by different types of organization.

\subsection{Implications for Practice}

Managers of both for-profit and not-for-profit organizations face a more multi-faceted world. Multiple objectives as a root to sustainability are increasingly acknowledged (Laplume et al., 2008; Pfeffer, 2009). Further, knowledge is spread across organizations (Pisano \& Verganti, 2008; Powell et al., 1996; Walter, Kellermanns, \& Lechner, 2010). This makes understanding legitimacy in contexts where power is diffused increasingly pertinent. Pluralism has consequently been depicted as increasingly typical, not restricted to traditional examples in the public sector (e.g., Glynn et al., 2000; Jarzabkowski \& Fenton, 2006; Jarzabkowski et al., 2009a). If we accept this assumption this means a pluralistic understanding of legitimacy is also pertinent for practitioners. 'Legitimacy strategies in 
pluralistic contexts' (as in the framing here) then becomes the standard experience of legitimation for organizations full-stop. Indeed, a prime motivation of this research was an ontological one: incorporating pluralism was seen as reflective of what organizations and managers are actually faced with and do.

Incorporating insights from institutional theory at the organizational level to focus on the practical activity of organizations is said to increase its utility outside academia (Lawrence, et al., 2009, p. 2). The stories here indicate for managers something about how they can manage their organization's legitimacy in complex contexts: they can implement any of the strategies suggested. This contrasts with many traditional studies of legitimacy which instead outlined broad institutional pressures to which whole organizational fields conform. Such an approach tells managers little about how a specific organization, such as their own, navigates the complex array of assessments of their desirability and appropriateness. Instead, this thesis assumes that strategies implemented by managers matter and provides pointers regarding how legitimacy can be successfully managed. In this way the framework provided enables increased insight for managers regarding their current approach to pluralism and prompt discussion regarding future, potentially more beneficial, strategic options.

Propositions 1-4 hold potential implications for practice. The connection made between perspectives of pluralism and legitimacy strategies provides organizations with a sense of which strategic responses make sense considering their particular situation. For example, awareness of the existence of persistent perceptions of incompatibility between objectives suggests managers explore whether opportunities for contraction exist (e.g., Proposition 1). Such propositions suggest that efforts to influence perceptions (either their own or those of their staff) might better support the strategy they are currently implementing, or wish to in the future are worthwhile. For example, communicating points of compatibility within divergence in an effort to change perceptions is proposed as important for enabling a transcension strategy. Initial practices associated with transcension can then be used to reinforce the growing perception of compatibility. Another implication also concerns individual leaders: awareness of their own perceptions of their pluralistic context becomes critical. 
The propositions focused on how organizations can combine strategies also provide insight for practice. They suggest that managers view individual strategies as components that create a complex whole made up of multiple, potentially paradoxical, strategies. Managers are prompted to be innovative in their approach to pluralism and the management of their stakeholders. For example, they can implement a contraction strategy in one area while embracing pluralism in another. The message here is that complete "resolution" cannot be expected in such contexts. Managers can, however, still aim for a degree of transcension, at least in some areas. For example, attempts to articulate an overarching vision within complexity appears worthwhile. This is potentially a more empowering message than that contained in studies that outline on-going compromise and grudging acceptance of divergent demands by stakeholders.

A particularly successful strategic combination is also proposed here between negotiation and transcension. This provides a concrete suggestion regarding how organizations might navigate pluralistic legitimacy demands; the findings suggest that the least risky strategy in pluralistic contexts maybe one with an integrative impulse. By contrast, a combination of contraction and negotiation is suggested to be a more difficult strategic combination (Figure 6.5). For example, in CoRE 2 such a combination was shown to be a potentially less successful one. Such insight provides broad guidance for managers seeking to shift strategies that they are currently dissatisfied with.

The selection of NZ's science sector as an empirical setting was motivated by a view of the importance of the RS\&T sector to NZ's future. This fact has been proposed but the difficulties inherent in linking science activity to a more prosperous future is also acknowledged (Callaghan, 2009; Crown Research Institute Taskforce, 2010; Fox, 2009). The hope is that this study offers those navigating this specific context insight into the associated difficulties and potential successful organizational strategies. That pluralism exists in NZ's RS\&T sector has been widely outlined by literature (Davenport et al., 2003; Devine, 2003; Leitch \& Davenport, 2005). This study focuses on how that can be managed. Ziman states of the changes that have brought this increased pluralism that: 
Nostalgia is a fruitless sentiment...The real question is not whether the structural transition is desirable, or could have been avoided: it is how to reshape the research system to fit a new environment without losing the features that have made it so productive in the past (Ziman, 1994, p. viii)

Although not addressing this question at the sector or policy level, this thesis suggests ways this can be achieved at the organizational level. The constraints faced by these organizations are very real and have been outlined here and elsewhere. However, despite this, opportunities for "creative enactment" (Alexander, 1996) exist for NZ science organizations. The findings here provide examples and link these to strategic processes that other organizations within this sector could be guided by.

\subsection{Future Research Avenues}

This section highlights some questions that this thesis has left me enthusiastic to explore. Within this discussion the limitations of the current study are also outlined as representing opportunities for further investigation.

Increased access in exploring pluralism. Future research could increase understanding into pluralism through more broad-based access. Limitations associated with access in this study are acknowledged (Chapter 3; also Chapter 4, footnote 21). That this may have affected the findings is recognized. For example, the implications of not including clients in the HTSUs, administrative staff in the CRIs, or the community in the CoREs are recognized as possibly limiting the degree of pluralism observed. Access limitations were based on a predetermined understanding of the relevant tensions to specific science organizations, pragmatic constraints (such as confining the number of interviews at the CEO's request), and a focus on the stakeholders identified as central to the emerging tensions in initial interviews within each organization. In addition, a full appreciation of legitimacy strategies over time demands longitudinal engagement. While the retrospective aspects of the interviews as well as the secondary data assisted in a degree of understanding regarding legitimacy strategies over time, the unit of analysis remained largely a "snapshot." Longitudinal access would enable further exploration of whether legitimacy strategies change over time and to what extent they are characterized by inertia and a desire for organization consistency (Kraatz and Block, 2008). 
Future generalization. While the strengths of qualitative cases studies are espoused and made use of here, their limitations are also recognized. Aligned with the post-positivist approach adopted, analytical generalizability has been achieved rather than statistical generalizability (Flyvbjerg, 2006; Yin, 2009). The empirical understanding remains grounded within the specific cases encountered and the generalizations remain "petite": they refer to, refine or modify existing theorizations. They have not been "tested" or generalizabled to populations (Stake, 1995; Yin, 2009). Future research could operationalize the associated propositions to test their generalized applicability. In particular, investigation of the proposed association between perceptions and resulting strategies could suit a large-scale quantitative research design. Further, the proposition regarding common combinations of strategies (and their potential link to measures of organizational success) could be explored through such an approach. In such research, attention would need to be given to issues such as ensuring participants were able to report the existence of multiple strategies, not only the most dominant. Similarly, many statistical studies have focused on a specific practice, such as downsizing, as signifying institutional resistance (Greenwood et al., 2010; Marquis \& Lounsbury, 2007). The framework developed here, and associated combinatorial approach proposed, is potentially more challenging to quantify as it is situated at the organizational level and encompasses multiple practices. In contrast to a focus on a specific practice, this would be more demanding in terms of devising appropriate research instruments.

Combinations of strategies or new legitimacy strategies? An issue I was conscious of during data analysis was whether the etic-level categorization was constraining. Sub-themes were initially developed during the analysis process without reference to the broad framework. However, whether some of these strategies, either singularly or through their close association with other strategies, exist outside the theoretical framework remains an avenue for future exploration. For example, utilizing democratic principles and structures was a strategy not previously outlined in the literature. It was classified as a negotiation strategy due to it being a forum for active and ongoing discussion between stakeholders and focused on adapting to multiple stakeholder demands (in comparison to seeking to manipulate them) (Chapter 5). However, that "democracy" contained elements that could perhaps be defined as indicative of transcension was also alluded to. Similarly, the dynamics of transcension and negotiation are suggested as being closely related. Does this close 
association, the overlap represented in the adapted framework depicted in Figure 6.5, represent a combination of negotiation and transcension or is it better represented as a new strategic process?

In addition, with regards to negotiation, a large variety of different sub-strategies were found. For example, the dynamic balance evident within CRI 1 and CORE 1 was quite different from the grudging "compromise" associated with other cases (e.g., CoRE 2, CRI 2). Future research can perhaps focus on further defining a collaborative/competitive distinction to differentiate two distinct forms of negotiation. Through developing such a distinction, it could be found that a particular type of negotiation may be connected with transcension strategies (e.g., CoRE 1, CRI 1), with the other being more likely to be combined with segregative strategies (e.g., CoRE 2, CRI 2). Such a re-conceptualization involving two broad types of negotiation might explain the prevalence of negotiation and why it was less clearly associated with particular perceptions of pluralism. A limitation is, therefore, that such distinctions within the negotiation category were perhaps largely subsumed within the broader categorization used.

While acknowledging these issues, maintaining the distinctions in Kraatz and Block's (2008) framework was helpful in enabling an understanding of combinations of strategies. It helped focus analytical attention on multiple but distinct strategies within the organizations rather than subsuming them within a broader single category. This developed a combinatorial understanding. Further, the use of an overarching framework allowed me to comment directly on an available broad strategy framework. As Pache and Santos (2010) state, within the literature this remains a novel approach. Practically, the abductive use of the overarching framework also helped avoid the "death by data asphyxiation" that authors warn of vis-à-vis qualitative case studies (Eisenhardt, 1989, p. 540; Pettigrew, 1990).

To conclude, this research is recognized as partly constrained by the applied framework. As the post-positivist perspective suggests, empirical observations are necessarily selective and underdetermined by theory (Crotty, 1998; Phillips \& Burbules, 2000). My goal has been to establish whether the framework is a warranted account and a useful way of understanding the research problem (Patton, 2002a). Other frameworks may still, however, have uncovered aspects that this particular framing did not. Future research could more explicitly 
focus on developing organizational level strategies that exist outside the framework used here.

Enacted environments. That organizations enact, to a degree, their environment is tentatively suggested as a frame for understanding the link between perspectives of pluralism and particular strategies. Through their perceptions of their environment organizational actors partially create that context in which they are strategizing (Alexander, 1996). This was outlined by Smircich and Stubbart (1985, p. 724) who suggest that "a pattern of enactment establishes the foundation of organizational reality, and in turn has effects in shaping future enactments." This concept is aligned with resource dependence theory (Pfeffer \& Salancik, 1978) which has been depicted as foundational to understanding legitimacy strategy. The position here is reflected by Alexander's (1996, p. 830) observation regarding the constraints of enactment: "clearly, even if [actors] are free to choose within a set of possibilities, the universe of possibilities is determined by funding." In other words, organizations cannot "enact" any environment they desire (Jauch \& Kraft, 1986; Pfeffer \& Salancik, 1978). A constructivist perspective would have, instead, further grounded multiple aspects of this thesis within the implications of an "enactment" frame.

Further, the question of causality within the association between the strategies and stakeholder perspectives has not been answered here. Whether the strategies adopted are behind the creation of perceptions (e.g., transcension may foster particular perceptions of objective divergence and power diffusion) or whether the perceptions are behind the adoption of particular strategies remains open. As Figure 7.2 suggests, the complexity associated with this question means that it is not surprising that these issues have not been made complete sense of here. The suggestion is that future research seeking to explore causality in this way embraces rather than limits the ongoing iterative dynamic between the different components. 
Figure 7.2 Strategic enactment: a framework for more investigation

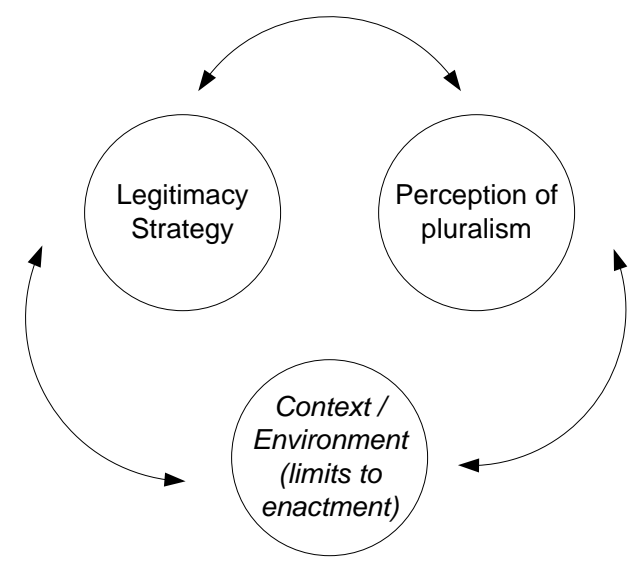

Additional limitations related to propositions 1-4. Future research could strengthen the proposed association between particular perceptions of pluralism and negotiation and compartmentalization strategies. First, with compartmentalization, there were fewer fully developed examples in the dataset and CoRE 2 sat outside the suggested dynamic through not reporting compartmentalization as a prominent strategy. As a consequence, the theorized link between compartmentalization and perceptions of higher degrees of diffused power and objective divergence requires further investigation. Indeed, reflecting a similar issue raised by Montgomery and Oliver (1996), decoupling as a strategy perhaps made sense with regards to some of the cases. However, their data, like mine, did not capture the distinction between substantive and symbolic responses that decoupling entails. For example, CoRE 2 may have tried to decouple its primary focus on science excellence from its reporting requirements to government. Yet the ability to delineate symbolic and substantive responses was beyond the capacity of the dataset here. The understanding here was, instead, located primarily in stakeholder perceptions and their reporting of the strategies, which did not enable assessments of symbolic versus substantive action.

Negotiation was shown to be a widely reported strategy associated with many different combinations of strategies. A link between 'negotiation' and specific perceptions of pluralism was therefore less explicit (Chapter 6). Again, future research can unpick whether negotiation is broadly associated with particular perceptions, or whether it is instead best viewed as a strategy that is useful across a variety of contexts, frequently in combination with other strategies. Further distinctions regarding negotiation as a category, something discussed above, could be used to explore this issue. Perhaps different types of negotiation 
are more likely to be associated with different perceptions of pluralism? For example, 'balance' is potentially particularly associated with perceptions of a degree of commensurability and therefore frequently combined with transcension strategies (e.g., CoRE 1 and CRI 1). Meanwhile, 'compromise', with its associated grudging trade-offs, might be likely to be linked with perceptions of incommensurability and, therefore, more frequently combined with segregative strategies (e.g., CoRE 2, CRI 2).

Further elaboration of legitimacy's dimensions. This study has primarily focused on evaluative legitimacy: normative, pragmatic, and regulative assessments of desirability and appropriateness (Suchman, 1995). By asking for and exploring participants perceptions I focused on their evaluations of the organizations rather than their taken-for-granted assumptions. As such, the relationship of cognitive legitimacy to the question of strategizing within pluralism remained largely unaddressed. Some institutional theorists suggest that cognitive legitimacy becomes less prevalent in pluralistic settings. Stryker (2000, p. 189) suggests that "cognitive taken-for-grantedness is likely to disappear...in an arena in which two or more institutional logics are available to provide alternative behavioural scripts." This is linked to evaluative definitions: a focus on divergence and tension meant my research questions necessarily emphasized what was not taken-for-granted. However, institutional theory would suggest that cognitive legitimacy, for example, what was 'unable' or 'questionable', still defined the realm and domain of the debate. An example is seen in how the need for HTSUs to provide a return on investment was not questioned or discussed, merely the degree of primacy and urgency associated with this demand. However, Deephouse \& Suchman (2008) highlight the difficulty of researching taken-for-grantedness: it is an issue experienced by the legitimacy literature more broadly. Deephouse and Suchman consequently suggest that the operationalization of legitimacy focused on its sources (stakeholders) rather that its dimensions. This advice was followed here.

Another aspect that could have been explored further in this dataset is the effect of regulative legitimacy. In particular, a greater degree of agency to (successfully) implement some strategies such as contraction may be associated with a lack of regulative legitimacy. For example, the legitimacy demands of CRIs and CoREs were explicitly translated in government policy, as well as reporting and selection criteria. By contrast, the demands placed on HTSUs were not expressed in such a way. This potentially explains the relative 
capacity for HTSU 2 to implement a contraction strategy. By contrast, CoRE 2 was ultimately unable to do so because of regulative demands associated with CoRE re-funding (Oliver, 1991).

These two points suggest that a more fine-grained treatment of legitimacy dimensions may provide additional insight into legitimacy strategies within pluralism.

Potential of a critical paradigm. Another area for further exploration is the role power, in the critical sense, could play in understanding legitimacy in pluralistic settings (Courpasson, 2000; Gordon et al., 2009; Vaara et al., 2006; Van Leeuwen \& Wodak, 1999). Legitimacy, based on its Weberian foundation, is also the "recognition of the right to govern." It justifies why some individuals hold power and others give their consent and submit to authority. It provides "solid grounds for domination" (Courpasson, 2000, p. 143). This issue is raised because scientists were depicted here as semi-autonomous knowledge workers whose legitimacy demands count. This has perhaps overshadowed an alternative description, for example, one that includes fuller appreciation of the limited options for scientist workers within the NZ context, an issue mentioned by interviewees. An interpretation of the data highlighting the subtle primacy of the managerial and commercial over the science-worker and the scientific may have resulted. This provides an alternative framing to the one used here where the autonomy of the "knowledge worker" was seen as part of the pluralism the organizations were navigating.

Combining legitimacy strategy frameworks. The importance of language was highlighted by some interviewees. For example:

Quite often it's just a re-expression. Trying to develop some commonality around language. (CEO, CRI 1)

Issues concerning language could have been more explicitly focused upon in this study. Currently there are two broad research strands of understanding regarding 'legitimacy strategies.' The one that this research is based on is directed at the organizational level and incorporated organizational practices (e.g., Kraatz \& Block, 2008). Another has a more micro conception of strategy focused at the 'language' level of rhetoric or discourse (e.g., Suddaby \& Greenwood, 2005). These two distinct types of legitimacy strategy framework at different levels of analysis have infrequently been brought together. Incorporating both within a 
single study would represent a novel contribution to an understanding of legitimacy strategy. In particular, the data coded using the broad strategic categories, transcension, negotiation, compartmentalization, contraction, could be explored for the associated rhetorical or discourse legitimacy strategies at play. Questions such as whether particular strategies in the model here are associated with or particularly supported by specific rhetorical strategies (e.g., Erkama \& Vaara, 2010) could be investigated.

Pluralism and legitimacy: Some tensions. Two tensions were raised in the literature review as existing between legitimacy theory and pluralism (Section 2.3.3). First, is the tension between ambiguity (outlined as important strategically in pluralistic settings) and clarity (outlined as important in terms of attaining legitimacy) (Stone \& Brush, 1996). Second, is the tension between consistency (over time and between responses, for example) and conformity (to many different demands) (Kraatz \& Block, 2008). These two tensions were observable in the background of my analysis and it would perhaps be illuminating to further understand the role of these tensions. In particular, the relationship between these tensions can be further explored. For example, strategically utilizing ambiguity may enable an organization to simultaneously be both consistent (with regards to its overarching vision) and inconsistent (in its response to immediate stakeholder demands) and, thus, navigate this tension. Similarly, consistency over time in relation to an 'overarching objective' could build stakeholder clarity regarding the centrality of that objective as the organization's basis of legitimacy. At the same time, the broad nature of that vision simultaneously allows a degree of ambiguity and 'inconsistent' relationships to that objective. This is perhaps particularly descriptive of HTSU 1 and its use of an overarching objective. The next step is perhaps to move beyond an 'either/or' conception to explore how organizations can instead adopt a 'both/and' approach to managing these tensions (Lewis, 2000). For example, investigating how organizations can be both consistent and inconsistent at different levels of stakeholder interaction as a way of managing legitimacy (Smith et al., 2010).

\subsection{Concluding Comments}

Through engagement with both Kraatz and Block's (2008) framework and the six focal organizations I am left with an impression of the potential of organizations to thrive within pluralism. The strategic innovativeness exhibited by some organizations and their capacity 
to benefit from pluralism was something that I had not been expecting. In retrospect, this was, however, something for which Kraatz and Block laid the theoretical grounding:

We acknowledge that pluralism problematizes legitimacy, but we also suggest that organizations may benefit from it and thrive in its midst. We think that future research might give more attention to the possibility that organizational legitimacy can be additive or even multiplicative, rather than zero-sum...we see no obvious reason to predict that an organization cannot fulfil multiple purposes, embody multiple values (or logics) and successfully verify multiple institutionally-derived identities. Indeed, we think that organizations that embody multiple values and are successful at more than one thing....may be especially legitimate for that very reason (Kraatz \& Block, 2008, p. 261).

Based on my findings I end with the same point here, albeit with the following additional caveats. First, the "problematic" nature of the legitimacy/pluralism dynamic means organizations are as likely to experience the traditionally expressed negative association between legitimation and pluralism as they are to grasp the potential inherent in it. The risks and difficulties associated with pluralism highlighted in some organizations here prevent naivety in this regard. Second, an ongoing need for negotiation does not negate the "transcension" picture in the way Kraatz and Block appear to assume. Partial adaptation, compromise, and balancing are, instead, part of how organizations can productively 'thrive' within pluralism. This is distinct from the implicitly negative depiction of negotiation Kraatz and Block promulgate in their comparisons between it and their advocated transcension strategy.

A danger in this message is perhaps that of expecting too much of organizations and those managing them. However, the realization that organizations can encompass divergent legitimacy demands is also an empowering one (Kraatz \& Block, 2008). An interviewee encapsulates what I mean by this:

It's what I call 'raising the sights.' It's about scientists who often get bogged down, because we're so focused on our work we often get bogged down with the irritations of the context that we're working in...by lifting our sights we're empowered. (Director, CoRE 1)

To reiterate, that organizations can benefit from the complexity in their context, capturing the 'creative chances' at the 'clashing point' (Snow, 1959), was a strong message within the empirical data.

A central argument promulgated here is that managing legitimacy in pluralistic contexts is likely to involve implementing multiple strategies simultaneously. This moves beyond much 
of the available theoretical and empirical studies. These have tended to instead focus on idiosyncratic responses and/or implicitly assumed the implementation of a single dominant strategy. Understanding the complexity of organizational pluralism, as well as the reference to a broad legitimacy strategy framework, has informed a more nuanced view of legitimation. Overall, this research has hopefully extended legitimacy theory while also reflecting more fully on the complexity within which organizations actually engage in legitimation (Glynn et al., 2000). 


\section{References}

Aaltonen, K., \& Sivonen, R. (2009). Response strategies to stakeholder pressures in global projects. International Journal of Project Management, 27, 131-141.

Ackroyd, S. (2004). Methodology for management and organisation studies: Some implications of critical realism. In S. Fleetwood \& S. Ackroyd (Eds.), Critical realist applications in organisation and management studies (pp. 137163). London: Routledge.

Ackroyd, S., \& Fleetwood, S. (2000). Realism in contemporary organisation and management studies. In S. Ackroyd \& S. Fleetwood (Eds.), Realist perspectives on management and organisations (pp. 3-25). London: Routledge.

Aldrich, H., \& Baker, T. (2001). Learning and legitimacy: Entrepreneurial responses to the emergence of new populations and organizations. In C. B. Schoonhoven \& E. Romanelli (Eds.), The entrepreneurship dynamic: Origins of entrepreneurship and the evolution of industries (pp. 207-235). Stanford: Stanford University Press.

Aldrich, H., \& Fiol, C. (1994). Fools rush in? The institutional context of industry creation. Academy of Management Review, 19(4), 645-670.

Alexander, V. (1996). Pictures at an exhibition: Conflicting pressures in museums and the display of art. The American Journal of Sociology, 101(4), 797-839.

Alvesson, M., \& Sveningsson, S. (2003). Good visions, bad micro-management and ugly ambiguity: Contradictions of (non)leadership in a knowledge-intensive organization. Organization Studies, 24(6), 961-988.

Andriopoulos, C., \& Lewis, M. (2009). Exploitation-exploration tensions and organizational ambidexterity: Managing paradoxes of innovation. Organization Science, 20(4), 696717.

Archibald, M. (2008). The impact of density dependence, sociopolitical legitimation and competitive intensity on self-help/mutual-aid formation. Organization Studies, 29(1), 79-101.

Arndt, M., \& Bigelow, B. (2000). Presenting structural innovation in an institutional environment: Hospitals' use of impression management. Administrative Science Quarterly, 45(3), 494-522. 
Arnold, E. (2005). Reflections on devolving funding in vote RS\&T: A view from abroad for MoRST NZ. Technopolis.

Ashforth, B., \& Gibbs, B. (1990). The double-edge of organizational legitimation. Organization Science, 1(2), 177-194.

Atkinson, P., \& Coffey, A. (2002). Revisiting the relationship between participant observation and interviewing. In J. Gubrium \& J. Holstein (Eds.), Handbook of Interview Research. Thousand Oaks, CA: Sage.

Aurini, J. (2006). Crafting legitimation projects: An institutional analysis of private education businesses. Sociological Forum, 21 (1), 83-111.

Bamberger, P. (2008). Beyond contextualization: Using context theories to narrow the micro-macro gap in management research. Academy of Management Journal, 51(5), 839-846.

Bansal, P., \& Clelland, I. (2004). Talking trash: Legitimacy, impression management, and unsystematic risk in the context of the natural environment. Academy of Management Journal, 47(1), 93-103.

Barron, D. N. (1998). Pathways to legitimacy among consumer loan providers in New York City, 1914-1934. Organization Studies, 19(2), 207-233.

Battilana, J., \& Dorado, S. (2010). Building sustainable hybrid organizations: The case of commercial microfinance oragnziations. Academy of Management Journal, 53(6), 1419-1440.

Battilana, J., Leca, B., \& Boxenbaum, E. (2009). How actors change institutions: Towards a theory of institutional entrepreneurship. Academy of Management Annals, 3(1), 65107.

Baum, J., \& Oliver, C. (1991). Institutional linkages and organizational mortality. Administrative Science Quarterly, 36(2), 187-218.

Baum, J., \& Oliver, C. (1992). Institutional embeddedness and the dynamics of organizational populations. American Sociological Review, 57(4), 540-559.

Baum, J., \& Powell, W. (1995). Cultivating an institutional ecology of organizations: Comment on Hannan, Carroll, Dundon, and Torres. American Sociological Review, 604), 529-538. 
Becker, H. (1992). Cases, causes, conjunctures, stories and imagery. In C. C. Ragin \& H. S. Becker (Eds.), What is a case? Exploring the foundations of social inquiry (pp. 205216). Cambridge: Cambridge University Press.

Beekun, R. I., \& Badawi, J. A. (2005). Balancing ethical responsibility among multiple organizational stakeholders: The Islamic perspective. Journal of Business Ethics, 60, 131-145.

Belk, R. (2005). The cult of Macintosh. Consumption, markets and culture, 8(3), 205.

Berg, B. (2004). Qualitiative research methods for the social sciences (5th ed.). New York: Pearson.

Bergene, A. (2007). Towards a critical realist comparative methodology: Context-sensitive theoretical comparison. Journal of Critical Realism, 6(2), 5-27.

Berger, P., \& Luckmann, T. (1966). The social construction of reality: A treatise in the sociology of knowledge. New York: Doubleday \& Company. Inc. .

Beverland, M., \& Luxton, S. (2005). Managing integrated marketing communication (IMC) through strategic decoupling: How luxury wine firms retain brand leadership while appearing to be wedded to the past. Journal of Advertising, 34(4), 103-116.

Bhaskar, R. (1979). The possibility of naturalism: A philosophical critique of contemporary human sciences. Brighton: The Harvester Press Limited.

Bhaskar, R. (1989). Reclaiming reality: A critical introduction to contemporary philosophy. London: Verso.

Bigelow, B., \& Stone, M. (1995). 'Why don't they do what we want? An exploration of organziational responses to institutioanl pressures in community health centres. Public Administration Review, 55, 183-192.

Binder, A. (2007). For love and money: Organizations' creative responses to multiple environmental logics. Theory and Society, 36, 547-571.

Boxenbaum, E., \& Jonsson, S. (2008). Isomorphism, diffusion and decoupling. In R. Greenwood, C. Oliver, K. Sahlin \& R. Suddaby (Eds.), The Sage handbook of organizational institutionalism (pp. 78-98). Los Angeles, CA: Sage.

Boyatzis, R. (1998). Transforming qualitative information: Thematic analysis and code development. Thousand Oaks, CA: Sage.

Boyd, J. (2000). Actional legitimation: No crisis necessary. Journal of Public Relations Research, 12(4), 341-353. 
Boyle, M. (2004). Walking our talk: Business schools, legitimacy and citizenship. Business \& Society, 43(1), 37-68.

Bridger, G. (2009, 29th September). Scientists need to be entrepreneurs. The Dominion Post $\begin{array}{llll}\text { Retrieved } \quad \text { 30th 2009, from } & \text { October, }\end{array}$ www.stuff.co.nz/business/industries/2911941/Scientists-need-to-be-entrepreneurs

Bridwell-Mitchell, E. (2008, 2-4 July). Making sense of conflicting instituional logics. Paper presented at the EGOS Colloquium, Barcelona.

Britten, D., \& Scott, F. (2009, 27 August). When science meets the meets the market. The Independent Financial Review Retrieved 30th October, 2009, from http://www.knowledgebasket.co.nz/search/doc_view.php?d1=magz/text/ind/2009/08/IFR09082700141189 55267-BW.html

Brown, A. (1994). Politics, symbolic action and myth making in pursuit of legitimacy. Organization Studies, 15(6), 861-878.

Brown, A. (1995). Managing understanding: Politics, symbolism, niche marketing and the quest for legitimacy in IT implementation. Organization Studies, 16(6), 951-969.

Brunsson, N. (2002). The organization of hypocrisy: Talk, decisions and actions in organizations. Herndon, VA: Copenhagen Business School Press.

Bryson, J. (1988). Strategic planning for public and nonprofit organizations. San Francisco, CA: Jossey-Bass.

Burgoyne, J. (1994). Stakeholder analysis. In C. Cassell \& G. Symon (Eds.), Qualitiative methods in organziational research (pp. 187-207). London: Sage.

Callaghan, P. (2009). Wool to Weta: Transforming New Zealand's culture and economy. Auckland: Auckland University Press.

Carroll, G., \& Hannan, M. (1989). Density dependence in the evolution of populations of newspaper organization. American Sociological Review, 54(4), 254-541.

Carter, N. (2005). Leadership and management. Journal for Waldorf/Redolf Steiner Teachers, オ1), 16-22.

Casinader, J. (2010, 12 February). Saving Science. Idealog Retrieved 3rd March, 2010, from http://m.idealog.co.nz/magazine/25/saving-science

CCMAU (Crown Company Monitoring Advisory Unit), \& The Treasury. (2007, 29 October). Owner's expectations manual for Crown Research Institutes. 
Cherryholmes, C. (1992). Notes on pragmatism and scientific realism. Educational Researcher, 14, 13-17.

Clemens, E., \& Cook, J. (1999). Politics and institutionalism: Explaining durability and change. Annual Review of Sociology, 25, 441-466.

Coffey, A., \& Atkinson, P. (1996). Making sense of qualitiative data: Complementary research stratgies. Thousand Oaks: Sage.

Cohen, L., Duberley, J., \& McAuley, J. (1999). Fuelling discovery or monitoring productivity: Research scientists' changing perceptions of management. Organization, 6(3), 473497.

Cohen, L., Manion, L., \& Morrison, K. (2000). Research methods in education (5th ed.). London: Croom Helm.

Cohen, M., \& March, J. (1986). Leadership and ambiguity: The American college president. Boston: Harvard Business School Press.

Cohen, M., March, J., \& Olsen, J. (1972). A garbage can model of organizational choice. Administrative Science Quarterly, 17, 1-25.

Colyvas, J. (2007). From divergent meanings to common practices: The early institutionalization of technology transfer in the life sciences at Stanford University. Research Policy, 36, 456-476.

Colyvas, J., \& Powell, W. (2006). Roads to Institutionalization: The Remaking of Boundaries between Public and Private Science. Research in Organizational Behavior, 27, 305353.

Colyvas, J., \& Powell, W (2007). From vulnerable to venerated: The institutionalization of academic entrepreneurship in the life sciences. Research in the Sociology of Organizations, 25: 219-259.

Constas, M. (1992). Qualitative analysis as a public event: The documentation of category development procedures. American Education Research Journal, 29(2), 253-266.

Contractor, N., \& Ehrlich, M. (1993). Strategic ambiguity in the birth of a loosely coupled organization: The case of a $\$ 50$-million experiment. Management Communication Quarterly, 6(3), 251-281.

Cooper, D., Hinings, B., Greenwood, R., \& Brown, J. (1996). Sedimentation and transformation in organizational change: The case of Canadian law firms. Organizational Science, 17(4), 623-647. 
Courpasson, D. (2000). Managerial strategies of domination: Power in soft bureaucracies. Organization Studies, 21(1), 141-161.

Covaleski, M., \& Dirsmith, M. (1988). An institutional perspective on the rise, social transformation, and fall of a university budget category. Administrative Science Quarterly, 33(4), 562-587.

Crabtree, B., \& Miller, W. (1999). Using codes and code manuals: A template organizing style of interpretation. In B. F. Crabtree \& W. L. Miller (Eds.), Doing qualitiative research (2nd ed.). Newbury Park, CA: Sage.

Creed, W., Scully, M., \& Austin, J. (2002). Clothes make the person? The tailoring of legitimating accounts and the social construction of identity. Organizational Science, 13(5), 475-496.

Creswell, J. (2009). Research design: Qualitiative, quantitiative and mixed methods approaches. Los Angeles, CA: Sage.

Creswell, J. W. (2007). Qualitative inquiry and research design. Thousand Oaks, CA: Sage.

Creswell, J. W., \& Miller, D., L. (2000). Determining validity in qualitative inquiry. Theory into Practice, 39(3), 124-130

Crotty, M. (1998). The foundations of social research. St Leonards, Australia: Allen \& Unwin.

CCMAU (Crown Company Monitoring Advisory Unit). (2007). Owner's Expectations Manual for Crown Research Institutes. Wellington: CCMAU.

Crown Research Institute Act 1992 (1992).

Crown Research Institute Taskforce. (2010). How to enhance the value of New Zealand's investment in Crown Research Institutes. Wellington, New Zealand: MoRST.

D'Aunno, T., Sutton, R., \& Price, R. (1991). Isomorphism and external support in conflicting institutional environments: A study of drug abuse treatment units. Academy of Management Journal, 34(3), 636-661.

D'Auuno, T., Succi, M., \& Alexander, J. (2000). The role of institutional and market forces in divergence organziational change. Administrative Science Quarterly, 45(4), 679-703.

Dacin, M. (1997). Isomorphism in context: The power and prescription of institutional norms. Academy of Management Journal, 20(1), 46-81.

Danermark, B., Ekstrom, M., Jakobsen, L., \& Karlsson, J. (2002). Explaining Society - Critical realism in the social sciences. London: Routledge. 
Davenport, S., \& Bibby, D. (2007). Contestability and contested stability: Life and times of CSIRO's New Zealand cousins, the Crown Research Institutes. Innovation: management, policy and practice, 9(2), 181-191.

Davenport, S., Grimes, C., \& Davies, J. (1999). Collaboration and organizational learning: A study of a New Zealand collaborative research program. International Journal of Technology Management, 18(3/4), 173-188.

Davenport, S., \& Leitch, S. (2005). Circuits of power in practice: Strategic ambiguity as delegation of authority. Organization Studies, 26(11), 1603-1623.

Davenport, S., Leitch, S., \& Rip, A. (2003). The 'user' in research funding negotiation processes. Science and Public Policy, 30(4), 239-250.

Deeds, D., Mang, P., \& Frandsen, M. (2004). The influence of firms' and industries legitimacy on the flow of capital into high-technology ventures. Strategic Organization, 2(1), 934.

Deephouse, D. (1996). Does isomorphism legitimate? Academy of Management Journal, 4(39), 1024-1039.

Deephouse, D., \& Carter, S. (2005). An examination of differences between organizational legitimacy and organizational reputation. Journal of Management Studies, 42(2), 329-360.

Deephouse, D., \& Suchman, M. (2008). Legitimacy in organizational institutionalism. In R. Greenwood, C. Oliver, K. Sahlin \& R. Suddaby (Eds.), The Sage handbook of organizational institutionalism (pp. 49-77). Las Angeles, CA: Sage.

Denis, J., Lamothe, L., \& Langley, A. (2001). The dynamics of collective leadership and strategic change in pluralistic organizations. Academy of Management Journal, 44(4), 809-837.

Denis, J., Langley, A., \& Rouleau, L. (2006). The power of numbers in strategizing. Strategic Organization, 4(4), 349-377.

Denis, J., Langley, A., \& Rouleau, L. (2010). The practice of leaderhsip in the messy world of organziations. Leadership, 676), 67--88.

Denis, J., Langley, A., \& Rouleau, L. (2007). Strategizing in pluralistic contexts: Rethinking theoretical frames. Human Relations, 6011), 179-215.

Denzin, N. (1989). The Research Act (3rd ed.). Englewood Cliffs: Prentice Hall. 
Denzin, N., \& Lincoln, Y. (2005). Introduction: The discipline and practice of qualitative research. In N. K. Denzin \& Y. S. Lincoln (Eds.), The SAGE handbook of qualitative research (3rd ed., pp. 1-32). Thousand Oaks: Sage.

Devine, S. (2003). A systems look at the science reforms. New Zealand Science Review, 60(23), 70-74.

Devine, S., \& Webb, C. (2004). Competitive funding: A game theory analysis of how research organisations adapt their behaviour in the New Zealand competitively funded science system. Science and Public Policy, 31(5), 407-414.

Dewey, J. (1938). Logic: The theory of inquiry. London: Allen \& Unwin.

DiMaggio, P. (1988). Interest and agency in institutional theory. In L. G. Zucker (Ed.), Institutional Patterns and Organizations: Culture and Environment. Cambridge, MA: Ballinger.

DiMaggio, P., \& Powell, W. (1983). The iron cage revisted: Institutional isomorphism and collective rationality in organizational fields. American Sociological Review, 48(2), 147-160.

DiMaggio, P., \& Powell, W. (1991). Introduction. In W. W. Powell \& P. J. DiMaggio (Eds.), The new institutionalism in organizational analysis. Chicago: The University of Chicago Press.

Dingwall, R. (1997). Accounts, interviews and observations. In G. Miller \& R. Dingwall (Eds.), Context and method in qualatitive research. London: Sage.

Djokovic, D., \& Souitaris, V. (2008). Spinouts from academic institutions: a literature review with suggestions for further research. The Journal of Technology Transfer, 33(3), 225-247.

Dobrev, S. (2001). Revisiting Organizational Legitimation: Cognitive Diffusion and Sociopolitical Factors in the Evolution of Bulgarian Newspaper Enterprises, 18461992. Organization Studies, 22(3), 419.

Donaldon, T., \& Preston, L. (1995). The stakeholder theory of the corporation: Concepts, evidence and implications. Academy of Management Review, 20(1), 65-91.

Dorado, S. (2005). Institutional entrepreneurship, partaking, and convening. Organization Studies, 26(3), 385-414.

Dowling, J., \& Pfeffer, J. (1975). Organizational legitimacy: Social values and organizational behavior. The Pacific Sociological Review, 18(1), 122-136. 
Driscoll, C. (2006). The not so clear-cut nature of organizational legitimating mechanisms in the Canadian forest sector. Business and Society, 45(3), 322-353.

Driscoll, C., \& Crombie, A. (2001). Stakeholder legitimacy management and the qualified good neighbour: The case of Nova Nada and JDI. Business Society, 40, 442-471.

Duberley, J. (2007). Entrepreneurial academics: Developing scientific careers in university settings. Higher Education Quarterly, 61(4), 479-497.

Dubois, A., \& Gadde, L. (2002). Systematic combining: an abductive approach to case research. Journal of Business Research, 55(7), 553-560.

Dunn, M., \& Jones, C. (2010). Institutional logics and institutional pluralism: The contestation of care and science logics in medical education, 1967-2005. Administrative Science Quarterly, 55(1), 114-149.

Easton, B. (1997). The Commercialisation of New Zealand. Auckland: Auckland University Press.

Easton, G. (2000). Case research as a method for industrial networks: A realist apologia. In S. Ackroyd \& S. Fleetwood (Eds.), Realist perspectives on management and organisations (pp. 205-219). London: Routledge.

Edelman, L. (1992). Legal ambiguity and symbolic structures: Organizational mediation of civil rights law. American Journal of Sociology, 97(6), 47-94.

Edmeades, D. (2004). Is the commercial model appropriate for science? New Zealand Science Review, 61(3-4), 85-92.

Eisenberg, E. (1984). Ambiguity as strategy in organizational communication. Communication Monographs, 51, 227-242.

Eisenhardt, K. (1989). Building theories from case study research. Academy of Management Review, 14(4), 532-550.

Eisenhardt, K. M. (1991). Better stories and better constructs: The case for rigor and comparative logic. Academy of Management Review, 16(3), 620-627.

Eisenhardt, K., \& Graebner, M. (2007). Theory building from cases: Opportunities and challenges. Academy of Management Journal, 50(1), 25-32.

Elfring, T., \& Hulsink, W. (2003). Networks in entrepreneurship: The case of high-technology firms. Small Business Economics, 21, 409-422. 
Elsbach, K. (1994). Managing organizational legitimacy in the California Cattle Industry: The construction and effectiveness of verbal accounts. Administrative Science Quarterly, 39(1), 57-88.

Elsbach, K., \& Sutton, R. (1992). Acquiring organizational legitimacy through illegitimate actions: A marriage of institutional and impression management theories. Academy of Management Journal, 35(4), 699-738.

Epstein, E., \& Votaw, D. (1975). Legitimacy. In E. M. Epstein \& D. Votaw (Eds.), Rationality, legitimacy, responsibility: Search for new directions in business and society (pp. 6982). Santa Monica, CA: Goodyear Publishing Company Inc. .

Erickson, S. (2006). Extending institutional theory through image restoration and stakeholder saliency models: A case study of Arthur Andersen's inability to salvage organizational legitimacy. Unpublished PhD thesis, North Dakora State University of Agriculture and Applied Science, Fargo, North Dakota, USA.

Eriksson, P., \& Kovalainen, A. (2008). Qualitative methods in business research Los Angeles, CA: Sage.

Erkama, N., \& Vaara, E. (2010). Struggles over legitimacy in global organizational restructuring: A rhetorical perspective on legitimation strategies and dynamics in a shutdown case. Organization Studies, 31(7), 813-839.

Fiol, C., \& O'Connor, E. (2005). Stuff matters: Artifacts, identity, and legitimacy in the U.S. medical profession. In A. Rafaeli \& M. G. Pratt (Eds.), Artifacts and organizations: Beyond mere symbolism (pp. 241-258). London: Routledge.

Fiol, C., Pratt, M., \& O'Connor, E (2009). Managing intractable identity conflicts. Academy of Management Review, 34(1), 32-55.

Fiss, P. C., \& Zajac, E. J. (2004). The diffussion of ideas over contested terrain: The (non)adoption of a sharehodler value orientation among German firms. Administrative Science Quarterly, 61, 656-673.

Fiss, P. C., \& Zajac, E. J. (2006). The symbolic management of strategic change: Sensegiving via framing and decoupling. Academy of Management Journal, 49(6), 1173-1193.

Flick, U. (1992). Triangulation revisited: Strategy of validation or alternative? Journal for the Theory of Social Behaviour, 22(2), 175-197.

Fligstein, N. (1997). Social skill and institutional theory. American Behavioral Scientist, 40(4), 397-405 
Flyvbjerg, B. (2006). Five misunderstandings about case-study research. Qualitative Inquiry, 12(2), 219-245.

Foundation for Research Science \& Technology (FRST). (2008, May). Statement of Intent 2008-2011. Retrieved 18th March, 2009, from www.frst,govt.nz

Fox, A. (2009, December 8). Cashing in on ideas. Unlimited Retrieved 3rd August, 2010, from http://unlimited.co.nz/unlimited.nsf/growth/the-selling-point

Freeman, R. (1984). Strategic management: A stakeholder approach. Boston: Pitman.

Friedland, R., \& Alford, R. (1991). Bringing society back in: Symbols, practices, and institutional contradictions. In W. W. Powell \& P. J. DiMaggio (Eds.), The new institutionalism in organizational analysis (pp. 232-263). Chicago: The University of Chicago Press.

Friedman, A., \& Miles, S. (2002). Developing stakeholder theory. Journal of Management Studies, 39(1), 1-21.

Frooman, J. (1999). Stakeholder influence strategies. Academy of Management Review, 24(2), 191-205.

Galaskiewicz, J., \& Wasserman, S. (1989). Mimetic processes within an interorganziational field: An empirical test. Administrative Science Quarterly, 34, 434-479.

Galvin, T., Ventresca, M., \& Hudson, B. (2005). Contested industry dynamics: New directions in the study of legitimacy. International Studies of Management and Organization, 34(4), 56-82.

George, A., \& Bennett, A. (2004). Case studies and theory development in the Social Sciences. Cambridge, MA: MIT Press.

George, E., Chattopadhyay, P., Sitkin, S., \& Barden, J. (2006). Cognitive underpinnings of institutional persistence and change: A framing perspective. Academy of Management Review, 31, 347365.

George, G., Zahra, S., \& Wood, D. (2002). The effects of business-university alliances on innovative output and financial performance: a study of publicly traded biotechnology companies. Journal of Business Venturing 17, 577-609.

Gerring, J. (2007). Case study research: Principles and practice. New York: Cambridge University Press.

Glaser, B., \& Strauss, A. (1967). The discovery of grounded theory; Strategies for qualitative research. Chicago: Aldine Pub. Co. 
Glynn, M. (2000). When cymbals become symbols: Conflict over identity within a symphony orchestra. Organization Science, 11(3), 285-298.

Glynn, M. (2002). Chord and discord: Organizational crisis, institutional shifts, and the musical canon of the symphony. Poetics, 30, 63-85.

Glynn, M. A., \& Abzug, R. (2002). Institutionalizing identity: Symbolic isomorphism and organizational names. Academy of Management Journal, 45(1), 267-280.

Glynn, M., Barr, P., \& Dacin, M. (2000). Pluralism and the problem of variety. Academy of Management Review, 25(4), 726-734.

Glynn, M., \& Lounsbury, M. (2005). From the critics' corner: Logic blending, discursive change and authenticity in a cultural production system. Journal of Management Inquiry, 42(5), 1031-1055.

Gobo, G. (2008). Re-conceptualizing generalization: Old issues in a new frame The Sage handbook of social research methods (pp. 193-213). Los Angeles, CA: Sage.

Goodrick, E. (2002). From management as a vocation to management as a scientific activity: An institutional account of a paradigm shift. Journal of Management, 28(5), 649-668.

Goodstein, J. (1994). Institutional pressures and strategic responsiveness: Employer involvement in work-family issues. Academy of Management Journal, 372), 350-382.

Gordon, R., Kornberger, M., \& Clegg, S. (2009). Power, rationality and legitimacy in public organizations. Public Administration, 871), 15-34.

Gorman, P. (2010, 25 October). NZ 'needs to wake up' - top scientist. The Press, p. 11.

Gray, D. (2009). Doing research in the real world (2nd ed.). London: Sage.

Green, S., Jr. (2004). A rhetorical theory of diffusion. Academy of management Review, 29(4), 653-669.

Greenwood, R., Diaz, A., Li, S. X., \& Lorente, J. (2010). The multiplicity of institutional logics and the heterogeneity of organziational responses. Organization Science, 21(2), 521539.

Greenwood, R., \& Hinings, C. (1996). Understanding radical organziational change: Bringing together the old and the new institutionalism. Academy of Management Review, 21(4), 1022-1054.

Greenwood, R., Oliver, C., Sahlin, K., \& Suddaby, R. (2008). Introduction. In G. Royston, C. Oliver, K. Sahlin \& R. Suddaby (Eds.), Sage handbook of organizational institutionalism (pp. 1-46). Las Angeles, CA: Sage. 
Greenwood, R., \& Suddaby, R. (2006). Institutional entrepreneurship in mature fields: The big five accounting fields. Academy of Management Journal, 49(1), 27-48.

Greenwood, R., Suddaby, R., \& Hinings, C. (2002). Theorizing change: The role of profesisonal association in the transformation of institutionalized fields. Academy of Management Journal, 45(1), 58-80.

Guba, E. (1978). Towards a methodology of naturalistic inquiryin educational evaluation. Los Angeles: University of California.

Guba, E. (1990). The alternative paradigm dialog. In E. G. Guba (Ed.), The paradigm dialog (pp. 17-27). Newbury Park, CA: Sage.

Guba, E., \& Lincoln, Y. (1994). Competing paradigms in qualitative research. In N. K. Denzin \& Y. S. Lincoln (Eds.), Hanbook of qualitative research (pp. 105-117). Thousand Oaks, CA: Sage.

Hagedoorn, J. (2002). Inter-firm R\&D partnerships: An overview of major trends and patterns since 1960. Research Policy 31, 477-492.

Hamilton, E. (2006). An exploration of the relationship between loss of legitimacy and the sudden death of organizations. Group Organization Management, 31(3), 327-358.

Hammersley, M. (1992). What's wrong with ethnography? Methodological explorations. London: Routledge.

Hammersley, M. (2001). Ethnography and realism. In A. Huberman \& M. Milles (Eds.), The qualitative reseachers companion (pp. 65-80). Thousand Oaks, CA: Sage.

Hammersley, M. (2003). Recent radical criticism of interview studies: Any implications for the sociology of education? British Journal of Sociology of Education, 24(1), 119-126.

Hammersley, M., \& Gomm, R. (2008). Asessing the radical critique of interviews. In M. Hammersley (Ed.), Questioning qualtiative inquiry: Critical essays (pp. 89-100). Los Angeles, CA: Sage.

Hannan, M., \& Carroll, G. (1992). Dynamics of organizational populations: Density, legitimation, and competition. New York: Oxford University Press.

Hannan, M., \& Carroll, G. (1995). Theory building and cheap talk about legitimation: Reply to Baum and Powell. American Sociological Review, 60(4), 539-544.

Hannan, M., Carroll, G., Dundon, E., \& Torres, J. (1995). Organizational evolution in a multinational context: Entries of automobile manufacturers in Belgium, Britain, France, Germany, and Italy. American Sociological Review, 60(4), 509-528. 
Hannan, M., \& Freeman, J. (1984). Inertia and organizational change. American Sociological Review, 49(2), 149-164.

Hannigan, J., \& Kueneman, R. (1977). Legitimacy and public organizations: A case study. Canadian Journal of Sociology, 2(1), 125-135.

Harrison, D., \& Easton, G. (2004). Temporally embedded case comparision in industrial marketing research. In S. Fleetwood \& S. Ackroyd (Eds.), Critical realist applications in organisation and management studies (pp. 194-210). London: Routledge.

Hartley, J. (2004). Case study research. In C. Cassell \& G. Symon (Eds.), Essential guide to qualitative methods in organizational research (pp. 323-348). London: Sage.

Haveman, H. (1993). Follow the leader: mimeticisomorphism and entry into new markets. Administrative Science Quarterly, 38, 593-627.

Hearit, K. (1995). "Mistakes were made": Organizations, apologia, and crises of social legitimacy. Communication Studies, 46(1-2), 1.

Heimer, C. (1999). Competing institutions: Law, medicine, and family in neonatal intensive care. Law \& Society Review, 33(1), 17-66.

Heugens, P., \& Lander, M. (2009). Structure! Agency! (And other quarrels): A meta-analysis of institutional theories of organization. Academy of Management Journal, 52(1), 61-85.

Higgins, M., \& Gulati, R. (2006). Stacking the deck: The effects of top management backgrounds on investor decisions. Strategic Management Journal, 27, 1-25.

Hillman, A. (2005). Politicians on the board of directors: Do connections affect the bottom line? Journal of Management, 31(3), 464-481.

Hinings, C., Greenwood, R., Reay, T., \& Suddaby, R. (2004). The dynamics of change in organziational fields Handbook of organziational change and innovation (pp. 304323). New York: Oxford University Press.

Hirsch, P., \& Bermiss, Y. (2009). Institutional "dirty" work: Preserving institutions through strategic decoupling. In T. B. Lawrence, R. Suddaby \& B. Leca (Eds.), Institutional work: Actors and agency in institutional studies of organizations (pp. 262-283). Cambridge, New York: Cambridge University Press.

Hoffman, A. (1999). Institutional Evolution and Change: Environmentalism and the U.S. Chemical Industry. Academy of Management Journal, 42(4), 351-371. 
Holstein, J., \& Gubrium, J. (2004). The active interview. In D. Silverman (Ed.), Qualitative research: Theory, methods and practice (2nd ed., pp. 140-161). London: Sage.

Honig, M., \& Hatch, T. (2004). Crafting coherence: How schools strategically manage multiple, external demands. Educational Researcher, 33, 16-30.

Huberman, A., \& Miles, M. (2001). The qualitative reseachers companion. Thousand Oaks, CA: Sage.

Hudson, B. (2008). Against all odds: A consideration of core-stigmatised organizations. Academy of Management Review, 33(1), 252-266.

Humphreys, M., \& Brown, A. (2002). Narratives of organizational identity and identification: A case study of hegemony and resistance. Organization Studies, 23(3), 421-447.

Hung, C.-C., \& Whittington, R. (1997). Stratgies and institutions: A pluralistic account of strtagies in the Taiwanese computer industry. Organization Studies, 18(4), 551-575.

Hussey, J., \& Hussey, R. (1997). Business research: A practical guide for undergraduate and postgraduate students. London: Macmillan.

Hybels, R. (1995). On legitimacy, legitimation and organizations: A critical review and integrative theoretical model. Best Paper Proceedings of the Academy of Management, 241-245.

Ingram, P., \& Simons, T. (1995). Institutional and resource dependence: Determinants of responsiveness to work-family issues. Academy of Management Journal, 38(5), $1466-1482$.

Järvensivu, T., \& Törnroos, J. (2010). Case study research with moderate constructionism: Conceptualization and practical illustration. Industrial Marketing Management, 39(1), 100-108.

Jarzabkowski, P., \& Fenton, E. (2006). Strategizing and organizing in pluralistic contexts. Long Range Planning, 39, 631-648.

Jarzabkowski, P., Matthiesen, J., \& Van de Ven, A. (2009a). Doing which work? A practice approach to institutional pluralism. In T. B. Lawrence, R. Suddaby \& B. Leca (Eds.), Instituonal work: Actors and agency in institutional studies of organizations (pp. 284316). Cambridge, New York: Cambridge University Press.

Jarzabkowski, P., \& Sillince, J. (2007). A rhetoric-in-context approach to building commitment to multiple strategic goals. Organization Studies, 28(11), 1639-1665. 
Jarzabkowski, P., Sillince, J., \& Shaw, D. (2009b). Strategic ambiguity as a rhetorical resource for enabling multiple interests. Human Relations, 63(2), 219-248.

Jauch, L., \& Kraft, K. (1986). Strategic management of uncertainty. Academy of Management Review, 11(4), 777-790.

Jensen, M. (2002). Value maximization, stakeholder theory and the corporate objective function. Business Ethics Quarterly, 12(2), 235-256.

Johnson, C., Dowd, T., \& Ridgeway, C. (2006). Legitimacy as a social process. Annual Review of Sociology, 32, 53-78.

Jones, T. (1995). Instrumental stakeholder theory: A synthesis of ethcis and economics. Academy of Management Review, 20(2), 404-437.

Jordan, N., \& Atkinson, P. (2003). Development of science discoveries in the New Zealand Crown Research Institutes. New Zealand Science Review, 60(2-3), 91-95.

Kahney, L. (2004). The cult of Mac. San Francisco: No Starch Press.

Katz, D., \& Kahn, R. (1966). The social psychology of organizations. New York: Wiley.

Ketokivi, M., \& Mantere, S. (2010). Two strategies for inductive reasoning in organazational research. Academy of Management Review, 35(2), 315-333.

King, N. (2004a). Using interviews in qualitative research. In C. Cassell \& G. Symon (Eds.), Essential guide to qualitative methods in organizational research (pp. 11-22). London: Sage.

King, N. (2004b). Using templates in the thematic analysis of text. In C. Cassell \& G. Symon (Eds.), Essential guide to qualitative methods in organizational research (pp. 256270). London: Sage.

Kitchener, M. (2002). Mobilizing the logic of managerialism in professional fields: The case of academic health centre mergers. Organization Studies, 23(3), 391-420.

Knockaert, M., Lockett, A., Ucbasaran, D., \& Clarysse, B. (2006). Outside board availability and composition in high tech start-ups. Frontiers of Entrepreneurship Research, 26(15), 1-14.

Kolk, A., \& Levy, D. (2001). Corporate strategy, climate change and oil multinationals. European Management Journal, 19(5), 501-509.

Kostova, T., Roth, K., \& Dacin, M. (2008). Institutional theory in the study of multinational corporations: A critique and new directions Academy of Management Review, 33(4), 994-1006. 
Kostova, T., \& Roth, K. (2002). Adoption of an organizational practice by subsidiaries of multinational corporations: Institutional and relational effects. Academy of Management Journal, 45(1), 215-233.

Kostova, T., \& Zaheer, S. (1999). Organizational legitimacy under conditions of complexity: The case of the multinational enterprise. Academy of Management Review, 24(1), $64-81$.

Koza, M., \& Lewin, A. (1998). The co-evolution of strategic alliances. Organization Science, 9(3), 255-264.

Kraatz, M., \& Block, E. (2008). Organizational implications of institutional pluralism. In R. Greenwood, C. Oliver, K. Sahlin \& R. Suddaby (Eds.), The Sage handbook of organizational institutionalism (pp. 243-275). Los Angeles: Sage.

Lampe, M. (2001). Mediation as an ethical adjunct of stakeholder theory. Journal of Business Ethics, 31, 165-173.

Laplume, A., Sonpar, K., \& Litz, R. (2008). Stakeholder theory: Reviewing a theory that moves us. Journal of Management, 34(6), 1152-1189.

Lawrence, T. (1999). Institutional strategy. Journal of Management, 25(2), 161-188.

Lawrence, T., \& Suddaby, R. (2006). Institutions and institutional work. In S. R. Clegg, C. Hardy \& W. R. Nord (Eds.), Handbook of Organization Studies (pp. 215-254). London: Sage.

Lawrence, T., Suddaby, R., \& Leca, B. (2009). Introduction: Theorizing and studying institutional work. In T. Lawrence, R. Suddaby \& B. Leca (Eds.), Institutional work: Actors and agency in institutional studies of organizations (pp. 1-27). Cambridge, New York: Cambridge University Press.

Leiblein, M., \& Reuer, J. ( 2004). Building a foreign sales base: the roles of capabilities and alliances for entrepreneurial firms. Journal of Business Venturing, 19, 285-307.

Leitch, S., \& Davenport, S. (2005). The politics of discourse: Marketization of the New Zealand science and innovation system. Human Relations, 58(7), 891-912.

Levy, D., \& Scully, M. (2007). The institutional entrepreneur as modern prince: The strategic face of power in contested fields. Organization Studies, 28(7), 971-991.

Levy, D., \& Kolk, A. (2002). Strategic responses to global climate change: Conflicting pressures on multinationals in the oil industry. Business and Politics, 4(3), 275-300. 
Lewis, M. (2000). Exploring paradox: Toward a more comprehensive guide. Academy of Management Review, 25(4), 760-776.

Lindblom, C. (1965). The intelligence of democracy: Decision making through mutual adjustment. New York: The Free Press.

Lounsbury, M. (2002). Institutional transformation and status mobility: The professionalization of the field of finance. Academy of Management Journal, 45(1), 255-266.

Lounsbury, M. (2007). A tale of two cities: Competing logics and practice variation in the professionalizing of mutual funds. Academy of Management Journal, 50(2), 289-307.

Lounsbury, M., \& Glynn, M. (2001). Cultural entrepreneurship: Stories, legitimacy, and the acquisition of resources. Strategic Management Journal, 22, 545-564.

Mabry, L. (2008). Case study and social research. The Sage handbook of social research methods (pp. 214-227). Los Angeles, CA: Sage.

MacLean, T., \& Behnam, M. (2010). Organizations: The dangers of decoupling: The relationship between compliance programs, legitimacy perceptions, and institutionalized misconduct. Academy of Management Journal, 53(6), 1499-1520.

Maharey, S. (2001, 4 October). Applications called for new Centres of Research Excellence fund. Beehive Retrieved 14 September, 2009, from http://www.beehive.govt.nz/release/applications-called-new-centres-researchexcellence-fund

Maharey, S. (2003, 19 February). Centres of Research Excellence - signed, sealed and delivered. Beehive Retrieved 14th September 2009, from http://www.beehive.govt.nz/release/centres-research-excellence-\%E2\%80\%93signed-sealed-and-delivered

Mallon, M., Duberly, J., \& Cohen, L. (2005). Careers in public sector science: orientations and implications. R\&D Management, 35(4), 395-407.

Marquis, C., Glynn, M., \& Davis, G. (2007). Community isomorphism and corporate social action. Academy of Management Review, 32(3), 925-945.

Marquis, C., \& Lounsbury, M. (2007). Vive la reistance: Competing logics and the consolidation of U.S. community banking. Academy of Management Journal, 50(4), 799-820. 
Mars, M., \& Lounsbury, M. (2009). Raging against or with the private marketplace? Logic hybridity and eco-entrepreneurship. Journal of Management Inquiry, 18(1), 4-13.

Marshall, C., \& Rossman, G. (2006). Designing qualitative research (4th ed.). Thousand Oaks: Sage.

Massey, J. (2001). Managing organizational legitimacy: Communication strategies for organizations in crisis. The Journal of Business Communication, 38(2), 153-183.

Maurer, J. (1971). Legitimation, social responsibility and regulation. In J. G. Maurer (Ed.), Readings in organizational theory: Open-system approaches (pp. 361-363). New York: Random House.

Maxwell, J. (1992). Understanding and Validity in Qualitative Research. Harvard Educational Review, 62(3), 279-300.

Maykut, P., \& Morehouse, R. (1994). Beginning qualitative research: A philosophic and practical guide, London; Washington D.C.: Falmer Press.

McKinlay Douglas Limited. (2002). Crown Research Institutes: Governance \& Capability. Tauranga.

Mendelow, A. (1991). Stakeholder mapping. Proceedings of the Second International Conference on Information Systems, Cambridge, MA.

Meyer, J., \& Scott, W. (1983). Centralization and the legitimacy problems of local government. In J. Meyer \& W. R. Scott (Eds.), Organizational environments: Ritual and rationality (pp. 199-215). Beverly Hills: Sage.

Meyer, J., Scott, W., \& Strang, D. (1987). Centralization, fragmentation, and school district complexity. Administrative Science Quarterly, 32(2), 186-201.

Meyer, J., \& Rowan, B. (1977). Institutionalized organizations: Formal structure as myth and ceremony. The American Journal of Sociology, 83(2), 340-363.

Meyer, M. (2003). Academic entrepreneurs or entrepreneurial academics? Research-based ventures and public support mechanisms. R\&D Management, 33(2), 107-115.

Meyer, R., \& Hammerschmid, G. (2006). Changing institutional logics and executive identities. American Behavioral Scientist, 49(7), 1000-1014.

Meyer, R., \& Hollerer, M. (2010). Meaning structures in a contested issue field: A topographic map of sharheolder value in Austria. Academy of Management Journal, 53(6), 1241-1262. 
Miles, M. \& Huberman, A., (1994). Qualitative data analysis : an expanded sourcebook (2nd edition ed.). Thousand Oaks, CA: Sage.

Miller, D., \& Chen, M. (1994). Source and consequences of competitive inertia: A study of the U.S. airline industry. Administrative Science Quarterly, 39, 1-23.

Miller, J., \& Glassner, B. (2004). The "inside" and the "outside": findings realities in interviews. In D. Silverman (Ed.), Qualitative Research: Theory, Methods and Practice (2nd ed., pp. 125-139). London: Sage.

Miller, K. (2000). Common ground from the post-positivist perspective: From "straw person" argument to collaborative coexistence. In S. R. Corman \& M. S. Poole (Eds.), Perspectives on organizational communication: Finding common ground (pp. 46-67). New York: Guilford.

Ministry of Research Science and Technology (MoRST) (2006). Research and Development in New Zealand: A Decade in Review. . Wellington: MoRST.

MoRST. (2008). Government's agenda for New Zealand research, science and technology. Wellington: MoRST.

MoRST and Crown Company Monitoring Advisory Unit. (2003). An appraisal of Crown Research Institutes 1992 - 2002. Wellington.

Mintzberg, H. (1978). Patterns in strategy formation. Management Science, 24(9), 934.

Mintzberg, H. (2009). Rebuilding companies as communities. Harvard Business Review, $877 / 8), 140-143$.

Mintzberg, H., \& Waters, J. (1985). Of strategies, deliberate and emergent. Strategic Management Journal, 6, 257-572.

Mitchell, R., Agle, B., \& Wood, D. (1997). Toward a theory of stakeholder identification and salience: Defining the principle of who and what really counts. Academy of Management Review, 22(4), 853-886.

Molz, R. (1995). The theory of pluralism in corporate governance: A conceptual framework and empirical test. Journal of Business Ethics, 14(10), 789-804.

Montgomery, K., \& Oliver, A. (1996). Responses by professional organizations to multiple and ambiguous institutional environments: The case of AIDs. Organization Studies, $174), 649-671$.

MoRST \& Statistics New Zealand. (2006). Research and Development in New Zealand. Wellington: MoRST \& Statistics New Zealand. 
New Zealand Government. (2002, 6 March). Research excellence centres 'future focused'. $\begin{array}{llll}\text { Retrieved } & 14 & \text { September } & \text { from }\end{array}$ http://www.scoop.co.nz/stories/PA0203/S00115.htm

New Zealand Government. (2006a, 11 August). Funding boost for world class research. $\begin{array}{llll}\text { Retrieved } \quad \text { 14th } & \text { September }\end{array}$ http://www.scoop.co.nz/stories/PA0608/S00183.htm

New Zealand Government. (2006b, 22 June). Funding for Centres of Research Excellence. Scoop. Retrieved 14th September, 2009, from http://www.scoop.co.nz/stories/PA0606/S00435.htm

New Zealand Government. (2007, 5 June). Supporting world-class research. Retrieved 14th September 2009, from http://www.scoop.co.nz/stories/PA0706/S00053.htm

Noaks, L., \& Wincup, E. (2004). Criminological research: understanding qualitative methods. London: Sage.

Nutt, P. (1984). A strategic planning network for nonprofit organizations. Strategic Management Journal, 5(1), 57-75.

O'Donovan, G. (2002). Environmental disclosures in the annual report: Extending the applicability and predictive power of legitimacy theory. Accounting, Auditing \& Accountability Journal, 15(3), 344-371.

O'Leary, Z. (2004). The essential guide to doing research. London: Sage.

O'Reilly, C. \& Tushman, M. (2004). The ambidextrous organization. Harvard Business Review, $82(4), 74-81$.

Oliver, C. (1991). Strategic responses to institutional processes. Academy of Management Review, 16(1), 145-179.

Orton, J. D., \& Weick, K. E. (1990). Loosely coupled systems: A reconceptualization. Academy of Management Review, 15(2), 203-223.

Orum, A., Feagin, J., \& Sjoberg, G. (1991). The nature of case study. In J. Feagin, A. Orum \& G. Sjoberg (Eds.), A case for case study. Chapel Hill, NC: University of North Carolina Press.

Owen-Smith, J., \& Powell, W. W. (2001). Careers and contradictions: Faculty responses to the transformation of knowledge and its uses in the life sciences. Research in the Sociology of Work, 10, 109-140. 
Owen-Smith, J., \& Powell, W. W. (2003). The expanding roles of university patenting in the life sciences. Research Policy, 32(9), 1695-1711.

Pache, A., \& Santos, F. (2010). When worlds collide: The internal dynamics of organizational responses to conflicting institutional demands. Academy of Management Review, 35(3), 455-476.

Parker, S. (2002). The littlest clue: The resurgence of New Zealand science. Lower Hutt, NZ: Industrial Research Ltd.

Parsons, T. (1960). Structure and process in modern societies. Glencoe: Free Press.

Patton, M. Q. (2002a). Qualitative research and evaluation methods. Thousand Oaks, CA: Sage.

Patton, M. Q. (2002b). Two decades of developments in qualitiative inquiry: A personal experiential perspective. Qualitiative Social Work, 1(3), 261-283.

Perkmann, M., \& Spicer, A. (2008). How are management fashions institutionalized? The role of institutional work. Human Relations, 61(6), 811-844.

Perrow, C. (1970). Organizational analysis: A sociological view. London: Tavistock Publications.

Pettigrew, A. M. (1990). Longitudinal field research on change: Theory and practice. Organization Science, 1(3), 267-292.

Pfeffer, J. (2009). Shareholders first? Not so fast... Harvard Business Review, 8777/8), 90-91.

Pfeffer, J., \& Salancik, G. R. (1978). The external control of organizations: A resource dependence perspective. New York: Harper \& Row.

Phillips, D. C., \& Burbules, N. C. (2000). Postpositivism and educational research. New York: Rowman \& Littlefield Publishers Inc.

Phillips, N., Lawrence, T. B., \& Hardy, C. (2004). Discourse and Institutions. Academy of Management Review, 29(4), 635-652.

Piekkari, R., Welch, C., \& Paavilainen, E. (2008). The Case Study as Disciplinary Convention: Evidence From International Business Journals. Organizational Research Methods, 12(3), 567-589.

Pisano, G. \& Verganti, R. (2008). Which kind of collaboration is right for you? Harvard Business Review, 86(12), 78-86.

Pollock, T. \& Rindova, V. (2003). Media legitimation effects in the market for initial public offerings. Academy of Management Journal, 46(5), 631-642. 
Poole, M. \& Van de Ven, A. (1989). Using paradox to build management and oragnization theories. Academy of Management Review, 14(4), 562-578.

Potter, J. (2006). Interpreting qualitative data. In D. Silverman (Ed.), Qualitiative Research. London: Sage.

Powell, W., Owen-Smith, J., \& Colyvas, J. (2007). Innovaton and emulation: Lessons from American universities in selling private rights to public knowledge. Minerva, 45(2), $121-142$.

Powell, W. (1991). Expanding the scope of institutional analysis. In W. W. Powell \& P. J. DiMaggio (Eds.), The new institutionalism in organizational analysis (pp. 183-203). Chicago: University of Chicago Press.

Powell, W., Koput, K., \& Smith-Doerr, L. (1996). Interorganizational collaboration and the locus of innovation: Networks of leanring in biotechnology. Administrative Science Quarterly, 41(1), 116-145.

Pratt, M., \& Foreman, P. (2000). Classifying managerial responses to multiple organizational identities. Academy of Management Review, 25(1), 18-42.

Purdy, J. \& Gray, B. (2009). Conflicting logics, mechanisms of diffusion, and multilevel dynamics in emerging institutional fields. Academy of Management Journal, 52 (2), $355-380$.

Quinn, R. \& Cameron, K. (1988). Organizational paradox and transformation. Cambridge: Ballinger Publishing Company.

Ragin, C. (1992). "Casing" and the process of social inquiry. In C. C. Ragin \& H. S. Becker (Eds.), What is a case? Exploring the foundations of social inquiry (pp. 217-226). Cambridge: Cambridge University Press.

Raine, J., \& Beukman, C. (2002). University technology commercialisation offices - A New Zealand perspective. International Journal of Technology Management, 24(5/6), 627-647.

Rao, H., Monin, P., \& Durand, R. (2003). Institutional change in Toque Ville: Nouvelle cuisine as an identity movement in French gastronomy. The American Journal of Sociology, 108(4), 795-843.

Reay, T., \& Hinings, C. (2005). The recomposition of an organizational field: Health care in Alberta. Organization Studies, 26(3), 351-384. 
Reay, T., \& Hinings, C. (2009). Managing the rivalry of competing institutional logics. Organization Studies, 30(6), 629-652.

Reed, M. (2005). Reflections on the 'realist turn' in organization and management studies. Journal of Management Studies, 42(8), 1621-1644.

Rescher, N. (1993). Pluralism, Against the demand for consensus. Oxford: Clarendon Press.

Revington, M. (2008, 2nd March). Commercialising innovation. Retrieved March 3, 2008, from http://unlimited.co.nz/unlimited.nsf/growth/commercialisinginnovation?Opendocument\&HighLight=2,commercialising, innovation, Revington

Richardson, A. \& Dowling, J. (1986). An integrative theory of organizational legitimation. Scandinavian Journal of Management Studies, November, 91-108.

Richardson, A. (1985). Symbolic and substantive legitimation in professional practice. Canadian Journal of Sociology, 10(2), 139-152.

Ring, P., \& Perry, J. (1985). Strategic management in public and private organizations: Implications of distinctive contexts and constraints. Academy of Management Review, 192), 276-286.

Rip, A. (2004). Strategic research, post-modern universities and research training. Higher Education Policy, 17, 153-166.

Rogers, E. (2001). A theoretical look at firm performance in high-tech organisation: What does existing theory tell us? Journal of High Technology, 12, 39-61.

Rowley, T. (1997). Moving beyond dyadic ties: A network theory of stakeholder influences. Academy of Management Review, 22(4), 887-910.

Royal Society of NZ. (2008). A science manifesto or plan for the recovery of New Zealand science. Wellington: RSNZ.

Ruef, M., \& Scott, W. (1998). A multidimensional model of organizational legitimacy: Hospital survival in changing institutional environments. Administrative Science Quarterly, 43(4), 877-904.

Rutherford, M. W., \& Buller, P. F. (2007). Searching for the legitimacy threshold. Journal of Management Inquiry, 16(1), 78-92.

Salancik, G., \& Pfeffer, J. (1977). Who gets power - And how they hold on to it. Organizational Dynamics, 5, 3-21. 
Sampat, B., \& Nelson, R. (2002). The evolution of university patenting and licensing procedures: An empirical study of institutional change. Advances in Strategic Management, 19(135-164).

Saunders, M., Lewis, P., \& Thornhill, A. (2007). Research methods for business students. Harlow, England: Prentice Hall.

Sayer, A. (1992). Method in social science: A realist approach (2nd ed.). London: Routledge.

Sayer, A. (2004). Forward: Why critical realism? In S. Fleetwood \& S. Ackroyd (Eds.), Critical realist applications in organisation and management studies (pp. 6-25). London: Routledge.

Scott, W. (1991). Unpacking institutional arguments. In W. W. Powell \& P. J. DiMaggio (Eds.), The new institutionalism in organizational analysis (pp. 164-182). Chicago: University of Chicago Press.

Scott, W. (1995). Institutions and organizations (1st ed.). Thousand Oaks, CA: Sage.

Scott, W. (2001). Institutions and organizations (2nd ed.). Thousand Oaks, CA: Sage.

Scott, R. W. (2009). Comparing organizations: Empirical and theoretical issues. In B. G. King, T. Felin \& D. A. Whetten (Eds.), Studying Differences between organizations: Comparative approaches to organziational research (Research in the Sociology of Organizations)(Vol. 26, pp. 45-62): Emerald Group Publishing Limited.

Scott, W., \& Meyer, J. (1991). The organization of societal sectors: Propositions and early evidence. In W. W. Powell \& P. J. DiMaggio (Eds.), The new institutionalism in organizational analysis. Chicago: University of Chicago Press.

Scott, W, Ruef, M., Mendel \& Caronna, C. (2000). Institutional change and health care organizations: From professional dominance to managed care. Upper Saddle River, NJ: Prentice Hall.

Seale, C. (1999). Quality in qualitative research. Qualitative Inquiry, 5(4), 465-478.

Selznick, P. (1949). TVA and the grass roots. Berkeley, CA: University of California Press.

Selznick, P. (1957). Leadership in Administration. New York: Harper \& Row.

Selznick, P. (1992). The moral commonwealth: Social theory and the promise of community. Berkley: University of California Press.

Selznick, P. (1996). Institutionalism "old" and "new". Administrative Science Quarter/y(41), 270-277. 
Seo, M., \& Creed, W. (2002). Institutional contradictions, praxis, and institutional change: A dialectical perspective. Academy of Management Review, 27(2), 222-247.

Sethi, S. (1979). A conceptual framework for environmental analysis of social issues and evaluation of business response patterns. Academy of Management Review, 4(1), $63-74$.

Shane, S., \& Venkataraman, S. (2000). The promise of entrepreneurship as a field of study. . Academy of Management Review, 25, 217-226.

Silverman, D. (2005). Doing qualitative research: A practical handbook (2nd ed.). London, Thousand Oaks, New Delhi: Sage.

Silverman, D. (2006). Interpreting qualitative data. London, Thousand Oaks, New Delhi: Sage.

Simpson, B. (2004). After the reforms: how have public science research organisations changed? R\&D Management, 34(3), 253-266.

Simpson, B., \& Craig, J. (1997). A policy for science innovation: The New Zealand experience. Science and Public Policy, 24(2), 70-78.

Singh, J., Tucker, D., \& House, R. (1986). Organizational legitimacy and the liability of newness. Administrative Science Quarterly, 31(2), 171-193.

Smircich, L., \& Stubbart, C. (1985). Strategic management in an enacted world. Academy of Management Review, 10(4), 724-736.

Smith, W., Binns, A., \& Tushman, M. (2010). Complex business models: Managing strategic paradoxes simultensously. Long Range Planning, 43, 448-461.

Smith, W., \& Lewis, M. (2011). Toward a theory of paradox: A dynamic equilibrium model of organizing. Academy of Management Review 36(2), 381-403.

Smith, W., \& Tushman, M. (2005). Managing stratgeic contradictions: A top management model for managing innovation streams. Organization Science, 16(5), 522-536.

Snow, C. (1959). The two cultures and the scientific revolution. Cambridge: Cambridge University Press.

Sommer, J. (2010). 2008 Survey of New Zealand scientists and technologists. New Zealand Science Review, 671), 1-40.

Sonpar, K., Pazzaglia, F., \& Kornijenko, J. (2010). The paradox and constraints of legitimacy. Journal of Business Ethics, 95(1), 1-21.

Stake, R. (1995). The art of case study research. Thousand Oaks, CA: Sage. 
Stake, R. (2005). Qualitative case studies. In N. K. Denzin \& Y. S. Lincoln (Eds.), The SAGE handbook of qualitative research (3rd ed., pp. 443-462). Thousand Oaks: Sage.

Stinchcombe, A. (1965). Organizations and social structure. In J. G. March (Ed.), Handbookof Organizations (pp. 153-193.). Chicago: Rand-McNally.

Stone, M., \& Brush, C. (1996). Planning in ambiguous contexts: The dilemma of meeting needs for commitment and demands for legitimacy. Strategic Management Journal, $17,633-652$.

Stryker, R. (2000). Legitimacy processes as institutional politics: Implications for theory and research in the sociology of organizations. Research in the Sociology of Organizations, $17,179-223$.

Suchman, M. (1995). Managing legitimacy: Strategic and institutional approaches. Academy of Management Review, 20(3), 571-610.

Suddaby, R., \& Greenwood, R. (2005). Rhetorical strategies of legitimacy. Administrative Science Quarterly, 50, 35-67.

Sundaram, A., \& Inkpen, A. (2004). The corporate objective revisited. Organization Science, 15(3), 350-363.

Taula, L. (2006 ). New Zealand Centres of Research Excellence. Unpublished Master Thesis, Victoria University of Wellington, Wellington.

Terreberry, S. (1968). The evolution of organizational envrionments. Administrative Science Quarterly, 12(4), 590-613.

Tertiary Education Commission (TEC). (2006). CoREs selection framework. Wellington: TEC.

TEC. (2009). Centres of Research Excellence. Retrieved 12th October, 2008, from http://www.tec.govt.nz/templates/standard.aspx?id=587

Tesch, R. (1990). Qualitiative research: Analysis types and software tools. New York: Falmer. Thompson, J. (1967/2005). Organizations in action: Social science bases of administrative theory. Edison, NJ: Transaction Publishers.

Thornton, P. (2002). The rise of the corporation in a craft industry: Conflict and conformity in institutional logics. Academy of Management Journal, 45(1), 81-101.

Thornton, P. (2004). Markets from cultures: institutional logics and organziational decisions in higher education publishing. Stanford, CA: Stanford University Press. 
Thornton, P., Jones, C., \& Kury, K. (2005). Institutional logics and institutional change in organizations: Transformation in accounting, architecture and publishing. Research in the Sociology of Organizations, 23, 125-170.

Thornton, P., \& Ocasio, W. (2008). Institutional logics. In R. Greenwood, C. Oliver, K. Sahlin \& R. Suddaby (Eds.), The Sage handbook of organizational institutionalism (pp. 99-129). Los Angeles: Sage.

Tolbert, P., \& Zucker, L. (1983). Institutional sources of change in the formal structure of organizations: The diffussion of civil service reform, 1880-1935. Administrative Science Quarterly, 30, 22-39.

Tolich, M., \& Davidson, C. (Eds.). (2003). Social science research in New Zealand: Many paths to understanding (2nd ed.). Auckland, NZ: Pearson Education NZ Ltd.

Townley, B. (2002). The role of competing rationalities in institutional change. Academy of Management Journal, 45(1), 163-179.

Tracey, P., Phillips, N., \& Jarvis, O. (2011). Bridging institutional entrepreneurship and the creation of new organizational forms: A multilevel model. Organization Science, $22(1), 60-80$.

Trochim, W. (1989). Outcome pattern matching and program theory. Evaluation and Program Planning, 12, 355-366.

Tsang, E., \& Kai-Man, K. (1999). Replication and theory development in organizational science: A critical realist perspective. Academy of Management Review, 24(4), 759780.

Vaara, E., \& Monin, P. (2010). A recursive perspective on discursive legitimation and organizational action in mergers and acquisitions. Organization Science, 21(1), 3-22.

Vaara, E., Tienari, J., \& Laurila, J. (2006). Pulp and paper fiction: On the discursive legitmation of global industrial restructuring. Organization Studies, 276), 789-810.

Vallas, S., \& Kleinman, D. (2008). Contradiction, convergence and the knowledge economy: the confluence of academic and commercial biotechnology. Socio-Economic Review, 6(2), 283-311.

Van Leeuwen, T. (2007). Legitimation in discourse and communication. Discourse and Communication, 1(1), 91-112.

Van Leeuwen, T., \& Wodak, R. (1999). Legitimizing immigration control: A discourse-historial analysis. Discourse Studies, 1(1), 83-118. 
Van Maanen, J., Sorensen, J., \& Mitchell, T. (2007). The interplay between theory and method. Academy of Management Review, 32, 1145-1154.

Van Teijlingen, E., \& Hundley, V. (2001). The importance of pilot studies. . Social Research Update, 35, 1-4.

Walter, J., Kellermanns, F., \& Lechner, C. (2010). Decision making within and between organizations: Rationality, politics, and alliance performance. Journal of Management, Published online before print doi:10.1177/0149206310363308

Weber, M. (1925/1968). Economy and Society (Vol. 1-3). New York: Bedminster Press Inc.

Werner, C., \& Baxter, L. (1994). Temporal qualities of relationships: organismic, transactional, and dialectical views. In M. Knapp \& G. Miller (Eds.), Handbook of interpersonal communication. Thousand Oaks, CA: Sage.

Westphal, J., \& Zajac, E. (1995). Substance and symbolism in CEO's long-term incentive plans. Administrative Science Quarterly, 39(367-390).

Westphal, J., \& Zajac, E. (2001). Decoupling policy from practice: The case of stock repurchase programs. Administrative Science Quarterly, 46(2), 202-228.

Wilkinson, B. (1996). Culture, instituions and businesses in East Asia. Organziation Studies, $17(3), 421-447$.

Williams, J. (2004). R\&D in the economy. Wellington: MoRST.

Winsley, P., \& Hammond, L. (1997). Policies for transforming the science and innovation system in New Zealand: 1988-97. Prometheus 15(2), 267-277.

Wolcott, H. (1990). Writing up qualitiative research. Newbury Park, CA: Sage.

Wolcott, H. (1994). Transformig qualitiative data: Description, analysis and interpretation. Thousand Oaks,CA: Sage.

Woodside, A., \& Wilson, E. (2003). Case study research methods for theory building. Journal of Business and Industrial Marketing, 18(6-7), 493-508.

Woodward, D., Edwards, P., \& Birkin, F. (1996). Organizational legitimacy and stakeholder information provision. British Journal of Management, 7(4), 329-347.

Yeung, H. (1997). Critical realism and realist research in human geography: A method or a philosophy in search of a method. Progress in Human Geography, 21(1), 51-74.

Yin, R. (2009). Case study research: Design and methods (4th ed.). Thousand Oakes, CA: Sage. 
Zilber, T. (2002). Institutionalization as an Interplay between actions, meanings, and actors: The case of a Rape crisis center in Israel. Academy of Management Journal, 45(1), 234-254.

Ziman, J. (1994). Prometheus bound: Science in a dynamic steady state. Cambridge: Cambridge University Press.

Zimmerman, M., \& Zeitz, G. (2002). Beyond survival: Achieving new venture growth by building legitimacy. Academy of Management Review, 273), 414-431.

Zucker, L. (1977). Institutionalization and cultural persistence. American Sociological Review, 726-743.

Zucker, L. (1983). Organizations as institutions. Research in the Sociology of Organizations, 2, $1-47$.

Zucker, L. (1989). Combining institutional theory and population ecology: No legitimacy, no history. American Sociological Review, 54, 542-545.

Zuckerman, E. (1999). The categorical imperative: Securities analysts and the illegitimacy discount. American Journal of Sociology, 104(5), 1398-1438. 


\title{
APPENDIXES
}

\author{
Appendix One: Participant Information Sheet
}

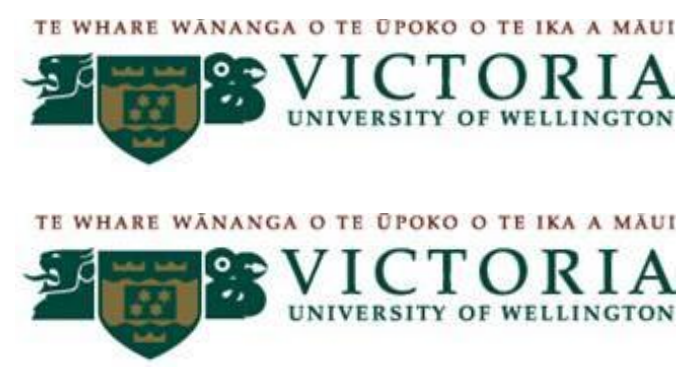

\section{Managing complex stakeholder relationships: The New Zealand's science sector}

I am carrying out research into New Zealand's high-tech research sector and invite you to participate. This research is for my PhD in Management at Victoria University Wellington, funded by the Tertiary Education Commission's Top Achievers Doctoral Scholarship.

My research will investigate how organizations manage complex stakeholder relationships. The aim is to gain insight into a range of different perspectives within New Zealand's hightech research sector and explore how these complex relationships and expectations are responded to by organizations. This should provide insight into both the multiplicity of opinions that exist and the most effective ways for managing this complexity. My case studies will include high-tech start-ups, Centres of Research Excellence and Crown Research Institutes.

To conduct this research I will be using interviews and secondary data (for example policy documents).

\section{How will you be affected and ethical issues:}

- The interview will take approximately 60 minutes and will be scheduled at a time that suits you.

- I would like to record the interview, but this would only be done with your consent. The recording will be transcribed by the researcher.

- I will be asking you about your views, expectations, and experiences of a particular organization. The questions will focus on different perceptions of the organisation and what the organization does to manage these.

- The organisation has agreed to participate in this project and provided names of potential interviewees for my research.

- While the organization has agreed to be included in this research you are under no obligation to participate and can pull out, without providing a reason, before data collection is completed (likely June 2010).

- I will talk to people individually and in confidence - quotations will not name the individuals interviewed but merely the broad stakeholder group they identify with. I will ask you to indicate a suitable position descriptor (e.g., manager, scientist or employee) to use where appropriate. The organisation will not be provided with the details of who has participated or have access to confidential data. 
- The organization will be referred to by organizational type rather than by name and no identifying information (for example location or size) will be included.

- $\quad$ All information will be stored securely in either a locked cabinet or password protected file before being destroyed.

- Upon completion of the project I will provide a summary of my findings to all participants.

- If you agree to be interviewed I will ask you to fill in a research agreement form that, together with this information sheet, outlines your role in the project and how I will respect your rights as a research participant.

Thank you for your time and help in making this study possible. If you have any queries please phone, email or write to the researcher Rebecca Bednarek, or my supervisors Urs Daellenbach or Sally Davenport.

Researcher: Rebecca Bednarek

Victoria Management School

Victoria University of Wellington

Phone: 044639693

Email: rebecca.bednarek@vuw.ac.nz

Supervisors: Associate Prof. Urs Daellenbach Victoria Management School Victoria University of Wellington Phone: 044635732

Email: urs.daellenbach@vuw.ac.nz
Prof. Sally Davenport

Victoria Management School Victoria University ofWellington Phone: 044635144

Email:sally.davenport@vuw.ac.nz 


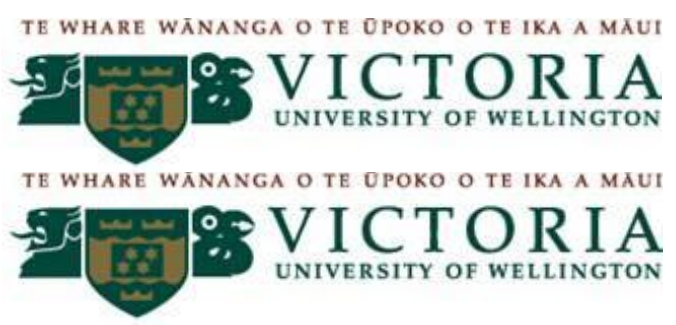

Managing complex stakeholder relationships: New Zealand's science sector.

Researcher: Rebecca Bednarek, Doctoral Candidate, Victoria Management School, Victoria University Wellington.

Please read and check off the following conditions associated with participating in this study.

"I have read the Research Project Information Sheet for this study and have had the details of the study explained to me. My questions about the study have been answered to my satisfaction, and I understand that I may ask further questions at any time."

"I understand that my participation in this study is voluntary and that I may withdraw from the interview or decline to answer any particular questions in the study. I may withdraw from this project prior to June 2010 without providing reasons. I understand that if I withdraw any data provided will be destroyed or returned to me."

"I understand that any information or opinions I provide will be kept confidential and reported only in an aggregated/non-attributable form. For instance I will be referred to by a generic position descriptor (such as manager or government employee) which I have the option to help decide upon."

$\square$ "I understand that the information obtained will be stored in a locked cabinet or password protected file. All tape recordings will be wiped after they have been transcribed. All data will be destroyed within three years of the completion of my PhD."

"I understand that the information I provide may be used as part of a PhD thesis and may also be published and presented."

"I understand that a summary of the research will be provided at the completion of my PhD (likely late 2011)

I agree / do not agree to the interview being recorded

Any more conditions to be written in by the participant:

Participant:

Signature...

Date 


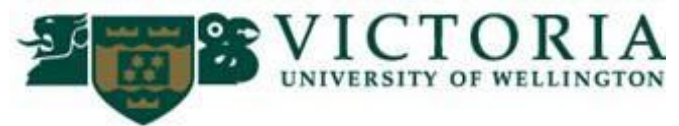

\begin{tabular}{l|l}
\hline TO & Rebecca Bednarek \\
\hline COPY TO & Urs Dallenbach; Sally Davenport \\
\hline FROM & $\begin{array}{l}\text { Maggie Teleki-Rainey; } \\
\text { On behalf of Dr. Sudan Corbett, Chair, Pipitea Human Ethics } \\
\text { Committee }\end{array}$ \\
\hline
\end{tabular}

\begin{tabular}{l|l}
\hline DATE & 16 March 2009 \\
\hline
\end{tabular}

\begin{tabular}{l|l}
\hline SUBJECT & HEC application - approval \\
\hline
\end{tabular}

REF :RM 16342

To :Rebecca Bednarek

On behalf of: Susan Corbett, Chair, Pipitea Human Ethics Committee.

Please note that the Human Ethics Committee has reviewed and approved your application for the project "Organisational legitimacy in pluralistic contexts: Strategic management of salient and contradictory stakeholder demands".

Regards

Maggie.

Maggie Teleki-Rainey

Senior Administrator, Faculty Research

Room - RH 1205

Faculty of Commerce and Administration

Victoria University of Wellington

Te Whare Wānanga o te Ūpoko o te Ika a Māui

PO Box 600

Wellington 6140

New Zealand

Phone : + 6444635943

E-Mail : Maggie.Teleki-Rainey@vuw.ac.nz

Web : www.vuw.ac.nz 


\section{Appendix Four: Interview Schedule ${ }^{27}$}

\begin{tabular}{|c|c|c|}
\hline $\begin{array}{l}\text { Interview } \\
\text { Steps }\end{array}$ & Questions [Managers] & Questions: other stakeholders [employees and external stakeholders] \\
\hline $\begin{array}{l}\text { Introduction } \\
\text { questions }\end{array}$ & $\begin{array}{l}\text { - Tell me a little about the organization? } \\
\text { - What is your role/how long have you been involved with the } \\
\text { organization? }\end{array}$ & $\begin{array}{l}\text { - Tell me a little about [organization } \mathrm{x}] / \text { group of organizations? } \\
\text { - What is your connection to organization/s }[\mathrm{x}] \text { ? } \\
\text { - How long have you been connected to the organization? }\end{array}$ \\
\hline $\begin{array}{l}\text { Legitimacy } \\
\text { and } \\
\text { stakeholders } \\
\text { [diffused } \\
\text { power] }\end{array}$ & $\begin{array}{l}\text { - Who are the key stakeholders that your organization depends on? } \\
\text { - What criteria do those stakeholders use to assess your organization's } \\
\text { desirability and appropriateness? e.g., probe: any differences? } \\
\text {-What are your own assessments/expectations of the organisation } \\
\text { based on? }\end{array}$ & $\begin{array}{l}\text { - Who are the key stakeholders involved in the organizations? } \\
\text { - As a [particular stakeholder] what determines the desirability and } \\
\text { appropriateness of the organization?; e.g., prompt: How do you assess } \\
\text { the desirability and appropriateness of the organization? } \\
\text { - In general, what is your perception of the organization? }\end{array}$ \\
\hline $\begin{array}{l}\text { Divergent } \\
\text { objectives / } \\
\text { tensions }\end{array}$ & $\begin{array}{l}\text { - Is the organization required to meet multiple, potentially quite } \\
\text { divergent, objectives? [probe e.g., any specific tension points?]. } \\
\text { - Do different stakeholders have different expectations of what is } \\
\text { appropriate and desirable? }\end{array}$ & $\begin{array}{l}\text { - Is the organization required to meet multiple, potentially quite } \\
\text { divergent, objectives? [i.e., tensions.]. } \\
\text { - Do your assessments of what is desirable and appropriate differ from } \\
\text { other stakeholders? }\end{array}$ \\
\hline $\begin{array}{l}\text { Legitimacy } \\
\text { strategies } \\
\text { [amidst } \\
\text { pluralism] }\end{array}$ & $\begin{array}{l}\text { - What, if anything, has [organization } \mathrm{x} \text { ] done to increase perceptions of } \\
\text { its desirability and appropriateness? } \\
\text { - How has the organization managed divergent expectations of what is } \\
\text { desirable and appropriate?; e.g., prompt: How has the organization } \\
\text { managed its divergent objectives? } \\
\text { - What has been particularly successful in managing divergent } \\
\text { perceptions of desirability and appropriateness? }\end{array}$ & $\begin{array}{l}\text { - What, if anything, has the organization done that has increased your } \\
\text { perceptions of its desirability and appropriateness? } \\
\text { - How has the organization managed divergent expectations of what is } \\
\text { deniable and appropriate?; e.g., prompt: How has the organization } \\
\text { managed its divergent objectives? } \\
\text { - What has been particularly successful in managing divergent } \\
\text { perceptions of desirability and appropriateness? }\end{array}$ \\
\hline $\begin{array}{l}\text { Summary } \\
\text { questions }\end{array}$ & $\begin{array}{l}\text { - What does a desirable and appropriate [organization } \mathrm{x} \text { ] look like? } \\
\text { - Anything else to do with the management of the various placed on the } \\
\text { organization? }\end{array}$ & $\begin{array}{l}\text { - What does a desirable and appropriate [organization } \mathrm{x} \text { ] look like? } \\
\text { - Anything else at all you want to say, or expected I would ask and } \\
\text { haven't? }\end{array}$ \\
\hline
\end{tabular}

${ }^{27}$ The interview protocol was used flexibly. Similar questions were asked of each interviewee, but the probes/prompts and direction of each interview varied to fit the flow of the interview. Further, depending on the timing/flow of the interview not every question was asked directly in all 58 interviews. The questions were more general for external stakeholders (e.g., public sector managers), i.e., focused on CRIs generally rather than a specific CRIs but moved through the same sequence of questioning and focused on surfacing examples. Finally, some interesting strategic dynamics frequently were raised by the interviews prior to the "strategy" stage of the interview itself. For example, many interviewees independently moved from defining multiple objectives to outlining how they were managed. Any issues raised were then picked up on again in that third stage of the interview. 


\section{Appendix Five: NVivo Coding: An Example (CRI 1)}

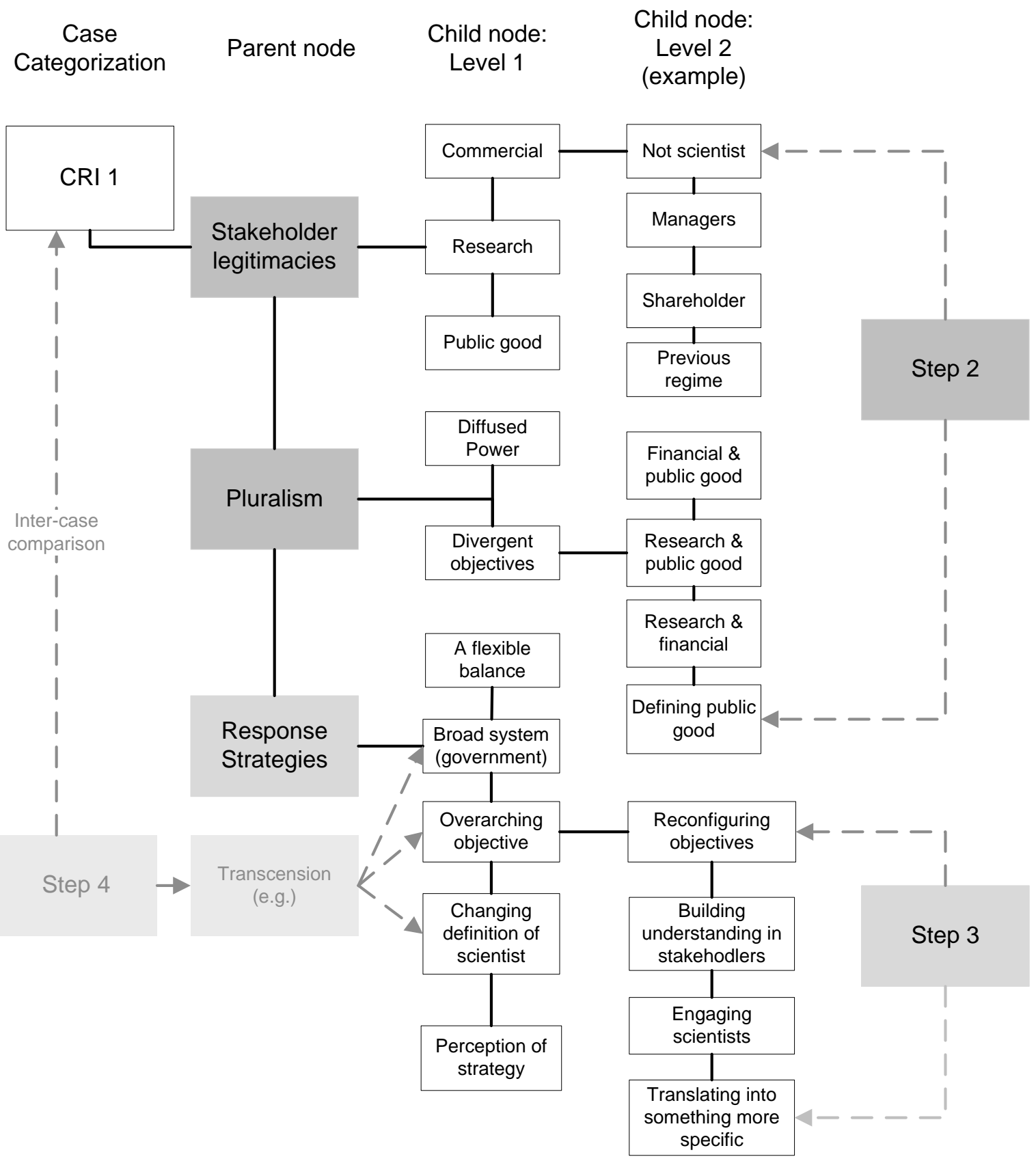

